\title{
Assessment of Ecosystem Services and Water Accounting Methodologies for Integrated Water Resources Management in water scarce basins
}

\section{PhD Thesis}

Programa de Doctorado en Ingeniería del Agua y Medioambiental

\author{
Author: $\quad$ Andrea Momblanch Benavent \\ Directors: Joaquín Andreu Alvarez \\ Javier Paredes Arquiola
}

Research funded by the Support Programme for Research and Development of Universitat Politècnica de València - Reference contract 4234 of "Programa para la formación de personal investigador con cargo a los fondos generados por las estructuras de investigación Subprograma 2 - 2013" 

A la gent que vull, perquè fa del món un lloc meravellós

We forget that the water cycle and the life cycle are one. Jacques Cousteau

Tell me and I will forget. Show me and I may remember. Involve me and I will understand.

Benjamin Franklin 



\section{Acknowledgements}

Along the 3 years of my PhD research, I have had the support of many people that have contributed to it in many ways. I would like to thank all of them for their priceless input.

First of all, I thank my Directors, Joaquín Andreu and Javier Paredes-Arquiola, for their trust in me and their wise guidance along the process. For all that they have taught me about the research world that will accompany me in my professional future. I also thank Abel Solera for his generous advice whenever I have asked for it. Many thanks to the rest of the Water Resources Engineering group, my colleagues, with whom I have been so happy to share my everyday life, knowledge and experiences for countless hours, and that I will consider my friends forever. I am proud of having grown professionally in a group of such human quality.

I would also like to thank the dedication and advice of Jeffery D. Connor during my stay at the CSIRO. It was an unforgettable experience. Thanks to his fabulous family for being so kind to me. I am also very thankful to Neville D. Crossman and the rest of the Ecosystem Science Unit for their comradeship.

My gratitude to all the co-authors of the papers I have published along the way for transmitting me different points of view that have enriched me and my work. Besides, thanks to them for generously letting me include our common work as part of the Thesis.

Thanks to the Júcar and Duero River Basin District Authorities, and to the Catalan Water Agency for providing me with the necessary data for the cases of study.

I appreciate the funds received through the Support Programme for Research and Development of Universitat Politècnica de València for the $\mathrm{PhD}$ development and the research placement at CSIRO.

Last but not least, I would like to express my gratitude to my family and friends: 
Als meus pares per ser els millors del món i haver-me fet la persona que sóc. A la meva germana perquè ens cuidem l'una a l'altra. Al meu germà per preocupar-se per mi encara que jo no m'entere i per regalar-me unes nebodes que em sorprenen a cada moment. A Rafa per voler-me com sóc i compartir les aventures que ens proposem, perquè junts podem amb tot. A les velites que s'alegren per tot el que faig encara que no ho entenguen. A les ties i tios, cosines i cosins, cunyades i cunyats, i als que ja no estan però sempre recordem. A les meves amigues perquè sou meravelloses $i$ vos necessite sempre. A tots gràcies per celebrar amb mi les bones noticies, que per sort han sigut unes quantes; per llevar-me del cap els mals pensaments que de vegades arriben en les hores baixes $i$ fer-me confiar en que puc aconseguir tot el que em propose. Gràcies per deixar-me ser part de la vostra vida, perquè fa que la meva valga la pena.

Finally, thanks to those who will read this thesis, for their interest in my research. 


\section{Abstract}

Even though practical water resources planning and management has evolved greatly, there is still a mismatch between it and Integrated Water Resources Management. In light of the European Water Framework Directive and other European Policies related to water and sustainability, the Ecosystem Services assessment and Water Accounting methodologies have been identified as tools that can help approaching Integrated Water Resources Management.

However, the existing methodologies are disconnected from the real requirements of water resources planning and management in complex river basins such as the ones suffering from water scarcity. The Water Accounting frameworks adopt a financial accounting perspective that is too exhaustive for the purpose of transmitting the relevant water stocks and flows for water managers and users in a river basin, and that entail less accuracy in the global water balance. Also, the analysed Ecosystem Assessment Tools overlook the influence of water management as well as the temporal and spatial variability of water resources and demands.

This Thesis proposes methodologies for Water Accounting and Ecosystem Services Assessment which overcome the identified limitations and are especially adapted to be implemented in water scarce river basins. The Australian Water Accounting Standards are simplified to avoid exhaustive accounting for the sake of accuracy and transparency of water management information. An improved version is fully designed, and some criteria are proposed to guide its implementation at river basin scale with the purpose of improving public information and governance. A set of Integrated Water Resources Management Tools embedded in the Decision Support System AQUATOOL is tailored with economic information in order to obtain the benefits of three Freshwater Ecosystem Services considering the influence of water management with a detailed time step.

The application of the resulting methodologies to different cases of study show the relevance of adopting a water management perspective in order to capture all the complexity of water scarce river basins in the results, so that they are useful for informed decision making. The Water Accounting results disclose synthesised and relevant information for water users and 
other stakeholders about the state of water resources and their allocation and supply during the analysed period. The Freshwater Ecosystem Services assessment results reveal helpful to classify water bodies or watersheds according to their capacity to provide environmental benefits, and to analyse the tradeoffs between the traditional water demands and the Ecosystem Services beneficiaries.

Finally, the methodologies are put into context inside the Integrated Water Resources Management process that covers the target variables to consider, the tools that allow analysing the influence of management actions on them, the indicators that are more informative to water managers, and the ways to transmit the information to the general public. Furthermore, the types of analyses which can be conducted with the proposed methodologies are detailed, and illustrated with examples in scientific literature.

The presented research is based on published work, which is expanded or detailed, and includes other non published material. The result is a Thesis that provides improved results and conclusions with respect to the stand-alone papers. 


\section{Resumen}

A pesar de que la planificación y gestión de los recursos hídricos ha evolucionado enormemente, existe todavía discordancia entre la misma y la Gestión Integrada de Recursos Hídricos. A la luz de la Directiva Europea Marco del Agua y otras Políticas Europeas relacionadas con el agua y la sostenibilidad, la Contabilidad del Agua y la evaluación de los Servicios de los Ecosistemas se han identificado como herramientas que pueden ayudar a aproximarse a la Gestión Integrada de Recursos Hídricos.

Sin embargo, las metodologías existentes actualmente están desconectadas de los requisitos reales de la planificación y gestión de los recursos hídricos en cuencas hidrográficas complejas como las que sufren de escasez hídrica. Los marcos de Contabilidad del Agua adoptan una perspectiva de contabilidad financiera que es demasiado exhaustiva para el propósito de transmitir información relevante sobre las reservas y flujos a los gestores y usuarios del agua en una cuenca, y conllevan menos precisión en el balance global de agua. Además, las herramientas analizadas para la evaluación de los Servicios de los Ecosistemas pasan por alto la influencia de la gestión del agua así como la variabilidad temporal y espacial de los recursos hídricos y las demandas.

Esta Tesis propone metodologías para la Contabilidad del Agua y la Evaluación de los Servicios de los Ecosistemas que superan estas limitaciones y que están especialmente adaptadas para su implementación en cuencas con escasez de agua. Los Estándares Australianos de Contabilidad del Agua se simplifican para evitar la contabilidad exhaustiva a favor de la precisión y la transparencia en la información sobre la gestión del agua. Se diseña una versión mejorada y se proponen algunos criterios para guiar su implementación a escala de cuenca con el propósito de mejorar la información pública y la gobernanza. Un conjunto de herramientas para la Gestión Integrada de Recursos Hídricos que forman parte del Sistema Soporte a la Decisión AQUATOOL se une con información económica para obtener los beneficios generados por tres Servicios de los Ecosistemas de Agua Dulce considerando la influencia de la gestión del agua a una escala temporal detallada. 
La aplicación de las metodologías resultantes a distintos casos de estudio muestra la relevancia de adoptar una perspectiva de gestión del agua para capturar en los resultados la complejidad de las cuencas con escasez de agua, de modo que sean útiles para la toma de decisiones informadas. Los resultados de Contabilidad del Agua muestran información sintética y relevante para los usuarios del agua y otros actores interesados sobre el estado de los recursos hídricos, y su asignación y suministro durante el periodo analizado. Los resultados de la evaluación de los Servicios de los Ecosistemas de Agua Dulce se revelan útiles para clasificar las masas de agua o subcuencas de acuerdo con su capacidad para proporcionar beneficios ambientales y para analizar el equilibrio entre las demandas de agua tradicionales y los beneficiarios de los Servicios de los Ecosistemas.

Finalmente, las metodologías se ponen en contexto dentro del proceso de Gestión Integrada de Recursos Hídricos que abarca las variables objetivo a considerar, las herramientas que permiten analizar la influencia de las acciones de gestión sobre ellas, los indicadores más informativos para los gestores del agua, y los modos de transmitir la información al público en general. Además, se detallan e ilustran con ejemplos en la literatura científica los tipos de análisis que pueden llevarse a cabo mediante las metodologías propuestas.

La investigación que se presenta está basada en trabajos publicados, que se expanden o detallan, e incluye material no publicado. El resultado es una Tesis que proporciona resultados y conclusiones mejorados respecto a los artículos independientes. 


\section{Resum}

A pesar que la planificació i la gestió dels recursos hídrics ha evolucionat enormement, existeix encara discordancia entre aquesta i la Gestió Integrada de Recursos Hídrics. A la llum de la Directiva Europea Marc de l'Aigua i altres Polítiques Europees relacionades amb l'aigua i la sostenibilidad, la Comptabilitat de l'Aigua i l'avaluació dels Serveis dels Ecosistemes s'han identificat com a ferramentes que poden ajudar a aproximar-se a la Gestió Integrada de Recusos Hídrics.

No obstant això, les metodologies existents actualment estan desconnectades dels requeriments reals de la planificació i gestió dels recursos hídricos en conques hidrogràfiques complexes com les que pateixen d'escassesa hídrica. Els marcs de Comptabilitat de l'Aigua adopten una perspectiva de Comptabilitat financera que és massa exhaustiva per al propòsit de transmetre informacó relevant sobre les reserves i fluxes als gestors i usuaris de l'aigua en una conca, i comporten menys precisió al balanç global de l'aigua. A més, les ferramentes analitzades per a l'avaluació dels Serveis dels Ecosistemes passen per alt la influència de la gestió de l'aigua així com la variabilitat temporal i espacial dels recursos hídrics i les demandes.

Aquesta Tesi proposa metodologies per a la Comptabilitat de I'Aigua i l'Avaluació dels Serveis dels Ecosistemes que superen aquestes limitacions i que estan especialment adaptades per a la seva implementació en conques amb escassesa d'aigua. Els Estàndards Australians de Comptabilitat de l'Aigua es simplifiquen per evitar la comptabilitat exhaustiva a favor de la precisió i la transparència en la informació sobre la gestió de l'aigua. Es dissenya una versió millorada i es proposen alguns criteris per guiar la seva implementació a escala de conca amb el propòsit de millorar la informació pública i la governança. Un conjunt de ferramentes per a la Gestió Integrada de Recursos Hídrics que formen part del Sistema Suport a la Decisió AQUATOOL s'uneix amb informació econòmica per obtindre els beneficis generats per tres Serveis dels Ecosistemes d'Aigua Dolça considerant la influència de la gestió de l'aigua a una escala temporal detallada. 
L'aplicació de les metodologies resultants als distints casos d'estudi mostren la rellevància d'adoptar una perspectiva de gestió de l'aigua per capturar als resultats la complexitat de les conques amb escassesa d'aigua, de manera que siguen útils per a la presa de decisions informades. Els resultats de la Comptabilitat de l'Aigua mostren informació sintètica i rellevant per als usuaris i altres actors interessats sobre l'estat dels recursos hídric, i la seua assignació i subministrament al llarg del període analitzat. Els resultats de l'avaluació dels Serveis dels Ecosistemes d'Aigua Dolça es revelen útils per classificar les masses d'aigua o subconques d'acord amb la seva capacitat per proporcionar beneficis ambientals i per analitzar l'equilibri entre les demandes d'aigua tradicionals i els beneficiaris dels Serveis dels Ecosistemes.

Finalment, les metodologies es posen en context dins del procés de Gestió Integrada de Recursos Hídrics que abarca les variables objectiu a considerar, les ferramentes que permeten analitzar la influència de les accions de gestió sobre elles, els indicadors més informatius per als gestors de l'aigua, i les maneres de transmetre la informació al públic en general. A més, es detallen i il lustren amb exemples en la literatura científica els tipus d'anàlisis que es poden portar a terme mitjançant les metodologies propostes.

La investigació que es presenta està basada en treballs publicats, que s'expandeixen o detallen, i inclou material no publicat. El resultat és una Tesis que proporciona resultats i conclusions millorades respecte als articles independents. 


\section{General index}

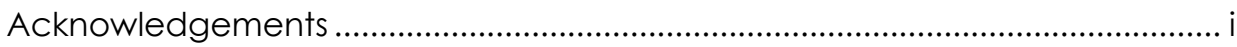

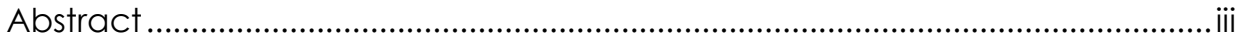

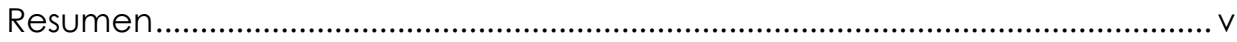

Resum …….........................................................................................

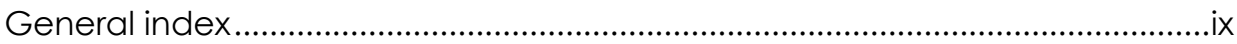

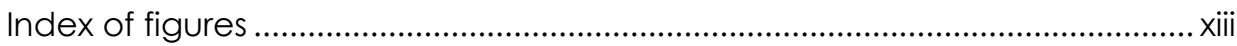

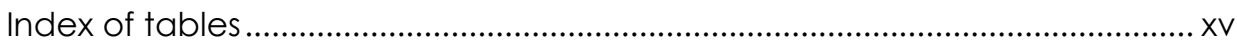

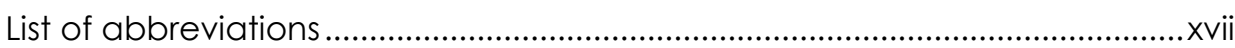

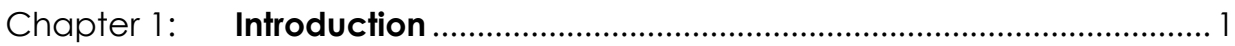

1.1 Water resources management in water scarce regions ......................... 3

1.2 Moving towards Integrated Water Resources Management ................. 4

1.3 Methodologies to support IWRM …………...........................................

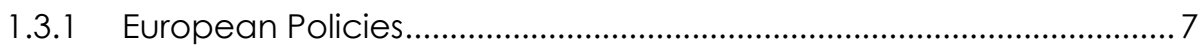

1.3.2 Review of hydro-economic models................................................. 9

1.3.3 Summary of methodologies ................................................................. 10

1.4 Motivation, scope and objectives of the research ................................ 11

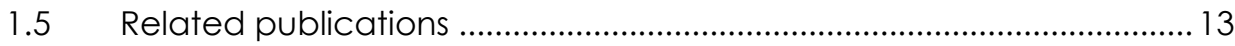

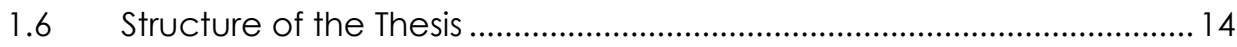

Chapter 2: State of the Art ......................................................................... 17

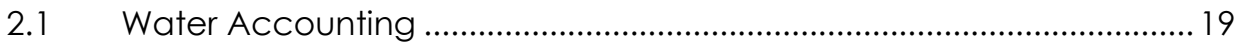

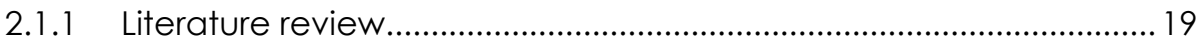

2.1.1.1 Economic water accounting .................................................... 19

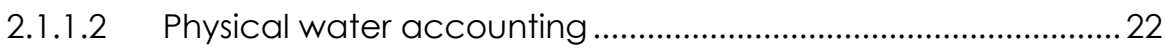

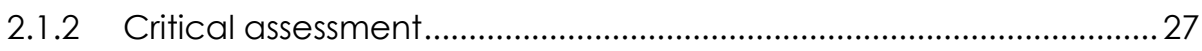

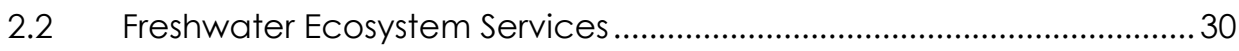

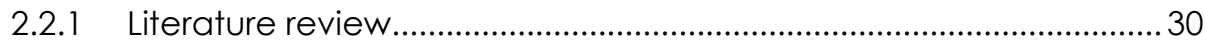

2.2.1.1 Ecosystem Services frameworks ..................................................... 31

2.2.1.2 Models for ecosystem services assessment.................................34

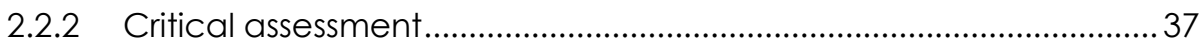

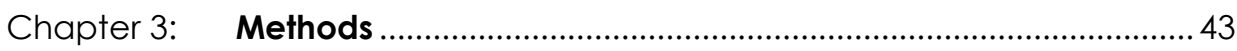

3.1 The Australian Water Accounting Standard ............................................4 45 


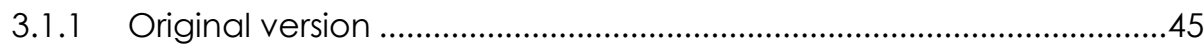

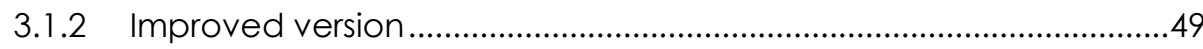

3.2 Integrated Water Resources Management Tools for Ecosystem Services assessment ......................................................................................

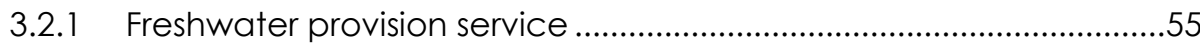

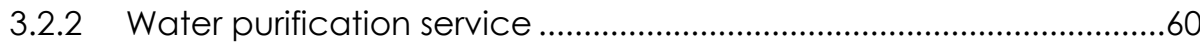

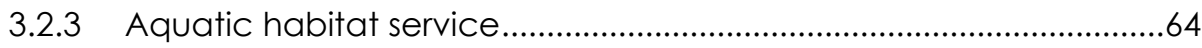

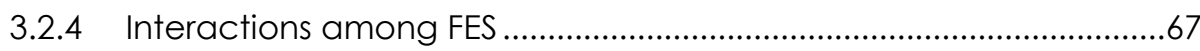

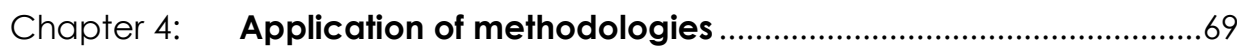

4.1 The Australian Water Accounting in the Júcar River Basin.....................71

4.1.1 Case study description .....................................................................

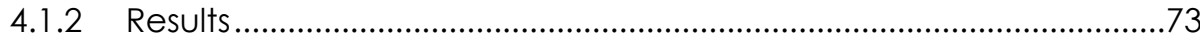

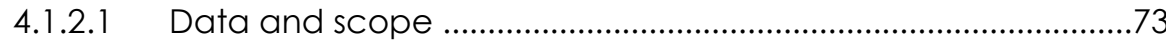

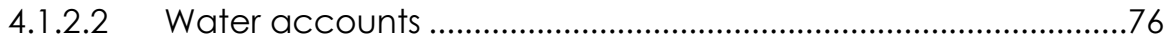

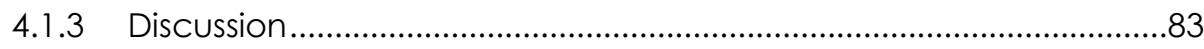

4.2 The Freshwater Provision Service in the Tormes River Basin ....................85

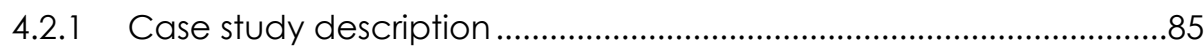

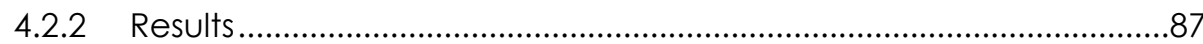

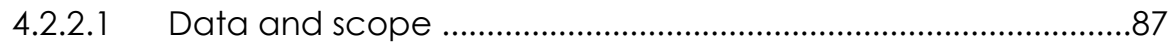

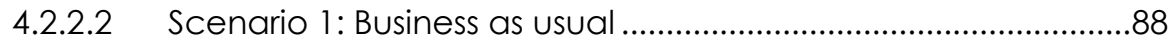

4.2.2.3 Scenario 2: Land use change .................................................90

4.2.2.4 Scenario 3: Water management change ..................................92

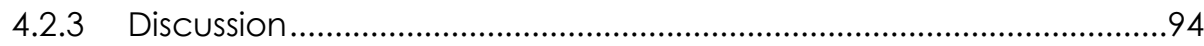

4.3 The Water Purification Service in the Llobregat River Basin ..................95

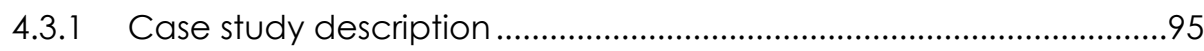

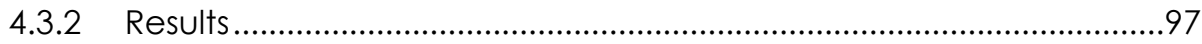

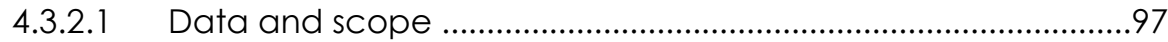

4.3.2.2 Scenario 1: Business as usual ........................................................99

4.3.2.3 Scenario 2: Implementation of measure M12.1 ......................104

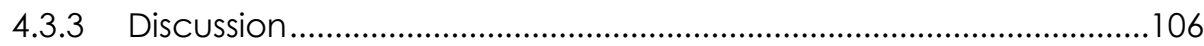

4.4 The Aquatic Habitat Service in the Turia River Basin ............................107

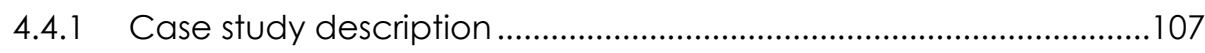

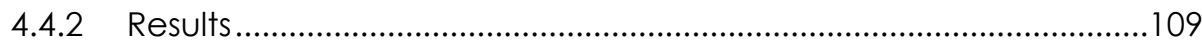




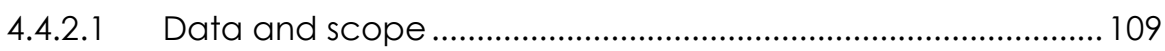

4.4.2.2 Scenario 1: Business as usual...................................................... 112

4.4.2.3 Scenario 2: Fishing oriented management ............................... 114

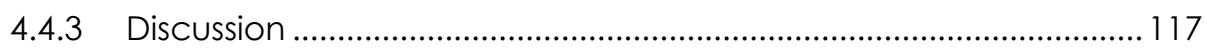

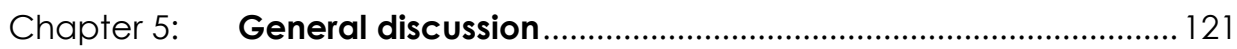

$5.1 \quad$ Key findings and recommendations ................................................. 123

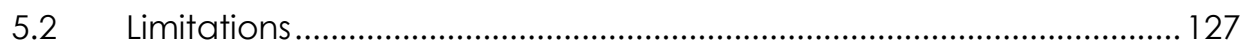

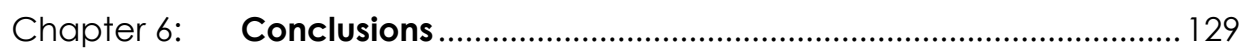

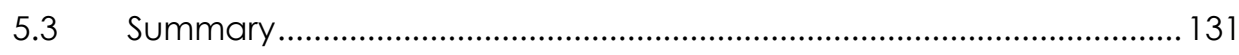

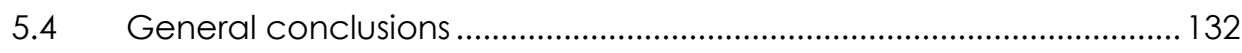

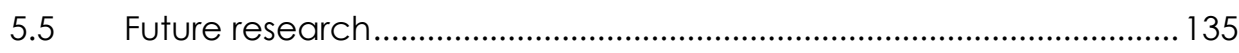

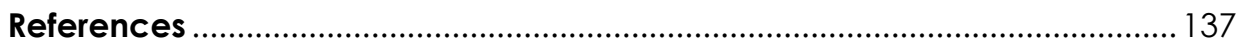

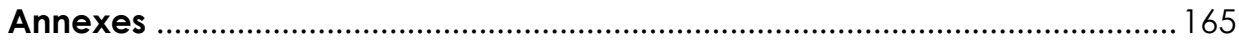

Al. Adapting water accounting for integrated water resource management. The Júcar Water Resource System (Spain) ........................... 167

A.2 Using ecosystem services to represent the environment in hydro-

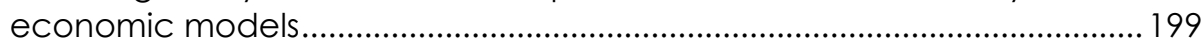

A.3 Integrating ecosystem services in river basin management plans ..... 236

A.4 License agreement for Momblanch et al. 2014 ..................................... 262

A.5 License agreement for Momblanch et al. 2016 ….................................. 268

A.6 License agreement for Terrado et al. 2016 ............................................. 274

A.7 Detailed water accounts for the Júcar River Basin in the hydrological year $2007 / 2008$ in its original and improved versions....................................2 278 



\section{Index of figures}

Figure 1. Conceptual diagram of IWRM

Figure 2. Variables considered under the scope of the present Thesis. Grayed variables have been analysed in previous research.

Figure 3. Resource Base sheet of the WA+ (Karimi et al., 2013a). ..................... 24

Figure 4. Ecosystem services cascade exemplifying some effects of river flow change due to water management. Modified by Momblanch et al. (2016) from Potschin and Haines-Young (2011).

Figure 5. Methodology for the assessment of the FPS

Figure 6. Obtaining of the gross benefit from a demand curve. Adapted from Momblanch et al. (under review).

Figure 7. Water tracer diagram for the mapping of the FPS..............................58

Figure 8. Methodology for the assessment of the WPS.

Figure 9. Representation of the beneficial fraction of the WPS for a certain water demand for a particular pollutant.

Figure 10. Methodology for the assessment of the AHS.

Figure 11. Location of the study area. Adapted from Momblanch et al. (2014).

Figure 12. Simplified diagram of the JRB including the most relevant elements for water management (Momblanch et al., 2014).

Figure 13. Location of the study area. Adapted from Momblanch et al. (under review).

Figure 14. Simplified diagram of the ToRB including the most relevant elements for water management.

Figure 15. Demand curves adapted for the demands in the simplified ToRB. 88

Figure 16. Water supply to the TORB demands from each watershed for

scenario 1. Adapted from Momblanch et al. (under review).

Figure 17. Annual series of the FPS economic value and contribution of each watershed in scenario 1 (Momblanch et al., under review).

Figure 18. Water supply to the TORB demands from each watershed for scenario 2

Figure 19. Annual series of the FPS economic value and contribution of each watershed in scenario 2 .

Figure 20. Water supply to the ToRB demands from each watershed for scenario 3

Figure 21. Annual series of the FPS economic value and contribution of each watershed in scenario 3.

Figure 22. Monthly comparison of the water resources and the irrigation demands.

Figure 23. Monthly fraction contributed by each watershed to the Salamanca City demand in scenario 1.

Figure 24. Location of the study area.

Figure 25. Simplified diagram of the LRB including the most relevant elements for water management. Adapted from Momblanch et al. (2015)..... 
Figure 26. Monthly series of ammonium concentration at the intakes of the Terrassa, Abrera DWTP and Sant Joan Despí DWTP with and without the effect of the WPS, and legal threshold of ammonium for drinking water.

.

Figure 27. WPS monthly benefit for urban demands in the LRB......................101

Figure 28. Average WQI with and without the WPS, and annual variation in

the water bodies of the LRB...................................................................102

Figure 29. WPS monthly benefit for bathing uses in the LRB ...........................102

Figure 30. Annual provision of the WPS by the different water bodies in the LRB in 2002/03 (a), 2003/04 (b), 2004/05 (c), 2005/06 (d), 2006/07 (e), and 2008/09 (f)............................................................................................ 103

Figure 31. Average WQI with and without the WPS, and annual variation in the water bodies of the LRB in scenario 2 . .105

Figure 32. Marginal annual benefit of the WPS with the implementation of measure M12.1 in the LRB in 2002/03 (a), 2003/04 (b), 2004/05 (c), 2005/06 (d), 2006/07 (e), and 2008/09 (f)................................................105

Figure 33. Location of the study area............................................................... 107

Figure 34. Simplified diagram of the TURB including the most relevant elements for water management.

Figure 35. WUA - flow curves for the relevant species for fishing in the TURB.

Figure 36. Location of the fishing water bodies in the TURB, including: the identifier of the water body, the type of fishing area (free or reserve), the fishable species, and the WUA - flow curve used. Sources: Consellería de Agricultura, Medio Ambiente, Cambio Climático y Desarrollo Rural (2015) and Consellería de Infraestructuras, Territorio y Medio Ambiente (2015).

Figure 37. AHS monthly benefit for recreational fishing in the TURB................112 Figure 38. AHS annual benefit by water body considering biomass (a) and population (b) as distribution criteria.

Figure 39. Annual provision of the AHS by the different water bodies in the TURB.

Figure 40. Management changes introduced in scenario 2 .

Figure 41. AHS monthly benefit for recreational fishing in the TURB in scenario

2.

Figure 42. AHS annual benefit by water body considering biomass (a) and population (b) as distribution criteria in scenario 2 .

Figure 43. Annual provision of the AHS by the different water bodies in the TURB in scenario 2.

Figure 44. Comparison of the volumes stored in the Benagéber and Loriguilla reservoir in scenarios 1 and 2 .

Figure 45. IWRM components and application diagram. 


\section{Index of tables}

Table 1. Contribution of the identified methodologies to the different aspects of IWRM.

Table 2. Water accounts in the SEEA-Water. Accounts in brackets are supplementary.

Table 3. Main groups of accounting concepts in the AWAS statements. ...... 25

Table 4. Summary table of the suitability assessment of water accounting frameworks for IWRM in water scarce regions.

Table 5. Comparative of most relevant standard ES assessment frameworks.

Table 6. Water-related ES in the CICES framework. Adapted from Momblanch et al. (2016).

Table 7. Structure of Al, accounting terms, and mathematical relationships among them.

Table 8. Structure of A2, accounting terms, and mathematical relationships among them.

Table 9. Structure of A3, accounting terms, and mathematical relationships among them.

Table 10. The structure and content of the improved AWAS.

Table 11. ES included in hydro-economic modelling studies. Adapted from Momblanch et al. (2016).

Table 12. Data sources and estimation strategies employed to fill out the water accounts for the JRB. Adapted from Momblanch et al. (2014)....76

Table 13. Statement of water assets and water liabilities (A1) for the JRB in the hydrological year 2007/2008 in its original and improved version. Figures are in $\mathrm{Mm}^{3}$. Adapted from Momblanch et al. (2014).

Table 14. Statement of changes in water assets and water liabilities (A2) for the JRB in the hydrological year $2007 / 2008$ in its original and improved version. Figures are in $\mathrm{Mm}^{3}$. Adapted from Momblanch et al. (2014)..... 80

Table 15. Statement of physical water flows (A3) for the JRB in the hydrological year 2007/2008 in its original version. Figures are in $\mathrm{Mm}^{3}$. Adapted from Momblanch et al. (2014).

Table 16. Statement of physical water flows (A3) for the JRB in the hydrological year 2007/2008 in its improved version. Figures are in $\mathrm{Mm}^{3}$. Adapted from Momblanch et al. (2014).

Table 17. Unaccounted for difference calculation in A2 for the surface water resources of the JRB in the hydrological year 2007/2008 in its improved version. Adapted from Momblanch et al. (2014).

Table 18. Unaccounted for difference calculation in A2 for the groundwater resources of the JRB in the hydrological year 2007/2008 in its improved version. Adapted from Momblanch et al. (2014).

Table 19. Water quality thresholds for urban and irrigation demands. ............98

Table 20. Treatment costs per unit of pollutant mass......................................98

Table 21. WTP per unit of WQI per person. .......................................................98

Table 22. Summary of fishing regulations in the TURB. ....................................... 111 



\section{List of abbreviations}

$\begin{array}{ll}\text { AHS } & \text { Aquatic Habitat Service } \\ \text { ARIES } & \text { Artificial Intelligence for Ecosystem Services } \\ \text { AWAS } & \text { Australian Water Accounting Standards } \\ \text { CICES } & \text { Common International Classification of Ecosystem Services } \\ \text { DWTP } & \text { Drinking water treatment plant } \\ \text { ES } & \text { Ecosystem Services } \\ \text { ET } & \text { Evapotranspiration } \\ \text { FES } & \text { Freshwater Ecosystem Services } \\ \text { FPS } & \text { Freshwater Provision Service } \\ \text { GPWAR } & \text { General Purpose Water Accounting Reports } \\ \text { HSM } & \text { Habitat suitability model } \\ \text { HTS } & \text { Habitat time series } \\ \text { InVEST } & \text { Integrated Valuation of Ecosystem Services and Tradeoffs } \\ \text { ISIC } & \text { International Standard Industrial Classification of All Economic } \\ & \text { Activities } \\ \text { IWMI-WA } & \text { Water Accounting of the International Water Management } \\ & \text { Institute } \\ \text { IWRM } & \text { Integrated Water Resources Management } \\ \text { JRB } & \text { Júcar River Basin } \\ \text { LRB } & \text { Llobregat River Basin } \\ \text { MA } & \text { Millennium Ecosystem Assessment } \\ \text { RBMP } & \text { River Basin Management Plan } \\ \text { RRM } & \text { Rainfall-runoff model } \\ \text { SEEA-Water } & \text { System of Environmental-Economic Accounting for Water } \\ \text { TEEB } & \text { The Economics of Ecosystems and Biodiversity } \\ \text { TEV } & \text { Total Economic Value } \\ \text { TORB } & \text { Tormes River Basin } \\ \text { TURB } & \text { Turia River Basin } \\ \text { UK NEA } & \text { United Kingdom National Ecosystem Assessment } \\ \text { WA } & \text { Water Accounting } \\ \text { WA+ } & \text { Water Accounting Plus } \\ \text { WAM } & \text { Water allocation model } \\ \text { WFD } & \text { European Water Framework Directive } \\ \text { WPS } & \text { Water Purification Service } \\ \text { WQI } & \text { Water Quality Index } \\ \text { WQM } & \text { Water quality model } \\ \text { WTP } & \text { Willingness to pay } \\ \text { WUA } & \text { Weighted Usable Area } \\ \text { WWTP } & \text { Wastewater treatment plant } \\ & \end{array}$





\section{Chapter 1: Introduction}





\subsection{Water resources management in water scarce regions}

Water scarcity is one of the main concerns for water resources managers in arid and semi-arid regions (Cirilo, 2008). It is the result of water demands being a big portion, or even exceeding, the renewable water resources in time and space. Historically, water scarce regions have adapted to the endemic lack of water by building dams and other hydraulic infrastructures (Estrela et al., 1996; Loucks and van Beek, 2005) with the aim of increasing water resources availability. With time, the higher control over water resources has underpinned human development (World Bank, 2016) that generally brings urban, agricultural and industrial expansion. Inevitably, as water demands grow and diversify, the allocation problems become more complex.

At this point, water managers should look for more systematic approaches to allocate water resources, define water saving strategies, and establish regulatory frameworks and plans. It could be considered a transit from a sectoral approach to more holistic water resources management (Cao, 2006). The use of models has revealed essential to work with several variables and scales interacting in time and space (Jakeman and Letcher, 2003; McIntosh et al., 2008). Different models have been used such as hydrological, water allocation, and aquifer models. All together, they allow performing scenario analyses to test different sets of measures and management options that provide indicators of water supply reliability, status of reserves and water balances (Andreu et al., 2008). In general, these models are dynamic, so that they can represent the seasonal and interannual variability of water resources which are crucial in water scarce regions, and usually consider spatial distribution as well. This evidences the complexity of water resources management in water scarce regions, even if only quantitative aspects are regarded.

A good example of the described evolution of water planning and management in water scarce regions is Spain. In the early $20^{\text {th }}$ century, Spanish water policies consisted in planning hydraulic works to serve the existing water uses. It was almost a matter of storing and carrying water from the sources to the demands (Hernández, 1994). In order to perform these tasks, the first River Basin Agencies were created in 1926. With this, Spain 
Assessment of Ecosystem Services and Water Accounting Methodologies for Integrated Water Resources Management in water scarce basins

became (most likely) the first country in the world to establish water management activities at river basin scale (Embid, 2003).

Along the central decades of the century, traditional agriculture evolved toward industrial agriculture (García-Delgado, 1976), population grew and large migrations from rural areas to cities took place (Slomp, 2004). This brought about increased pressures over water resources and posed new problems for decision makers. The necessary mental shift in water resources management to cope with this new reality arrived with the publication of the Royal Decree 3029/1979 (Ministerio de Obras Públicas y Urbanismo, 1980), which regulated the preliminary studies for water resources evaluation, water demands estimation and definition of use priorities for water resources planning. This, together with the first serious drought of the century, fostered the enactment of the new Spanish Water Law in 1985 (Jefatura del Estado, 1985). Besides, by incorporating modern hydrological concepts (e.g. including surface and groundwater under the competence of water mangers) and setting environmental objectives, the new law established water resources planning as the main tool to develop water policies based on the integrated vision of the hydrological cycle, with rationality and economy. Afterwards, the redefinition of River Basin Agencies in 1987, and the publication of new regulations in 1988 (Ministerio de Obras Públicas y Urbanismo, 1988) were the breeding ground for the development of the first River Basin Management Plans (RBMP), which were mostly published in 1998 , and the National Water Management Plan (Jefatura del Estado, 2001; 2005). Models played a key role in the development of these plans, as they were used to assess water resources availability, estimate the regulated water resources and define operation rules for the water resources systems, among other purposes. Finally, it is worthy to highlight that, even though this generation of water management plans defined measures to protect the environment, their main purpose was still satisfying human water demands.

\subsection{Moving towards Integrated Water Resources Management}

Overall, water planning and management can be recognised as one of the most relevant issues to attend regarding environmental degradation (Cao, 2006; Grafton et al., 2013). Land use changes, hydraulic infrastructures and 
water management strategies alter the natural patterns of water along river systems (Richter and Thomas, 2007), since they retain, transport, uptake and divert water according to the needs of existing water uses. Moreover, urbanization, industrialisation and intensive agriculture produce increasing pollution which results in the impairment of water quality (Momblanch et al., 2015).

However, water planning and management can also be part of the solution of the abovementioned environmental problems. The Integrated Water Resources Management (IWRM), is defined as the coordinated development and management of water, land and related resources to maximise economic and social welfare without compromising the sustainability of vital ecosystems (Global Water Partnership, 2012). It includes both the planning and management stages which have different purposes and time horizons (i.e. long term, assessment of demands and resources, and infrastructures development; and medium-short term and operation of water resources systems, respectively). The IWRM was recognised as the most capable tool for water resources sustainable development at the World Summit on Sustainable Development of 2002 and the Third World Water Forum in 2003 (Rahaman and Varis, 2005). The potential of IWRM for reconciling human uses and the environment in water scarce basins has been explicitly highlighted (Garrote et al., 2016).

This change of paradigm requires accounting for the satisfaction of human needs, and the protection of land and aquatic environments as inextricably dependent variables (Bakker, 2012). According to its definition, IWRM can be conceptualised in five topics which are interdependent. Under each general topic, specific variables are considered based on the Global Water Partnership analysis (2000). The first topic is quantitative management that accounts for the definition of water demands and establishes the priorities of use and the exploitation strategy of water resources. Secondly, land-water interaction implies considering the influence of catchment management over water availability and diffuse pollution, and the importance of the relationship between surface and groundwater. In the third place, environmental sustainability calls for the definition of environmental flows which sustain aquatic and related ecosystems, for the preservation of good water quality, and for taking into account the benefits of protecting nature. 
Assessment of Ecosystem Services and Water Accounting Methodologies for Integrated Water Resources Management in water scarce basins

The fourth topic is the maximisation of economic benefit which can be achieved by promoting the role of economic productivity in the efficient allocation of water and demands management (Cao, 2006), and fostering economic instruments such as water pricing policies for efficient water use (Ward and Pulido-Velazquez, 2009) and costs recovery of water services (Heinz et al., 2007). The final topic is maximisation of social welfare that requires improving water governance with the involvement of stakeholders in water management decisions since deciding on the best trade-off is a political issue rather than a technical one (Loucks and van Beek, 2005). This translates into the need for establishing effective public participation mechanisms at all stages of water management which have to be supported by adequate information and control instruments (Momblanch et al., 2014).

Figure 1 presents the quantitative management at the core of IWRM, since it is the main driver for the whole framework. The two-direction arrows represent dependencies between quantitative management and the other topics. For example, water allocation is dependent on the availability of water resources, but at the same time operation rules affect surfacegroundwater relationship due to water withdrawals. On the other hand, the surrounding arrows represent the relationships among the four secondary topics. For instance, hydrological processes and diffuse pollution determine the temporal patterns of environmental flows and in-stream water quality, respectively.

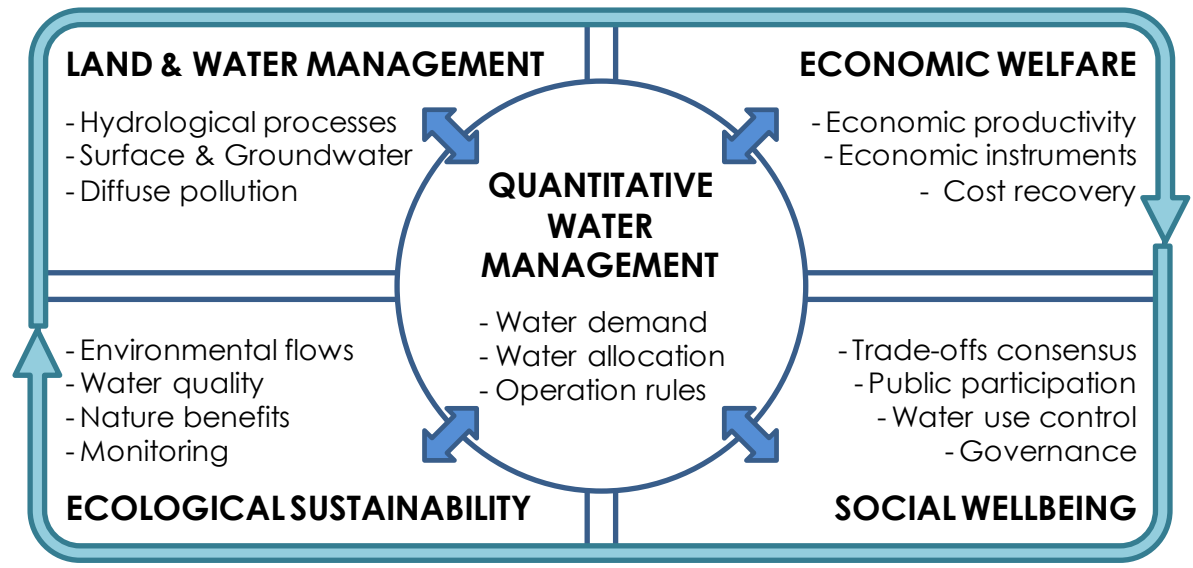

Figure 1. Conceptual diagram of IWRM. 
Introduction

Taken as a whole, moving towards IWRM implies stronger water requirements of environmental uses and, consequently, the reduction of the available water resources for economic uses. This poses a big challenge for water scarce river basins. Under these circumstances, drought periods could develop into problems like low supply reliabilities for non-priority water uses (e.g. agricultural), and high risk of supply deficit for priority uses (e.g. urban); and even for the environmental requirements themselves.

Given the complexity of IWRM, it is necessary to use methodologies and tools that provide support to water managers in order to make informed and sound decisions (Global Water Partnership, 2000; Andreu et al., 2008). This has brought about models to evolve towards new approaches like Decision Support Systems, experts systems, collaborative planning and management, and dynamic decision systems, among others (Solera, 2003). Common to all these models is their ability to reflect political and social priorities, and compare management alternatives with transparency. However, the practical implementation of IWRM is frequently less integrated than it should be, with fragmented applications and focused on the traditionally dominant water uses (Cook and Spray, 2012; Everard, 2014). In order to address the gap between theory and practice, the first step is identifying the methodologies that can contribute to the diverse topics included in IWRM, and then propose a framework that facilitates their common implementation.

\subsection{Methodologies to support IWRM}

\subsubsection{European Policies}

The European Water Framework Directive (WFD) (European Parliament and Council, 2000) supposed a boost for the implementation of IWRM in Europe. The main aim of this directive is achieving the good ecological status of European water bodies by 2015, under consideration of their quantitative and qualitative status, and introducing economic instruments to incentivise sustainable water use. To do so, the Common Implementation Strategy published several guidance documents that recommend some methodologies which are in line with the topics and sub-topics of IWRM identified in the previous section. In reference to quantitative management, 
Assessment of Ecosystem Services and Water Accounting Methodologies for Integrated Water Resources Management in water scarce basins

the Guidance Document No. 34 (DG Environment, 2015b) identifies water accounting (WA) as a useful tool for guiding efficient allocation and control of water resources. Regarding the analysis of impacts on the ecological status, Guidance Document No. 3 (IMPRESS, 2003) proposes modelling approaches such as water quality river network models, and stream habitat models as suitable to support this task. Besides, this Guidance highlights diffuse pollution catchment models as a way to evaluate land management impacts. Furthermore, Guidance Document No. 31 (DG Environment, 2015a) defines environmental flow as "a hydrological regime consistent with the achievement of the environmental objectives of the WFD in natural surface water bodies as mentioned in Article 4(1)" and so its estimation and practical implementation is inherent to the attainment of the WFD prescriptions. With respect to the economic instruments, Guidance Document No. 1 (WATECO, 2003) defines the assessment of the economic benefits of main water uses, and the evaluation of environmental costs and benefits as part of the integration of economy into water management. The former would serve as an additional criterion for the efficient allocation of water among different users, while the later would be part of the estimation of the cost of water services.

Together with the WFD, many other initiatives have been fostered by European institutions intending to support sustainability of water resources and associated ecosystems. Europe 2020 (European Commission, 2010) is the growth strategy established by the European Union that stands for sustainable economic and social growth. Under this umbrella, the European Commission launched the European Biodiversity Strategy to 2020 (European Commission, 2011) whose main target is to reverse biodiversity loss and promote resource efficiency. It encompasses the Habitats (European Council, 1992) and Birds (European Parliament and Council, 2009) Directives that aim to protect habitats and species belonging to Natura 2000 sites (i.e. Sites of Community Importance and Special Protection Areas) which, in some cases, bear aquatic ecosystems (Schmedtje et al., 2011). The Biodiversity Strategy claims that environmental degradation is due to the lack of assigning a value to biodiversity, and because it is not factored into decision making. It deems ecosystem services (ES) assessment as a powerful tool to support decision makers in order to determine the best use of scarce 
resources by assigning a value to the services provided by nature and to find funding sources that back sustainability measures.

Also fitting into the overall resource-efficiency objective of Europe 2020, A Blueprint to safeguard Europe's Water Resources (European Commission, 2012a) was published to capture the experience gained during the implementation of the first RBMP under the WFD, and the Review of the Policy on Water Scarcity and Droughts (European Commission, 2012b). It proposes a series of fundamental actions to be undertaken in response to the diverse problems that should be addressed for water resources management in the different member states. The Blueprint states that quantitative aspects, aggravated by population growth and climate change, are the biggest hurdle for water resources sustainability, and that key issues to confront them are increasing water efficiency and improving governance. In relation to water use control and governance, the Blueprint regards WA as a useful method to compile water data which provides a real picture of water availability in a single information source. This is relevant for sound water allocation because it provides key information for water management. Moreover, the Blveprint stresses the interconnection between land use and water quantity and quality, and calls for land use improvement by means of the coordination with spatial planning.

\subsubsection{Review of hydro-economic models}

The review of hydro-economic models conducted in Momblanch et al. (2016) highlights that the environment is likely to be the IWRM component with the worst representation in current water management analyses. Previous reviews are consistent with this finding and conclude that in-stream environmental uses are seldom represented in hydro-economic models (Ringler and Cai, 2006; Ward and Pulido-Velazquez, 2008; Harou et al., 2009; Ward and Pulido-Velazquez, 2009).

By reviewing 95 studies which apply hydro-economic models for water management analysis at river basin scale including environmental aspects, Momblanch et al. (2016) find that representation of environmental values is patchy in most applications. From all the original set of studies, only 34 include environmental impacts in economic optimisation functions. The environmental aspects covered vegetation and fauna, water quality and 
Assessment of Ecosystem Services and Water Accounting Methodologies for Integrated Water Resources Management in water scarce basins

flood control. Most studies only analysed one (e.g. Cai et al., 2002; Divakar et al., 201 1; Mullick et al., 2013) or two (e.g. Lund and Ferreira, 1996; Babel et al., 2005; Kahil et al., 2015) environmental aspects and only five papers included more than three (Hurd et al., 1999; Grossmann and Dietrich, 2012; Bekchanov et al., 2015a; Bekchanov et al., 2015b; Bekchanov et al., 2015c). Moreover, some studies included very broad and vague environmental components such as wetlands or environmental flows which may disguise internal tradeoffs of the aggregated environmental values (Momblanch et al., 2016). Regarding the economic valuation, no systematic approaches were found, being the broad environmental concepts the ones with highest dispersion of valuation techniques.

The main recommendation arising from the review, is that the ES approach can be useful to screen the possible environmental aspects impacted by water management (Momblanch et al., 2016). Besides it can help guiding the economic valuation by providing well established and systematic valuation methods recommended in ES literature (Momblanch et al., 2016).

\subsubsection{Summary of methodologies}

Summing up, the methodologies which are more synergistic with IWRM, as identified above, are presented in Table 1. They can be organised in five groups according to the aspects of IWRM to which they contribute the most.

\begin{tabular}{|l|l|l|l|l|l|}
\hline & $\begin{array}{l}\text { Quant. } \\
\text { manag. }\end{array}$ & $\begin{array}{l}\text { Land \& } \\
\text { water }\end{array}$ & $\begin{array}{l}\text { Environ. } \\
\text { sustain. }\end{array}$ & $\begin{array}{l}\text { Economic } \\
\text { welfare }\end{array}$ & $\begin{array}{l}\text { Social } \\
\text { welfare }\end{array}$ \\
\hline $\begin{array}{l}\text { Diffuse pollution } \\
\text { modelling }\end{array}$ & & & & & \\
\hline $\begin{array}{l}\text { In-stream water } \\
\text { quality modelling }\end{array}$ & & & & & \\
\hline $\begin{array}{l}\text { Habitat suitability } \\
\text { modelling }\end{array}$ & & & & & \\
\hline $\begin{array}{l}\text { Environmental } \\
\text { flows definition }\end{array}$ & & & & & \\
\hline $\begin{array}{l}\text { Ecosystem Services } \\
\text { Assessment }\end{array}$ & & & & & \\
\hline $\begin{array}{l}\text { Assessment of } \\
\text { water use benefits }\end{array}$ & & & & & \\
\hline Water Accounting & & & & & \\
\hline
\end{tabular}

Table 1. Contribution of the identified methodologies to the different aspects of IWRM. 


\subsection{Motivation, scope and objectives of the research}

This Thesis is based on preceding research whose objective was establishing a modelling methodology to integrate aspects of water resources and diffuse pollution evaluation, water allocation, in-stream water quality modelling, and habitat suitability for aquatic species (Momblanch, 2013). Such research concluded that the connection among the models allows analysing possible tradeoffs between water uses and the environmental status, with the aim of finding a satisfactory solution that balances human water uses and environmental water requirements in complex management scenarios. It also recognised that if all the models are integrated into a single platform (i.e. Decision Support System), the transfer of results is easier and allows massive simulations. Momblanch (2013) based the analysis on a set of Simulation-Indicators that represent the temporal evolution of the different objectives analysed, as well as on Tradeoff-Indicators that synthesise the state of the system along the simulated period for an easy comparison of management alternatives.

In line with the implementation gap identified between IWRM definition and implementation, the general objective of this research is to harmonise the traditional water management in water scarce regions with IWRM by adopting a set of recommended methodologies and tools (see Table 1), and proposing an application framework. Some of the methodologies have been applied in other studies such as the assessment of environmental flows under consideration of water management, habitat modelling and water quality in the Tormes River Basin (Paredes-Arquiola et al., 2014b), and the modelling of water quality under drought conditions in the Llobregat River Basin (Momblanch et al., 2015). The assessment of the economic benefits of water use by means of hydro-economic models has also been widely studied as a way to contribute to IWRM (Booker et al., 2012). Other methodologies have just recently been analysed on this regard, such as ES (Liv et al., 2013) and WA (Pedro-Monzonís et al., 2016b).

Nonetheless, casuistry across European waters is very diverse (European Commission, 2012a), and key issues for IWRM are not common to all regions. Neither are the preexisting legal regulations and water management practices. For example, as highlighted in Section 1.1., the complexity and 
Assessment of Ecosystem Services and Water Accounting Methodologies for Integrated Water Resources Management in water scarce basins

specific features that water management in scarce river basins entails is an added difficulty for the implementation of IWRM. Since the selection of tools should be context-dependent (Global Water Partnership, 2000), it is very important to identify methodologies which are suitable to move water management toward IWRM in water scarce regions. Therefore, prior to adopting any methodology, it should be tested and adapted to the specific conditions and requirements.

Amongst the methodologies identified in the previous section, the specific requirements that ES assessment tools and WA methodologies should possess as regard to their implementation in water scarce river basins still remain untested. The present research focuses on these methodologies (see Figure 2), even though it makes use of the previous results and modelling approaches in Momblanch (2013). Some clarifications should be made yet. In the first place, all ES assessment frameworks consider the economic benefits of water use as a provisioning service and, thus, this aspect is indirectly examined in this research. Secondly, the ES assessment methodology is limited to the processes occurring in the aquatic domain, freshwater ES (FES), that are related to the spatial and temporal scale of water resources management in water scarce regions. These scope constraints are further detailed in section 3.2.

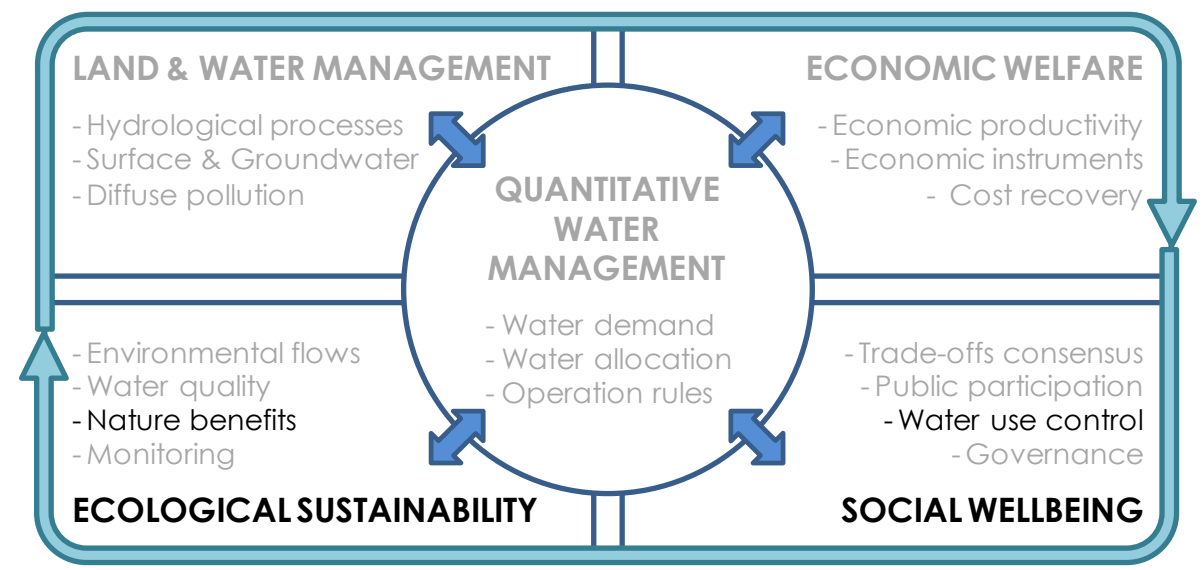

Figure 2. Variables considered under the scope of the present Thesis. Grayed variables have been analysed in previous research. 
Based on the above, the specific objective of this Thesis is analysing and testing WA and FES assessment as potential methodologies to support IWRM in water scarce basins. The subsequent sub-objectives are the following:

a) Analysis of WA and FES assessment methodologies and their potential to support IWRM.

b) Applicability of both methodologies in water scarce regions.

c) Recommendation of improvements in the application of the methodologies in water scarce regions.

\subsection{Related publications}

Part of this Thesis has been included in three articles published in peer reviewed journals indexed in the Journal Citations Reports, and in one article submitted to one of these journals. The references are listed below and the author versions of the papers are included in Annexes A.1 to A.3:

- Directly included in the Thesis, for which the required permits have been obtained from the co-authors and the Publishers (see License agreements in Annexes A.4 to A.6):

- Momblanch, A., Andreu, J., Paredes-Arquiola, J., Solera, A., \& Pedro-Monzonís, M. (2014). Adapting water accounting for integrated water resource management. The Júcar Water Resource System (Spain). Journal of Hydrology, 519, Part D, 3369-3385. doi: 10.1016/j.jhydrol.2014.10.002

- Momblanch, A., Connor, J. D., Crossman, N. D., ParedesArquiola, J., \& Andreu, J. (2016). Using ecosystem services to represent the environment in hydro-economic models. Journal of Hydrology, 538, 293-303. doi: 10.1016/i.jhydrol.2016.04.019

- Terrado, M., Momblanch, A., Bardina, M., Boithias, L., Munné, A., Sabater, S., Solera, A., \& Acuña, V. (2016). Integrating ecosystem services in river basin management plans. Journal of Applied Ecology, n/a-n/a. doi: 10.1111/1365-2664.12613

- Directly included in the Thesis and submitted to a journal. Currently under review: 
- Momblanch, A., Paredes-Arquiola, J., \& Andreu, J. (under review). Improved modelling of the freshwater provisioning ecosystem service in water scarce river basins. Journal of Environmental Modelling and Software.

- Supporting the general methodology of the thesis:

- Andreu, J., Momblanch, A., Paredes, J., Pérez, M.Á., Solera, A. (2012). Potential role of standardized water accounting in Spanish basins, in: Godfrey, J.M., Chalmers, K. (Eds.), Water Accounting. International Approaches to Policy and Decision-Making. Edward Elgar, Cheltenham.

- Paredes-Arquiola, J., Solera, A., Martinez-Capel, F., Momblanch, A., \& Andreu, J. (2014). Integrating water management, habitat modelling and water quality at the basin scale and environmental flow assessment: case study of the Tormes River, Spain. Hydrological Sciences Journal, 59(3-4), 878-889. doi: 10.1080/02626667.2013.821573

- Momblanch, A., Paredes-Arquiola, J., Munné, A., Manzano, A., Arnau, J., \& Andreu, J. (2015). Managing water quality under drought conditions in the Llobregat River Basin. Science of the Total Environment, 503-504, 300-318. doi: 10.1016/i.scitotenv.2014.06.069

\subsection{Structure of the Thesis}

Even though this Thesis is partially based on published work, papers are specifically defined for the purpose of dissemination rather than for providing detailed information. Hence, for the sake of easy reading, understandability, as well as the inclusion of non published research, the present document combines and reorganises the published and new material. The result is a document that follows the traditional structure of a Thesis.

The present introductory chapter has stated the research gap, and the general and specific objectives addressed in the research. Subsequently, the state of the art (Chapter 2) summarises the existing background of the WA and ES methodologies under study. It includes a description of the 
theoretical frameworks, application examples and a critical argumentation that leads to a final proposal of the methodologies that are to be further developed along the Thesis.

Chapter 3 describes the adaptation and design of the WA and ES methodologies to make them suitable for the purpose of supporting IWRM in water scarce river basins. These methodologies are then applied to different cases of study in Chapter 4 in which their potential to provide valuable information for IWRM in water scarce river basins is analysed by means of scenario analyses.

Chapter 5 draws the general results of the research and highlights the key findings of the Thesis. It also reflects the limitations associated with the development and implementation of the diverse methodologies. Finally, Chapter 6 summarises the whole research, sets the final conclusions that can be inferred from the Thesis development, and recognises the future research lines that arise from the present work. 



\section{Chapter 2: \\ State of the Art}



This chapter reviews the existing frameworks and tools for the implementation of WA and FES assessment. For both methodologies, a review of literature and applications is presented in first place (sections 2.1.1 and 2.2.1). Subsequently, the diverse frameworks and tools are critically appraised regarding their potential to contribute to IWRM considering the specific difficulties of water scarce regions highlighted in the Introduction. Since these methodologies have been developed outside the scope of IWRM, it is presumable that they neglect fundamental aspects for IWRM. Their limitations in this regard are identified in sections 2.1.2 and 2.2.2 in order to guide their adaptation before they can be practically applied.

\subsection{Water Accounting}

\subsubsection{Literature review}

WA can be generally defined as the systematic process of identifying, recognising, quantifying, reporting and assuring information about water use in form of water balances in a spatial domain in a certain format (Bureau of Meteorology, 2012). There are two mainstream practices for WA: the economic WA and the physical WA. The first one binds hydrological and economic information together and enables deriving indicators on water resources availability, water use intensity and productivity (UNSD, 2012), while the later only presents physical information on water availability and use together with their corresponding indicators.

\subsubsection{Economic water accounting}

This type of WA originated in France (Margat, 1983; Weber, 1984) and the Netherlands (Keuning and De Haan, 1996; Rossum et al., 2010) in relation with environmental accounts linked to the System of National Accounts (European Commission et al., 1993). Later, it was adopted by the Organisation for Economic Co-operation and Development, the United Nations and the World Bank, resulting in the System of EnvironmentalEconomic Accounting for Water (SEEA-Water) (UNSD, 2012). Currently, it is the most spread WA framework (Momblanch et al., 2014). Besides, it is recommended by the European Commission because it enables calculating the cost of water for the different users as an approximation to the cost recovery established by the WFD. 
Assessment of Ecosystem Services and Water Accounting Methodologies for Integrated Water Resources Management in water scarce basins

The SEEA-Water, summarised in Table 2, comprises seven Flow accounts, and two Asset accounts. Moreover, it includes the Water Quality account and the Water Resource Valuation account, but there is not general consensus about their content and structure yet and, thus, little progress has been achieved (Ahmad et al., 2010). The Flow accounts present the data in physical units. They include the Physical Use table, which shows water withdrawals from the environment by economic activities for direct use or distribution, and the Physical Supply table, which shows water returns to the environment by economic activities and the supply to other economic activities. The Emission accounts contain the gross and net emissions of selected pollutants in treated or untreated wastewater by each economic activity into the environment. Finally, the Hybrid Supply table and the Hybrid Use table combine water volumes and monetary values. The former includes the cost of the water services for their providers, the amount of water supplied and the emissions of pollutants. The later covers the cost of the service for the consumers, the gross fixed capital formation, the exportations in economic units, and the volume of water received from the service providers or extracted from the environment. All these tables have a similar format which presents the water flow concepts (e.g. water source or destination) in rows, and the economic activities supplying or using water in columns, identified according to International Standard Industrial Classification of All Economic Activities (ISIC) (United Nations, 2008).

The second group of SEEA-Water accounts are the Asset accounts. They refer to water volumes and comprise the Asset account, which describes the available water resources at the beginning and at the end of the reported period for the diverse water sources, as well as the changes during the period; and the Matrix of flows between water sources distinguishing reservoirs, lakes, rivers, snow/glaciers, groundwater, soil water and other resources in the territory. For a better insight into water information, the SEEAWater proposes up to six additional tables which complement some of the previously mentioned accounts which are shown in brackets in Table 2 .

From the SEEA-Water accounts, it is possible to derive key water management indicators such as the Non-Sustainable Water Use index, the Relative Water Stress index, the Water Reuse index and the Groundwater Development index (UNSD, 2012; Pedro-Monzonís et al., 2015). Moreover, 
from the Hybrid accounts it is feasible to obtain productivity indicators like the Relative Importance of Agriculture in the Economy and the Industrial Water Productivity (UNSD, 2012). Many more indicators can be obtained using the data in the SEEA-Water account, however the procedure to obtain them is not fully developed, or other external data is needed for their calculation. Further details on the content and structure of this accounting framework, as well as on the calculation of the indicators can be found in UNSD (2012).

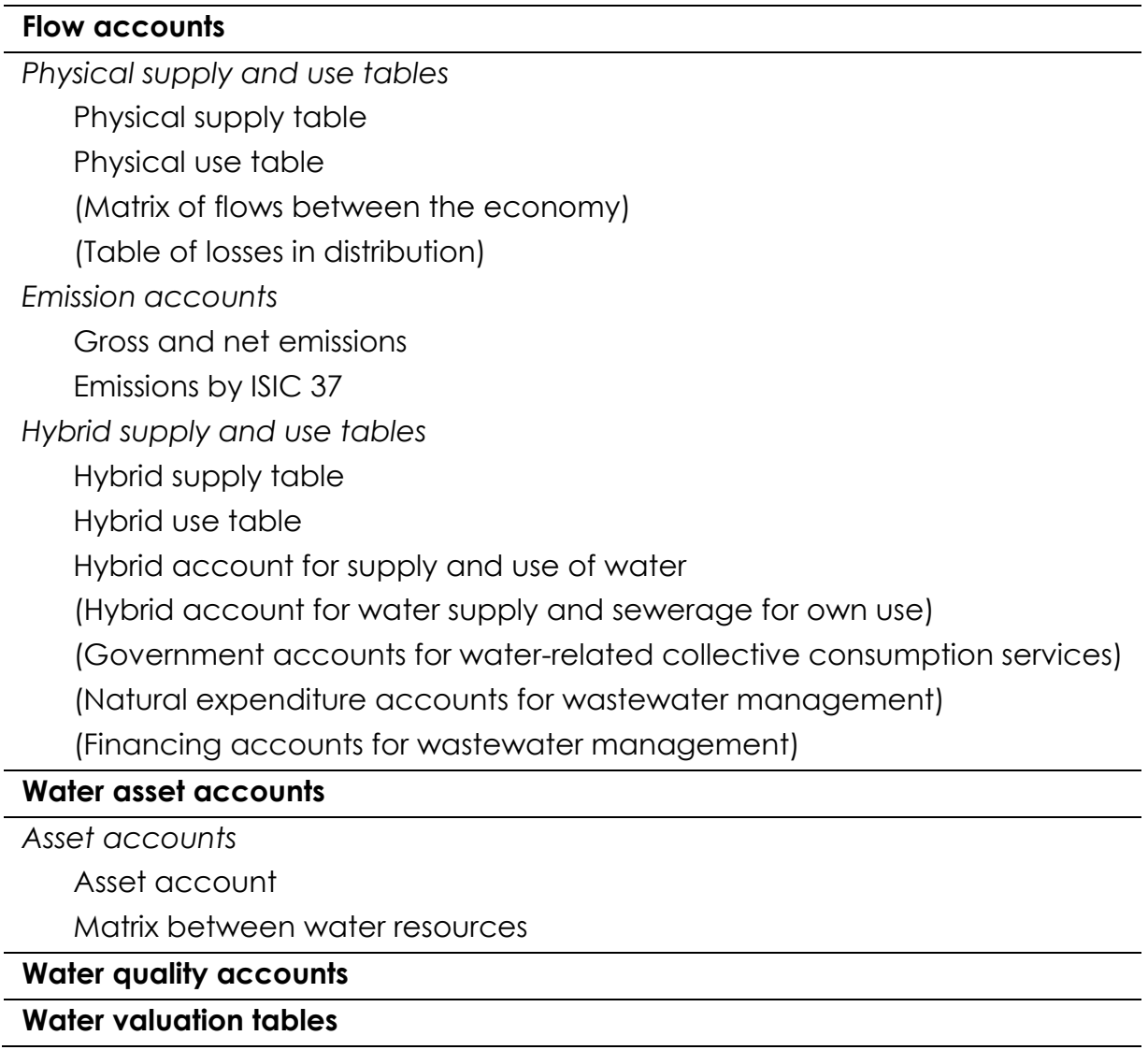

Table 2. Water accounts in the SEEA-Water. Accounts in brackets are supplementary.

This WA framework was initially designed to be implemented annually at national scale; some examples are the applications in Australia (Vardon et al., 2007) and China (Gan et al., 2012). However, its utilization at river basin scale has turned to be more relevant with many examples such as the 
Assessment of Ecosystem Services and Water Accounting Methodologies for Integrated Water Resources Management in water scarce basins

Orange River Basin (Lange et al., 2007), the Vit River Basin (Dimova et al., 2014), the Arno River Basin (Mazzanti et al., 2014), the Duero River Basin (Vicente et al., 2016), the Júcar River Basin (Pedro-Monzonís et al., 2016b), and the Vélez River Basin (Pedro-Monzonís et al., 2016a). Most of these applications propose the use of hydrological and water allocation models in order to generate all the necessary data to fill out the physical tables, instead of combining it with measurements (Dimova et al., 2014; PedroMonzonís et al., 2016a; Pedro-Monzonís et al., 2016b; Vicente et al., 2016). The hydrological models are useful to obtain water stocks and flows related to the water soil balance and surface-groundwater relationships, while the water allocation models allow filling out the water supply and use items as well as testing different management scenarios to be compared through the water accounts. Using models also provides results at a finest time scale and, thus the application cases are implemented at monthly or seasonal scale rather than annual. Regarding hybrid tables, there is a general awareness that direct sources of economic data to fill them in are absent (DG Environment, 2015b; Borrego-Marín et al., 2016). Hence, some studies obtain them only partially or adopt simplified variations (Lange et al., 2007; PedroMonzonís et al., 2016b) and some other do not even implement them (Dimova et al., 2014; Pedro-Monzonís et al., 2016a). The emission accounts are also sparsely represented in practical applications.

\subsubsection{Physical water accounting}

The physical WA has more diverse origins and is more commonly used by water management related entities to control the water they manage. Some examples are the Exploitation Reports by Spanish River Basin Agencies, the Rhur River Association water use reports (Ruhrverband, 2014), and the Colorado River Accounting and Water Use Report for Arizona, California, and Nevada (U.S. Department of the Interior et al., 2016). Two physical WA frameworks should be highlighted for their standardisation basis. These are the Water Accounting of the International Water Management Institute (IWMI-WA) (Molden, 1997) and the Australian Water Accounting Standards (AWAS) (Bureau of Meteorology, 2012).

The Water Accounting of the International Water Management Institute

The IWMI-WA (Molden, 1997) and its improved version Water Accounting Plus (WA+) (Karimi et al., 2013a), aim at establishing the procedure to describe 
the status of water resources and the way they are affected by water uses, as well as identifying water saving and productivity increase opportunities, and supporting the water allocation process. They consider the water balance components at certain spatial scale and classify them according to their use and productivity. In the new version, WA+, information is presented in four sheets which are inspired by the financial bookkeeping sheets of a company. The Resource Base sheet is similar to the Assets and liabilities financial sheet and shows water inflows, depletion processes within the domain and the outflows. From the gross inflow entering the domain through precipitation, upstream runoff, water transfers or desalination, and the changes in water storages, the net inflow can be calculated. This net inflow is divided into landscape evapotranspiration (ET) and exploitable water, which are respectively equivalent to the green water and the blue water defined by Hoekstra and Hung (2002) in the Water Footprint approach. The landscape ET is broken down into land categories regarding the level of human intervention on them. Part of the exploitable water cannot be used inside the domain because it is committed to downstream water uses. From the available water within the domain, one part is depleted as a result of water management and water losses, and there is a remainder water volume which could be used to improve water management but leaves the domain due to lack of regulation capacity or deficient management strategies. Figure 3 presents the content of the Resource Base sheet.

Further detailing the information of the Resource Base sheet, the WA+ includes three more accounts. The Evaporation sheet is comparable to the Profit and loss/expenditure sheet of a company. It classifies the ET processes into managed, manageable and non-manageable. Additionally, it organises the type of water depletion into interception, transpiration and evaporation, which can be considered beneficial or non-beneficial processes depending on whether positive effects can be derived from them or not. The Productivity sheet, which is similar to the Profit sheet of a business, describes the agricultural biomass production per unit of water, and relates it to $\mathrm{CO}_{2}$ sequestration by means of the carbon assimilation capacity of crops. Finally, the Withdrawal sheet reminds of the cash book of a company. It provides information about the flows related to the (blve) water managed inside the domain including water withdrawals, consumptions and returns. 
Assessment of Ecosystem Services and Water Accounting Methodologies for Integrated Water Resources Management in water scarce basins

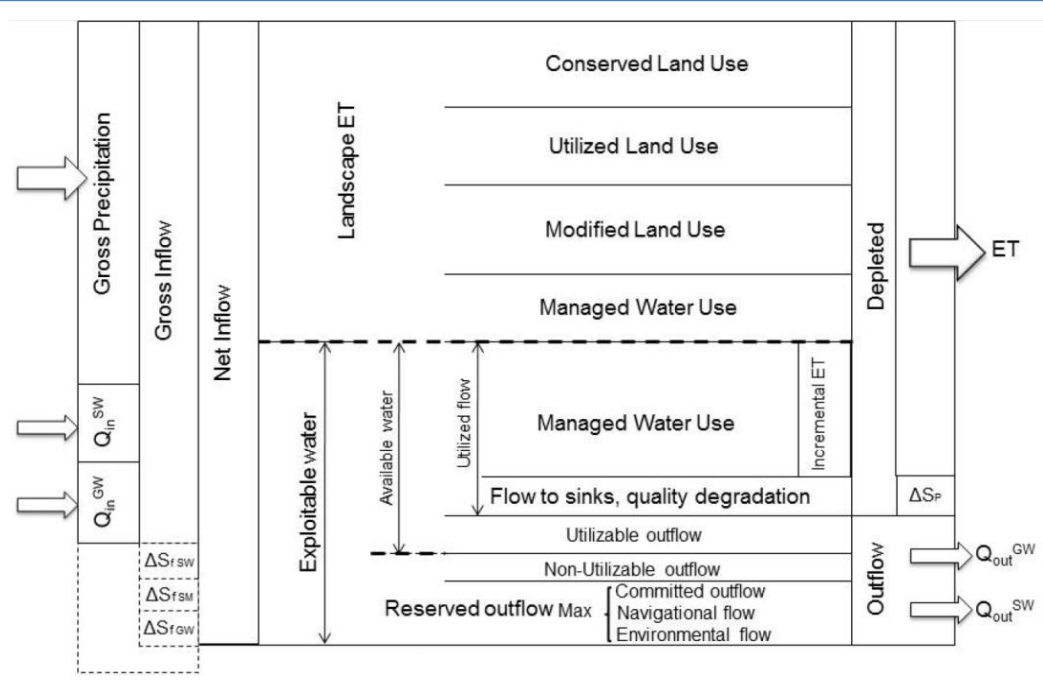

Figure 3. Resource Base sheet of the WA+ (Karimi et al., 2013a).

All the information summarised in the WA+ sheets can be directly translated into performance indicators of the status of water resources and their level of exploitation. From the Resource Base sheet, the Exploitable water fraction, the Storage change fraction, the Available water fraction, the Basin closure fraction and the Reserved outflows fraction can be derived. The data on the Evapotranspiration sheet contributes to estimating the Transpiration fraction, the beneficial ET fraction, the Managed ET fraction, the Agricultural ET fraction and the Irrigated ET fraction. At last, the Groundwater withdrawal fraction, the Classical irrigation efficiency and the Recoverable fraction are derived from the Withdrawal sheet. Further details on the content and structure of this accounting framework, as well as on the calculation of the indicators can be found in Karimi (2013a).

As stated by Karimi et al. (2013a), the recommended accounting period for IWMI-WA and WA+ is one year, but it can be applied at seasonal or shorter scales as far as data are available. The IWMI-WA framework was designed to be applied to irrigation schemes. Nonetheless, the IWMI-WA methodology has been applied in numerous river basins (Molden, 1997; Roost et al., 2003; Peranginangin et al., 2004; Shilpakar et al., 2011). Conversely, the WA+ was created with a river basin scale scope. Some examples of implementation of the improved methodology WAt are the Indus (Karimi et al., 2013b), Awash (Karimi et al., 2015), Okavango (Droogers et al., 2010), and the Ca 
(Bastiaanssen et al., 2015) river basins, and partial applications in the Incomati, Mara, and Naivasha river basins (Water Accounting+, 2016). The WA+ study cases emphasise the importance of remote sensing data in order to calculate the diverse ET components. Some of them also comment on the importance of models to generate the information regarding groundwater storage and flows (Bastiaanssen et al., 2015; Karimi et al., 2015).

\section{The Australian Water Accounting Standards}

The AWAS results from the National Water Initiative, an extensive reform related to water management undertaken by the Australian government around 2004. The reform proposed the establishment of water markets which brought about the need for improved water use control. The AWAS define the content and presentation of the General Purpose Water Accounting Reports (GPWAR). These reports are meant to improve transparency towards water users, so that they can comprehend and evaluate the decisions made by water managers of a certain water entity. The GPWAR include a description of the water entity domain, an assurance statement for the content of the report, the water accounts (Table 3), and supporting information which includes explanations about the origin of the data presented in the accounts and the associated calculation errors, as well as other relevant aspects for water management (Australian Accounting Standard Board and Bureau of Meteorology, 2012).

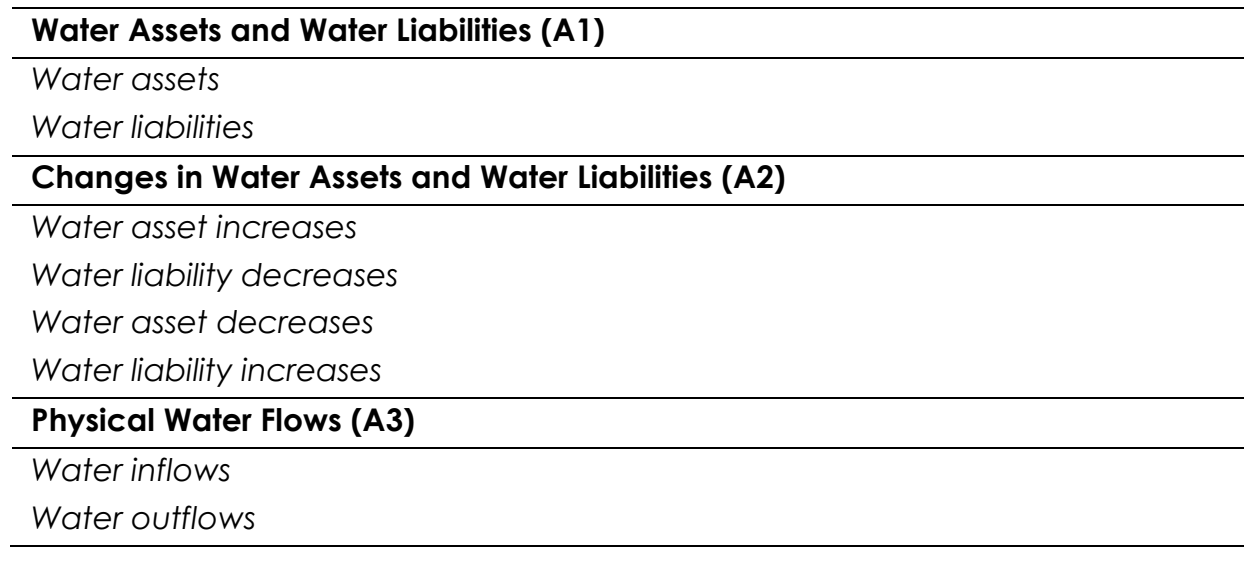

Table 3. Main groups of accounting concepts in the AWAS statements.

The water accounts are based on the Framework for the Preparation and Presentation of Financial Statements of companies (Australian Accounting 
Assessment of Ecosystem Services and Water Accounting Methodologies for Integrated Water Resources Management in water scarce basins

Standard Board, 2004). Consequently, there are significant similarities between the water accounts and financial accounts regarding terminology and format (Momblanch et al., 2014). As explained in Momblanch et al. (2014), the Water Assets and Water Liabilities account (A1) is comparable to the Statement of Financial Position of a Company which shows its assets and financial obligations or liabilities at the end of a reporting period. In parallel, Al contains the water resources possessed by the water entity physically or for vested right (assets) and the water supply duties acquired during the reporting period that are to be supplied in the next period (liabilities). The second account, Changes in Water Assets and Water Liabilities (A2), is inspired by the Financial Performance of a company. This account shows the gains and losses (of water or money) taking place in the reporting period physically or for vested right in accordance with the accrual basis of financial accounting. A1 and A2 apply the accrual basis of financial accounting by which the transactions and transformations are recognised when the decisions or commitments that give rise to them occur, regardless of the realisation of the physical transaction or consumption. Finally, the account of Physical Water Flows (A3) is analogous to the Cash Flows account in financial accounting. It presents the physical inflows and outflows which occur in the reporting period.

Based on financial balances, some indicators can be derived from the water accounts, which provide information about the changes occurred in the water entity and that link the figures in the different water accounts. These indicators are the Changes in net water resources and the Changes in net water storage, and the Unaccounted for difference which quantifies the global error in the estimation of all the values in the water accounts. Further details on the content and structure of this accounting framework can be found in Bureau of Meteorology (2012).

According to the AWAS, the GPWAR should be published on annual basis by water reporting entities. These entities have the responsibility to inform their users about the water or water rights they hold and transfer, the direct or indirect claims to water, or the inflows and/or outflows of water (Momblanch et al., 2014). Water entities such as River Basin Agencies, water supply companies and irrigation associations fit the definition of water reporting entities. This makes evident the flexibility of the application scale of the 
AWAS. Most examples of application of the AWAS are limited to Australian water reporting entities, including the regions of Adelaide, Sydney, Canberra, Melbourne, Perth, Ord and Daly, and the basins of the MurrayDarling, Burdekin and South East Queensland rivers, from 2010 to 2015 for all of them (Bureau of Meteorology, 2016). However, there are some examples of their application in other countries such as South Africa (Hughes et al., 2012) or Spain (Andreu et al., 2012; Momblanch et al., 2014). A general critique is the lack of sufficient and reliable information to complete all the accounting concepts (Hughes et al., 2012) that forces the use of models and indirect estimations (Momblanch et al., 2014).

\subsubsection{Critical assessment}

As highlighted in the introduction, the ever growing complexity of water management and the need to achieve IWRM calls for better coordination, accountability and accounting for water. WA can be considered as an accurate technique to assist in transparent management of a scarce resource, such as water, by recording and reporting the relevant data about its availability and use (Lund, 2012; Momblanch et al., 2014). This, potentially leads to more efficient water use and improved governance capacity in water resources management (Momblanch et al., 2014).

Accountants have traditionally dealt with inventory management, national accounts preparation and the presentation of decision making information, and so they could provide useful advice for the successful development of this new type of accounting (Ahmad et al., 2010). The application of financial accounting principles to water as well as setting an accounting standard and reporting framework is supported by the general public (Tello et al., 2016). In fact, as it can be observed in section 2.1.1, all WA frameworks have somehow adopted a financial accounting approach. Because of this, they tend to be very exhaustive and include not only the relevant information for water users but the description of the whole water cycle, (Momblanch et al., 2014). Given that water volume and flow measurements are much more inaccurate than currency appraisal, such a detailed WA may have a detrimental effect on the primary purpose of WA transmitting uncertainty rather than assurance (Momblanch et al., 2014). 
Assessment of Ecosystem Services and Water Accounting Methodologies for Integrated Water Resources Management in water scarce basins

In order to define the desirable features of WA standards, we should look at the purposes of their application. The European policies analysed in section 1.3.1 consider WA as a useful tool in order to achieve efficient allocation, control and governance of water resources. As established by the WFD, water management is performed at river basin scale and, therefore, WA should be applicable at this spatial domain (Dimova et al., 2014). In line with this, and from the IWRM perspective, WA should present complete information about water flows and storages relevant for the functioning of the water management system and which can be controlled by water managers (Momblanch et al., 2014). Moreover, WA should follow standard procedures for the compilation and presentation of information, and use a clear and intuitive nomenclature (Momblanch et al., 2014). Besides, the ideal situation would be having accurate records for all accounted terms which enable genuinely detailed accounting (Momblanch et al., 2014) and minimising the use of secondary data such as model results. These features can be used as assessment criteria to determine the potential of the diverse WA frameworks to contribute to IWRM in water scarce regions.

The SEEA-Water proposes a standardised way of compiling water information in line with the System of National Accounts (SNA). Thus, it uses double-entry tables similar to the ones in the SNA which are clear and understandable. Besides, its emphasis is on the integration of environment-economic data to support the development of indicators for sustainability (Mungatana and Hassan, 2012). However, the different water uses are classified based on the ISIC which provides much detail for industrial users, while it groups irrigation users, which in many regions represent up to $80 \%$ of total water demand, in a single column. The ISIC does not match the way in which stakeholders perceive reality, what hinders the transmission of information. Finally, compiling economic water accounts for a river basin poses special difficulties because information about costs of water services for users and producers are usually compiled at administrative scale rather than at river basin scale (Lange et al., 2007; Dimova et al., 2014).

The IWMI-WA is very intuitive since information is presented with the traditional water balance format (inflows, use/consumption, and outflows). If the representation of water flows is detailed enough it provides information to assess the water management carried out by the different water uses in 
the accounting domain, which can be the river basin. However, it does not propose a standard presentation of WA information and some of the concepts it uses are subjective (e.g. beneficial versus non-beneficial consumption). The improved version, WA+, partially solves the mentioned drawbacks as it follows the bookkeeping financial standards to organise information. Nevertheless, it still requires a value judgement to define beneficial and non-beneficial processes (Karimi et al., 2013a).

Analysing the AWAS according to the assessment criteria, it fits most of them. AWAS proposes standardised water accounts with a straightforward structure. Information is classified and presented in a way that allows the end user to comprehend it and derive benefits from the availability of the information (Mungatana and Hassan, 2012). It focuses on the monitoring of water and subsequent reporting rather than providing statistics (Chalmers et al., 2009). Furthermore, it can be easily applied at different spatial scales including the river basin scale. Besides, the application of the accrual basis of financial accounting allows representing the commitments that the entity has towards its users through the explicit reckoning of water allocations which are the previous stage to water supply. However, unlike the SEEAWater, the AWAS does not consider water quality and economic aspects.

A common feature of all the analysed WA frameworks is that they identify and present the different water sources in the accounting domain. This is crucial in water scarce river basins where the state of water reserves determines the activation of additional resources to assure the water supply (Pedro-Monzonís et al., 2016b). Nonetheless, none of them is able to represent water flows between the same type of water resources (surface or groundwater). Also regardless the WA framework, the use of models is unavoidable since the required amount of physical information to fill in the water accounts is huge. However, the IWMI-WA, WA+ and AWAS only require models for groundwater concepts being possible to determine the rest of values from direct or indirect measurements. On the contrary, the SEEAWater also needs models to complete some figures in the Asset Accounts (Pedro-Monzonís et al., 2016a) like the water supplies from reservoirs and rivers, and the IWMI-WA and the WA+ rely on remote sensing data for many WA concepts mostly regarding ET (Karimi et al., 2013b; Karimi and Bastiaanssen, 2015). 
Assessment of Ecosystem Services and Water Accounting Methodologies for Integrated Water Resources Management in water scarce basins

Table 4 summarises the compliance of the different WA frameworks with the assessment criteria previously defined. According to these desirable features, the WA+ and the AWAS are the most suitable WA frameworks to support IWRM in water scarce regions. If we also take into account that the AWAS is the framework which requires less information from models, it can be considered as the most recommendable.

\begin{tabular}{|c|c|c|c|c|c|}
\hline & 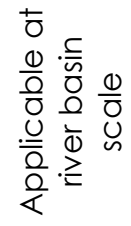 & 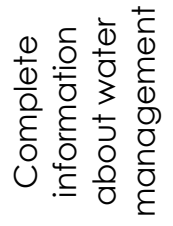 & 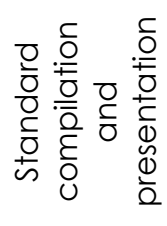 & 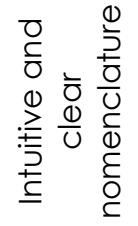 & 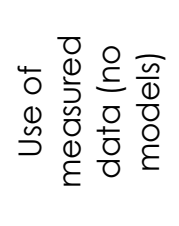 \\
\hline SEEA-Water & & $x$ & $x$ & & \\
\hline IWMI-WA & $x$ & $x$ & & $x$ & $(X)$ \\
\hline WA+ & $x$ & $x$ & $x$ & $x$ & $(X)$ \\
\hline AWAS & 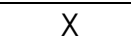 & $\bar{x}$ & $\bar{x}$ & $\bar{x}$ & $(X)$ \\
\hline
\end{tabular}

Table 4. Summary table of the suitability assessment of water accounting frameworks for IWRM in water scarce regions.

\subsection{Freshwater Ecosystem Services}

\subsubsection{Literature review}

ES are defined as "the conditions and processes through which natural ecosystems, and the species that make them up, sustain and fulfil human life" (Daily, 1997), or in a simpler way as "the benefits people obtain from ecosystems" (MA, 2003). The origin of the concept dates back between the late 70s and early 80s (Haines-Young and Potschin, 2010). However, it was with the publication of the Millennium Ecosystem Assessment (MA) (2003) when it notably emerged as a methodology for natural capital evaluation, seeking for environmental preservation and the application of multidisciplinary approaches (Munns et al., 2015). The number of studies quantifying and valuing ES has risen exponentially since then (Fisher et al., 2009; Potschin and Haines-Young, 2011), as well as the amount of tools available for ES assessment. The following sections describe the main frameworks and tools related to ES. 


\subsubsection{Ecosystem Services frameworks}

The MA was the first international standard proposing a method to link the services provided by ecosystems and human well-being. It classifies ES into four categories. The provisioning services are the goods produced by nature which are directly consumed by people such as fish; the regulating services involve the ecosystem processes that maintain and moderate environmental conditions like water purification by wetlands; the cultural services include non-material benefits such as recreational, educational, aesthetic and spiritual; and the supporting services underpin the other three categories through soil formation for example.

The MA was the trigger that spread the ES approach, by stressing the loss of ES at global scale and its consequences for human well-being. Afterwards, other standard ES classifications have been proposed such as The Economics of Ecosystems and Biodiversity (TEEB, 2010), the Common International Classification of Ecosystem Services (CICES) (Haines-Young and Potschin, 2013), and the United Kingdom National Ecosystem Assessment (UK NEA, 2011). As presented in Table 5, these ES frameworks coincide in organising the ES into provisioning, regulating and cultural categories depending on the way benefits are perceived by people. They only consider final services, for which a benefit to people can be derived, no matter if they are end products or environmental processes. Hence, they claim for the exclusion of the supporting services which are best regarded as intermediate services or ecological functions, with the aim of avoiding double counting and highlighting the environment-economy connection (Haines-Young and Potschin, 2009). This connection is best demonstrated by the ES cascade (Potschin and Haines-Young, 2011) (Figure 4) which shows the causal links from a change in biophysical state to the ecosystem change and the impact on ES, benefits and human welfare (Momblanch et al., 2016). Notice that, as commented in the introduction, the provision of water for human uses is considered an ES and, therefore, the economic benefits of water supply are implicit in the ES assessment. 
Assessment of Ecosystem Services and Water Accounting Methodologies for Integrated Water Resources Management in water scarce basins

\begin{tabular}{|c|c|c|c|}
\hline MA & TEEB & CICES & UK NEA \\
\hline \multicolumn{4}{|c|}{ Provisioning } \\
\hline Food & Food & Nutrition & Food \\
\hline Freshwater & Water & Water & Water supply \\
\hline Fibre & Raw materials & \multirow{4}{*}{ Materials } & Fibre, energy \\
\hline Genetic resources & Genetic resources & & Bioprospecting \\
\hline $\begin{array}{l}\text { Biochemical } \\
\text { resources }\end{array}$ & $\begin{array}{l}\text { Medicinal } \\
\text { resources }\end{array}$ & & Medicinal plants \\
\hline \multirow[t]{2}{*}{ Ornamental } & Ornamental & & \\
\hline & & $\begin{array}{l}\text { Materials \& energy } \\
\text { from animals }\end{array}$ & \\
\hline \multicolumn{4}{|c|}{ Regulating } \\
\hline Climate regulation & Climate regulation & \multirow{2}{*}{$\begin{array}{l}\text { Global climate } \\
\text { regulation }\end{array}$} & Climate regulation \\
\hline $\begin{array}{l}\text { Air quality } \\
\text { regulation }\end{array}$ & $\begin{array}{l}\text { Air quality } \\
\text { regulation }\end{array}$ & & Pollution control \\
\hline & & \multirow{2}{*}{$\begin{array}{l}\text { Mediation of waste } \\
\& \text { toxics }\end{array}$} & Noise regulation \\
\hline \multirow{4}{*}{ Water regulation } & Water treatment & & Pollution control \\
\hline & $\begin{array}{l}\text { Regulation of } \\
\text { water flows }\end{array}$ & Hydrological cycle & \\
\hline & Extreme events & Flood protection & Flood protection \\
\hline & Erosion control & $\begin{array}{l}\text { Mass flow } \\
\text { stabilisation }\end{array}$ & Erosion control \\
\hline Soil formation & $\begin{array}{l}\text { Maintenance of } \\
\text { soil fertility }\end{array}$ & Soil formation & \\
\hline Pollination & Pollination & Pollination & Pollination \\
\hline Pest regulation & \multirow{2}{*}{ Biological control } & Pest control & Pest regulation \\
\hline Disease regulation & & Disease control & Disease regulation \\
\hline \multirow{2}{*}{$\begin{array}{l}\text { Supporting } \\
\text { Primary production } \\
\text { \& nutrients cycle }\end{array}$} & $\begin{array}{l}\text { Lifecycle } \\
\text { maintenance }\end{array}$ & \multirow{2}{*}{$\begin{array}{l}\text { Lifecycle } \\
\text { maintenance }\end{array}$} & \\
\hline & $\begin{array}{l}\text { Maintenance of } \\
\text { genetic diversity }\end{array}$ & & \\
\hline \multicolumn{4}{|c|}{ Culfural } \\
\hline $\begin{array}{l}\text { Recreation and } \\
\text { eco-tourism }\end{array}$ & $\begin{array}{l}\text { Recreation and } \\
\text { eco-tourism }\end{array}$ & $\begin{array}{l}\text { Recreation and } \\
\text { tourism }\end{array}$ & $\begin{array}{l}\text { Wild species } \\
\text { diversity }\end{array}$ \\
\hline Aesthetic & Aesthetic & Aesthetic & \multirow{4}{*}{$\begin{array}{l}\text { Environmental } \\
\text { features }\end{array}$} \\
\hline Cultural diversity & Cultural diversity & Cultural diversity & \\
\hline $\begin{array}{l}\text { Spiritual and } \\
\text { religious values }\end{array}$ & Spiritual experience & $\begin{array}{l}\text { Symbolic, sacred or } \\
\text { religious }\end{array}$ & \\
\hline Educational values & Educational values & Educational values & \\
\hline
\end{tabular}

Table 5. Comparative of most relevant standard ES assessment frameworks. 


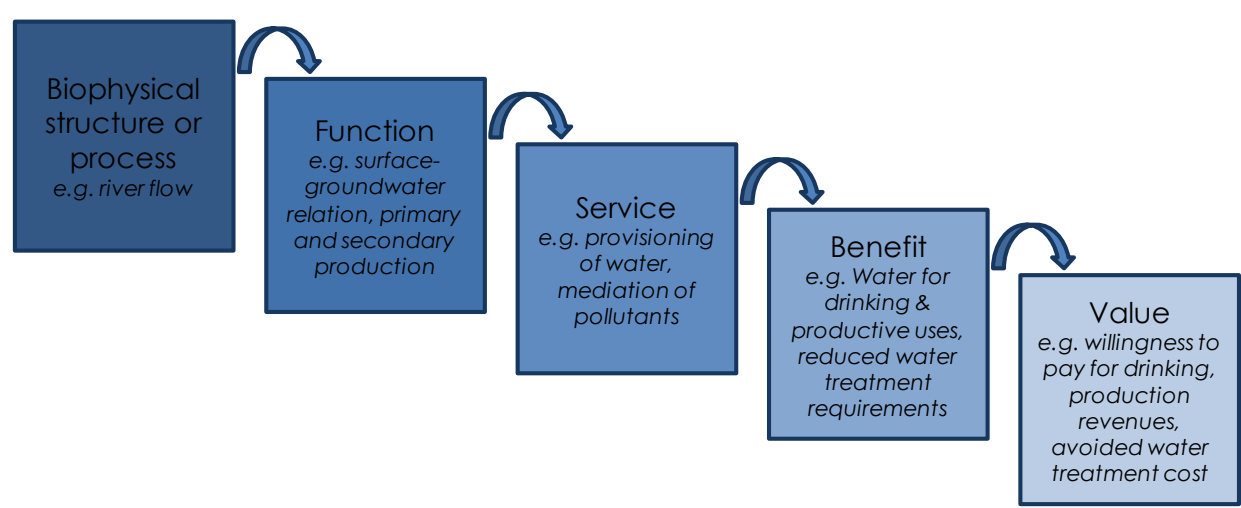

Figure 4. Ecosystem services cascade exemplifying some effects of river flow change due to water management. Modified by Momblanch et al. (2016) from Potschin and HainesYoung (2011).

Once the ES are identified and quantified in biophysical units, the benefits they provide should be valued in monetary units. Economic units are recommended as the language to report decision makers, since political decisions are often evaluated through cost-benefit assessments (Fisher et al., 2008). It is important to make clear that one ES can provide more than one benefit; for example, the water purification ES provides reduced water treatment requirements and improved opportunities for recreation such as bathing (Terrado et al., 2016a).

The ES approach adopts the utilitarian paradigm of value that is based on the principle of people's satisfaction. The total economic value (TEV) is a widely used framework for looking at the utilitarian value of ecosystems (Pearce et al., 1989). It is defined as the sum of the use and non-use values of all service flows now and in the future, valued for marginal changes in their provision (TEEB, 2010). The use and non-use values can be disaggregated into different components; direct and indirect use for the former, and bequest, altruist and existence values for the later. Each of these components can be valued using different valuation techniques depending on the type of benefit provided by the ES. A summary of the common standard valuation typologies found in literature (de Groot et al., 2002; Chee, 2004b; Tietenberg and Lewis, 2009; TEEB, 2010; Costanza et al., 2011) is presented in Momblanch et al. (2016): 
Assessment of Ecosystem Services and Water Accounting Methodologies for Integrated Water Resources Management in water scarce basins

- Market value or consumer surplus: For ES that produce goods with market prices, e.g. cultivated crop. If the price does not include the impact of use on their availability for other users and the environment, e.g. drinking water, the value is derived from the marginal willingness-to-pay using econometric approaches.

- Production-based: For ES which provide factors of production for goods or services traded on the market, e.g. water for agricultural production. Value is estimated as the contribution to the net revenues obtained from the produced good or service in the market.

- Cost-based: The value of the benefit is based on the costs of replacing the ES (replacement cost method), e.g. mediation of waste, or on the avoided mitigation damages given the presence of the ES (avoided cost method), e.g. flood protection.

- Revealed preferences: The travel cost method assumes that the benefit of an ES can be approximated with the expenses incurred to enjoy it, e.g. aquatic recreation by considering transportation expenses, on site spending and protected area entrance fees. The hedonic price method relates the benefit of an ES with the price variation of associated goods for different production levels or quality of the ES, e.g. aesthetic water related amenity by considering the difference in market prices for real estate assuming all variables influencing real estate sales are equal except the aesthetic ES.

- Stated preferences: Surveys designed to elicit the benefits people ascribe to an ES. Respondents are usually asked how much they would be willing to pay for a specific improvement in the ES (contingent valuation method), or they are asked to select one among a number of alternatives for improvement of the ES, where the price or cost required to pay for improved ES condition is a key attribute (choice experiment method). This method is applicable to non-consumptive ES such as aquatic biodiversity.

- Benefit transfer (or meta-analysis): Takes estimates of ES benefits from one site and applies them to another site.

\subsubsection{Models for ecosystem services assessment}

The rise of ES assessment as a methodology to support environmental management has been accompanied with the proliferation of simulation 
models for ES evaluation or ES tools. Simulation models are useful to perform scenario analyses that consider the effect of measures and policy instruments on target variables, which are basic to support informed decisions (Loucks and van Beek, 2005). In general, ES tools are helpful to provide a general picture of the state of several ES and their tradeoffs under different scenarios whilst they are attainable by non-experts (Terrado et al., 2014). They can potentially provide standard results which are comparable at different geographic regions, and can be easily parameterised, but each ES tool has a different approach to economic valuation, spatial and temporal representation of ES, and incorporates different biophysical models (Bagstad et al., 2013a). A thorough review of ES tools can be found in (Bagstad et al., 2013a).

The most known ES tool is probably Integrated Valuation of Ecosystem Services and Tradeoffs (InVEST) (Tallis et al., 2013). InVEST is a spatially explicit ES tool to estimate levels of different benefits at annual scale (Terrado et al., 2016a) consisting of nine marine and coastal models (i.e. coastal blue carbon, coastal vulnerability, fisheries, habitat risk, marine fish aquaculture, marine water quality, near shore waves and erosion, and offshore wind energy) and nine freshwater and terrestrial models (i.e. carbon sequestration, crop pollination, landscape habitat quality, recreation, reservoir hydropower production, scenic quality, sediment retention, and water purification by the landscape). It provides results in biophysical and monetary units as GIS maps. Tradeoffs between the different ES should be analysed by comparing the output maps of the different models (Bagstad et al., 2013b).

Regarding FES, InVEST only considers landscape processes (as opposed to instream processes) and applies simplified hydrological relationships whose main input is land use-land cover maps, which are linked to certain characteristics of biophysical parameters such as roots depth, nutrient retention capacity, and habitat types and sensitivity. The main application for InVEST is the assessment of impacts due to land cover change on multiple ES in large river basins (Nelson et al., 2009; Goldstein et al., 2012; Terrado et al., 2014), while the major limitation is its inability to represent temporal variability of processes, groundwater and water resources infrastructures and management (Vigerstol and Aukema, 2011). 
Assessment of Ecosystem Services and Water Accounting Methodologies for Integrated Water Resources Management in water scarce basins

Another well known, generalisable, open-source ES tool is the web-based software Artificial Intelligence for Ecosystem Services (ARIES) (Bagstad et al., 2011; Villa et al., 2014). It applies a probabilistic Bayesian network approach which uses a library of models and spatial data to quantify ES flows and uncertainty when little data is available (Bagstad et al., 2013b), but it also allows employing biophysical relationships when enough data is accessible (Vigerstol and Aukema, 2011). The ES that can be assessed with ARIES are carbon sequestration, flood regulation, coastal flood regulation, nutrient regulation, sediment regulation, water supply, fisheries, pollination, aesthetic, open space proximity, and recreation. ARIES provides quantitative, spatially explicit results that account for uncertainty in a timeframe ranging from hours to years, but do not value the ES in economic units (Villa et al., 2014). The output maps show the location of ES production and consumption as well as the flow paths between them (Vigerstol and Aukema, 2011). This ES tool is best suited to applications in land use planning for protection and restoration of areas providing many ES (Bagstad et al., 2013b; Villa et al., 2014), and not so much for FES. The main drawback of ARIES is its complexity, which can hinder the understanding of the modelled processes and the results for decision makers and stakeholders (Vigerstol and Aukema, 2011).

On the other hand, as highlighted in Momblanch et al., (under review) there are many studies that focus on one ES and apply very detailed models that are able to represent the processes involved with high accuracy (Lonsdorf et al., 2009; Kovacs, 2012; Honey-Rosés et al., 2013; Bryan et al., 2014; Bagdon et al., 2016). In the case of FES, traditional water resources management tools or IWRM tools can be adapted to conduct FES assessments (Vigerstol and Aukema, 2011; Dennedy-Frank et al., 2016). Hydrological models such as SWAT (Arnold et al., 1998) or VIC (Liang et al., 1994) have been used for this purpose, and compared with the results of ES tools (Vigerstol and Aukema, 2011; Dennedy-Frank et al., 2016). Besides, water allocation models like WEAP could be utilised (Yates et al., 2005; Vigerstol and Aukema, 2011), as well as water quality models (Keeler et al., 2012), and habitat suitability models (CSIRO, 2012) among others. A detailed description of IWRM tools can be found in Momblanch (2013). 


\subsubsection{Critical assessment}

The ES assessment is recognised by some authors as a systematic way to implement IWRM (Roy et al., 2011; Kandulu et al., 2014). More specifically, it is a thorough way to analyse the relevant environmental impacts of water management using the environment-economy connection (Momblanch et al., 2016). Actually, there is a strong relationship between ES and IWRM concepts (Cook and Spray, 2012; Vlachopoulou et al., 2014) since they both promote management of land and water resources ensuring the sustainability of ecosystems. These concepts are not just linked by their definitions. In fact, water resources management determines the state of some FES like water purification in rivers and lakes; and FES like water provision for economic uses have a direct influence in the water resources systems functioning (Momblanch, 2013). Thus, the FES assessment can be considered a promising approach to improve environmental sustainability in IWRM.

From the attempts to apply the MA framework, some inconsistencies have arisen. Boyd and Banzhalf (2007) argued that the use of "ecological function", "service" and "benefit" in the MA framework was unclear, while Wallace (2007; 2008) considered that MA confused ends with means what can lead, for instance, to double counting when conducting valuation. Many authors have contributed to the discussion about what should be considered as an ES. Some of them defend that only the end-products of nature should be accounted for (MA, 2005; Wallace, 2007), while others believe that also some environmental processes should be included as long as they contribute to human welfare (Boyd and Banzhaf, 2007; Costanza, 2008; Fisher and Turner, 2008).

Trying to overcome these conflicts, the TEEB, the CICES and the UK NEA proposed removing the supporting category. However, the TEEB includes the habitat category that seems to have a supporting role (Haines-Young and Potschin, 2009). Something similar happens with the CICES and the UK NEA classifications, which include as ES the maintenance of nursery populations and habitats, and the wild species diversity, respectively. By doing this, they try to highlight the importance of biodiversity in any typology that support the anthropocentric arguments for natural capital conservation (HainesYoung and Potschin, 2009). The solution adopted in most studies to assess 
Assessment of Ecosystem Services and Water Accounting Methodologies for Integrated Water Resources Management in water scarce basins

these fuzzy ES is to associate them with concrete benefits to humans such as food provision or recreation, and the solution to avoid double counting is to account only for the part of the value which ultimately relies on the specific habitat (Liquete et al., 2016). Another example of deficiencies which are made evident during practical implementation of ES assessments is the independent consideration of water regulation and water provisioning by all ES classifications. As stated by Maes et al. (2011), the water regulation refers to the water storage potential of the landscape and it is strongly related with the water provisioning service. Because of that, making the distinction between both based on surface and subsurface flow is unclear. Consequently, they are to be considered as a single FES in the present research.

Despite the differences between ES classifications and their imperfections, all of them are necessary for different analytical purposes to reflect the complexity of nature and its processes (Costanza, 2008). Overall, the use of an ES framework is a systematic and thorough way to select the relevant impacts likely affected by water management actions (Momblanch et al., 2016). Since none of the ES frameworks is free of criticism, the set of ES to assess in the current research is mostly based on the CICES because it is the most complete and detailed framework (see Table 5), but proposes some adaptations which are presented in section 3.2. Table 6 shows the ES which are potentially provided by freshwater bodies (i.e FES). In line with Momblanch et al. (2016), the water bodies comprise all the river basin elements which can be affected by water management (quantity and quality); rivers including riverbed and riverbanks; wetlands considering the different types (e.g. US Hydro-geomorphic classification or the simplification proposed by Turner et al. (2008); aquifers; and reservoirs).

\begin{tabular}{|c|c|c|c|}
\hline & Division & Group & Class \\
\hline \multirow{8}{*}{ 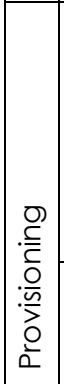 } & \multirow{6}{*}{ Biomass } & \multirow{4}{*}{ Nutrition } & Wild plants, algae and their outputs \\
\hline & & & Wild animals and their outputs \\
\hline & & & Plants and algae from in-situ aquaculture \\
\hline & & & Animals from in-situ aquaculture \\
\hline & & \multirow{2}{*}{ Water } & Surface water for drinking \\
\hline & & & Ground water for drinking \\
\hline & \multirow[t]{2}{*}{ Materials } & Biomass & $\begin{array}{l}\text { Fibres and other materials from plants, algae } \\
\text { and animals for direct use or processing }\end{array}$ \\
\hline & & & Materials from plants, algae and animals for \\
\hline
\end{tabular}


State of the art

\begin{tabular}{|c|c|c|c|}
\hline & Division & Group & Class \\
\hline & & & agricultural use \\
\hline & & & Genetic materials from all biota \\
\hline & & \multirow{2}{*}{ Water } & Surface water for non-drinking purposes \\
\hline & & & Ground water for non-drinking purposes \\
\hline & \multirow{4}{*}{$\begin{array}{l}\text { Mediation of } \\
\text { waste, toxics and } \\
\text { other nuisances }\end{array}$} & \multirow{2}{*}{$\begin{array}{l}\text { Mediation by } \\
\text { biota }\end{array}$} & $\begin{array}{l}\text { Bio-remediation by micro-organisms, algae, } \\
\text { plants, and animals }\end{array}$ \\
\hline & & & $\begin{array}{l}\text { Filtration/sequestration/storage/accumulation } \\
\text { by micro-organisms, algae, plants, and } \\
\text { animals }\end{array}$ \\
\hline & & \multirow{2}{*}{$\begin{array}{l}\text { Mediation by } \\
\text { ecosystems }\end{array}$} & $\begin{array}{l}\text { Filtration/sequestration/storage/accumulation } \\
\text { by ecosystems }\end{array}$ \\
\hline & & & $\begin{array}{l}\text { Dilution by atmosphere, freshwater and } \\
\text { marine ecosystems }\end{array}$ \\
\hline \multirow{8}{*}{ 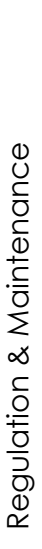 } & \multirow{4}{*}{$\begin{array}{l}\text { Mediation of } \\
\text { flows }\end{array}$} & \multirow{2}{*}{ Mass flows } & Mass stabilisation and control of erosion rates \\
\hline & & & Buffering and attenuation of mass flows \\
\hline & & \multirow[t]{2}{*}{ Liquid flows } & $\begin{array}{l}\text { Hydrological cycle and water flow } \\
\text { maintenance }\end{array}$ \\
\hline & & & Flood protection \\
\hline & \multirow{4}{*}{$\begin{array}{l}\text { Maintenance of } \\
\text { physical, } \\
\text { chemical, } \\
\text { biological } \\
\text { conditions }\end{array}$} & \multirow{2}{*}{$\begin{array}{l}\text { Lifecycle } \\
\text { maintenance, } \\
\text { habitat and } \\
\text { gene pool }\end{array}$} & Pollination and seed dispersal \\
\hline & & & Maintaining nursery populations and habitats \\
\hline & & \multirow{2}{*}{\begin{tabular}{|l|} 
Atmospheric \\
composition and \\
climate \\
regulation
\end{tabular}} & $\begin{array}{l}\text { Global climate regulation by reduction of } \\
\text { greenhouse gas concentrations }\end{array}$ \\
\hline & & & Micro and regional climate regulation \\
\hline \multirow{11}{*}{$\begin{array}{l}\overline{0} \\
\frac{D}{\partial} \\
\frac{1}{\partial} \\
U\end{array}$} & \multirow{7}{*}{$\begin{array}{l}\text { Physical and } \\
\text { intellectual } \\
\text { interactions }\end{array}$} & \multirow{2}{*}{$\begin{array}{l}\text { Physical and } \\
\text { experiential } \\
\text { interactions }\end{array}$} & $\begin{array}{l}\text { Experiential use of plants, animals and land- } \\
\text { /seascapes }\end{array}$ \\
\hline & & & Physical use of land-/seascapes \\
\hline & & \multirow{5}{*}{$\begin{array}{l}\text { Intellectual and } \\
\text { representative } \\
\text { interactions }\end{array}$} & Scientific \\
\hline & & & Educational \\
\hline & & & \begin{tabular}{|l|} 
Heritage, cultural \\
\end{tabular} \\
\hline & & & Entertainment \\
\hline & & & Aesthetic \\
\hline & \multirow{4}{*}{$\begin{array}{l}\text { Spiritual, symbolic } \\
\text { and other } \\
\text { interactions }\end{array}$} & \multirow{2}{*}{$\begin{array}{l}\text { Spiritual and/or } \\
\text { emblematic }\end{array}$} & Symbolic \\
\hline & & & Sacred and/or religious \\
\hline & & Other cultural & Existence \\
\hline & & outputs & Bequest \\
\hline
\end{tabular}

Table 6. Water-related ES in the CICES framework. Adapted from Momblanch ef al. (2016).

Valuation of FES benefits can be carried out by using value functions (or demand functions) for different beneficiaries and ES which are sensitive to 
Assessment of Ecosystem Services and Water Accounting Methodologies for Integrated Water Resources Management in water scarce basins

the variation in the physical variables such as water flow and volume (Momblanch et al., 2016). For a complete valuation, these functions should include the TEV. However, in practice, only a partial TEV is obtained by considering the direct and indirect use values only. Exceptions are the spiritual, religious and bequest ES for which their non-use value is commonly considered. The different benefits provided by ES can be valued with more than one valuation method, and sometimes data availability determines the method which can be used. Nonetheless, following a preference order for each type of ES adds rigour and comparability to the results (de Groot et al., 2002). Market valuation methods are appropriate for the valuation of provisioning ES, cost-based methods are more suited to regulating ES, while revealed and stated preferences methods are preferable for cultural ES (Turner et al., 2008; TEEB, 2010). It should be highlighted that there are not proper valuation methods for supporting ES since they, by definition, do not translate into benefits to people.

Probably, the main difficulty to conduct ES assessments is the lack of reliable economic data and knowledge about underlying biophysical processes, especially critical thresholds and system irreversibilities in the ecosystems response functions (Momblanch et al., 2016). Hence, the assessment of uncertainty associated to biophysical and economic variables, as well as the number of ES included in the analysis should be considered (Boithias et al., 2016). This has to be also taken into account when selecting the ES which are useful to support decision making, since in some cases the inclusion of additional ES does not influence the decision path (Kandulu et al., 2014) but adds uncertainty to the results.

Relative to the practical implementation of ES assessment, science tends to put the focus on formal links between ES status to the benefits they provide, while managers are concerned about the easiness to include the models and results into decision-making process (Dennedy-Frank et al., 2016). In this regard, ES tools come up as an easy way to conduct estimations of the natural capital (Momblanch et al., under review). However, they incorporate simplified biophysical models which disregard relevant underlying processes at local scale and, thus, do not provide accurate results (Keeler et al., 2012; Bagstad et al., 2013a). Furthermore, as commented in the previous section, ES tools usually make use of proxy information such as land cover and, 
according to Eigenbro et al. (2010), proxies are recommended to analyse general trends in ES, but not for identifying hotspots or priority areas for multiple services. All this is, in general, incompatible with the need for accurate information to support decision making given that the ideal ES assessment should ensure biophysical realism of ecosystem data and models, and consider local tradeoffs (Seppelt et al., 2011).

As regard to the application of ES for IWRM, ES tools are focused on the ES provided by the landscape (e.g. pollination, carbon sequestration, sediment and nutrient retention by the landscape) and overlook most FES (e.g. water purification in rivers and lakes, and fish production). For the few FES that are included in ES tools, the influence of water management and infrastructures is not considered in detail. This is a serious drawback for ES tools to be used in water scarce regions in which both river and landscape natural processes are affected in many aspects by the intense exploitation of water resources, and changing management rules (Momblanch et al., under review).

In this context, models traditionally used for IWRM (Momblanch, 2013) are a good alternative to ES tools. In first place, these models have the aim of realistically representing water management impacts on water availability, water quality and derived variables (Davies and Simonovic, 2011). Secondly, several models for IWRM can be linked to faithfully reproduce the natural processes underpinning FES, and their results can be easily tailored to quantify them (Momblanch et al., under review). It can be argued that IWRM models which are sufficiently complex to do so are more difficult to parameterise. Thus, potential gains in accuracy associated with applying IWRM tools for FES assessment should be balanced with the increase of complexity (Bagstad et al., 2013a). The positive aspect is that IWRM models have broad scientific recognition and are already being applied in many places to support decision making (Vigerstol and Aukema, 2011), especially in water scarce regions as commented in the introduction.

The recommendation resulting from the critical assessment is that the ES frameworks should be used as guides to screen the environmental impacts of water management and their connection with benefits to humans. The link of commonly used tools for IWRM (i.e. hydrological, water allocation, water quality and habitat suitability models) is a good solution to support FES implementation in water scarce regions. From the results of these models, the 
Assessment of Ecosystem Services and Water Accounting Methodologies for Integrated Water Resources Management in water scarce basins

biophysical quantification of FES can be derived, and by using the most suitable valuation methods for each ES type it is possible to complete the assessment. Moreover, accounting for uncertainty and critical thresholds adds soundness to the analysis. 
Chapter 3:
Methods 

In this chapter, the previously selected methodologies for water accounting (i.e. AWAS) and FES assessment (i.e. linked IWRM models) are described in detail so that the subsequent applications are well documented. Given the complexity for the implementation of IWRM in water scarce regions, any methodology should be adjusted prior to its application. Consequently, the final methodologies proposed here are adapted or designed according to the characteristics identified in the critical assessments of sections 2.1.2 and 2.2.2 for the purpose of supporting IWRM in water scarce regions.

\subsection{The Australian Water Accounting Standard}

\subsubsection{Original version}

As previously commented, the Al account contains the water assets and the water liabilities at the end of the reporting period applying the accrual basis of financial accounting. This means that not only are the physical volumes registered in the accounts (e.g. water stored in reservoirs and aquifers) but also the volumes about which the entity has use rights or transfer duties without physically possessing or transferring them (e.g. pending water transfers to/from other regions), according to the accrual basis of financial accounting. This information is useful to provide a real picture of water availability which is one of the expected benefits of water accounting as stated in the Blueprint. Table 7 presents the accounting terms that are deduced from A 1 , as well as the equations which relate them.

\section{Water Assets and Water Liabilities (A1)}

\section{Water assets}

[water asset concepts:

- Landscape

- Reservoirs

- Aquifers

- $\quad$ Rivers

- Canals

- Inter-region claim on water of other entities]

Total water assets $=\Sigma$ [water asset concepts] (1)

Total water storage $=\Sigma$ [water assets physically owned] (2)

$\underline{\text { Water liabilities }}$ 
Assessment of Ecosystem Services and Water Accounting Methodologies for Integrated Water Resources Management in water scarce basins

Water Assets and Water Liabilities (A1)

[water liability concepts:

- Water allocation remaining

- Inter-region claim on water of the entity]

Total water liabilities $=\Sigma$ [water liability concepts] (3)

Final net water resources (4) = (1) - (3)

Initial net water resources (5)

Changes in net water resources $(6)=(4)-(5)$

Final water storage $(7)=(2)$

Initial water storage (8)

Changes in water storage (9) = (7) - (8)

Table 7. Structure of A1, accounting terms, and mathematical relationships among them.

From the total water assets (1) and total water liabilities (3) it is possible to calculate the final net water resources (4). The same concept for the previous reporting period is registered in $\mathrm{Al}$ as the initial net water resources (5). From these two values the changes in net water resources (6) are derived. If only the water assets physically owned by the entity are considered, the total water storage (2) is estimated, which is equal to the final water storage (7). The same concept for the previous reporting period is registered in $\mathrm{Al}$ as the initial water storage (8). The changes in water storage (9) are calculated as the difference between final and initial water storages.

The account A2 includes the increases and decreases in water assets and water liabilities, also applying the accrual basis of financial accounting. The content of this account is relevant for the efficient allocation and control of water resources, since it shows the water inflows and outflows in the domain for the reporting period, as well as information directly related to water management such as the water allocated to each water demand and its adjustments along the reporting period, and the variations in inter-regional claims (see Table 3). Table 8 presents the accounting terms included in A2, and the mathematical relationships amongst them. 


\section{Changes in Water Assets and Water Liabilities (A2)}

Water asset increases

[water asset increase concepts:

- River inflow to region

- Returns from demands

- Transfer of inter-region claim on water of another entity

- Precipitation into landscape, reservoirs, rivers and canals

- Groundwater recharge from landscape

- $\quad$ Increase of inter-region claim on water of another entity]

Total water asset increases $=\Sigma$ [water asset increase concepts] (10)

Water liability decreases

[water liability decrease concepts:

- Water allocation adjustments

- Decrease of inter-region claim on water of the entity]

Total water liability decreases $=\sum$ [water liability decrease concepts] (11)

Total increase in water resources $(12)=(10)+(11)$

\section{Water asset decreases}

[water asset decrease concepts:

- $\quad$ River \& groundwater outflow from region

- $\quad$ Transfer of inter-region claim on water of the entity

- Evapotranspiration from landscape, reservoirs, rivers and canals

- Deep leakages from surface water

- Decrease of inter-region claim on water of another entity]

Total water asset decreases $=\Sigma$ [water asset decrease concepts] (13)

Water liability increases

[water liability increase concepts:

- Initial water allocation

- Water allocation announcements

- Increase of inter-region claim on water of the entity]

Total water liability increases $=\Sigma$ [water liability increase concepts] (14)

Total decrease in water resources $(15)=(13)+(14)$

Changes in net water resources $(16)=(12)-(15)$

Unaccounted for difference $1(17)=(6)-(16)$

Table 8. Structure of A2, accounting terms, and mathematical relationships among them. 
Assessment of Ecosystem Services and Water Accounting Methodologies for Integrated Water Resources Management in water scarce basins

The information in A2 allows the obtaining of the changes in net water resources (16), which should be equal to the same indicator calculated in Al (6). However, these values seldom coincide due to errors in measurements and records, or due to omissions of certain flows or volumes in the accounts (Momblanch et al., 2014). The Unaccounted for difference 1 (17) quantifies the global error made in the application of the accounting methodology, and provides an estimate of the accuracy of the water accounts.

The account A3 is very similar to A2 but it does not apply the accrual basis of the financial accounting. On the contrary, this account only registers the physical water inflows and outflows that, concerning water management, refer to water diversion to demands and water transfers to/from other regions. Table 9 presents the accounting terms included in $\mathrm{A} 3$, as well as the equations that relate them.

\section{Physical Water Flows (A3)}

\section{Water inflows}

[water inflow concepts:

- River inflow to region

- Returns from demands

- Transfer of inter-region claim on water of another entity

- Precipitation into landscape, reservoirs, rivers and canals

- Groundwater recharge from landscape]

Total water inflows $=\Sigma$ [water inflow concepts] (18)

\section{Water outflows}

[water outflow concepts:

- River \& groundwater outflow from region

- Transfer of inter-region claim on water of the entity

- Evapotranspiration from landscape, reservoirs, rivers and canals

- Deep leakages from reservoirs and canals

- Water allocation diversion]

Total water outflows $=\Sigma$ [water outflow concepts] (19)

Changes in water storage $(20)=(18)-(19)$

Unaccounted for difference $2(21)=(9)-(20)$

Table 9. Structure of A3, accounting terms, and mathematical relationships among them. 
Similarly to A2, the changes in water storage in A3 (20) must coincide with the value estimated in Al (9). However, they do not usually match for the same reasons commented for the changes in net water resources in A2. Thus, the Unaccounted for difference 2 (21) is calculated as an indicator of precision in the accounting by subtracting the changes in water storage estimated in A3 (20) to the ones estimated in A1 (9).

Apart from the presented relationships, there are other agreements that should be accomplished to ensure that all the information in the different accounts is consistent. With the aim of preserving the balance of the water demands and other concepts subject to liabilities like inter-region transfers, the figures in A3 should be deductible from the information in A1 and A2 (22). For example, the initial water allocation, plus the water allocation announcement and minus the adjustment of water allocation in A2 should be equal to the water allocation diversion in A3, plus the water allocation remaining in $\mathrm{A} 1$. Because of the reconciliation between the accounts, the unaccounted for difference terms estimated in A2 and A3 must be equal, otherwise it would mean that there is a conceptual error in the global water balance (Momblanch et al., 2014).

\subsubsection{Improved version}

As highlighted in the review of the state of the art, water accounting takes its inspiration from the financial accounting. That is why the AWAS is very exhaustive in the accounting of all water storage and flow records inside the accounting domain and it extends the water accounting to the physical boundary of the entity (Momblanch et al., 2014), which in the case of IWRM is the river basin. This means that all the elements involved in the hydrological cycle are represented in the accounts. This can be very useful for the description of the hydrological behaviour of the river basin, but is far from being functional to support water management control and use efficiency (Momblanch et al., 2014).

In the first place, all the concepts included in the original version of the accounts are not usually compiled by water management entities in water scarce regions; for instance the water storage in rivers and canals. The estimation of these concepts is less reliable than for other commonly used variables, such as water stored in reservoirs, what goes against the accuracy 
Assessment of Ecosystem Services and Water Accounting Methodologies for Integrated Water Resources Management in water scarce basins

of the accounting and the feeling of control. Moreover, they represent an insignificant proportion of the total water assets in river basins. This brings us to the second point of the reasoning, which is the disparity in the orders of magnitude of the accounting concepts proposed in the original version. For example, precipitation to and evapotranspiration from the landscape can be almost 5 times bigger than the total water supply to the demands (Momblanch et al., 2014), while they do not provide so relevant information for water management. In addition, despite the accuracy in the estimation of these large figures that new technologies such as earth observation bring (Karimi and Bastiaanssen, 2015), small errors in their obtaining may disguise other more significant values and increase the unaccounted for difference term (Momblanch et al., 2014). All together reduces the capacity of water accounts to transmit relevant, reliable and clear information to water users, and limits the potential of water accounting as a methodology to support water management control and use efficiency.

For the above reasons, the information included in the accounts should be limited to the manageable elements of the river basin. These include the different types of exploitable water resources (e.g. reservoirs, aquifers, and water transfers), the water allocated and supplied to the different users from the diverse sources by means of the existing infrastructures, and the complementary accounting terms necessary to close the global water balance. In this way, the significance, clarity and accuracy of the information presented in the accounts must improve (Momblanch et al., 2014).

As highlighted by Momblanch et al. (2014) the exclusion of certain accounting terms from the original version of the water accounts do not void the validity of the water balance in the improved version. On one hand, the effect of excluding terms of small magnitude is absorbed by the errors in other (larger) concepts (Momblanch et al., 2014). On the other hand, terms of large orders of magnitude have to be replaced by equivalent elements in the accounts in order to keep the water balance. For instance, the effects of precipitation and evapotranspiration on water availability are represented in the accounts by means of the total runoff (Momblanch et al., 2014).

The proposal to improve the AWAS accounts lies in excluding the ungovernable water assets from Al (i.e. landscape, rivers and canals) and 
Methods

their complementary terms in A2 and A3 (e.g. precipitation on the landscape, evaporation from rivers and canals). Besides, the improved version removes $A 3$, since its information is redundant with the content of A2. Instead, it is replaced with a new table which summarises the most relevant information of water demands. This is water allocation, water supply, supply deficits or surpluses, water returns and water consumption. Note that the last term is not explicitly presented in the original version of the accounts. The structure and content of the improved AWAS accounts are shown in Table 10. Overall, this new version is closer to the water management perspective than the original version, which has a financial accounting approach (Momblanch et al., 2014).

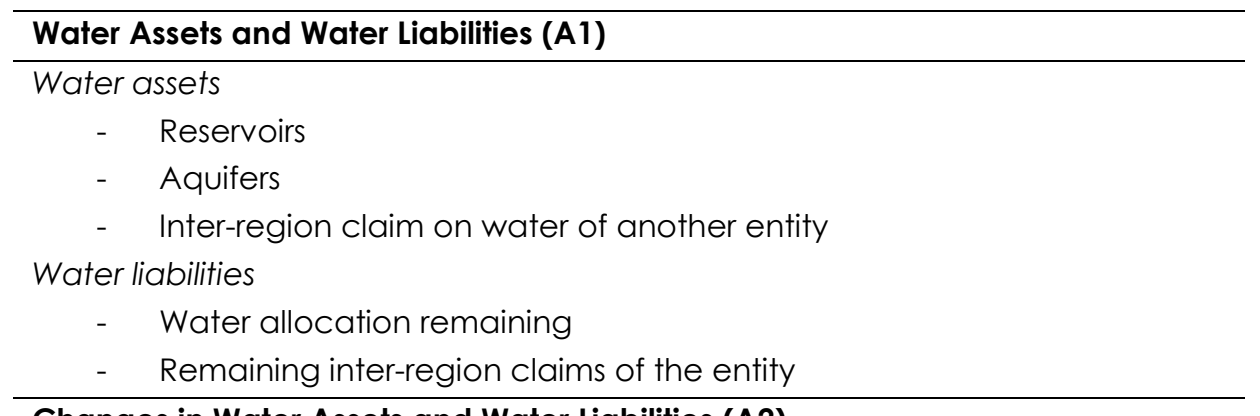

\section{Changes in Water Assets and Water Liabilities (A2)}

Water asset increases

- $\quad$ River inflow to the region

- Returns from demands

- Transfer of inter-region claim on water of another entity

- Precipitation into reservoirs

- Groundwater recharge from landscape

- Increase of inter-region claim on water of another entity

Water liability decreases

- Water allocation adjustments

- Decrease of inter-region claim on water of the entity

Water asset decreases

- River \& groundwater outflow from region

- Transfer of inter-region claim on water of the entity

- Evapotranspiration from reservoirs

- Deep leakages from surface water

- Decrease of inter-region claim on water of another entity

Water liability increases 
Assessment of Ecosystem Services and Water Accounting Methodologies for Integrated Water Resources Management in water scarce basins

- Initial water allocation

- Water allocation announcements

- Increase of inter-region claim on water of the entity

\begin{tabular}{l}
\hline Water Demands (A3) \\
\hline Water allocation \\
Water supply \\
Water supply deficit \\
Water supply surplus \\
Water return flow \\
Water consumption \\
\hline
\end{tabular}

Table 10. The structure and content of the improved AWAS.

Finally, the improved version of the accounts proposes the obtaining of the unaccounted for difference term for surface and groundwater separately, since the error made in the accounting of these two types of water source may have opposed signs and their addition would disguise the real total error in the water balance (Momblanch et al., 2014). In order to have a single unaccounted for difference figure, it is possible to aggregate the surface and groundwater errors in absolute values. Besides, so as to make the unaccounted for difference term more meaningful, the figure in $\mathrm{Mm}^{3}$ can be recalculated as a percentage of the total water supplied to the demands. This is a good indicator of the relative magnitude of the error compared to the amount of water for which the entity has management and supervision responsibilities (Momblanch et al., 2014).

\subsection{Integrated Water Resources Management Tools for Ecosystem Services assessment}

The review conducted by Momblanch et al. (2016), reveals the most relevant environmental impacts of water resources management considered in hydro-economic modelling applications. The study also concludes that the consideration of environmental impacts is patchy, and proposes the ES approach as a systematic way to classify and assess them. Table 11 shows the FES listed in section 2.2.2 which can be related to the environmental impacts of water resources management considered in the studies reviewed by Momblanch et al. (2016), together with the cites of the studies. From the table, it is easy to deduce that the most relevant FES from a 
water resources management perspective are surface and groundwater for drinking and non-drinking purposes, or freshwater provision; physical use of landscapes (mostly recreational fishing and boating in the case of FES); Filtration/sequestration/storage/accumulation, by micro-organisms, plants, animals and ecosystems, and dilution by freshwater ecosystems, or water purification; and wild animals and their outputs (commercial fishing). Thus, these are the critical FES to be included in IWRM, and whose assessment methodologies are developed along this section.

\begin{tabular}{|c|c|}
\hline Class & Papers \\
\hline $\begin{array}{l}\text { Wild animals and their } \\
\text { outputs (commercial } \\
\text { fishing) }\end{array}$ & $\begin{array}{l}\text { (Watkins Jr and McKinney, 1999; Ringler et al., 2004; Ringler } \\
\text { and Cai, 2006; Mullick et al., 2013; Bekchanov et al., 2015a; } \\
\text { 2015b; 2015c) }\end{array}$ \\
\hline $\begin{array}{l}\text { Surface and } \\
\text { groundwater for } \\
\text { drinking and non- } \\
\text { drinking purposes }\end{array}$ & $\begin{array}{l}\text { (Brown et al., 1990; Booker and Young, 1991; Booker and } \\
\text { Young, 1994; Booker, 1995; Lund and Ferreira, 1996; Ward } \\
\text { and Lynch, 1996; 1997; Hurd et al., 1999; Watkins Jr and } \\
\text { McKinney, 1999; Cai et al., 2002; Ringler et al., 2004; } \\
\text { Assimacopoulos et al., 2005; Babel et al., 2005; Booker et } \\
\text { al., 2005; Ringler and Cai, 2006; Ward et al., 2006; Ward and } \\
\text { Pulido-Velázquez, 2008; Ward and Pulido-Velazquez, 2009; } \\
\text { Divakar et al., 201 1; Grafton et al., 201 1; Grossmann and } \\
\text { Dietrich, 2012; Ward and Pulido-Velazquez, 2012; Davidson } \\
\text { et al., 2013b; a; Divakar et al., 2013; Mullick et al.., 2013; } \\
\text { Debnath, 2014; Bekchanov et al., 2015a; Bekchanov et al., } \\
\text { 2015b; Bekchanov et al., 2015c; Debnath et al., 2015; Kahil } \\
\text { et al., 2015) }\end{array}$ \\
\hline $\begin{array}{l}\text { Filtration/sequestration } \\
\text { /storage/accumulatio } \\
\mathrm{n} \text { by micro-org., plants, } \\
\text { animals \& ecosystems }\end{array}$ & (Hurd et al., 1999; Assimacopoulos et al., 2005) \\
\hline $\begin{array}{l}\text { Dilution by freshwater } \\
\text { ecosystems }\end{array}$ & $\begin{array}{l}\text { (Brown et al., 1990; Booker and Young, 1991; Booker and } \\
\text { Young, 1994; Booker, 1995; Hurd et al., 1999; Divakar et al., } \\
\text { 2011; Divakar et al., 2013) }\end{array}$ \\
\hline Flood protection & $\begin{array}{l}\text { (Lund and Ferreira, 1996; Hurd et al., 1999; Yang and Cai, } \\
2011 \text { ) }\end{array}$ \\
\hline $\begin{array}{l}\text { Global climate } \\
\text { regulation }\end{array}$ & (Grossmann and Dietrich, 2012) \\
\hline $\begin{array}{l}\text { Experiential use of } \\
\text { plants, animals and } \\
\text { landscapes (tourism) }\end{array}$ & $\begin{array}{l}\text { (Bekchanov et al., 2015a; Bekchanov et al., 2015b; } \\
\text { Bekchanov et al., 2015c; Kahil et al., 2015) }\end{array}$ \\
\hline
\end{tabular}


Assessment of Ecosystem Services and Water Accounting Methodologies for Integrated Water Resources Management in water scarce basins

\begin{tabular}{|l|l|}
\hline Class & Papers \\
\hline \multirow{3}{*}{$\begin{array}{l}\text { Physical use of } \\
\text { landscapes } \\
\text { (recreation) }\end{array}$} & $\begin{array}{l}\text { (Booker, 1995; Ward and Lynch, 1996; 1997; Hurd et al., } \\
\text { Booker et al., 2005; Ward et al., 2006; Ward and Pulido- } \\
\text { Velazquez, 2008; 2009; Yang and Cai, 201 1; Grossmann } \\
\text { and Dietrich, 2012; Ward and Pulido-Velazquez, 2012; } \\
\text { Debnath, 2014; Debnath et al., 2015) }\end{array}$ \\
\hline $\begin{array}{l}\text { Symbolic (habitat and } \\
\text { biodiversity) }\end{array}$ & (Grossmann and Dietrich, 2012; Bryan et al., 2013) \\
\hline
\end{tabular}

Table 11. ES included in hydro-economic modelling studies. Adapted from Momblanch ef al. (2016).

It should be noted that some benefits of the physical use of landscape (i.e. recreational fishing) and the production of wild animals and their outputs (e.g. commercial fishing) are very similar since they are based on the capacity of the environment to maintain fish population. They could be considered as specific benefits to people provided by the habitat category of ES commented in section 2.2.2. In line with this point of view, the present research proposes the same modelling approach to assess the recreational and commercial fishing as a single ES named aquatic habitat service.

Since the range of IWRM tools is vast and the capabilities of each model are very diverse, it is necessary to define the set of models that are to be used prior to design the methodologies for FES assessment. As commented in the introduction, this thesis is based on preceding research (Momblanch, 2013) which used a chain of IWRM tools to analyse the tradeoffs between water uses and the environment. The tools are integrated into the Decision Support System AQUATOOL (Andreu et al., 1996). AQUATOOL is a geo-referenced database system which provides a common interface, data and results management tools for different modules directed to analyse the key aspect of water resources planning and management at river basin scale (Momblanch et al., under review). For more than 20 years, it has been designed following well established methodologies for water resources systems analysis. Hence, the present research makes use of this platform that facilitates the transfer of results between models, and allows massive simulations, which are useful to carry out scenario analyses (Momblanch, 2013). 
Methods

Regarding the temporal step to be used for the FES assessment, the MA (2003) states that each ecosystem process exhibits a characteristic scale; this is the typical extent or duration over which the process has its impact. The majority of models in AQUATOOL work at a monthly step. However, they can be adapted to other time scales if it is convenient for the faithful representation of the FES. Thus, this issue is discussed and justified in the methodological description of each FES.

\subsubsection{Freshwater provision service}

Brauman et al. (2007) define the Freshwater Provision Service (FPS) as an ES describing the modification of water used for extractive (e.g. municipal, agricultural, and industrial) and in situ purposes (e.g. hydropower generation, water recreation, and transportation) by ecosystems. It is provided by the landscape where the precipitation is transformed into runoff. Terrestrial ecosystems partly determine landscape features like water retention capacity of soils, percolation, and, even, slope. In turn, these features affect the rainfall-runoff processes occurring in the landscape. The beneficiaries of the service are the different water sectors and users; i.e. urban, agricultural, industrial, hydropower, and recreational uses depending on water quantity such as boating and bathing. Moreover, the FPS is the trigger for many ecosystem processes which rely on water abundance, and its temporal and spatial distribution (Momblanch et al., under review).

For the assessment of this FES, it is necessary to represent the rainfall-runoff processes, the water distribution along water bodies, and the water supply to the diverse users. Hence, the proposed methodology comprises a rainfallrunoff model (RRM) and a water allocation model (WAM) as the basic IWRM tools to perform the FPS quantification. Besides, it is necessary to assign an economic value to the water supplied (benefit) by using economic functions and to spatially map the production of the ES by using a water tracer. Figure 5 shows the diagram of the modelling methodology for the assessment of the FPS. 


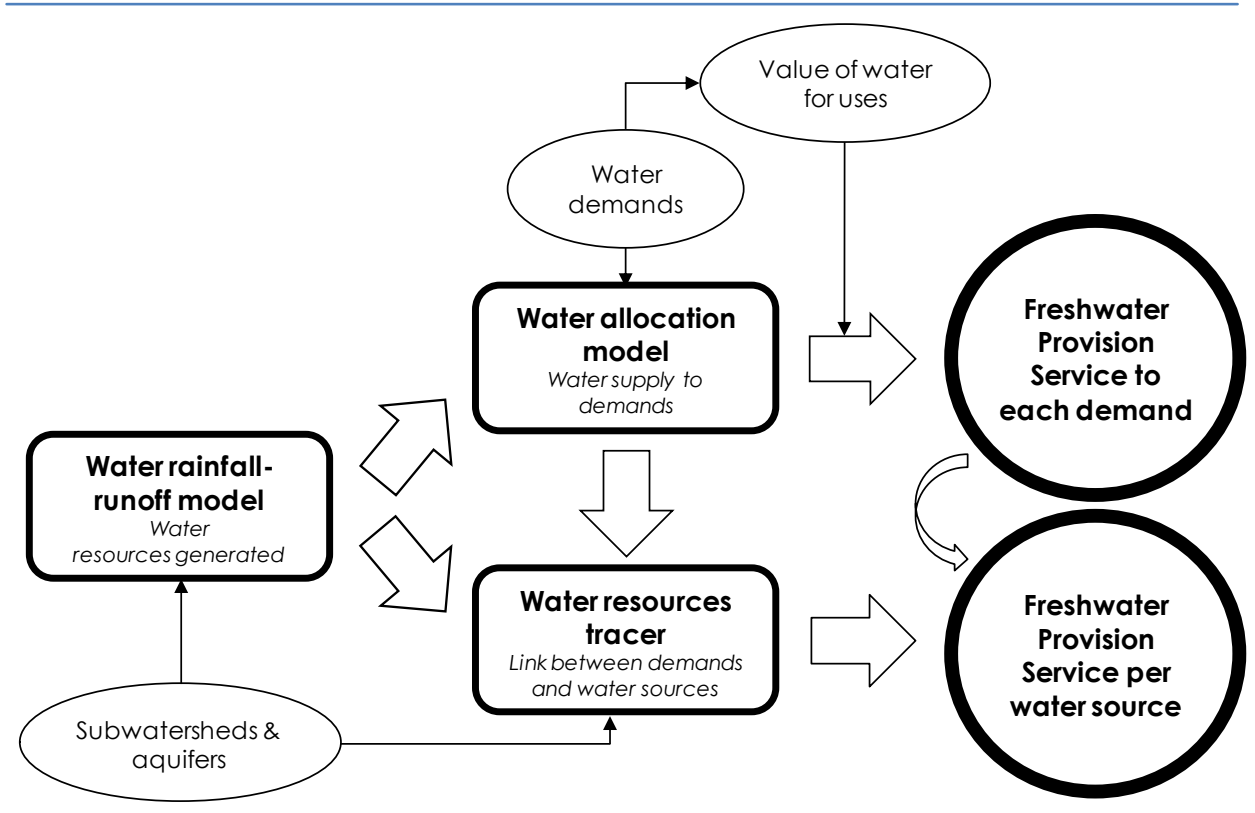

Figure 5. Methodology for the assessment of the FPS.

In the first place, the RRM calculates the water resources generated in each subwatershed and aquifer. This requires a distributed or semi-distributed model with explicit consideration of surface and groundwater runoff (Momblanch et al., under review). The hydrological module of AQUATOOL, EVALHID (Paredes-Arquiola et al., 2014a), allows choosing among three different RRM approaches: Témez (1977), HBV (Bergström, 1995), and SACSMA (Burnash et al., 1973). They are all deterministic physically-based conceptual models which are applied in a semi-distributed way and distinguish between surface and groundwater with different levels of detail in the vertical performance. The input data for these RRM are precipitation, potential evapotranspiration, the watersheds and related aquifers, and the landscape parameters specific for each model (Momblanch et al., under review).

Up to this point, the volume of water generated is known, but it can only be considered an ES if it is beneficial from a human perspective. In nonregulated or water abundant river basins, where water resources far exceed water demands and reservoirs do not affect river flow patterns, water users get the water that they need when they need it, and the use of another 
model apart from the RRM is avoidable. Nonetheless, the high level of flows regulation and sophistication of water management in water scarce river basins makes the use of WAM fundamental. The WAM is fed with the results of the RRM and data about water demands, infrastructures and management rules. Thus, it should consider surface and groundwater interaction, as well as being able to faithfully represent real water institutions and operation rules. The results from the WAM, the water supply to demands, represent the biophysical quantification of the FPS. The water allocation module of AQUATOOL, SIMGES (Andreu et al., 1996), is a simulationoptimisation model based on a flow network algorithm. It solves the management of complex water resources systems with surface and groundwater storage, intake, transport, artificial recharge, use and consumption elements. It also allows defining many types of management rules and the representation of the functioning of complex real water resources systems, as for instance, priorities in water uses (Momblanch, 2013).

In order to complete the ES assessment, economic valuation methods to estimate the benefits obtained from the water used by the different demands have to be applied. According to the valuation typologies described in section 2.2.1.1, the most suitable valuation technique for domestic water use or drinking water is the market valuation using the marginal willingness-to-pay of citizens. In the case of economic demands for which water is a production factor (e.g. agriculture, industry and hydropower) the production-based method is recommended instead. Finally, the travel cost method is the most adequate for recreational uses. The resulting relationship between water supply and economic value is commonly named as demand curve in hydro-economic models. Calculating the integral under the demand curve for the water supply resulting from the WAM, the gross economic benefit of the FPS for each water use is obtained (Momblanch et al., under review) (Figure 6).

As yet, the benefits provided by the FPS are assigned to their beneficiaries, and can be summed up to obtain the value of the ES for the entire river basin. Nevertheless, the results are much more relevant if they are associated to the water source, i.e. subwatershed or aquifer, which provides the service (Momblanch et al., under review). In other words, the production of the FPS benefits should be spatially mapped. This means to identify the 
Assessment of Ecosystem Services and Water Accounting Methodologies for Integrated Water Resources Management in water scarce basins

relationship between the water sources and the final water uses (Momblanch et al., under review). The FPS assessment methodology makes use of a water tracer (see Figure 7) based on the iterative execution of mass balance simulations, considering the movement of water along the river system resulting from the WAM. To do so, a fictitious conservative pollutant that is only affected by the convection driven by the water movement (C) is defined using the water quality module of AQUATOOL, GESCAL (ParedesArquiola et al., 2010), which is further described in section 3.2.2.

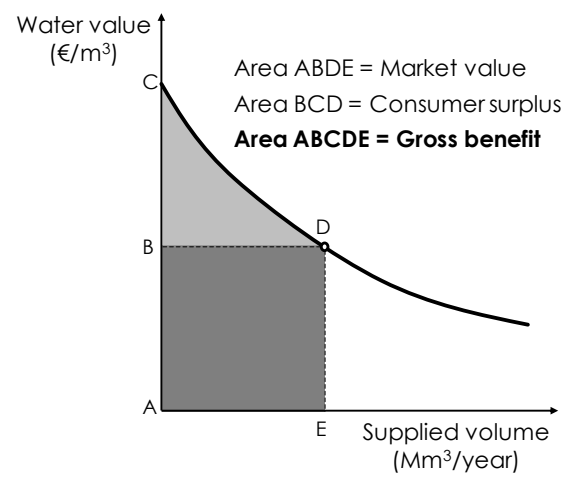

Figure 6. Obtaining of the gross benefit from a demand curve. Adapted from Momblanch ef al. (under review).

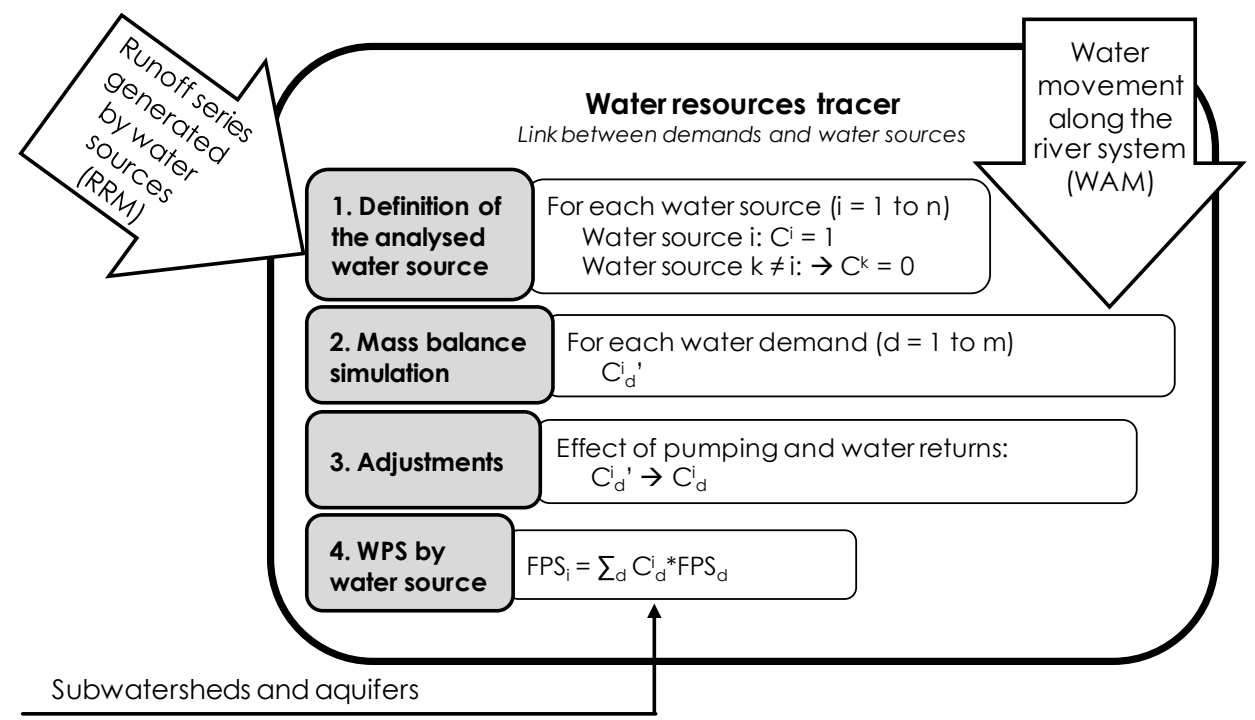

Figure 7. Water tracer diagram for the mapping of the FPS. 
It is necessary to run one simulation per water source. In each simulation, the concentration of the fictitious pollutant equals to 0 in the water generated by all sources $\left(C^{k}\right)$, except for the water source analysed in that specific execution of the tracer (i) for which the concentration equals to 1 ( $C^{i}$ ). Given that the pollutant is conservative, its concentration only varies due to dilution into water with a different pollutant concentration; in this case, concentration changes when water from the analysed source is mixed with water coming from other sources. Therefore, the concentration of the fictitious pollutant in the water extracted by a demand ( $\mathrm{C}^{i} \mathrm{~d}^{\prime}$ ) is equivalent to the fraction of the water supply to this water demand originated in the analysed water source. This value should be recalculated for demands receiving pumped water, since it does not get mixed with other water sources and its concentration remains constant, as opposed to groundwater runoff which propagates along the river system. In the case that water returns from demands exist, part of the water resources generated by the sources upstream the demand producing the return can be used more than once. Hence, it is necessary to conduct one additional simulation for each water return assigning it a concentration equal to 1. Knowing the proportion of the water returned which is used by the downstream demands, it is possible to adjust the fraction of water supplied by the upstream water sources to consider its indirect reuse. Once the necessary adjustments are made, the FPS per water source (FPSi) is calculated as sum of the FPS to each water demand (FPS ) times the proportion of water coming from the analysed water source $\left(\mathrm{C}^{i} \mathrm{~d}\right)$. A final aspect to consider is the influence of the initial concentration of the fictitious pollutant in reservoirs on the results of the water tracer. Therefore, a warm up period has to be considered in order to ensure that the results obtained are not biased by the initial concentration values assumed.

Finally, in regard to the time scale of the assessment, some considerations should be done. Demand curves are generally calculated on annual basis (Pulido-Velazquez et al., 2006), while the usual time step to analyse hydrological processes with the purpose of assessing water resources availability is the month or even the year (Borah et al., 2007). Hence, the monthly time step seems adequate to represent all the processes in the assessment of water management impacts on the FPS (Momblanch et al., under review). In order to operationalise the implementation of the 
Assessment of Ecosystem Services and Water Accounting Methodologies for Integrated Water Resources Management in water scarce basins

methodology, the monthly water supplies provided by the WAM need to be yearly accumulated as to be compatible with the demand curves. Once the annual economic value is calculated for each demand, it has to be disaggregated according to the monthly supply distribution (Momblanch et al., under review).

\subsubsection{Water purification service}

The Water Purification Service (WPS) represents the role of aquatic ecosystems to filter and decompose pollutants in water (La Notte et al., 2012) that result in its improved quality. Thus, the service is provided by water bodies such as rivers and lakes (or reservoirs), more precisely by the different physical and chemical processes which rely on biological processes or are controlled by them (Ostroumov, 2005; La Notte et al., 2015). Water purification also occurs in groundwater bodies through active biodegradation of contaminants, inactivation and elimination of pathogens, and nutrient recycling, but there is a lack of detailed information about groundwater properties that prevents its practical consideration (Griebler and Avramov, 2015). The beneficiaries of the WPS are drinking water treatment companies and industrial water users that have reduced water treatment requirements due to the oxidation of organic matter and nutrients degradation, amongst other pollutants; agricultural users which reduce production losses thanks to salt dilution; and recreational uses such as bathing that rely on water quality. An alternative to calculating the benefits for the different sectors is to consider the social benefits of improved water quality due to avoided environmental damages (Brink et al., 2011).

In order to assess the WPS, it is necessary to determine the degradation (evolution) of pollutants in each water body, which depends on the assimilation capacity of the existing ecosystems and flow fluctuations (Momblanch et al., 2015). Therefore, the assessment methodology proposed includes a WAM that provides the performance of the system regarding water flows, and a water quality model (WQM) that simulates the evolution of water quality in the river system. Even though the WPS has been limited to the water bodies, there is another component provided by the landscape which could be introduced in the methodology through a diffuse pollution model that would estimate the concentration of pollutants in the runoff 
entering the river system. Figure 8 shows the diagram of the modelling methodology for the assessment of the WPS.

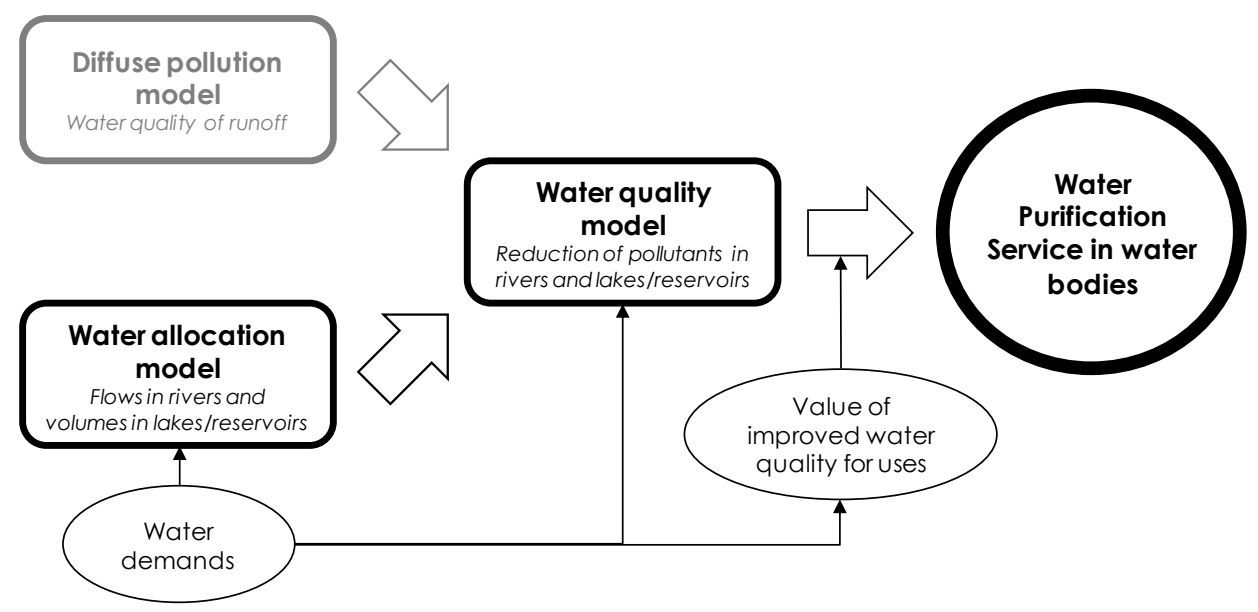

Figure 8. Methodology for the assessment of the WPS.

The WQM should be able to determine the variation of the concentration of different pollutants which are detrimental for the water uses, considering the physical, chemical and biological processes that occur in aquatic ecosystems. For that purpose, the WQM should be based on mechanistic equations which aim at representing the real processes involved in water quality evolution, as opposed to empirical formulations which are based on statistical relationships. Since the water purification processes are complex, it is important to find a model that at least describes the processes of interest for the ES assessment (La Notte et al., 2015). The GESCAL module in AQUATOOL matches this requirement. It is a mechanistic model which considers the convection, the dispersion and the most representative specific source and sink processes of several pollutants. It allows simulating biochemical oxygen demand, dissolved oxygen, organic nitrogen, ammonium, nitrates, organic phosphorus, phosphates, Chlorophyll-a, temperature, toxic pollutants and other constituents which can be defined by the user (Momblanch et al., 2015). Consequently, it requires as inputs the pollution entering the river system through the runoff and the discharges from water uses; the physical characteristics of the water bodies; the movement of water in the river system; and the quality parameters that are necessary to represent the behaviour of the different pollutants. 
Assessment of Ecosystem Services and Water Accounting Methodologies for Integrated Water Resources Management in water scarce basins

The reduction of pollution in each water body is quantified as the difference between the mass of pollutant at the entrance and at the outlet of the water body. However, the water quality melioration can only be considered as far as it benefits human uses. This can be estimated by comparing the water quality standards or recommendations for the diverse water uses with the water quality values at the locations where the resource is used or withdrawn. Thus, just the purification of pollution which exceeds the water quality thresholds is to be valued in economic units. To do so, it is necessary to compare the water quality thresholds with the pollution reaching the water demand locations considering that the WPS is not provided. If the pollution without the service is over the thresholds, the WPS provides a benefit (see Figure 9). Otherwise, the WPS cannot be valued in economic units since it is not considered beneficial for human purposes. Note that this process has to be conducted for each water use and each water pollutant potentially affecting the use.

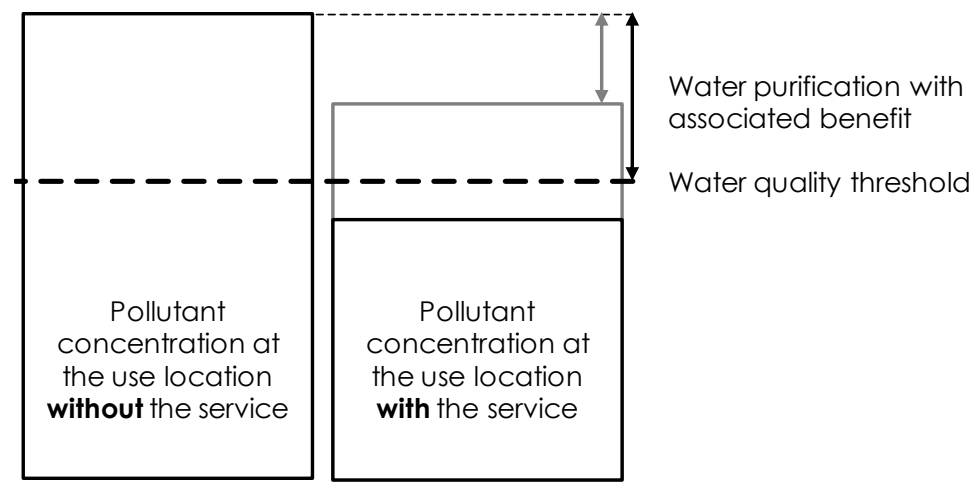

Figure 9. Representation of the beneficial fraction of the WPS for a certain water demand for a particular pollutant.

In order to obtain the concentration of pollutants without the effect of the WPS, the biological water quality parameters in GESCAL are voided. This is reasonable since the WPS is mostly underpinned by biological processes that are determined by the ecological status of aquatic ecosystems. Purely physical processes such as diffusion and sedimentation are not supposed to be affected by the deterioration of the service. Once the simulations with and without the WPS are conducted, the global benefit of the service is calculated as shown in equations 1 and 2 . 
Methods

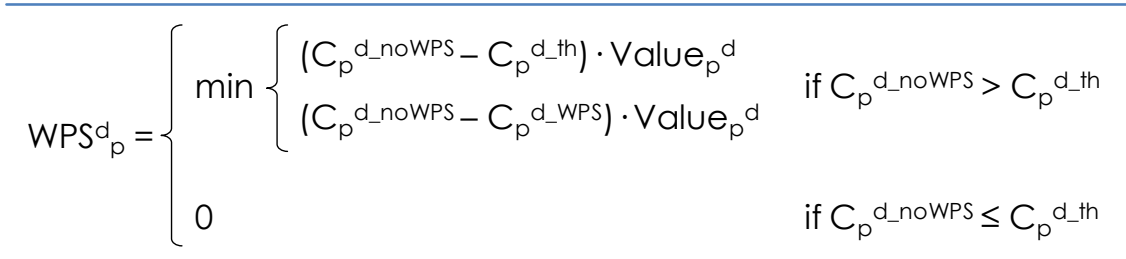

WPS $=\Sigma_{d} \Sigma_{p}$ WPS $_{p}$

where WPS $d_{p}$ is the value of the WPS for demand $d$ and pollutant $p ; C_{p} d_{\text {_nowPS }}$ is the concentration of pollutant $p$ at the location of demand $d$ without the effect of the service; $C_{p} d_{-}$wPS is the concentration of pollutant $p$ at the location of demand $d$ with the effect of the service; $C_{p} d_{-}$th is the threshold for pollutant $p$ which applies to demand $d$; and Valve ${ }^{d}$ is the value of one unit less of pollutant $p$ for demand $d$ (marginal cost); WPS is the total value of the service.

As it can be deduced from the equations above, the value to be assigned to the parameter Value ${ }^{d}$ varies depending on the water demand and the pollutant. For urban and industrial water uses the value is recognised as the treatment cost per unit of pollutant, while for agricultural water demands it is the variation in crop yield per unit of pollutant. In both cases the technique used for the WPS is the cost-based valuation. On the contrary, the value for recreational uses should be obtained using the travel cost method as the change in travel expenses per unit of pollutant or the contingent valuation as the willingness to pay for water quality changes in bathing areas (Terrado et al., 2016a). Commonly, the water quality thresholds for bathing uses are established only for a few pollutants, mostly microbiological. However, people value reductions in other water quality variables. Therefore, for the specific case of bathing uses, any reduction of pollution ( $C_{p}$ d_nowPS $-C_{p}{ }^{d} \_$wPS $)$is valued as a benefit.

Regarding the spatial mapping of the service, the total benefit of the WPS calculated in equation 2 has to be assigned to each water body (WPS $\mathrm{wb}_{\mathrm{w}}$ ) in accordance with the fraction of water purification provided to each demand for each pollutant ( $\%$ wb $\mathrm{d}, \mathrm{p})$. The equations to do so are: 


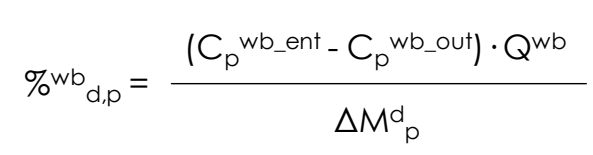

$$
\begin{aligned}
& \Delta M_{p}^{d}=\sum C_{p}{ }^{d} \_ \text {ent } \cdot Q^{d} \_ \text {ent }-\sum C_{p}{ }^{d} \_ \text {out } \cdot Q^{d} \_ \text {out }-C_{p} \text { d_wPS } \text {. Qups_d }
\end{aligned}
$$

where $C_{p}{ }^{w b}{ }_{2}$ ent is the concentration of pollutant $p$ at the entrance of the water body wb; $C_{p}$ wb_out is the concentration of pollutant $p$ at the outlet of the water body wb; $Q^{w b}$ is the flow in the water body $w b ; \Delta M^{d} p$ is the mass variation of pollutant $p$ up to the location of demand $d ; C_{p} d \_$ent is the concentration of pollutant $p$ of an inflow to the system upstream demand $d$; $Q^{d}$ _ent is the flow of an inflow to the system upstream demand $d ; C_{p} d_{-}$out is the concentration of pollutant $p$ of an outflow from the system upstream demand $d ; Q^{d} \_$out is the flow of an outflow from the system upstream demand $d$; and Qups_d is the flow just upstream demand $d$.

Summing up, the assessment of the WPS involves three modelling steps that are necessary to provide all the variables for the quantification and mapping of the service. Firstly, the SIMGES model is simulated to determine the flows in the river system. These are all variables named $Q$ in the above equations. Then, the GESCAL model is run without consideration of the WPS and provides the concentration of pollutants at the locations of the demands. Finally, GESCAL is simulated again applying the effect of the WPS. The results extracted of this simulation are the concentration of pollutants at the locations of the demands, the concentrations of pollutants at the entrance and outlet of each water body, as well as the concentrations of all the outflows from the system. The concentrations of the entrances to the system are inputs of the water quality model.

\subsubsection{Aquatic habitat service}

The Aquatic Habitat Service (AHS), as regarded in this research, represents the capacity of surface water bodies to provide suitable conditions for the development and maintenance of aquatic fauna populations. This is similar to the definition of InVEST for the terrestrial animal species in the landscape (Tallis et al., 2013), but it is adapted to surface water bodies. The beneficiaries of the AHS are professional and recreationist fishermen who 
Methods

exploit aquatic biota (Liquete et al., 2016), that is, fish and macroinvertebrates.

A major aspect that determines the suitability of aquatic habitats to be home to aquatic fauna is river flow (Bovee, 1982), since it modifies physical variables such as water depth, velocity and substrate which are of high importance for the usability of an habitat (Martínez-Capel et al., 2009). Thus, the proposed methodology should, first, provide the flows along the river network applying a WAM and, then, check the adequacy of these flows to generate appropriate conditions for the aquatic species inhabiting the different parts of the system by using a Habitat Suitability Model (HSM). Since habitat quality is considered a good proxy for species population (Terrado et al., 2016b), the outputs of the HSM can be translated into captures and, next, into economic benefits using the market valuation for commercial fishing (Tuya et al., 2014; Jackson et al., 2015) and the travel cost method for the recreational fishing (Shrestha et al., 2002; Alvarez et al., 2014). In the case of reservoirs, statistical relationships between the water level or volume in the reservoir, provided by SIMGES, and fish density can be used (Yang and Cai, 2011 ; Debnath, 2014). Figure 10 shows the diagram of the AHS evaluation.

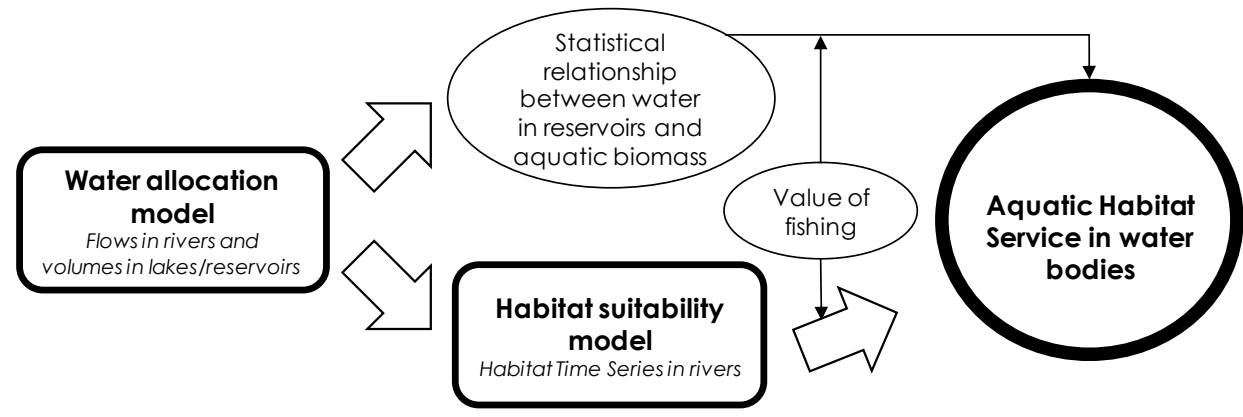

Figure 10. Methodology for the assessment of the AHS.

As described for the FPS, the SIMGES WAM calculates the river flows, taking into account the water management influence. The HSM included in AQUATOOL, CAUDECO (Paredes-Arquiola et al., 2013), uses the results of SIMGES as inputs and estimates the potential habitat available per river stretch for selected aquatic species depending on the river flow, as established by the Instream Flow Incremental Methodology (Bovee, 1982). To do so, it makes use of Weighted Usable Area (WUA) - flow curves obtained in 

Integrated Water Resources Management in water scarce basins

field works that are based on the preference of species for diverse values of velocity, water depth, and substrate. The outputs of CAUDECO are habitat time series (HTS) of potentially usable area in squared meters or as a percentage of the maximum WUA for the specie, size class and river stretch for each water body. By considering the habitat time series as production functions for potential population, it is possible to determine the biomass of aquatic species (Milhous, 1983; Waddle, 1998) if data about population density is available (Stempel, 1990). These results represent the biophysical quantification of the AHS.

Regarding the economic valuation, the benefit of the AHS has to be calculated only for the water bodies in which beneficiaries interact with it; this is, water bodies that contain fishing sites. In the case of commercial fishing the value of the service is directly obtained by multiplying the fish market price minus the production costs times the biomass. On the other hand, the recreational fishing requires the application of the travel cost method which includes the taxes to obtain fishing licences. In both cases, it is important to consider the limits of fish captures, and that the amount of biomass extracted for one purpose is not available for the other in order to avoid double counting. Equations 5 to 12 show the obtaining of the monthly global benefit of the AHS, adapted from (DG Environment, 2014; Terrado et al., 2016a). However, the equations could be modified depending on the legal regulations in each case study, in the sense of fishing priorities and limits of captures.

$$
\begin{aligned}
& T^{f}=\sum_{i} H T S_{i}^{f} \cdot \rho_{i}^{f}[\cdot W U A m a x] \\
& C F^{f}= \begin{cases}C F L^{f} & \text { if } C F L^{f}<T B^{f} \\
T B^{f} & \text { if } C F L^{f} \geq T B^{f}\end{cases}
\end{aligned}
$$

$$
\operatorname{AHS}\left(\mathrm{CF}^{f}\right)^{f}=\mathrm{CF}^{f} \cdot \text { Value }^{f}
$$

$$
R F= \begin{cases}\text { Coef } \cdot \sum_{f} \frac{\mathrm{TB}^{f}-\mathrm{CF}^{f}}{M a x C^{f}} & \text { if } \mathrm{TB}^{f}-C F^{f}>0 \\ 0 & \text { if } \mathrm{TB}^{f}-C F^{f}=0\end{cases}
$$


Methods

$$
A H S(R F)=R F \cdot L \_C O S t
$$

$$
A H S=A H S(R F)+\sum_{f} A H S\left(C F^{f}\right)^{f}
$$

where $\mathrm{TB}^{f}$ is the total biomass of species $f$; $\mathrm{HTS}_{\mathrm{i}} \mathrm{i}_{\text {is }}$ the HTS value of species $f$ for the water body $i$ which can be $\mathrm{m}^{2}$ or in \%; $\mathrm{p}_{\mathrm{i}}^{\mathrm{f}}$ is the average density of species $f$ in the water body $i$; WUAmaxif is the maximum WUA in water body $i$ by species $f$ in $m^{2}$ which is only considered in the equation if $\mathrm{HTS}_{\mathrm{i}} \mathrm{f}$ is in \% units, which is only multiplied if $\mathrm{HTS}_{\mathrm{i}} \mathrm{i}$ is in \%; TB is the total biomass; $\mathrm{CF}$ is the biomass available for commercial fishing for species $f$; $\mathrm{CFL}^{f}$ is the commercial fishing limit for species $f$; AHS $(C F)^{f}$ is the value of the AHS for commercial fishing of species $f$; Valuef is the marginal net market value of the species $f$; $C F$ is the biomass available for commercial fishing; RF is the number of licenses available for recreational fishing; Coef is a correction coefficient that correlates the number of licenses calculated with the real number of licenses issued; MaxCf is the maximum capture per licence; $\mathrm{AHS}(\mathrm{RF})$ is the value of the AHS for recreational fishing; L_Cost is the cost of recreational fishing licences; AHS is the total value of the service. Note that all variables are referred to monthly values.

Unlike the FPS and the WPS, it is assumed that the production and benefit of this service occur in the same water body. However, the calculation of the economic benefit has to be done for the global fish production because capture limits apply at river system or regional scale and fishermen change their fishing places. For the spatial mapping of the service two factors are considered to explain the fishing attendance to each water body. One is the proximity of the water body to populated areas, and the second is the proportion of biomass present in the water body. The relative importance of each criterion is introduced as a weight. Thus, the spatial mapping involves the allocation of the total value to each water body according population and biomass criteria, and a weighted sum to obtain the final value assigned to each water body.

\subsubsection{Interactions among FES}

Note that some ES contribute to more than one benefit and in other cases one benefit is provided by more than one ES (Costanza et al., 1997). This is 
Assessment of Ecosystem Services and Water Accounting Methodologies for Integrated Water Resources Management in water scarce basins

the case of the FPS and the AHS which are calculated assuming that the water quality is adequate, and thus rely on the WPS.

In the case of water for urban use, the FPS and the WPS can be accounted in the global FES assessment without risk of double counting since the beneficiaries of each service are different. In other words, the fact that the water quality at the Drinking Water Treatment Plants (DWTPs) intakes is not suitable for direct consumption does not affect the water uses, because treating the water to reach the legal thresholds is precisely the task of DWTPs. The case of industrial and agricultural uses is totally different. If the water quality at the location of the demand with the provision of the WPS ( $C_{p} d_{-}$WPS) is over the water quality threshold, the benefits of production decrease due to higher treatment costs for the industry (that are self-provided) or to reduced crop yields for the agricultural use. Thus, the WPS of these beneficiaries should be included in the global ES, but the extraordinary costs and reduced productivity should be rebound to the FPS valuation, diminishing it.

Regarding water uses such as bathing (regarded as FPS) or fishing (AHS), water quality values above the thresholds imply that the services cannot be provided. In other words, if the water quality is not suitable for bathing, the bathing area is closed and it does not matter how much water flow exists that can potentially provide the FPS. However, for the pollutants which do not have legal thresholds for this use, the benefit of improved water quality can be directly added to the global FES assessment without incurring in double counting. Similarly, if the concentration of certain pollutants (e.g. ammonium and toxics) is too high, fishes die and the AHS cannot be delivered.

In conclusion, once all the FES proposed are calculated, it is necessary to check any possible deviation from the assumptions on which they have been assessed and to apply corrections if necessary. In this way, conceptual and methodological mistakes are avoided making the outcome of the proposed methodology more reliable for decision makers. 


\section{Chapter 4: Application of methodologies}



The present chapter exemplifies the application of the formerly described methodologies in water scarce river basins. Different cases of study have been selected in order to cover diverse casuistries and management strategies. Nevertheless, all case studies are located in Spain for data availability reasons. The WA methodology is applied in the Júcar River Basin, the Tormes River Basin is used to show the applicability of the FPS, the Llobregat River Basin case study demonstrates the WPS, while the AHS is applied to the Turia River Basin.

\subsection{The Australian Water Accounting in the Júcar River Basin}

\subsubsection{Case study description}

The Júcar River Basin (JRB) is located in the eastern coast of the Spanish peninsula in the Júcar River Basin District (Figure 11). It has an area of $22,378.51 \mathrm{~km}^{2}$ with a mean annual precipitation of $475.2 \mathrm{~mm}$ and an average annual potential evapotranspiration of $926.6 \mathrm{~mm}$, which classifies it as a semiarid region, and produces a mean annual runoff of 1,605.4 $\mathrm{Mm}^{3}$. A diagram of the JRB system can be seen in Figure 12, including the main rivers, the Albufera wetland which is an emblematic natural feature classified as Natural Park, Natura 2000 and RAMSAR site, and the most relevant aquifers in the area that are connected to the surface water system in an intense and complex way. The most relevant elements related to water demands and management are also displayed in the diagram.

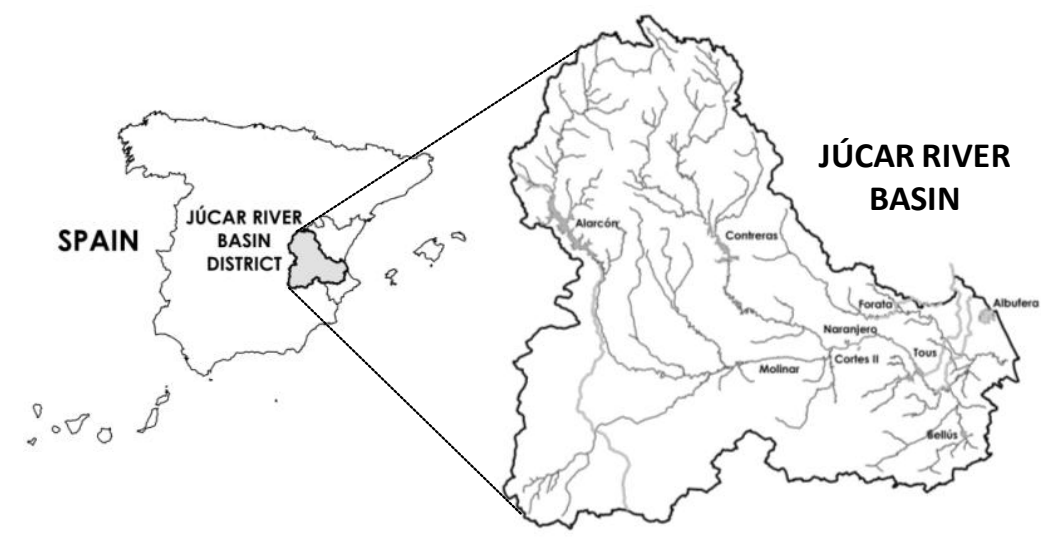

Figure 11. Location of the study area. Adapted from Momblanch et al. (2014). 
Assessment of Ecosystem Services and Water Accounting Methodologies for Integrated Water Resources Management in water scarce basins

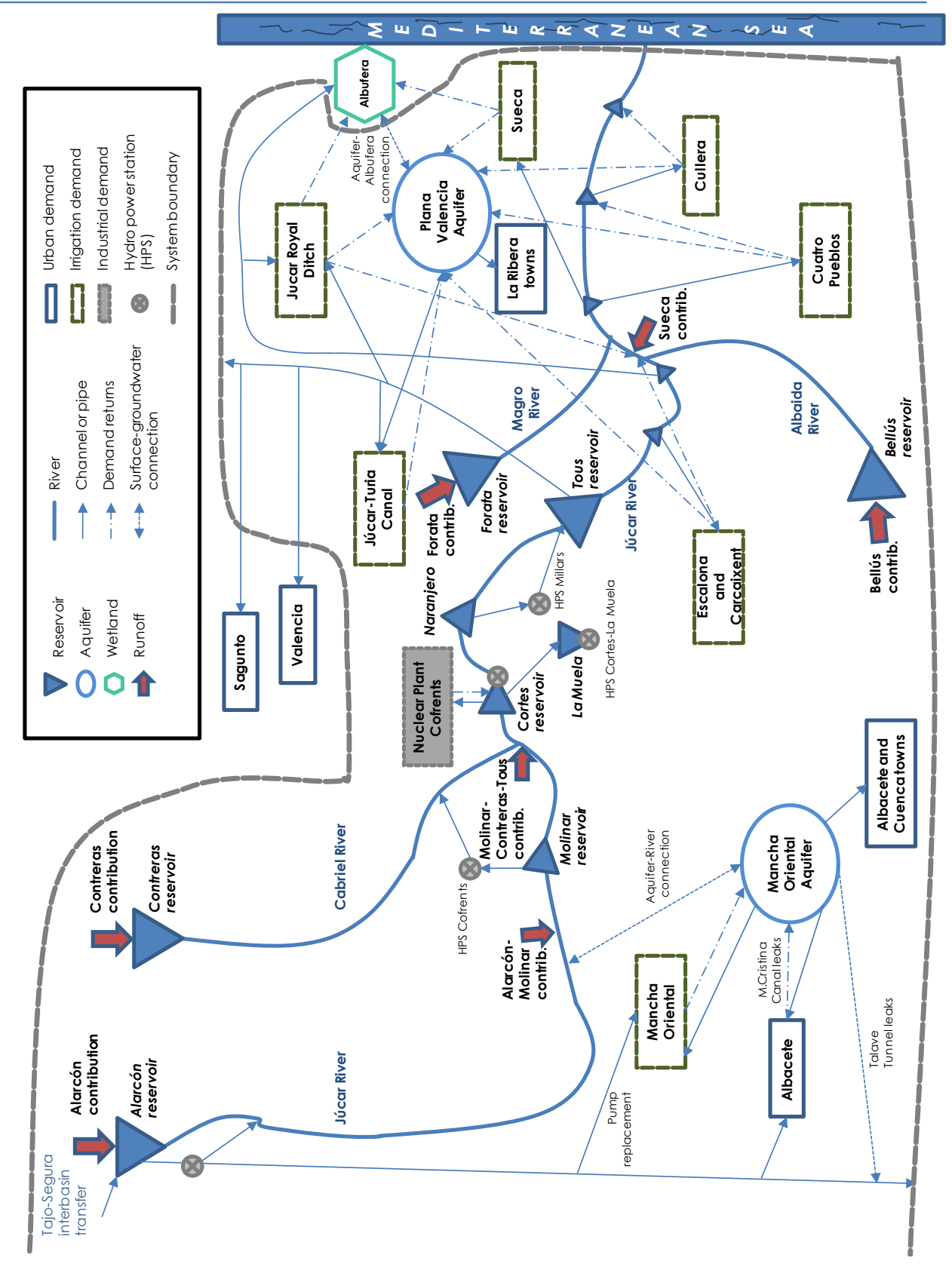

Figure 12. Simplified diagram of the JRB including the most relevant elements for water management (Momblanch et al., 2014). 
The level of exploitation of the JRB water resources is very high, being the ratio between total water demands and mean renewable water resources of 0.84. This value (close to 1) denotes the existence of water scarcity (Momblanch et al., 2014). To cope with this situation, the level of regulation and infrastructure development in the JRB is significant. Noted examples are the Alarcón, Contreras and Tous reservoirs, the Júcar-Turia canal, and the wells in the aquifers of Mancha Oriental and Plana de Valencia Sur. Moreover, the inter-basin transfer from the Tajo to the Segura river basins uses the Alarcón reservoir as an intermediate station. The inter-basin canal, which runs over the Mancha Oriental region, is used as a conveyance facility for the JRB water resources, and receives leakages from the aquifer that are compensated by the Tajo River Basin District Authority.

The JRB comprises many different uses that have diverse supply needs in terms of water quantity, reliability and priority. Surface water is mostly devoted to the urban supply of Valencia, Sagunto and Albacete cities, for the irrigation demands located downstream Tous reservoir, and for the refrigeration of Cofrentes Nuclear Plant. The remaining urban and agricultural water demands rely on groundwater (Momblanch et al., 2014).

\subsubsection{Results}

\subsubsection{Data and scope}

Since two variants of the AWAS water accounts have been presented in sections 3.1.1 (original version) and 3.1.2 (improved version), the results also comprise the implementation of these two versions in the JRB for the hydrological year 2007/2008. This is the last year of one of the most serious recorded droughts in the region. Thus, it is interesting to analyse the recovery of the system storages and the supply to the demands after the execution of water saving measures.

According to Momblanch et al. (2014), the implementation of the water accounts comprises 3 steps: determining the end users of the information and defining the boundaries of the accounting domain; selecting the elements and concepts to be included in the accounts; and quantifying the necessary figures to fill out the accounts. In the case of the JRB, the end users of the water accounts are the water managers, which aim for better control and efficiency use of water resources management, and the stakeholders 
Assessment of Ecosystem Services and Water Accounting Methodologies for Integrated Water Resources Management in water scarce basins

(mainly water users, and environmental and civil organisations) that receive information about the water allocation and supply to each demand, and the state of water reserves enabling them to understand the global functioning of the system (Momblanch et al., 2014). Regarding the boundaries of the accounting domain, they should consider the hydrological area but also the data availability and reliability. In line with the information requirements of the end users, the water assets, liabilities and flows to include in the accounting should be defined. For instance, due to the relevance of the conjunctive use of surface and groundwater in the JRB it is useful to account for these two water sources and their interactions in an explicit way. Besides, the specific characteristics of the water management in the reported river basin have to be represented. This implies that it is not possible to design a totally standard water accounting framework (Momblanch et al., 2014). For example, the water allocation remaining in the AWAS (see Table 7) responds to a management practice applied in Australia through which any water allocated to a demand that has not been used in the corresponding period is extended to the next period to be used by the same demand. On the contrary, non-supplied water in Spain does not continue linked to the original demand and is considered a saving that benefits the whole system.

At the final stage of the water accounting, all the data corresponding to the accounted items should be gathered. It is important to reflect about how to account for certain complex terms. For instance, environmental flows should be considered in some circumstances but not in others. If the environmental flow is defined downstream a reservoir, the water released to comply with the environmental requirement can be used by downstream water demands or can leave the accounting domain and be recorded as an outflow. Therefore, the environmental flow should not be computed as a reduction in water assets. On the contrary, if the environmental flow is established at the river mouth or at the outlet of a transboundary basin, it prevents this water volume to be used for other purposes and should be accounted as a reduction in the water resources of the basin. In this later case, the environmental flow does not have to be included as an outflow of the system with the aim of avoiding double counting. Another intricate example is the case of hydropower demands that are commonly assumed as non-consumptive water uses. However, they consume the equivalent to 
the net evaporation from the reservoirs that only have this energyproduction purpose. This can be reflected in the accounts through supply and return values of hydropower demands without considering the reservoir as a storage element, or accounting for the water balance in the reservoir without considering the supply and returns of the hydropower demand. In this application, the first option is used because it makes more evident the effect of this type of water use on the water resources of the basin. Another clear example of how the same flow can be accounted in different ways are the return flows from demands. In some cases, urban returns are treated in wastewater treatment plants which discharge water outside the accounting domain. Thus, it would be correct, from an accounting perspective, to omit the return flow in the accounts. Conceptually, this would mean that the water supplied to the demand is fully consumed, which is not real. In this case, it would be better to introduce in the accounts a return flow from the demand and record an outflow equivalent to the return.

As commented in chapter 2, the amount of information needed to complete all the accounting terms is considerable, and the data sources to obtain them cover direct measurements, indirect estimations and models. It is important to note that the source or estimation strategy is not decisive as far as there is coherence between the different accounted values no matter the data source used. Table 12 shows the estimation strategy used for the accounting concepts included in the AWAS accounts of the JRB. The information used for this study was generated, validated and stored by the JRB District Authority in several reports and databases.

\begin{tabular}{|c|c|c|}
\hline Data source & Water accounting concept and estimation strategy & $\begin{array}{l}\text { Data } \\
\text { type }\end{array}$ \\
\hline \multirow{3}{*}{$\begin{array}{l}\text { Direct } \\
\text { measurement }\end{array}$} & - Demands supply from surface water bodies & A \\
\hline & - Surface outflows to the sea: gauged flows & A \\
\hline & - Surface outflows through canals and ditches & A \\
\hline \multirow{4}{*}{$\begin{array}{l}\text { Mixed } \\
\text { estimation: } \\
\text { direct + indirect }\end{array}$} & $\begin{array}{l}\text { - Demands supply from groundwater bodies: pumped flow } \\
\text { + pumping time (electricity bills) }\end{array}$ & A \\
\hline & - Water stored in reservoirs: water level + bathymetric curves & B \\
\hline & $\begin{array}{l}\text { - Precipitation on the landscape, reservoirs, etc.: } \\
\text { interpolation of rainfall measurements }\end{array}$ & A \\
\hline & $\begin{array}{l}\text { - Surface runoff entering the water resources system: } \\
\text { gauged flows + natural regime restitution }\end{array}$ & A \\
\hline Indirect & - Return flows from water demands: theoretical return & A \\
\hline
\end{tabular}


Assessment of Ecosystem Services and Water Accounting Methodologies for Integrated Water Resources Management in water scarce basins

\begin{tabular}{|c|c|c|}
\hline Data source & Water accounting concept and estimation strategy & $\begin{array}{l}\text { Data } \\
\text { type }\end{array}$ \\
\hline \multirow[t]{5}{*}{ estimation } & coefficients from water management models & \\
\hline & $\begin{array}{l}\text { - Leakages from canals to aquifers: estimated coefficients } \\
\text { from water management models }\end{array}$ & B \\
\hline & $\begin{array}{l}\text { - Water storage in rivers and canals: Average flow + } \\
\text { simplified geometry }\end{array}$ & A \\
\hline & - Water stored in the landscape & B \\
\hline & - Water stored in aquifers & B \\
\hline \multirow{4}{*}{$\begin{array}{l}\text { From } \\
\text { hydrological } \\
\text { models }\end{array}$} & - Percolation from the landscape to aquifers & A \\
\hline & - Water exchange between rivers and aquifers & A \\
\hline & - Water transfers between aquifers & A \\
\hline & $\begin{array}{l}\text { - Evaporation and evapotranspiration from the landscape, } \\
\text { reservoirs, etc. }\end{array}$ & A \\
\hline
\end{tabular}

Table 12. Data sources and estimation strategies employed to fill out the water accounts for the JRB. Adapted from Momblanch et al. (2014).

A: Periodically along the studied period. The value is accumulated. B: At the end of the studied period. The value is punctual.

\subsubsection{Water accounts}

The original version of AWAS is applied to the JRB as a territory and includes all the elements proposed by the standard that are applicable in the study area (Momblanch et al., 2014). The improved version is applied to a simplified domain that only considers the relevant manageable elements of the JRB and contains the major reservoirs and aquifers, the most relevant water demands in supply priority and magnitude, and the flows corresponding to these elements (Momblanch et al., 2014) (Figure 12).

For an easier comparison, both versions of $\mathrm{A} 1$ and $\mathrm{A} 2$ are presented together in tables Table 13 and Table 14, while A3 versions are presented individually in tables Table 15 and Table 16 because they are not comparable. These tables are presented here in a compact version for simplicity reasons (i.e. the different water storage elements and demands have been aggregated into single values), but the complete versions can be found in Annex A.7. Moreover, Table 17 and Table 18 show the unaccounted for difference terms for surface and groundwater resources separately, in accordance with the proposed improvements, for the original and improved versions. 
WATER ASSETS

Surface water assets

Landscape water storage

Soil moisture - unsaturated zone

Surface water storage - unregulated

Unregulated river channel storage

Unregulated major storages (>1 $\left.\mathrm{Mm}^{3}\right)$

Surface water storage - regulated

Regulated river channel storage

Regulated major storages $\left(>1 \mathrm{Mm}^{3}\right)$

Regulated minor storages $\left(<1 \mathrm{Mm}^{3}\right)$

Water transport system storage

Distribution network carrier storage

Within transport system storage

Other surface water assets
Original Improved

285.90

0.48

$4.56 \quad 4.56$

3.55

289.35

289.35

1.76

0.47

0.00

586.07

293.91

$13,966.32$

$5,271.13$

Unconfined aquifer

$13,966.32$

$5,271.13$

TOTAL GROUNDWATER ASSETS

0.00

0.00

0.00

0.00

TOTAL OTHER WATER ASSETS

$14,552.39$

$5,564.04$

TOTAL WATER ASSETS

$14,552.39$

$5,564.04$

\section{WATER LIABILITIES}

Allocation remaining

Other water liabilities

TOTAL WATER LIABILITIES

0.00

0.00

Final net water assets

$14,552.39$

$5,564.04$

Initial net water resources

$14,411.52$

$5,509.52$

140.87

54.53

$14,552.39$

$5,564.04$

Final water storage

$14,411.52$

$5,509.52$

140.87

54.53

Table 13. Statement of water assets and water liabilities (A1) for the JRB in the hydrological year $2007 / 2008$ in its original and improved version. Figures are in $\mathrm{Mm}^{3}$. Adapted from Momblanch et al. (2014). 
Assessment of Ecosystem Services and Water Accounting Methodologies for Integrated Water Resources Management in water scarce basins

\section{WATER ASSET INCREASES}

In surface water

Precipitation

Into landscape

Into surface water - unregulated

$$
\begin{array}{r}
\text { River channel } \\
\text { Major storages }
\end{array}
$$

Into surface water - regulated

River channel

Major storages

Minor storages

Into other

Transport system

Transfer of inter-region claim on water of another entity

River inflow to region

To unregulated water storage

To regulated water storage

Groundwater discharges to surface water

To soil moisture - unsaturated zone

To surface water storage - unregulated

To surface water storage - regulated

To transport system

Groundwater extraction for surface water storage

Surface returns from urban demands

Surface water returns from irrigation demands

Surface returns from industrial demands

Desalinated water

Increase of inter-region claim on water of another entity
Original Improved

$6,448.83$

0.32

3.79

3.79

3.36

56.78

0.70

1.23

242.97

242.97

786.74

624.05

363.28

363.28

0.00

0.00

0.00

77.25

49.20

6.50

6.50

0.00

0.00

57.10

37.85

124.12

124.12

539.19

539.19

0.00

0.00

0.00

\section{In groundwater}

Recharge from surface water

From landscape

$$
\text { Precipitation }
$$

471.73

204.02

Irrigation demands returns

252.16

155.28

From surface water storage - unregulated

12.87

12.87

From surface water storage - regulated

0.00

0.00

From transport system

13.15

13.15

Entries of external groundwater

0.00

90.47

Artificial recharge

0.00

0.00

TOTAL WATER ASSET INCREASES

$9,462.08$

$2,523.52$

\section{WATER LIABILITIES DECREASES}

\section{In surface water}


Allocations adjustment

Urban allocations

$9.71 \quad 9.71$

Irrigation allocations

187.61

187.61

Industrial allocations

0.00

0.00

Environmental flows adjustment

Decrease of inter-region claim on water of the entity

$0.00 \quad 0.00$

In groundwater

Allocations adjustment

Urban allocations

$0.24 \quad 0.00$

Irrigation allocations

$38.42 \quad 32.70$

TOTAL WATER LIABILITY DECREASES

235.98

230.02

TOTAL WATER RESOURCES INCREASES

$9,698.08 \quad 2,753.54$

\section{WATER ASSET DECREASES}

In surface water

Evapotranspiration

From landscape

$6,373.36$

From surface water storage - unregulated

7.00

6.29

From surface water storage - regulated

33.65

26.06

From transport system

2.59

Groundwater recharges from surface water

From landscape

471.73

From surface water storage - unregulated

12.87

12.87

From surface water storage - regulated

0.00

0.00

From transport system

13.15

13.15

Environmental flows allocation

0.00

0.00

Artificial recharge

0.00

Outflows from region

Transfer of inter-region claim on water of the entity

Treated waste water

To the sea

To wetlands

37.67

37.67

To external surface bodies

\section{In groundwater}

Groundwater discharges to surface water

To soil moisture - unsaturated zone

To surface water storage - unregulated

0.00

To surface water storage - regulated

77.25

49.20

To transport system

6.50

6.50

Groundwater extraction for surface water storage

0.00

0.00 
Assessment of Ecosystem Services and Water Accounting Methodologies for Integrated Water Resources Management in water scarce basins

\begin{tabular}{|c|c|c|}
\hline Evapotranspiration from aquifers & 0.00 & 0.00 \\
\hline \multicolumn{3}{|l|}{ Outflows from region } \\
\hline To wetlands & 83.82 & 83.82 \\
\hline To the sea & 26.34 & 26.34 \\
\hline To other aquifers & 43.44 & 0.00 \\
\hline TOTAL WATER ASSET DECREASES & $7,743.26$ & 807.82 \\
\hline \multicolumn{3}{|l|}{ WATER LIABILITIES INCREASES } \\
\hline \multicolumn{3}{|l|}{ In surface water } \\
\hline \multicolumn{3}{|l|}{ Allocation to demands } \\
\hline Urban allocations & 124.01 & 124.01 \\
\hline Irrigation allocations & 736.86 & 736.86 \\
\hline Industrial allocations & 24.00 & 24.00 \\
\hline \multicolumn{3}{|l|}{ Allocations increase } \\
\hline Urban allocations & 0.00 & 0.00 \\
\hline Irrigation allocations & 0.00 & 0.00 \\
\hline Industrial allocations & 537.75 & 537.75 \\
\hline Environmental flows adjustment & - & - \\
\hline Decrease of inter-region claim on water of the entity & 0.00 & 0.00 \\
\hline \multicolumn{3}{|l|}{ In groundwater } \\
\hline \multicolumn{3}{|l|}{ Allocation to demands } \\
\hline Urban allocations & 69.04 & 42.69 \\
\hline Irrigation allocations & 648.07 & 482.35 \\
\hline \multicolumn{3}{|l|}{ Allocations adjustment } \\
\hline Urban allocations & 0.00 & 0.00 \\
\hline Irrigation allocations & 0.00 & 0.00 \\
\hline TOTAL WATER LIABILITY INCREASES & $2,139.73$ & $1,947.66$ \\
\hline TOTAL DECREASE IN WATER RESOURCES & $9,882.99$ & $2,755.48$ \\
\hline Changes in net water resources & -184.91 & -1.92 \\
\hline Unaccounted - for difference 1 & 325.78 & 56.45 \\
\hline
\end{tabular}

Table 14. Statement of changes in water assets and water liabilities (A2) for the JRB in the hydrological year $2007 / 2008$ in its original and improved version. Figures are in $\mathrm{Mm}^{3}$. Adapted from Momblanch et al. (2014).

\section{WATER INFLOWS}

Original

To surface water

Precipitation

$$
\begin{aligned}
& \text { Into landscape } \\
& \text { Into surface water - unregulated }
\end{aligned}
$$

River channel 
Into surface water - regulated

River channel

Major storages

56.78

Minor storages

0.70

Into other

Transport system

Transfer of inter-region claim on water of another entity

River inflow to region

To unregulated water storage

To regulated water storage

Groundwater discharges to surface water

To soil moisture - unsaturated zone

To surface water storage - unregulated

0.00

To surface water storage - regulated

77.25

To transport system

Groundwater extraction for surface water storage

Surface returns from urban demands

Surface water returns from irrigation demands

Surface returns from industrial demands

Desalinated water

Increase of inter-region claim on water of another entity

0.00

\section{To groundwater}

Recharge from surface water

From landscape

Precipitation

471.73

Irrigation demands returns

From surface water storage - unregulated

From surface water storage - regulated

From transport system

13.15

Entries of external groundwater

0.00

Artificial recharge

\section{TOTAL INFLOWS}

$\mathbf{9 , 4 6 2 . 0 8}$

\section{WATER OUTFLOWS}

\section{From surface water}

Evapotranspiration

From landscape

$6,373.36$

From surface water storage - unregulated

From surface water storage - regulated

33.65

From transport system

2.59

Groundwater recharges from surface water 
Assessment of Ecosystem Services and Water Accounting Methodologies for Integrated Water Resources Management in water scarce basins

From landscape

From surface water storage - unregulated

From surface water storage - regulated

From transport system

Supply to demands

Urban allocations

Irrigation allocations

549.25

Industrial allocations

561.75

Environmental flows allocation

Artificial recharge

0.00

Outflows from region

Transfer of inter-region claim on water of the entity

Treated waste water

To the sea

To wetlands

37.67

To external surface bodies

24.54

\section{From groundwater}

Groundwater discharges to surface water

To soil moisture - unsaturated zone

0.00

To surface water storage - unregulated

0.00

To surface water storage - regulated

77.25

To transport system

6.50

Groundwater extraction for surface water storage

0.00

Evapotranspiration from aquifers

0.00

Supply to demands

Urban allocations

Irrigation allocations

609.65

Outflows from region

To wetlands

To the sea

To other aquifers

TOTAL OUTFLOWS

$9,646.99$

Changes in net water storage

Unaccounted - for difference 2

325.78

Table 15. Statement of physical water flows (A3) for the JRB in the hydrological year $2007 / 2008$ in its original version. Figures are in $\mathrm{Mm}^{3}$. Adapted from Momblanch et al. (2014). 
Application of methodologies

\begin{tabular}{lrrrrrr}
\hline & Allocation & Supply & Deficit & Surplus & Return & Consum. \\
\hline Urban demands & 166.70 & 156.19 & 9.71 & 0.00 & 37.85 & 118.34 \\
Irrigation demands & $1,219.21$ & 991.16 & 220.31 & 0.00 & 279.40 & 711.76 \\
Industrial demands & 24.00 & 561.75 & 0.00 & 537.75 & 539.19 & 22.56 \\
\hline
\end{tabular}

Table 16. Statement of physical water flows (A3) for the JRB in the hydrological year 2007/2008 in its improved version. Figures are in $\mathrm{Mm}^{3}$. Adapted from Momblanch et al. (2014).

Initial surface water resources $\left(\mathrm{Mm}^{3}\right)$

Original Improved

Surface water resources increase $\left(\mathrm{Mm}^{3}\right)$

431.23

176.16

Surface water resources decrease $\left(\mathrm{Mm}^{3}\right)$

8.909.49

$2,245.06$

8.928 .52

$2,051.41$

Theoretical final surface water resources $\left(\mathrm{Mm}^{3}\right)$

412.20

369.81

Final surface water resources $\left(\mathrm{Mm}^{3}\right)$

586.07

293.91

Unaccounted for difference for surface water $\left(\mathrm{Mm}^{3}\right)$

173.87

$-75.90$

Unaccounted for difference for surface water (\%)

14.19

6.19

Table 17. Unaccounted for difference calculation in A2 for the surface water resources of the JRB in the hydrological year 2007/2008 in its improved version. Adapted from Momblanch et al. (2014).

$\begin{array}{lrr} & \text { Original } & \text { Improved } \\ \text { Initial groundwater resources }\left(\mathrm{Mm}^{3}\right) & 13.980 .29 & 5,333.36 \\ \text { Groundwater resources increase }\left(\mathrm{Mm}^{3}\right) & 788.58 & 495.34 \\ \text { Groundwater resources decrease }\left(\mathrm{Mm}^{3}\right) & 954.46 & 690.90 \\ & & \\ \text { Theoretical final groundwater resources }\left(\mathrm{Mm}^{3}\right) & 13.814 .41 & 5,137.80 \\ \text { Final groundwater resources }\left(\mathrm{Mm}^{3}\right) & 13.966 .32 & 5,270.13 \\ \text { Unaccounted for difference for groundwater }\left(\mathrm{Mm}^{3}\right) & 151.91 & 132.34 \\ \text { Unaccounted for difference for groundwater (\%) } & \mathbf{2 2 . 3 9} & \mathbf{2 6 . 8 8}\end{array}$

Table 18. Unaccounted for difference calculation in A2 for the groundwater resources of the JRB in the hydrological year $2007 / 2008$ in its improved version. Adapted from Momblanch et al. (2014).

\subsubsection{Discussion}

The information presented in the water accounts provides a picture of the functioning of the JRB during the hydrological year $2007 / 2008$. It is observable that the water storage in the basin increased during the period. However, the total water stored in the main reservoirs $\left(289.35 \mathrm{Mm}^{3}\right)$ was still significantly lower than the total capacity of these infrastructures 
Assessment of Ecosystem Services and Water Accounting Methodologies for Integrated Water Resources Management in water scarce basins

$\left(2,455.5 \mathrm{Mm}^{3}\right)$. In this scenario, the supply to the demands did not meet the initial water allocation according to the existing water rights. That was due to the drought situation that forced the implementation of water saving measures such as reductions in the supply to agricultural demands and the activation of emergency drought wells in many irrigation associations. Even though the figures show certain amount of urban deficit, there were not supply cuts to these high priority demands. The reduction in the supply was achieved through improvement of distribution networks, voluntary saving campaigns and changes in the use of water in public spaces. The total outflows represent about the $50 \%$ of the inflows (without considering precipitation and evapotranspiration to/from the landscape in the original version).

Apart from the general analysis, if the accounts are detailed enough (see complete versions in Annex A.7), they show the level of satisfaction of the diverse demands as well as the changes in the water storages on which they rely. This enables water users to understand the management of water resources conducted by the JRB District Authority, the main problems of water resources availability, and the tradeoffs among the diverse water users (Momblanch et al., 2014). Conversely, details regarding the precipitation on the landscape or in rivers, which are included in the original version of the accounts, are not very informative for these purposes. The adjustment of the accounting domain and the exclusion of the non-manageable elements in the improved water accounts reduce the volume of information presented and puts the focus on the key data for the evaluation and control of water management (Momblanch et al., 2014). This contributes to improve transparency towards water users and stakeholders and fosters effective public participation. Thus, comparing the original and improved versions based on the relevance of the presented information for a better control of water management and water use efficiency, the improved version is judged as more valuable.

Taking into consideration the unaccounted for difference value as reflect of the accuracy of the accounting, the improved version reveals more advisable. The unaccounted for difference terms, calculated separately for surface and groundwater and accumulated in absolute values, are $17.11 \%$ and $12.12 \%$ of the total water supply for the original and improved versions of 
the accounts, respectively. Note that in the case of the improved water accounting version, the water balance errors in surface and groundwater resources have different signs, and the global error calculated with these values would be misleading (Momblanch et al., 2014) since they are partially offset. Despite the fact that the difference between both errors is small, the improvement in the surface water balance is more significant, changing from $14.19 \%$ in the original version to $6.19 \%$ in the improved version. This is not the case of the error in groundwater accounting that remains almost constant and around $25 \%$ of the groundwater supply, due to the well-known difficulties in measuring groundwater stocks and flows (Momblanch et al., 2014). Thus, it seems that the thorough accounting of all hydrological cycle components does not produce better results than the accounting in a domain reduced to the manageable elements. Moreover, the improved version of the water accounts ensures the presentation of data with comparable orders of magnitude, and provides more faithful and clearer results (Momblanch et al., 2014).

Finally, there are other benefits derived from the application of water accounting as a methodology to support IWRM. The conceptualisation and selection of the river basin elements according to their importance for water management during implementation phase contributes to a better knowledge of the river basin, helps to detect data deficiencies and questions the status quo of water management elements (Momblanch et al., 2014). Furthermore, the periodical application of this methodology discloses the evolution and trends of water assets and demands that can be very useful for municipalities and irrigation associations that can learn from the data to improve their own water management (Momblanch et al., 2014).

\subsection{The Freshwater Provision Service in the Tormes River Basin}

\subsubsection{Case study description}

The Tormes River Basin (ToRB) belongs to the Duero River Basin District in Spain (see Figure 13). It covers an area of $9,568 \mathrm{~km}^{2}$ with an average precipitation of $529.9 \mathrm{~mm} /$ year and a potential evapotranspiration of $826.28 \mathrm{~mm} /$ year, resulting in a mean annual total runoff of $1,678.2 \mathrm{Mm}^{3}$. The ToRB spans from the mountainous region of Sierra de Gredos and, flows north-west until the 
Assessment of Ecosystem Services and Water Accounting Methodologies for Integrated Water Resources Management in water scarce basins

convergence with the Duero River, just downstream the Almendra reservoir. It counts with big Natura 2000 sites at the heading and at the lower part of the basin.

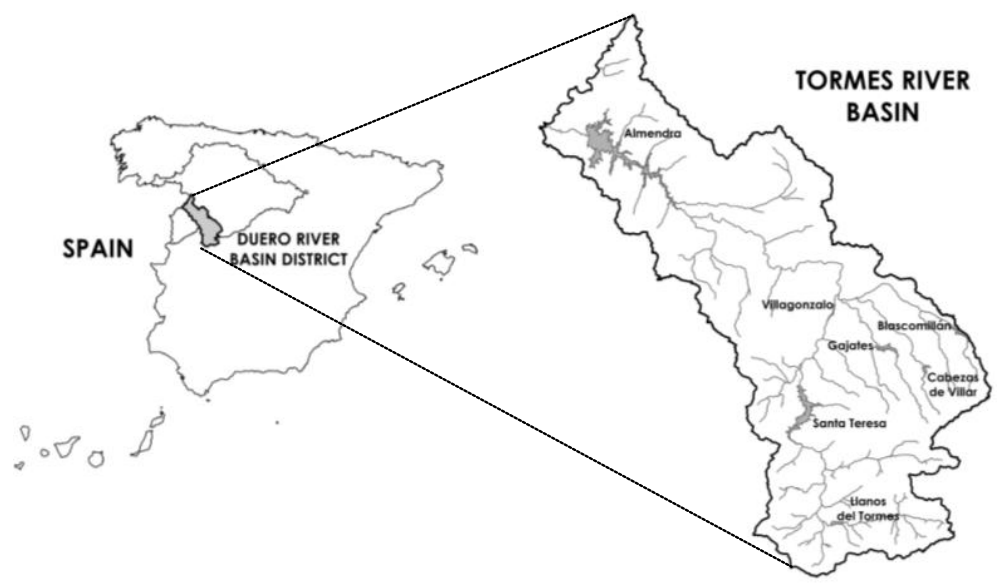

Figure 13. Location of the study area. Adapted from Momblanch et al. (under review).

The main water uses in the TORB are agriculture with a demand of $319.5 \mathrm{Mm}^{3} /$ year, urban demands that amount to $38.9 \mathrm{Mm}^{3} / y e a r$, and hydropower uses that are mostly run-of-river stations and, hence, do not determine water management. The total population in the TORB is around 280,000 inhabitants of which more than 160,000 live in the city of Salamanca. Even though the basin holds several reservoirs, only Santa Teresa performs hyper annual regulation, since the Almendra reservoir only serves downstream uses, which are outside the ToRB. The model used in this application is a simplification of the real system, and it only contains the urban demand of Salamanca with the highest supply priority, the irrigation demands grouped in three areas with equal supply priority, the Santa Teresa reservoir, and the inflows generated by all watersheds grouped into 4 (see Figure 14) (Momblanch et al., under review). 


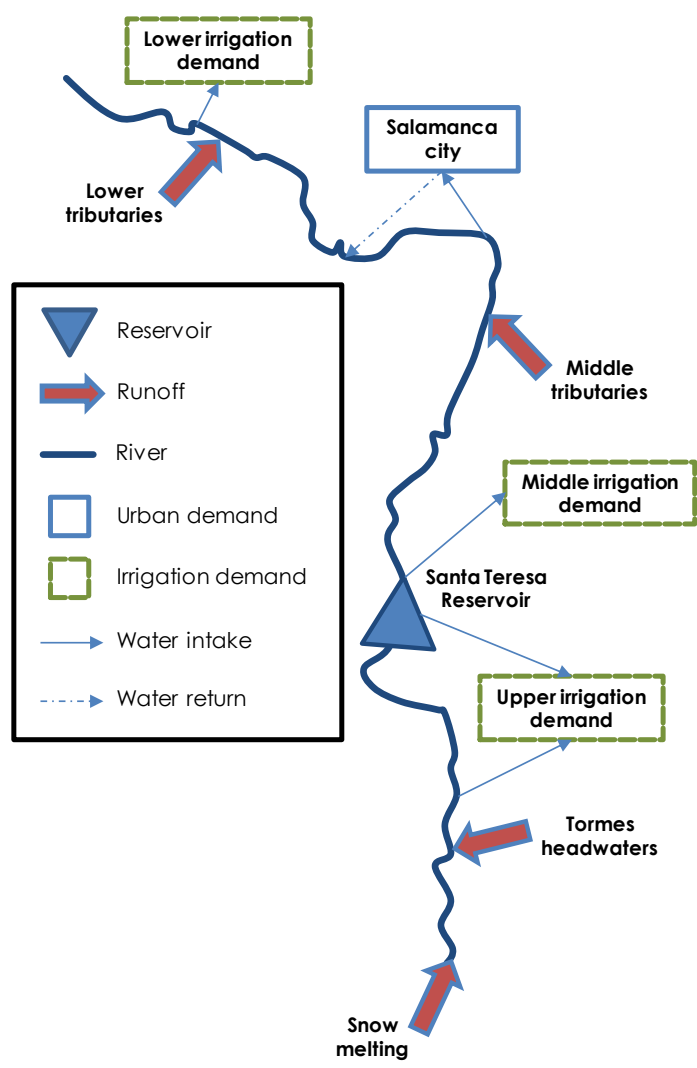

Figure 14. Simplified diagram of the ToRB including the most relevant elements for water management.

\subsubsection{Results}

\subsubsection{Data and scope}

The analysis of the FPS in the ToRB covers the period from October 1955 to September 2007 which includes a four-year dry episode in the basin from 1979 to 1983 . However, the simulations are run since 1950 in order to consider 5 years of warm up period which are necessary to eliminate the influence of the initial conditions used in the water tracer. The data available for the implementation of the case study are high resolution daily gridded datasets of climatic data (Herrera et al., 2012), maps of soil properties, and time series of runoff at certain points of the river basin that were used to build, calibrate and simulate the RRM EVALHID using the HBV model. Moreover, the mean monthly water demands, the characteristics of the Santa Teresa reservoir 
Assessment of Ecosystem Services and Water Accounting Methodologies for Integrated Water Resources Management in water scarce basins

and other water management infrastructures, and the historic stored volumes and supplies to demands are necessary to set up the WAM model with SIMGES. These data are available from the Duero River Basin District Authority. Furthermore, the data for the economic valuation of the FPS have been obtained from the Spanish Water Directorate. The demand curve for the Salamanca city is derived from the curve provided for all urban demands of the Duero River Basin District, while the demand curves for the three irrigation areas are obtained from the curve provided for all agricultural demands of the ToRB (Figure 15).
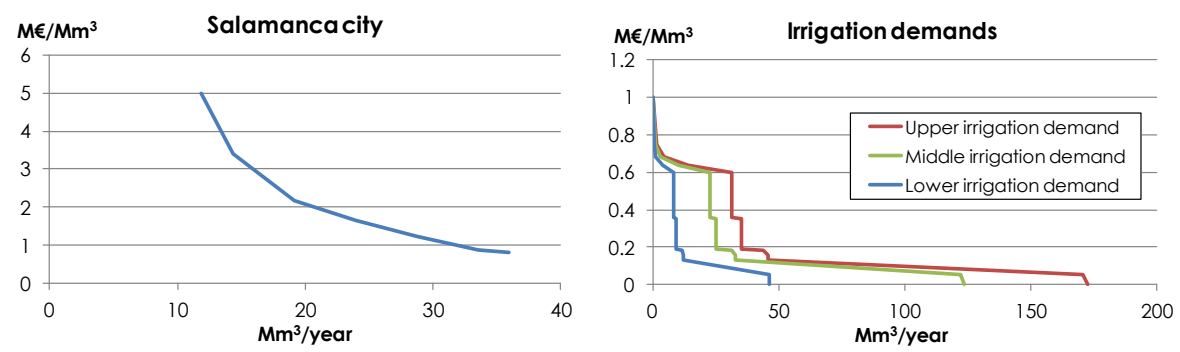

Figure 15. Demand curves adapted for the demands in the simplified ToRB.

By linking EVALHID and SIMGES to perform the analysis of the FPS it is possible to show that changes in the landscape and in water management have an impact on the final value of the service. Hence, the application case presents three different scenarios: business as usual, in which the baseline situation for land use and water management is considered; land use change, consisting in the urbanisation of part of the Tormes headwaters watershed; and water management change, represented through the removal of the Santa Teresa reservoir. The last scenario is probably the most interesting since it clearly shows the influence of water management on the delivery of the service, which is precisely the advantage of using IWRM models for FES assessment instead of ES tools as commented in section 2.2.2.

\subsubsection{Scenario 1: Business as usual}

Without applying any change to the land cover and water management in the ToRB, the Tormes headwaters watershed produces the larger water volume that represents $72.7 \%$ of the total water resource generation on average, followed by the Snow melting watershed with $24.4 \%$ of water production, the Middle tributaries that supply $1.6 \%$ of total runoff, and the 
Lower tributaries which produce $1.2 \%$. These results, together with the configuration of the system lead to the distribution of water supply to the demands from each watershed presented in Figure 16. It can be observed that all water demands receive a constant water volume every simulated year, which is coincident with their annual demand, except for the hydrological years 1980 and 1981 when all demands suffer from some supply deficit. Given the higher priority of the Salamanca City demand, it has the lowest deficit which only represents $3 \%$ of its annual demand. The irrigation demands have supply deficits around $18 \%$ and $2 \%$ of their corresponding annual demands in 1980 and 1981, respectively.
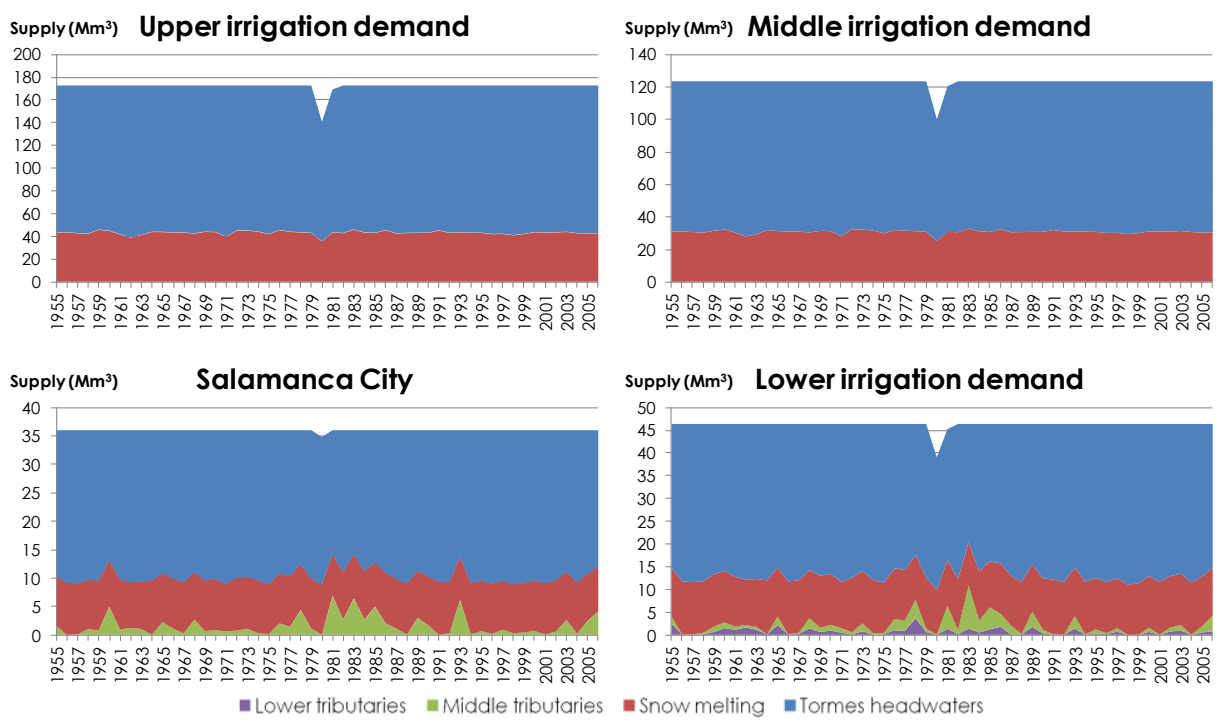

Figure 16. Water supply to the ToRB demands from each watershed for scenario 1. Adapted from Momblanch et al. (under review).

The annual value of the FPS in the ToRB reaches 175.2M€ throughout the analysed period, except for the years with deficit in which the value falls to $171 \mathrm{M} €$ in 1980 and $174.9 \mathrm{M} €$ in 1981 (Figure 17). The proportion of value provided by each watershed $(72.6 \%, 24.6 \%, 2.7 \%$, and $0.02 \%$ for the Tormes headwaters, Snow melting, Middle tributaries and Lower tributaries watersheds respectively) is very similar to the fraction of water resources produced. However, the relative importance of the Middle tributaries increases in the economic valuation as it provides a significant amount of 
Assessment of Ecosystem Services and Water Accounting Methodologies for Integrated Water Resources Management in water scarce basins

water to the urban demand that assigns a higher value to water resources than agricultural demands (Momblanch et al., under review).

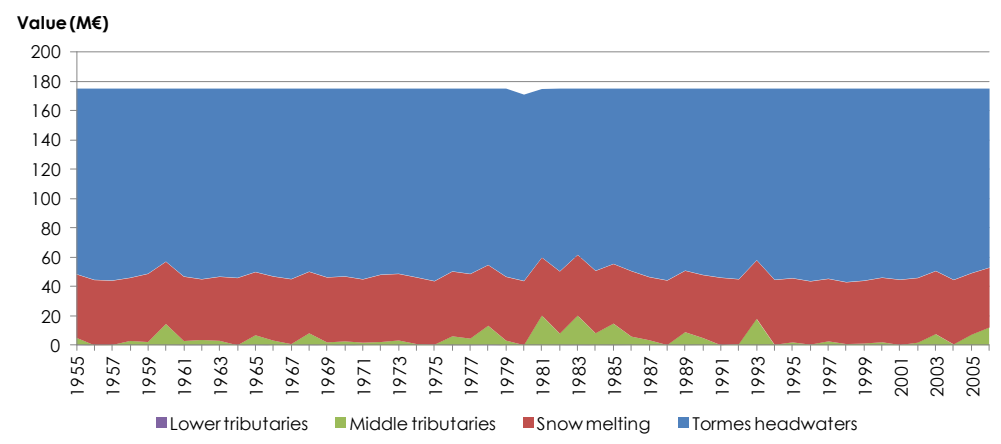

Figure 17. Annual series of the FPS economic value and contribution of each watershed in scenario 1 (Momblanch et al., under review).

\subsubsection{Scenario 2: Land use change}

The urbanisation of part of the Tormes headwater watershed, which was originally mostly covered by natural vegetation, is represented in the RRM through the reduction of evapotranspiration and infiltration (Yang et al., 2012a). Because the value of this application case relies on illustrating the FPS methodology and not on getting insight of the real behaviour of the ToRB, a constant reduction was applied along the simulated period, being $40 \%$ for the evapotranspiration and $10 \%$ for the infiltration (Momblanch et al., under review). This change makes the water resources produced by the Tormes headwaters rise from $427.8 \mathrm{Mm}^{3}$ to $463.0 \mathrm{Mm}^{3}$, whilst the water generated in the other watersheds remains constant. The observed increase in water production due to land use transformation from natural vegetation to urban is supported by some studies (Bao and Fang, 2007; Du et al., 2012; Wagner et al., 2013).

As shown in Figure 18, the effect of the land use change on the water supply to the demands is that all supply deficits in 1980 and 1981 are null or nearly zero. This is due to the fact that the water resources of the Tormes headwaters are generated upstream all water demands and, thus, they benefit from more water available. The distribution pattern of water resources along the river system is also affected by the increase in the Tormes headwaters production; this is, the fraction of water that each 
watershed supplies to each demand. If the annual supply to the demands varies, the economic value of the FPS also changes Figure 19. This is noticeable in 1980 and 1981 for which the values of the service increase in $4.2 \mathrm{M} €$ and $0.3 \mathrm{M} €$, respectively. As the system in scenario 2 has a distinct functioning to scenario 1 , the distribution of value among the watersheds is modified. In this case, the Tormes headwaters watershed is responsible for $74.5 \%$ or FPS value, the Snow melting watershed provides $23.2 \%$ of the value, $2.3 \%$ correspond to the Middle tributaries, and $0.02 \%$ to the Lower tributaries.
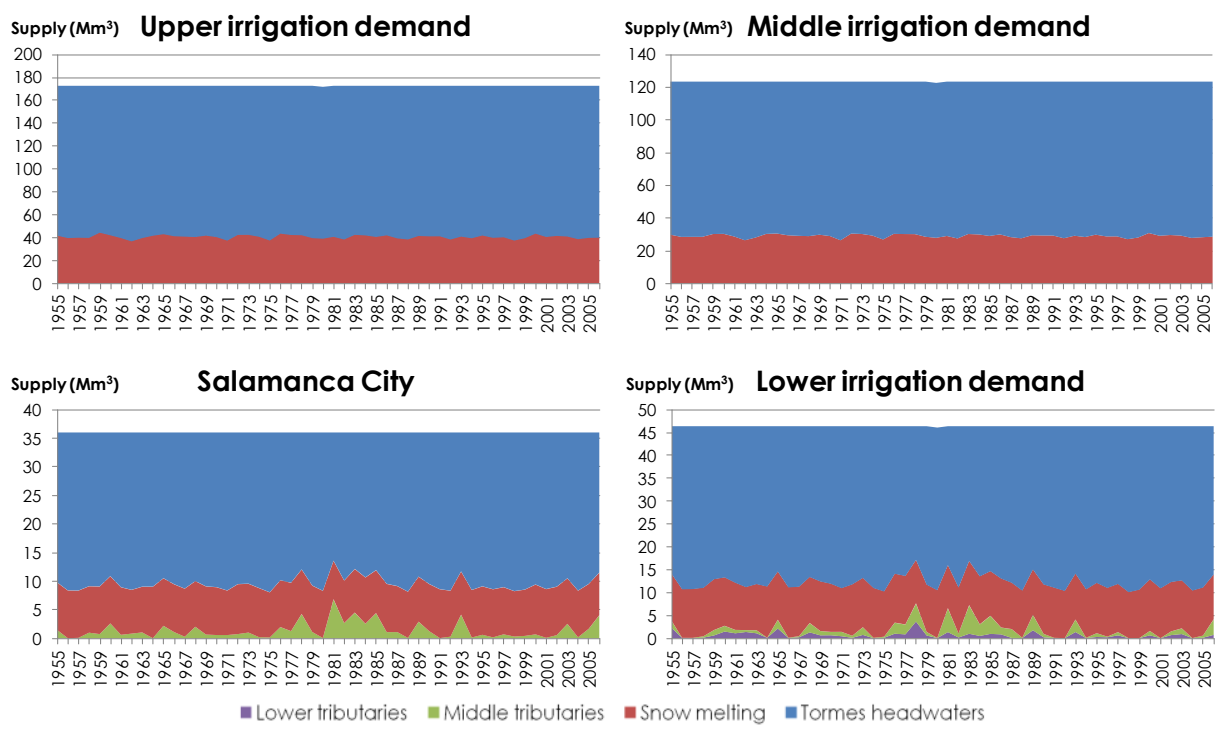

Figure 18. Water supply to the ToRB demands from each watershed for scenario 2.

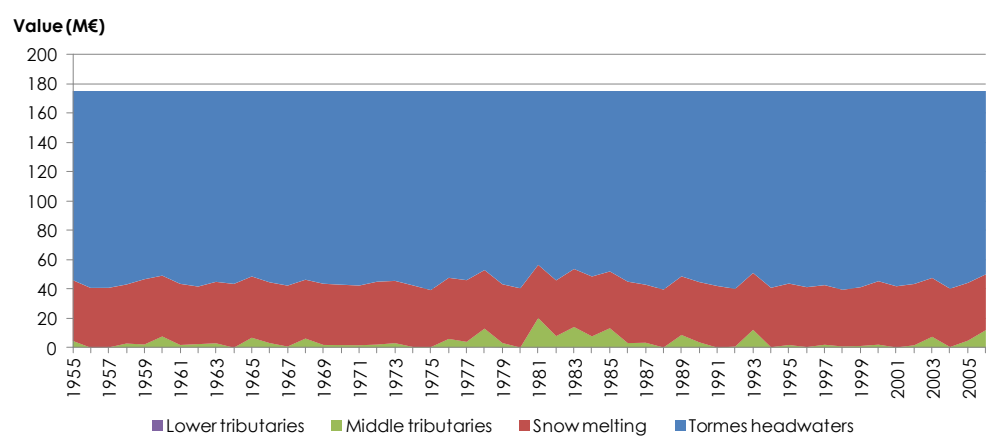

Figure 19. Annual series of the FPS economic value and contribution of each watershed in scenario 2. 
Assessment of Ecosystem Services and Water Accounting Methodologies for Integrated Water Resources Management in water scarce basins

\subsubsection{Scenario 3: Water management change}

In order to show the influence of water management in the assessment of the FPS, this scenario proposes introducing a drastic change in the water management of the TORB by means of voiding the Santa Teresa reservoir that can be easily done in the WAM SIMGES. This action does not affect the runoff generation by the different watersheds with respect to scenario 1 (Momblanch et al., under review). Nonetheless, as depicted in Figure 20, the impact on the supply to the demands is huge due to the lack of regulation capacity of the water resources provided by the most productive watersheds (i.e. Tormes headwaters and Snow melting). The only water demand with an acceptable water supply is Salamanca City because it has a high supply priority, but the irrigation demands barely get to the $40 \%$ of their annual demand most of the time (Momblanch et al., under review). In this scenario, Salamanca City proportionally receives more resources from the Tormes headwaters and the Snow melting watersheds, as they cannot be stored to be used in low flow periods.

When the supply values are translated into economic values by means of the demand curves, the result is an annual reduction in the FPS of 29.7M€ on average. Regarding the relative contribution of the watersheds to the total value of the service, it remains almost constant although the Tormes headwaters and the Snow melting watersheds slightly increase their provision (72.8\% and $26.3 \%$, respectively) by partly replacing the Middle tributaries $(0.9 \%)$ in the supply to Salamanca City (Momblanch et al., under review).

It is interesting to notice that the month with the lower economic value of the service in this scenario does not coincide with the previous scenarios (Figure 21). The explanation can be found in the monthly results presented in Figure 22. Even though the accumulated runoff from October 1980 to September 1982 is lower than the runoff from October 1989 to September 1991, the flows during the dry season are lower in the later period, and cause higher supply deficits to the irrigation demands. 

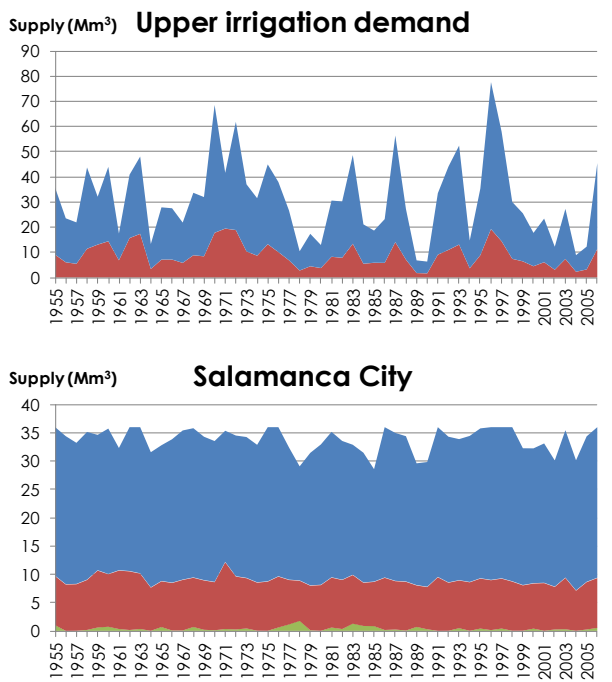

= Lower tributaries $=$ Middle tributaries
Supply $\left(\mathrm{Mm}^{3}\right)$ Middle irrigation demand
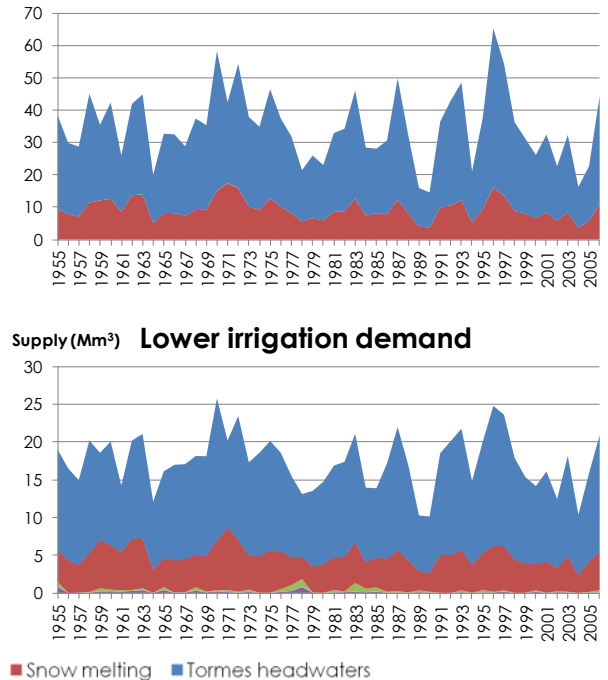

Figure 20. Water supply to the ToRB demands from each watershed for scenario 3.

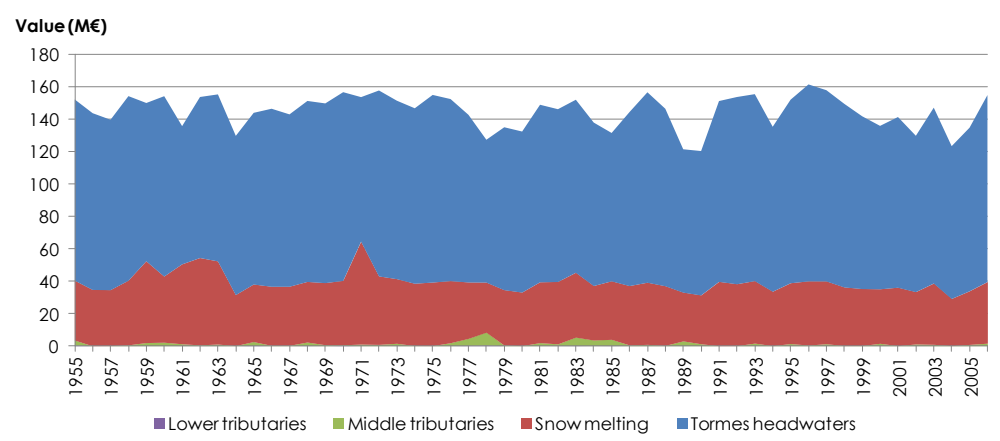

Figure 21. Annual series of the FPS economic value and contribution of each watershed in scenario 3.

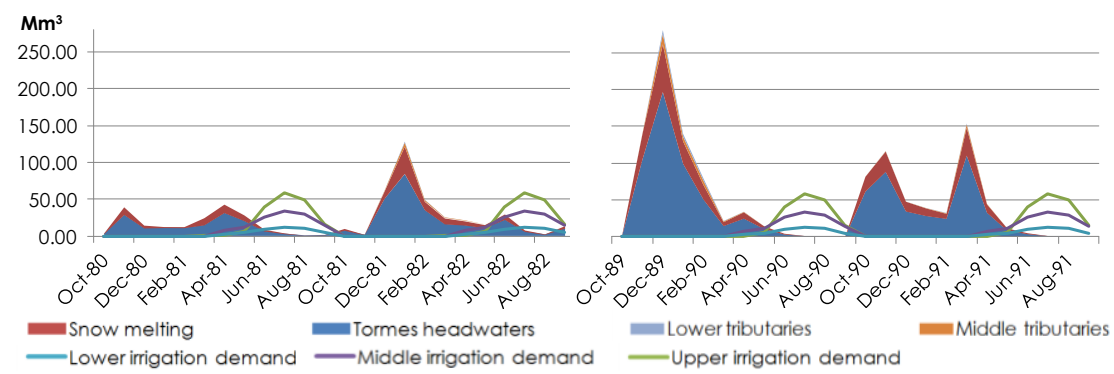

Figure 22. Monthly comparison of the water resources and the irrigation demands. 
Assessment of Ecosystem Services and Water Accounting Methodologies for Integrated Water Resources Management in water scarce basins

\subsubsection{Discussion}

As explained in Momblanch et al. (under review), the Tormes headwater is the most productive watershed from the water quantity and the economic perspectives, followed by the Snow melting watershed. The Middle tributaries are relevant to ensure a high supply reliability to the urban demand in scenarios 1 and 2; especially during the drought episode in which it provides most of the demanded water, when not all, for some months while the upstream resources are stored in the reservoir (Figure 23). Finally, the Lower tributaries play a minor role given that they are located at the end of the system and can only be used by the Lower irrigation demand. Due to the configuration of the ToRB infrastructures, each water demand can only use water from the upstream watersheds. If there were conveyance infrastructures to carry water and make it available upstream, the figures would vary.

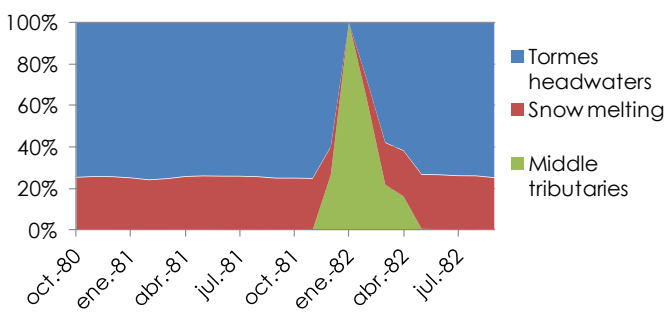

Figure 23. Monthly fraction contributed by each watershed to the Salamanca City demand in scenario 1.

The scenario analysis demonstrates the high influence that water management has on the FPS. The level of detail and accuracy that the WAM provides regarding water infrastructures (e.g reservoirs and transport networks) and management rules (e.g. supply priorities and hyper annual regulation) cannot be obtained with the existing ES tools. Another important advance of the proposed methodology, although not applied in the case study for the sake of simplicity, is the possibility to represent groundwater recharge through the RRM EVALHID, and groundwater regulation and exploitation with the WAM SIMGES.

The monthly time scale reveals appropriate to capture seasonal variability of water resources and demands, and their interaction. In fact, some of the analysed aspects in the application to the ToRB would have been disguised 
had the time scale been larger. Finally, the water tracer ensures that the mapping of the results reflects the real contribution of each watershed to the value of the FPS, including complex cases in which there are returns from demands, pumping from aquifers or infrastructures that modify the natural movement of water along the river system.

Some difficulties or limitations for the application of this methodology come from data acquisition. Demand functions are the most rigorous way to conduct a marginal economic valuation. However, they are not commonly produced due to the cost of the required studies; and, if generated, they are aggregated at regional scale, instead of detailed at water demand scale (Momblanch et al., under review). Another drawback is the lack of information about the modification of the parameters of the models (mainly the RRM) to represent changes introduced in each scenario, such as land use changes, which forces the adoption of simplifications and assumptions (Momblanch et al., under review) that go against the quality of the final output. However, problems with data are not specific for this methodology; in fact, they are common to all models.

\subsection{The Water Purification Service in the Llobregat River Basin}

\subsubsection{Case study description}

The Llobregat River Basin (LRB) is located in the North-East of Spain and is part of the internal basins of Catalonia (Figure 24). It covers $4,957 \mathrm{~km}^{2}$ that generate an average of $694 \mathrm{Mm}^{3} /$ year of total runoff from $672 \mathrm{~mm}$ of annual precipitation and $748 \mathrm{~mm}$ of annual potential evapotranspiration. The Llobregat River flows with North-South direction and discharges into the Mediterranean Sea close to the city of Barcelona. Its main tributaries are the Cardener and Anoia Rivers. 


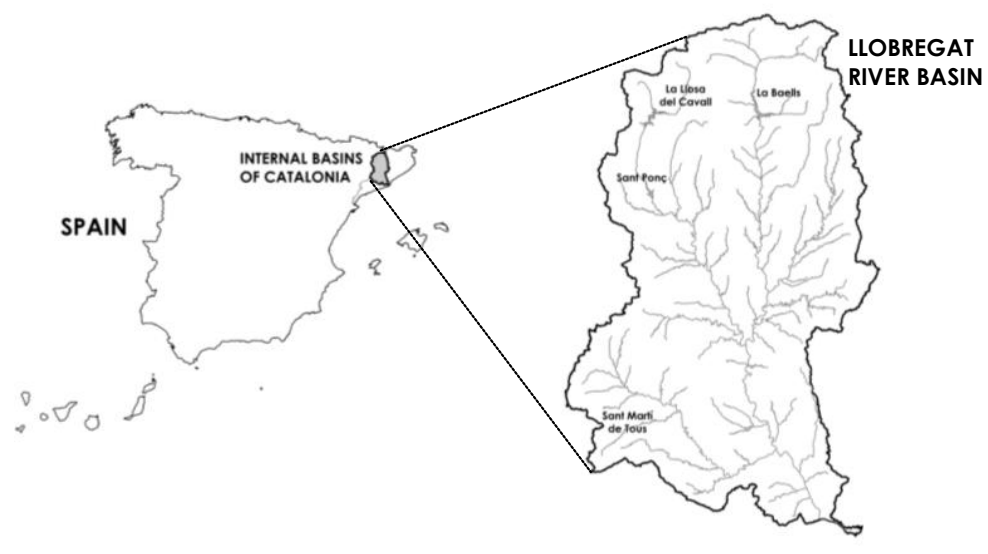

Figure 24. Location of the study area.

The majority of water resources are committed to urban uses, given that several highly populated cities with important industrial activity are located throughout the basin (Momblanch et al., 2015). The main urban demands are supplied by Sant Joan Despí drinking water treatment plant (DWTP) with a mean annual demand of $79.87 \mathrm{Mm}^{3}$, followed by the Abrera DWTP with an allocation of $64.99 \mathrm{Mm}^{3}$. The wastewater generated by urban demands is treated in wastewater treatment plants (WWTP) and returned to the river causing pollution problems, mostly in the lower part of the river basin. The agricultural demands account for a small part of the demand, as well as the industrial demands. However, they also contribute to the deterioration of the water quality conditions of the river. For this reason, apart from the regulation infrastructures to increase supply reliability in the basin, there are specific infrastructures that aim at reducing pollution problems. There is a canal that collects returns from industrial activities and discharges them directly into the sea. Another canal derives water resources from the Anoia River and the Rubí stream, and flows parallel to the Llobregat River to discharge just upstream its outlet (Momblanch et al., 2015). Figure 25 presents the main elements of the LRB. 


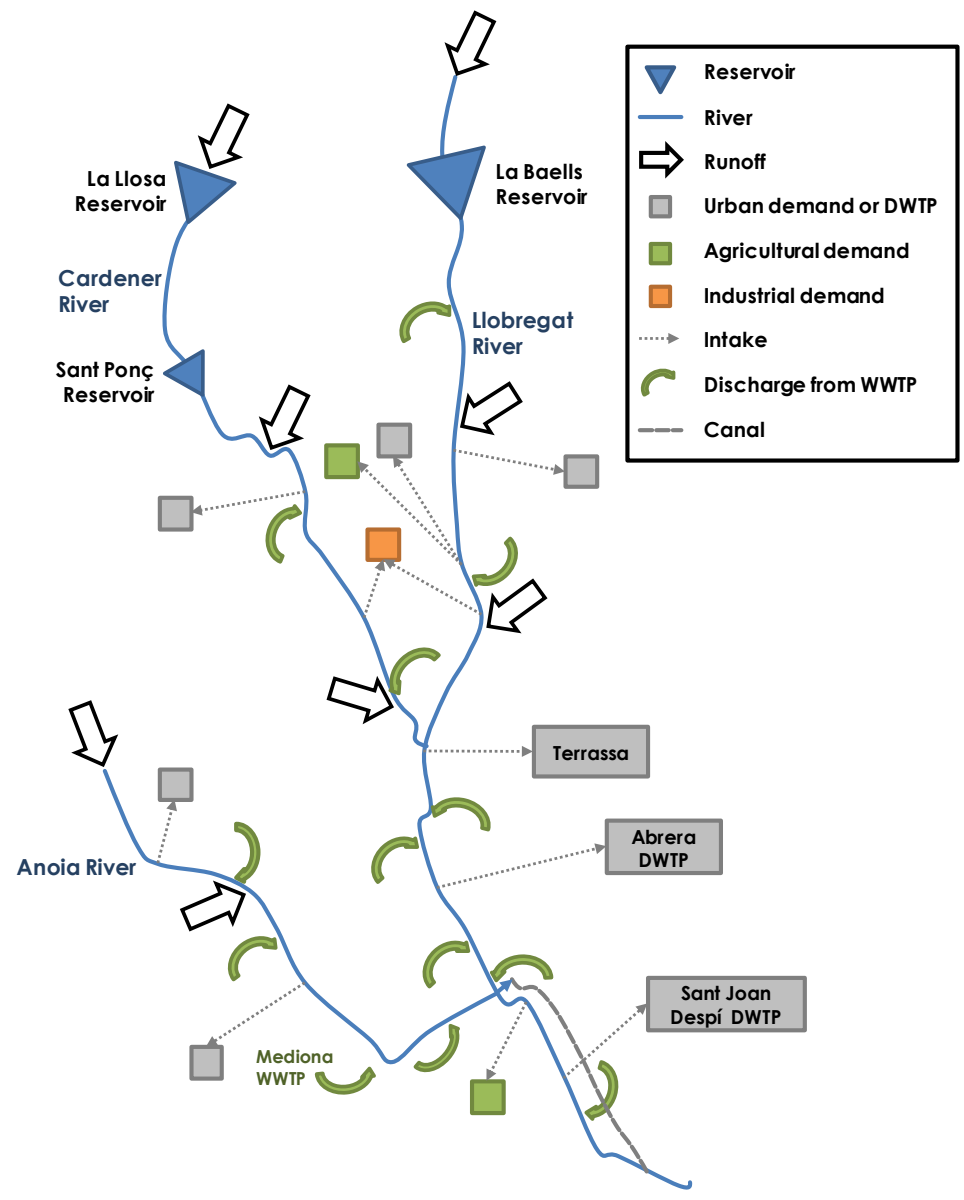

Figure 25. Simplified diagram of the LRB including the most relevant elements for water management. Adapted from Momblanch et al. (2015).

\subsubsection{Results}

\subsubsection{Data and scope}

The period analysed in this case study covers the hydrological years 2002 to 2007 that includes a recent drought episode in the region (October 2004 to September 2008). The required data for the implementation of the methodology for the assessment of the WPS include the data to feed the WAM SIMGES and the WQM GESCAL, as well as the economic information. As described in section 4.2.2, the data required to develop the SIMGES model for the LRB are the mean monthly water demands, the characteristics 
Assessment of Ecosystem Services and Water Accounting Methodologies for Integrated Water Resources Management in water scarce basins

of the water management infrastructures, and the historic stored volumes and supplies to demands. In the case of GESCAL, the necessary data are the effluents from the wastewater treatment plants, and the concentration of pollutants at some river sites. The full description of the construction, calibration and validation of both models can be found in Momblanch et al. (2015). All the information has been provided by the Catalan Water Agency.

Concerning the information for economic valuation, the water quality thresholds for the urban uses have been obtained from European Directives (European Council, 1980; 1998), while the consulted reference for agricultural uses has been Naifer et al. (2011) (Table 19). The treatment costs per unit of pollutant have been taken from Hernández-Sancho et al. (2010) and are shown in Table 20. Finally, the willingness to pay (WTP) for the changes in water quality has been obtained from Van Houtven et al. (2007), who use the Water Quality Index (WQI) (Saffran et al., 2001) to convert the specified water quality changes into a common metric (Table 21).

\begin{tabular}{lcccccc}
\cline { 2 - 7 } & $\begin{array}{c}\text { Conductivity } \\
(\mu \mathrm{S} / \mathrm{cm})\end{array}$ & $\begin{array}{c}\mathrm{CBOD} \\
(\mathrm{mg} / \mathrm{l})\end{array}$ & $\begin{array}{c}\text { Ammonium } \\
(\mathrm{mg} / \mathrm{l})\end{array}$ & $\begin{array}{c}\text { Nitrates } \\
(\mathrm{mg} / \mathrm{l})\end{array}$ & $\begin{array}{c}\text { Phosphates } \\
(\mathrm{mg} / \mathrm{l})\end{array}$ & $\begin{array}{c}\text { Dissolved } \\
\text { oxygen }(\mathrm{mg} / \mathrm{l})\end{array}$ \\
\hline Urban uses & 2500 & 5 & 0.5 & 50 & 5 & 7.5 \\
Irrigation uses & 7500 & - & - & - & - & - \\
\hline
\end{tabular}

Table 19. Water quality thresholds for urban and irrigation demands.

\begin{tabular}{lc}
\hline Cost $N(€ / \mathrm{kg})$ & 17.6 \\
Cost $P(€ / \mathrm{kg})$ & 33.3 \\
Cost CBOD $(€ / \mathrm{kg})$ & 0.036 \\
Cost salinity $(€ / \mathrm{kg})$ & 0.0054 \\
\hline
\end{tabular}

Table 20. Treatment costs per unit of pollutant mass.

WTP (€/WQI unit·person) 7.52

Table 21. WTP per unit of WQI per person.

The proposed methodology for the assessment of the WPS is applied in Terrado et al. (2016a), together with other ES, aiming at implementing a costbenefit analysis for the prioritisation of some management actions included in the programme of measures of the LRB Management Plan. The results presented in this section are more detailed than those included in the paper because they consider all forms of nitrogen and not only nitrates. The analysis is limited to the measures referred to the treatment of urban 
wastewater (measure M12) as it allows illustrating the rational of the proposed methodology better than the whole study. The application consists of two scenarios: the business as usual scenario in which the baseline situation for wastewater treatment is considered; and a scenario representing the construction of a new wastewater treatment plant (WWTP) with nutrient reduction.

\subsubsection{Scenario 1: Business as usual}

This application evaluates the WPS before the implementation of any measures and makes an initial diagnose of the production-benefit pattern of the service. The potential beneficiaries of the service are the urban, agricultural, industrial and bathing water uses in the LRB. As explained in section 3.2.2, the benefits to the three former uses are subject to the comparison between the legal thresholds and the concentrations at the use points, while for the later water use any reduction of pollution is perceived as a benefit.

Regarding the first group, beneficiaries of the service are identified with the application of SIMGES and GESCAL considering that the WPS is not acting. In this case, the urban demands of Terrassa, Abrera DWTP and Sant Joan Despí DWTP are the only demands benefitting from the WPS due to reduced treatment costs of ammonium, since for the rest of demands the concentrations of pollutants at their intakes are below the legal thresholds (Terrado et al., 2016a). As presented in Figure 26 the concentration of ammonium without the WPS is over the legal threshold for drinking water most of the simulated period. The evolution of ammonium concentration at the intakes of Terrassa and Abrera DWTP are very similar because of their proximity. More precisely, the series without WPS are identical, and the series with WPS diverge $0.007 \%$ on average.

When introducing the purification capacity of the river, the concentrations lower considerably. Nevertheless, the reduction only produces a benefit up to the legal threshold, as depicted in the graphics on the right side of Figure 26. It is important to highlight that in the case of Sant Joan Despí DWTP almost all the variation in the ammonium concentration with and without the service generate benefits, given that the concentrations with the WPS remain over the legal threshold most of the simulated period. 
Assessment of Ecosystem Services and Water Accounting Methodologies for Integrated Water Resources Management in water scarce basins

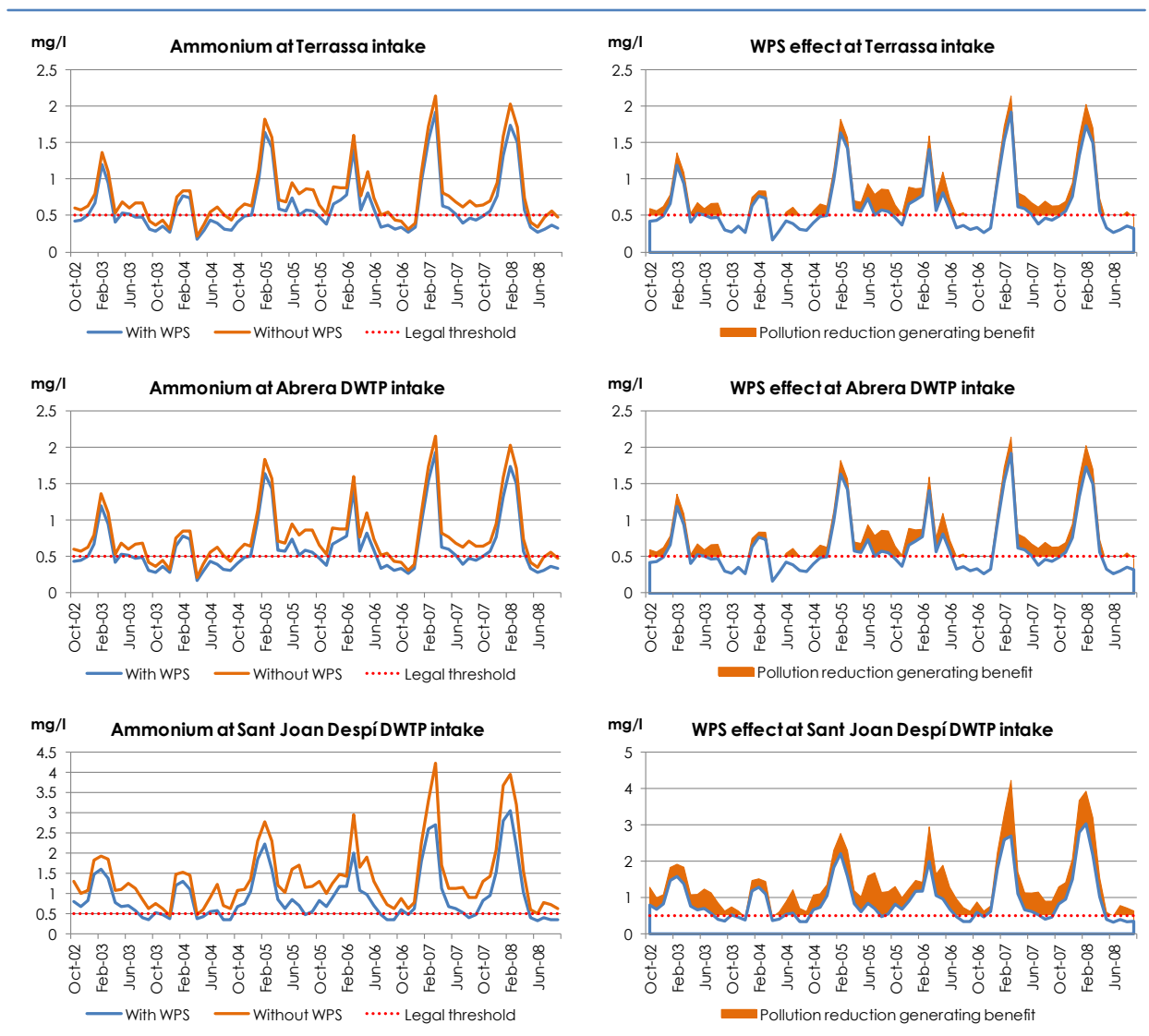

Figure 26. Monthly series of ammonium concentration at the intakes of the Terrassa, Abrera DWTP and Sant Joan Despí DWTP with and without the effect of the WPS, and legal threshold of ammonium for drinking water.

By considering the cost of treatment of nitrogen, and the conversion ratio between ammonium and total nitrogen, the monthly benefit provided by the WPS to the urban demands is obtained (Figure 27). By far, the most benefited water demand is Sant Joan Despí DWTP. This is due to the fact that the reduction of pollutant carried out by the WPS is larger at its intake, and also because the volume of water supplied to this demand is higher than to the others. In the case of Terrassa, the benefit is much lower than for Abrera DWTP, despite the fact that the reduction of pollution at their intakes is almost identical, due to the difference in the amount of water supplied (6.13 $\mathrm{Mm}^{3} /$ year for Terrassa). 


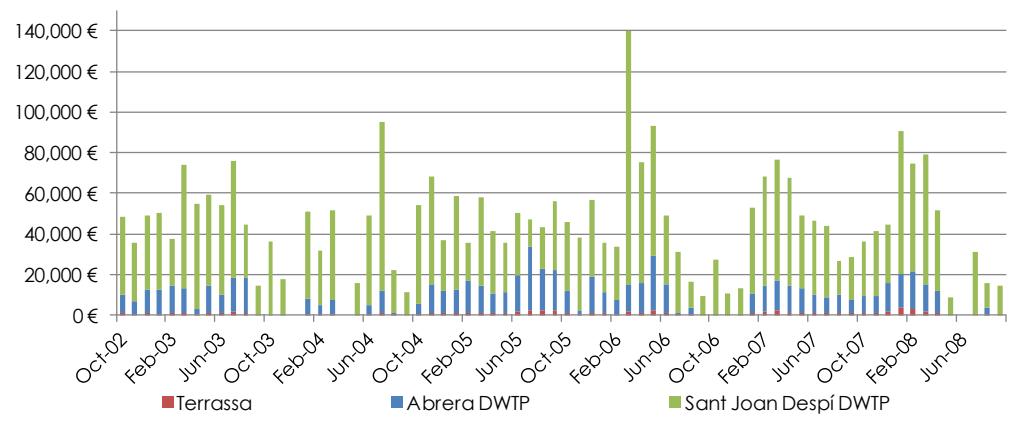

Figure 27. WPS monthly benefit for urban demands in the LRB.

On the other hand, the hypothetical bathing recreation activity is also benefited by the general water quality improvement provided by the WPS. For the valuation of this benefit the WQI with and without the WPS is compared at all water bodies as potential bathing sites. For most water bodies, the WQI do not present variation, as it is an aggregated index used to simplify water quality data, and compensates extreme variations in some variables (Tyagi et al., 2013). Figure 28 shows the WQI values with and without the WPS for the water bodies for which the WQI changed. The average WQI values are in general far above 60 , what means that the water quality is fair to good according to the Canadian Council of Ministers of the Environment (Neary et al., 2001).

Interestingly, the WQI without the service is higher than with the service for some water bodies. This situation can be explained by the degradation processes simulated in the WQM. When the WPS is considered, it reproduces the nitrogen cycle and, in some water bodies, it generates significant concentrations of ammonium and nitrates due to the hydrolysis of organic nitrogen and the nitrification of ammonium, respectively. In contrast, when the WPS is voided, the concentrations of these pollutants in the same water bodies are considerably lower while the organic nitrogen presents higher values because biological degradation processes do not take place. Moreover, the dissolved oxygen concentration is in general higher without the WPS since the biological degradation of organic matter and nitrogen forms is oxygen consuming. In the end, the sign of the WQI variation relies on the relative importance of the biological processes in each water body. 
Assessment of Ecosystem Services and Water Accounting Methodologies for Integrated Water Resources Management in water scarce basins

The benefit of the service for bathing uses is calculated by multiplying the variations in the WQI times the WTP for improved water quality times the population in the watershed associated to each water body (IDESCAT, 2012). Figure 29 presents monthly benefit of the WPS for recreational bathing uses. Despite the fact that some water bodies experience a reduction in the WQI due to the WPS, the global benefit is positive and much larger than the obtained for the urban uses.

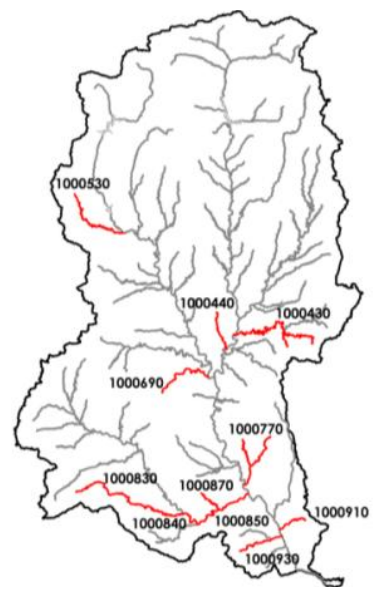

\begin{tabular}{|c|c|c|c|c|c|c|c|c|}
\hline & \multicolumn{2}{|c|}{ WQI } & \multicolumn{6}{|c|}{$\triangle W Q I$} \\
\hline & $\begin{array}{l}\text { With } \\
\text { WPS }\end{array}$ & $\begin{array}{c}\text { Without } \\
\text { WPS }\end{array}$ & $2002 / 03$ & $2003 / 04$ & $2004 / 05$ & $2005 / 06$ & 2006/07 & $2007 / 08$ \\
\hline 1000430 & 62.9 & 55.8 & 5.8 & 5.8 & 4.2 & 9.8 & 9.4 & 7.3 \\
\hline 1000440 & 72.8 & 73.0 & -0.2 & -0.2 & 0.0 & -0.1 & -0.1 & -0.4 \\
\hline 1000530 & 80.0 & 76.1 & 4.4 & 3.9 & 2.4 & 7.5 & 4.8 & 0.0 \\
\hline 1000690 & 93.1 & 95.0 & 0.0 & 0.0 & 0.1 & -5.7 & -5.8 & 0.0 \\
\hline 1000770 & 68.3 & 62.7 & 3.1 & 3.1 & 7.4 & 8.2 & 8.3 & 3.6 \\
\hline 1000830 & 84.3 & 90.3 & -6.3 & -3.5 & -2.6 & -9.3 & -9.6 & -4.4 \\
\hline 1000840 & 84.3 & 90.3 & -6.3 & -3.5 & -2.6 & -9.3 & -9.6 & -4.4 \\
\hline 1000850 & 84.1 & 85.9 & -0.5 & -0.6 & -1.9 & -2.4 & -2.5 & -2.8 \\
\hline 1000870 & 83.2 & 83.9 & -5.8 & -5.8 & 2.1 & 2.0 & -1.1 & 4.6 \\
\hline 1000910 & 92.4 & 88.4 & 0.0 & 0.0 & 0.0 & 4.4 & 12.7 & 7.0 \\
\hline 1000930 & 94.0 & 92.2 & 0.0 & 5.5 & 5.5 & 5.6 & -0.2 & -5.8 \\
\hline
\end{tabular}

Figure 28. Average WQI with and without the WPS, and annual variation in the water bodies of the LRB.

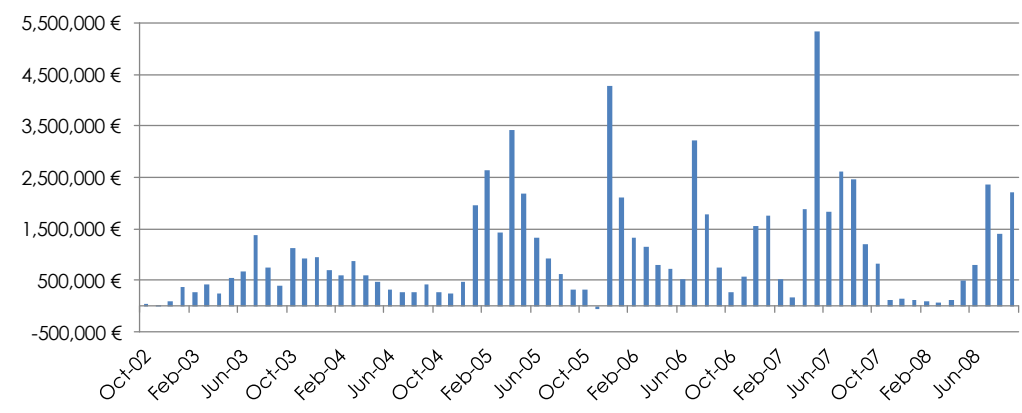

Figure 29. WPS monthly benefit for bathing uses in the LRB.

Once the different benefits associated to the WPS are calculated, they can be accumulated to obtain the global value of the WPS. It amounts to 77.5M€ for the whole simulated period. However, there is a significant temporal 
variability in the results. For example, the benefit in the most humid year (i.e. $2002 / 03$ ) is 5.8M€, while in the most dry year (i.e. 2006/07) it reaches $20.7 \mathrm{M} \epsilon$.

The final step of the WPS assessment is mapping the provision of the service by each water body. Figure 30 shows the annual results of the global WPS for the simulated water bodies. As it can be seen, there are some water bodies, including the reservoirs, that provide negative benefits. This is due to the fact that in these water bodies the rate of ammonium generation by the hydrolysis of organic nitrogen is faster than the rate of ammonium nitrification. Thus, the result is an increase in the concentration of ammonium along the water body that is considered a disbenefit. This effect does not occur to other water quality variables such as CBOD that can only enter the system from the landscape or human discharges. It does happen to the dissolved oxygen that is affected by many physical and biological processes (e.g. re-aireation and nitrification, respectively).
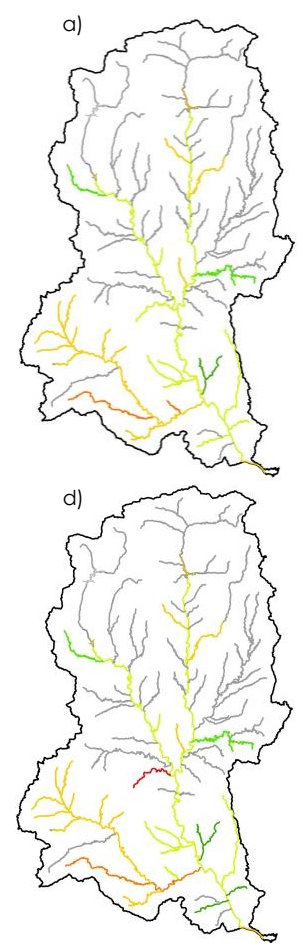
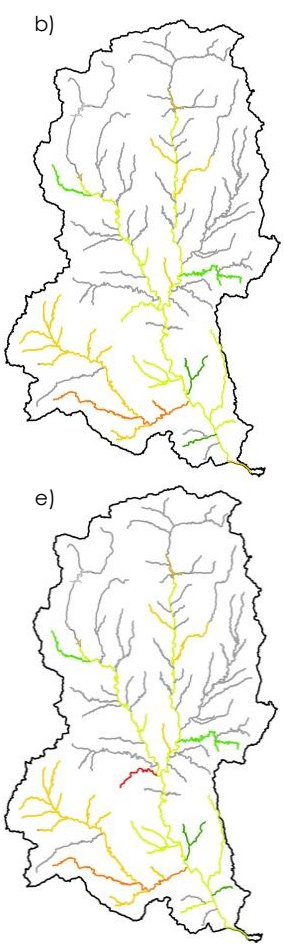
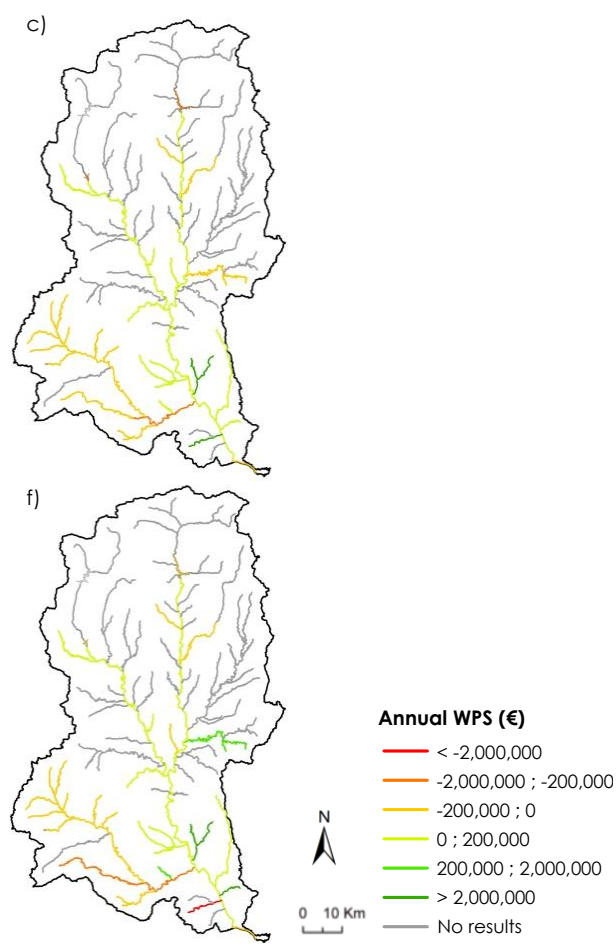

Figure 30. Annual provision of the WPS by the different water bodies in the LRB in 2002/03 (a), 2003/04 (b), 2004/05 (c), 2005/06 (d), 2006/07 (e), and 2008/09 (f). 
Assessment of Ecosystem Services and Water Accounting Methodologies for Integrated Water Resources Management in water scarce basins

Comparing the results of the six simulated years, most water bodies in the main Llobregat and Cardener courses maintain a provision of the service valued between 0 and $200,000 € /$ year. There are water bodies which provide both benefits and disbenefits depending on the year. For instance, Riera Cervelló (1000930) presents a value over $2 M €$ from 2003/2004 to 2005/2006 against a value below $-2 M €$ in $2007 / 2008$. The Anoia River provides disbenefits ranging from $-2 M €$ to 0 in most of its water bodies. They are exclusively related to the bathing uses, since the Anoia River is derived before its confluence with the Llobregat River and its water resources do not reach any of the urban demands. Finally, the "No result" values refer to water bodies excluded from the simulation. In the case of the LRB, the excluded tributaries and the headwater streams were not expected to have a significant impact on the WPS assessment, because they have low concentrations of pollutants and, hence, the margin for purification was small. The water bodies included in the models that do not contribute to satisfy any water use cannot be valued and provide "No result". However, this does not happen in the LRB,

\subsubsection{Scenario 2: Implementation of measure M12.1}

This scenario simulates the implementation of a tertiary treatment in the Mediona WWTP (M12.1), located in the Anoia River, as included in the program of measures of the LRB Management Plan. In order to reflect the effect of the measure on the WPS, it is necessary to modify the original discharge of the WWTP, by limiting the concentrations of nutrients to the values established for tertiary treatments. The values adopted are $15 \mathrm{mg} / \mathrm{l}$ for total nitrogen and $2 \mathrm{mg} / \mathrm{l}$ for total phosphorus, in line with the European legislation (European Council, 1991).

Given that the Anoia River is diverted before its confluence with the Llobregat River, the measure does not have any impact on urban demands. The only changes with respect to scenario 1 occur in the provision of the WPS to bathing uses downstream the Mediona WWTP discharge (Figure 31). The clear melioration of the WQI generates a global benefit of $100.5 \mathrm{M} €$. Thus, the marginal benefit of the application of the measure reaches $3 \mathrm{M} €$. The annual distribution of the marginal benefit is presented in Figure 32. According to the results, the water body 1000840 is more productive per length unit than 1000850, but they have similar contributions to the marginal benefit. 


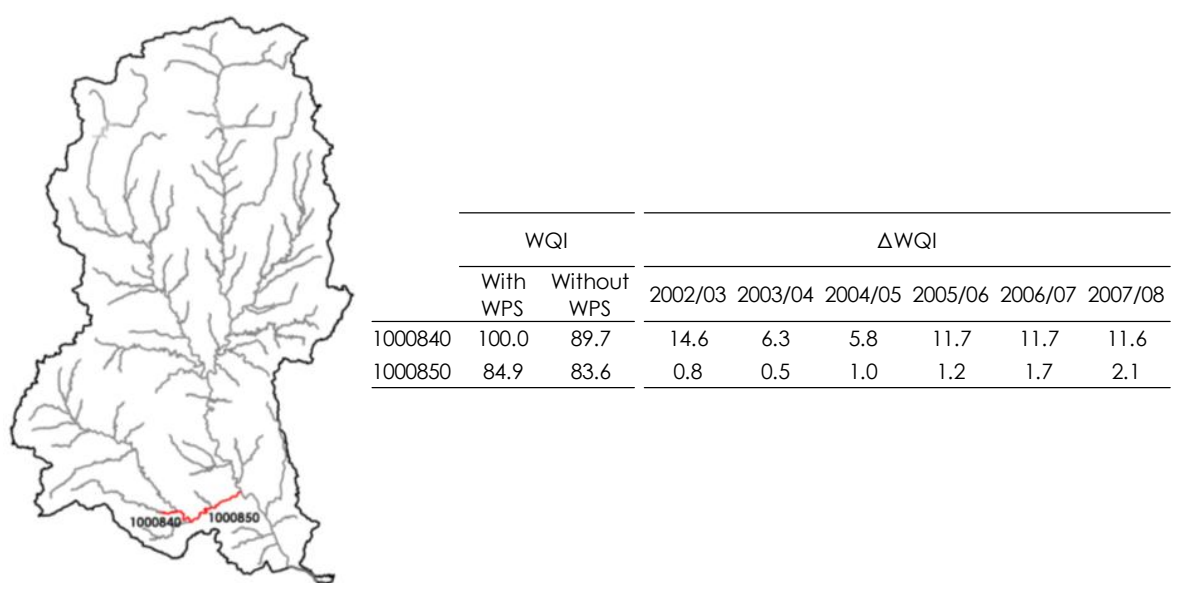

Figure 31. Average WQI with and without the WPS, and annual variation in the water bodies of the LRB in scenario 2.
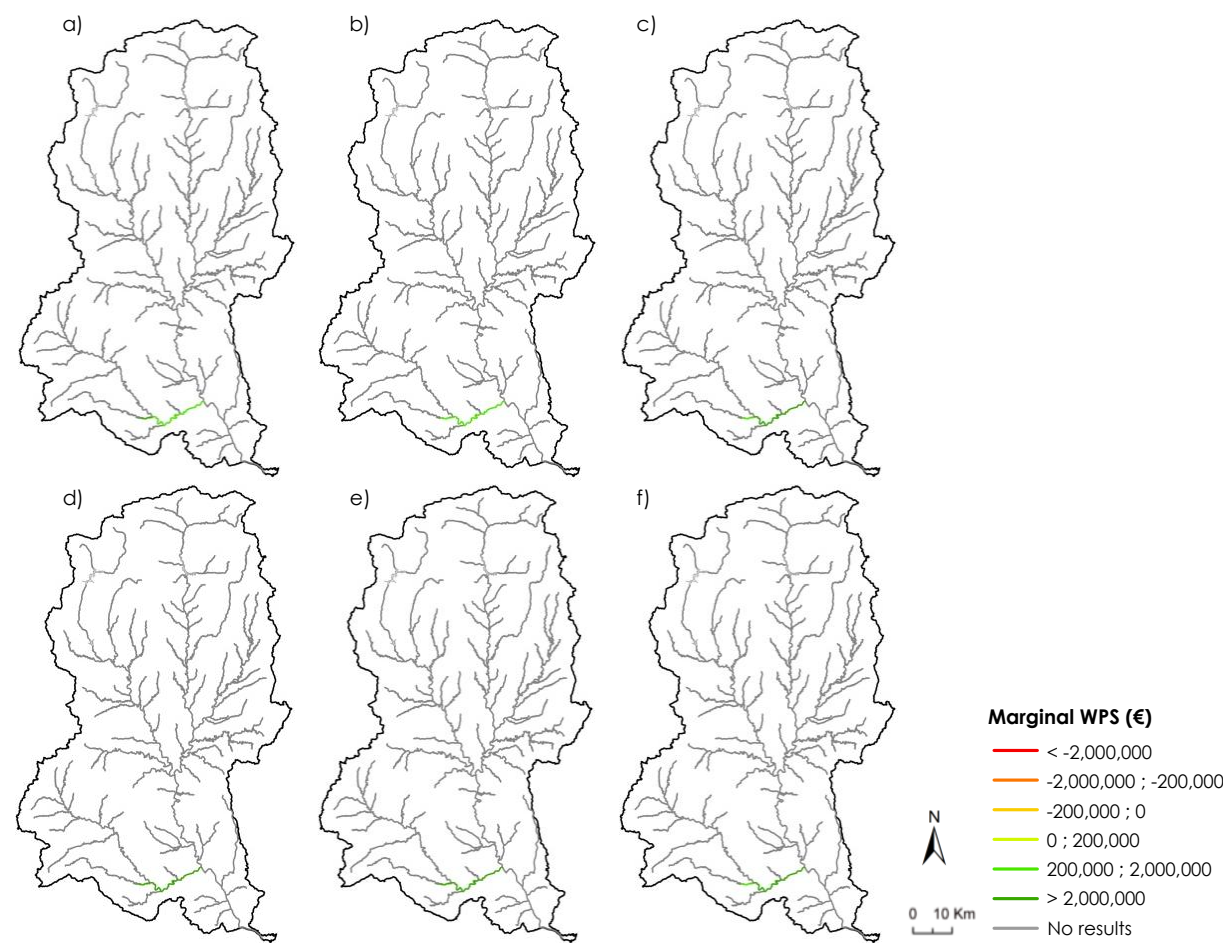

Figure 32. Marginal annual benefit of the WPS with the implementation of measure M12.1 in the LRB in 2002/03 (a), 2003/04 (b), 2004/05 (c), 2005/06 (d), 2006/07 (e), and 2008/09 (f). 
Assessment of Ecosystem Services and Water Accounting Methodologies for Integrated Water Resources Management in water scarce basins

\subsubsection{Discussion}

The application of the WPS to the LRB makes clear that the ecological functions underpinning the service in the Llobregat and Cardener Rivers are in tolerable conditions, but that they can improve if the pollution levels decrease, especially with regard to nutrients. The ecological status of the Anoia River is much more affected by the high concentrations of nutrients and salts, which get worse in drought conditions (Momblanch et al., 2015). Therefore, the service even provides negative benefits when nitrification exceeds denitrification. These disbenefits are relative, because the only way to remove organic nitrogen is through nitrification and if it is not performed by the water body, it will have to be removed by the DWTP. A way of considering the whole process of nitrogen removal (hydrolysis-nitrificationdenitrification) could be including the cost of the treatments of the precedent forms in the removal cost of a certain nitrogen form (i.e. the cost of ammonium removal would include the cost of organic nitrogen removal).

The proposed methodology reveals useful to test measures related to the improvement of water quality in terms of ES, such as the ones described in Terrado et al. (2016a). For examples, the results of scenario 2 demonstrate that the implementation of measure M12.1 drastically improves the situation in the Anoia River. Nonetheless, the results presented here are more detailed regarding the temporal scale and the number of water quality variables considered. Altogether brings different results such as the existence of benefits for urban uses that are disregarded if the ammonium is not accounted. The relevance of the urban benefits is, however, negligible compared to the benefits provided by the service to potential bathing uses which are 10 times larger than the former due to the economic valuation technique used. Finally, the results show the influence of river flows on the provision of the WPS, since similar pollution levels provide larger benefits in drier years. This makes evident the importance of this methodology for IWRM in water scare river basins because it helps to understand the possibilities that healthy river ecosystems provide in order to alleviate drought impacts.

The difficulties found in the application of the methodology are related to data. The treatment cost for the different pollutants is not generated by DWTPs or by water managers. For this case study the treatment costs have been transferred from a study which analysed the treatment costs in the 
Valencia region. This data transfer is reasonable because there is correspondence between the original study and the LRB. Moreover the water treatment costs are unlikely to change significantly if similar technologies are used, no matter the location of the DWTP. On the contrary, the values assigned to recreational bathing are very site-dependent. In this case, the value has been taken from a study in the United States, which introduces a significant degree of uncertainty in the results.

\subsection{The Aquatic Habitat Service in the Turia River Basin}

\subsubsection{Case study description}

The Turia River Basin (TURB) is the second largest river basin in the Júcar River Basin District and is bordering to the South with the JRB (Figure 33). The TURB has an area of $7,231.75 \mathrm{~km}^{2}$ that produce a total runoff of $471.9 \mathrm{Mm}^{3} /$ year resulting from an annual precipitation of $457.8 \mathrm{~mm}$ and a potential evapotranspiration of $833.6 \mathrm{~mm}$. The Turia River, as such, originates from the confluence of the Guadalaviar and the Alfambra Rivers and receives the water resources of some small tributaries before discharging into the Mediterranean Sea.

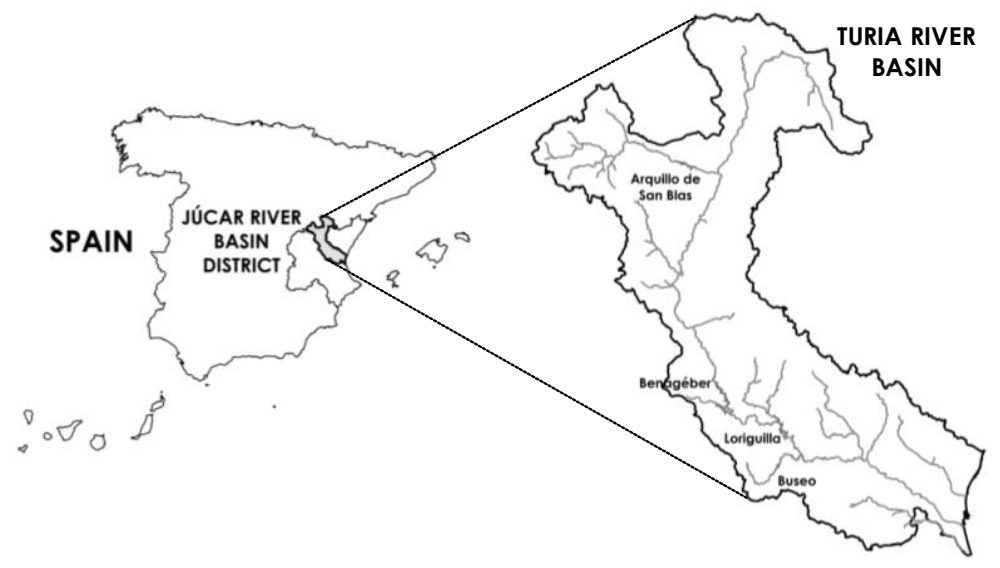

Figure 33. Location of the study area.

The total water demand reaches $583.65 \mathrm{Mm}^{3}$, what produces ratio between total water demands and mean renewable water resources of 1.24. This is possible with intensive reclaimed water use by the irrigation uses. The water 
Assessment of Ecosystem Services and Water Accounting Methodologies for Integrated Water Resources Management in water scarce basins

uses in the basin are dominated by agriculture, which accounts for more than $86 \%$ of total water demand, at the middle and lower part of the river basin. Urban demands represent around $14 \%$ of the total demand, and more than a half is used to partly supply the city of Valencia and its metropolitan area with around 1 million inhabitants. There are also several hydropower plants that are non-consumptive uses since they are mostly run-of-river stations or they do not have single-purpose associated reservoirs. The main reservoirs are Arquillo de San Blas, Benagéber and Loriguilla with a total capacity around $265 \mathrm{Mm}^{3}$, which are used for water resources regulation, recreation, and energy production. Figure 34 presents a simplified diagram of the TURB which includes the main features relevant for the case study.

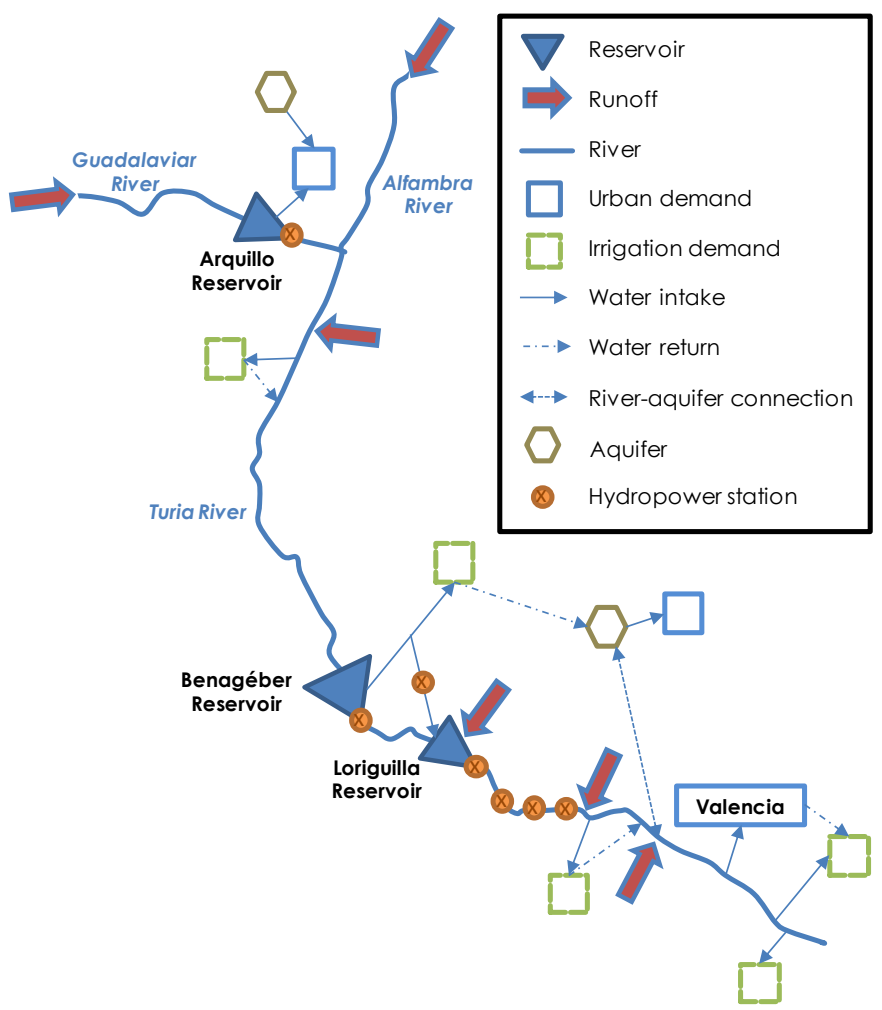

Figure 34. Simplified diagram of the TuRB including the most relevant elements for water management.

The TURB contains natural areas of high environmental value in its upper part, and the Turia Natural Park in the middle and lower parts with an extension of 
4.7ha and $35 \mathrm{~km}$ of length. This originates an intense nature-based recreation activity, which includes fishing. Recreational fishing is regulated by the regional government that establishes the fishing licences required, the open fishing seasons for the different species and other general rules (Consellería de Infraestructuras Territorio y Medio Ambiente, 2015). On the other hand, the commercial fishing in continental waters is non-existent in the study area (Mitchell et al., 2010). The fish species of special interest for their ecological and social value are Salmo trutta, Luciobarbus guiraonis, and Squalius pyrenaicus. The three species are present along the Turia River, except for the Salmo trutta which is not represented downstream the Benagéber reservoir to the river mouth. Another important natural feature related to the TURB, although located out of its boundaries, is the Albufera wetland that receives $10 \%$ of its total resources from this river basin.

\subsubsection{Results}

\subsubsection{Data and scope}

The period of analysis for the illustration of the AHS assessment methodology spans from the hydrological year 2004/2005 to 2013/2014. It includes a 3-year drought episode starting in 2006/07, and the beginning of a still ongoing dry period which stated in 2014. It is important to note that because of the application of many water saving measures, including the use of reclaimed wastewater for irrigation and irrigation turns among the farmers, the drought impacts on water uses were moderate. This case study aims at illustrating how water management can be oriented to improve the AHS even in difficult scenarios such as drought, and what are the tradeoffs with the other water uses in the basin. To do so, the business as usual scenario (scenario 1) is compared with a scenario in which more water is left in the water bodies with more potential for AHS provision (scenario 2).

In order to apply the methodology described in section 3.2.3, it is necessary to build a WAM and a HSM. The input data needed for WAM SIMGES has been already described in previous sections. Regarding the HSM CAUDECO, the data required for the implementation are the WUA - flow curves for the existing species (Figure 35), together with the bioperiods in which their different life stages are present. This information has been provided by the 
Assessment of Ecosystem Services and Water Accounting Methodologies for Integrated Water Resources Management in water scarce basins

JRB District Authority, since it was included in the River Basin Management Plans.
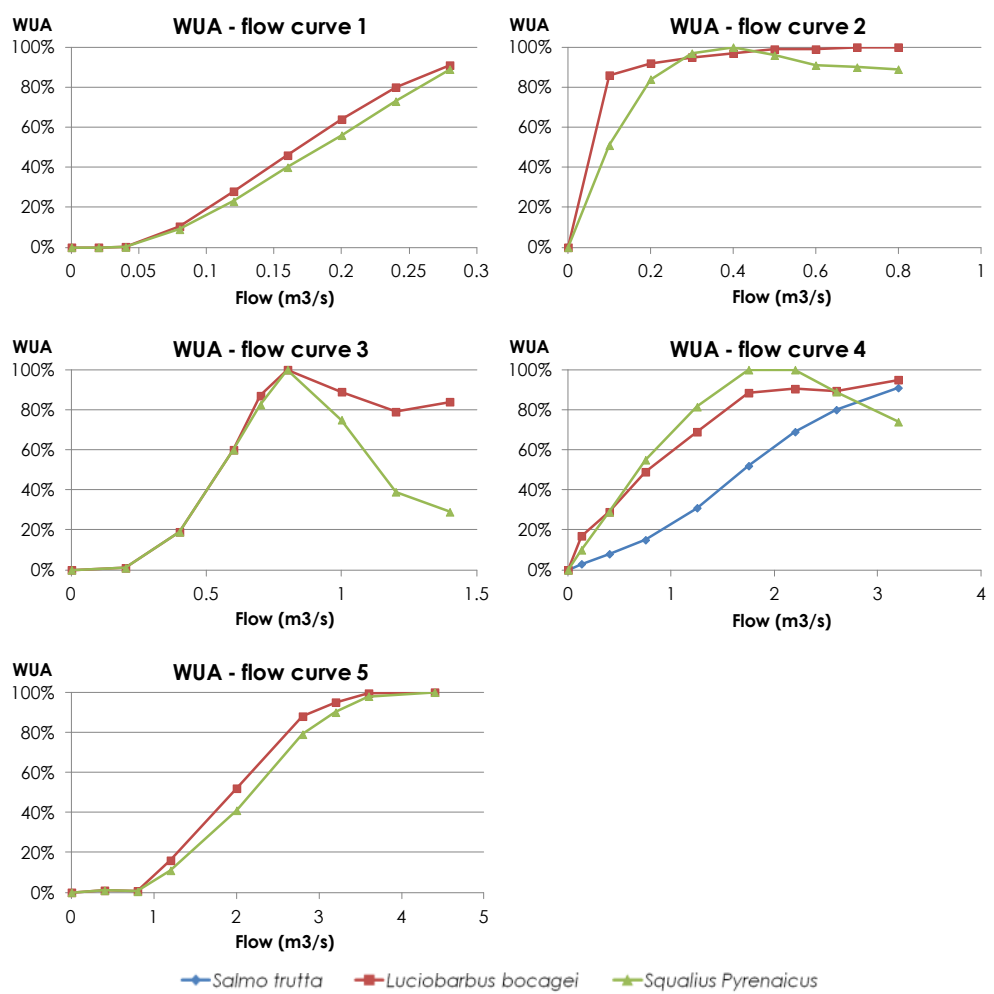

Figure 35. WUA - flow curves for the relevant species for fishing in the TURB.

For the valuation of the service, the permitted fishing areas, the fishable species and sizes, the fishing periods, the cost of fishing licences, and the maximum number of captures allowed per license have been identified from specific regulations and other public information from the regional government. Moreover, the common density of the species in Mediterranean rivers has been obtained from literature. Finally, the population with more potential access to each fishing area has been extracted from regional statistics. Figure 36 and Table 22 summarise all the information gathered, and the data sources. 
Application of methodologies

\begin{tabular}{|c|c|c|c|c|}
\hline General license & $6.64 € /$ year & \multicolumn{3}{|c|}{ (Generalitat Valenciana, 1997; 2013) } \\
\hline & S. trutta & L. bocagei & S. pyrenaic. & (Consellería de \\
\hline Fishable sizes & Adult & Adult & Adult & $\begin{array}{l}\text { Infraestructuras Territorio } \\
\text { y Medio Ambiente. }\end{array}$ \\
\hline Captures/day $\cdot$ license & 2 & 2 & 6 & 2015) \\
\hline $\begin{array}{l}\text { Density } \\
\text { (individuals } / \mathrm{m}^{2} \text { ) }\end{array}$ & 0.02 & 0.02 & 0.042 & $\begin{array}{l}\text { (Almeida Real, 2009; } \\
\text { Alcaraz-Hernández et } \\
\text { al., 2016; Olaya Marín et } \\
\text { al., 2016) }\end{array}$ \\
\hline
\end{tabular}

Table 22. Summary of fishing regulations in the TuRB.

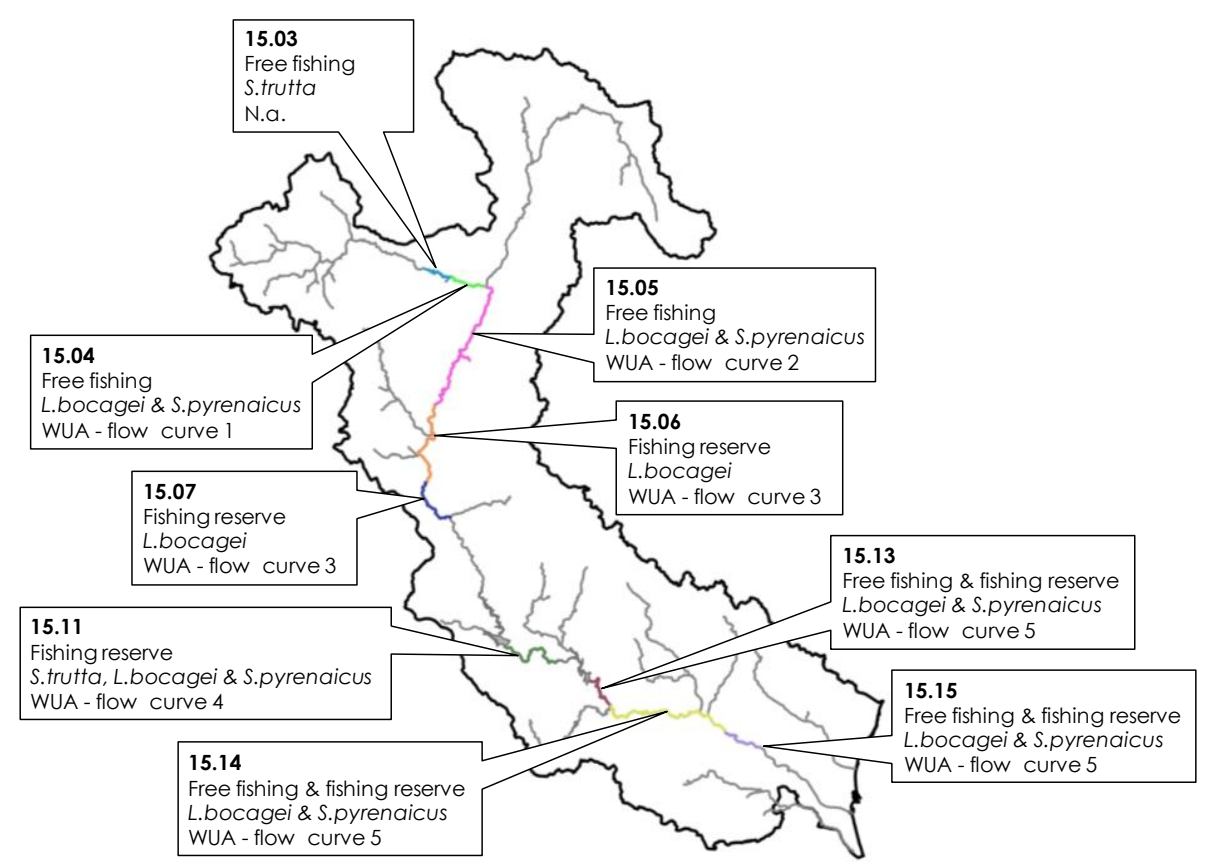

Figure 36. Location of the fishing water bodies in the TURB, including: the identifier of the water body, the type of fishing area (free or reserve), the fishable species, and the WUA flow curve used. Sources: Consellería de Agricultura, Medio Ambiente, Cambio Climático y Desarrollo Rural (2015) and Consellería de Infraestructuras, Territorio y Medio Ambiente (2015).

Of the $280 \mathrm{~km}$ length of the Turia River, around one half is fishable being distributed in $61 \mathrm{~km}$ of fishing reserves and $79 \mathrm{~km}$ for free fishing areas. An outstanding free fishing site in the basin is the Arquillo reservoir for which a density of Salmo trutta was estimated in 500 individuals/ $/ \mathrm{Mm}^{3}$ as the $10 \%$ of the density estimated by Ecohydros S.L. (2009) for a reservoir in the Ebro 
Assessment of Ecosystem Services and Water Accounting Methodologies for Integrated Water Resources Management in water scarce basins

River. From official statistics, the real amount of reserve fishing licenses was available for the period 2008 to 2013 , with an average of 1,800 licenses/year. These values were used to calculate the correction coefficient defined in Eq. 8 , as a way of calibration. Finally, for the spatial mapping of the service, the biomass production and human population closeness were assigned the same weight equal to 0.5 , because it was assumed that fishermen select fishing sites based on the proximity to their hometowns, but they also take into account information (mostly word of mouth) about the amount of potential captures.

\subsubsection{Scenario 1: Business as usual}

In this scenario, the baseline water management in the TURB is considered for the obtaining of the AHS benefits. The service produces around 2.6 million fish during the whole simulated period which provides a global benefit of $0.67 \mathrm{M} \epsilon$. This benefit corresponds to the issuing of 5,800 fishing licenses per year, being 4,000 for free fishing areas and 1,800 for fishing reserves, after correcting the calculated values with a factor of 1.6. The monthly distribution of the benefits is presented in Figure 37. As it can be observed, there is seasonality in the provision of the benefit that is related to the river flows. However, due to the strong regulation of the river system, the maximum flows occur in the dry months when water is discharged from the reservoirs to attend the irrigation demands. The effect of the drought episode from $2006 / 2007$ to $2008 / 2009$ is more pronounced in the crests than in the valleys of the benefit fluctuation, probably due to the reduction in the supplies to the agricultural demands as part of water saving measures mentioned above, which prevents the release of water from the reservoirs.

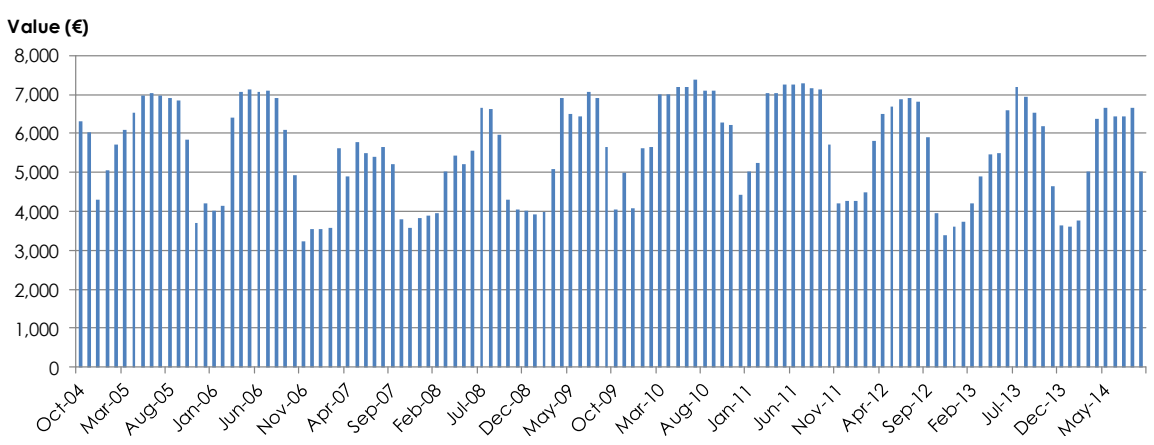

Figure 37. AHS monthly benefit for recreational fishing in the TURB. 
As regard to the spatial distribution of the service along the water bodies in the TURB, the results are mapped according to the relative biomass production and to the population in the subbasin associated to the water body (Figure 38). These results show that the most productive water bodies are 15.03, 15.13, and 15.14. The reasons for the low productivity of the other water bodies are diverse. For water bodies upstream the Benagéber reservoir (i.e. 15.04, 15.05, 15.06, and 15.07), the low biomass production is only caused by the small size of the riverbed and not by a lack of river flow. In fact, during all the simulation period the water flow through these water bodies is greater than the maximum defined in the WUA - flow curves. In the case of water bodies 15.11 and 15.15, the biomass production is low because the river flows are below the values that maximise the WUA. On the other hand, the water bodies which lay across the most populated areas and are, hence, more accessible to fishermen are 15.05 and 15.15. Even though the global benefit with both criteria is the same, the contribution of each water body is completely different. Thus, the result adopted is the arithmetic mean (Figure 39).

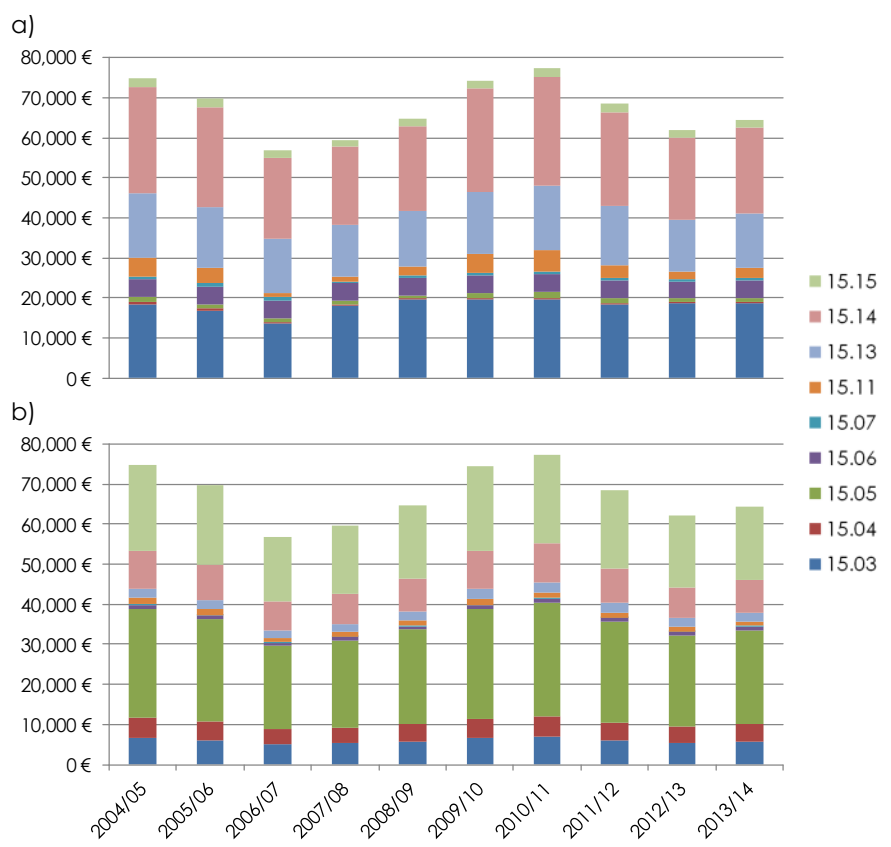

Figure 38. AHS annual benefit by water body considering biomass (a) and population (b) as distribution criteria. 
Assessment of Ecosystem Services and Water Accounting Methodologies for Integrated Water Resources Management in water scarce basins

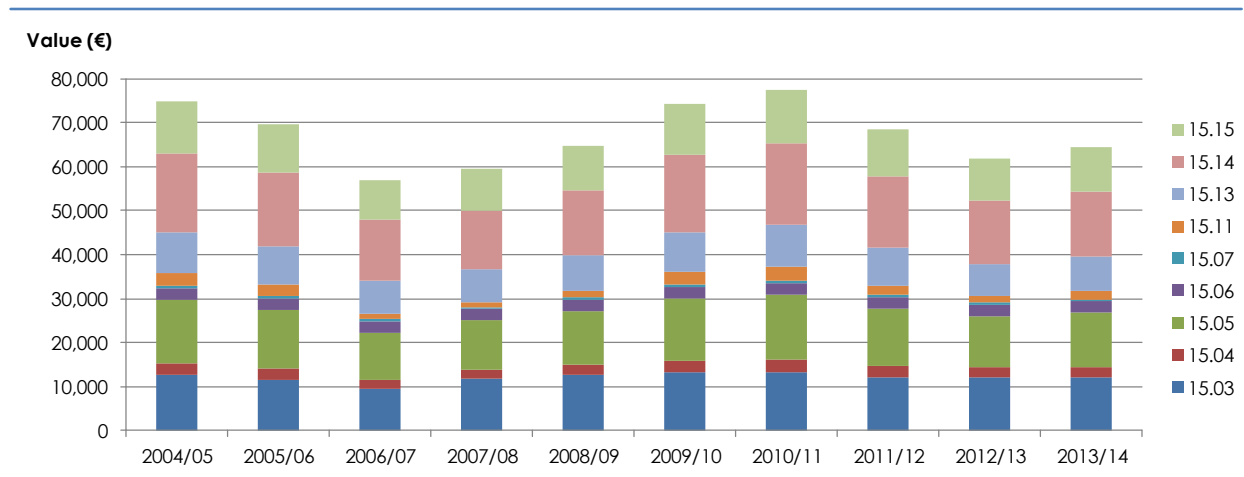

Figure 39. Annual provision of the AHS by the different water bodies in the TuRB.

\subsubsection{Scenario 2: Fishing oriented management}

The purpose of this scenario is changing the management of the system in order to increase the benefit provided by the AHS. This should be done by trying to maximise biomass production, because the population associated to each water body cannot be changed. As of the results of scenario 1, the best strategy is forcing larger flows or volumes in the water bodies which have room for improvement. These are 15.03, since the biomass in the reservoir relies on the stored volume and it is not at its maximum capacity; $15.11,15.13,15.14$ and 15.15 , as the river flows do not reach the magnitude that generates the maximum WUA for the fish species. To this end, the target volumes in the Arquillo reservoir are equalled to the maximum volumes and it is given a higher priority, making SIMGES to store more water in it. At the same time, a minimum flow of $8 \mathrm{Mm}^{3} /$ month is established downstream the Loriguilla reservoir that replaces the previous minimum flow of $1.3 \mathrm{Mm}^{3} /$ month. With this change, not only the flows downstream Loriguilla increase, but also the flows downstream Benagéber. Figure 40 summarises the changes introduced in the model.

The change in water management results in the increase of the global benefit of the AHS up to $0.71 \mathrm{M} €$. The monthly distribution of the value (Figure 41) follows the same seasonal pattern as in scenario 1. Nonetheless, the amplitude of the oscillation is smaller, since the low values rose around $1,000 € /$ month while the high values remained approximately in the same magnitudes. 


\begin{tabular}{lrrr} 
& & Sc. 1 & Sc. 2 \\
\hline & Oct. & 8.5 & 18.4 \\
& Nov. & 8.7 & 17.46 \\
& Dec. & 10 & 17.46 \\
& Jan. & 11.5 & 17.02 \\
& Feb. & 13 & 17.02 \\
& Mar. & 14 & 17.52 \\
Target volume of the & Apr. & 15.4 & 17.52 \\
Arquillo Reservoir (Mm ${ }^{3}$ ) & May & 15 & 19.48 \\
& Jun. & 15 & 19.33 \\
& Jul. & 13 & 21.02 \\
& Aug. & 11 & 18.4 \\
& Sept. & 9 & 18.4 \\
\hline Priority of the Arquillo Reservoir & 1 & -1 \\
\hline Minimum flow downstream the & 1.3 & 8 \\
Loriguilla Reservoir (Mm $\left.{ }^{3} / m o n t h\right)$ & & \\
\hline
\end{tabular}

Figure 40. Management changes introduced in scenario 2.

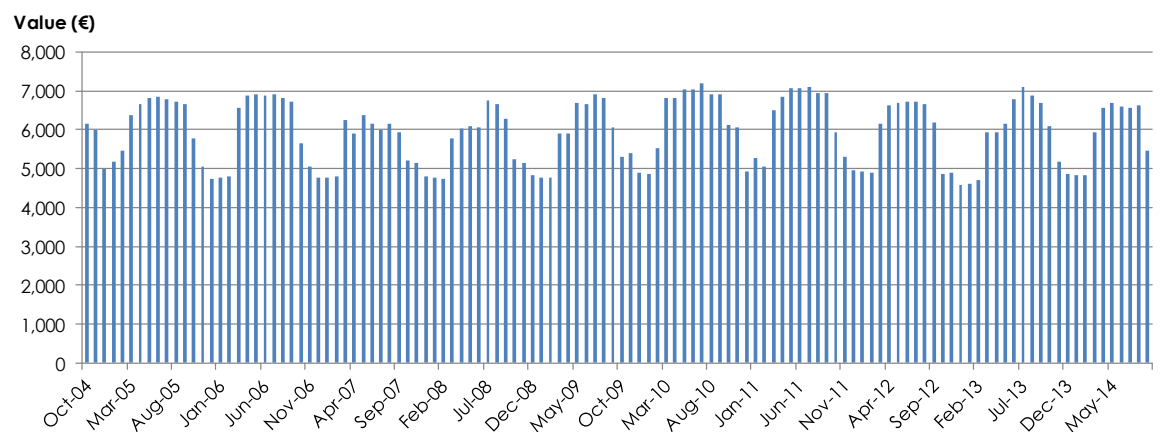

Figure 41. AHS monthly benefit for recreational fishing in the TURB in scenario 2 .

The biomass produced in water bodies $15.03,15.11,15.13,15.14$ and 15.15 augments as expected with the change in water management, being the larger changes for 15.03 and 15.14 (see Figure 42 - a). However, the difference with scenario 1 is not very significant. Considering the population as distribution criteria, the relative importance of each water body does not change because the population is the same in both scenarios (see Figure 42 - b). 

Integrated Water Resources Management in water scarce basins

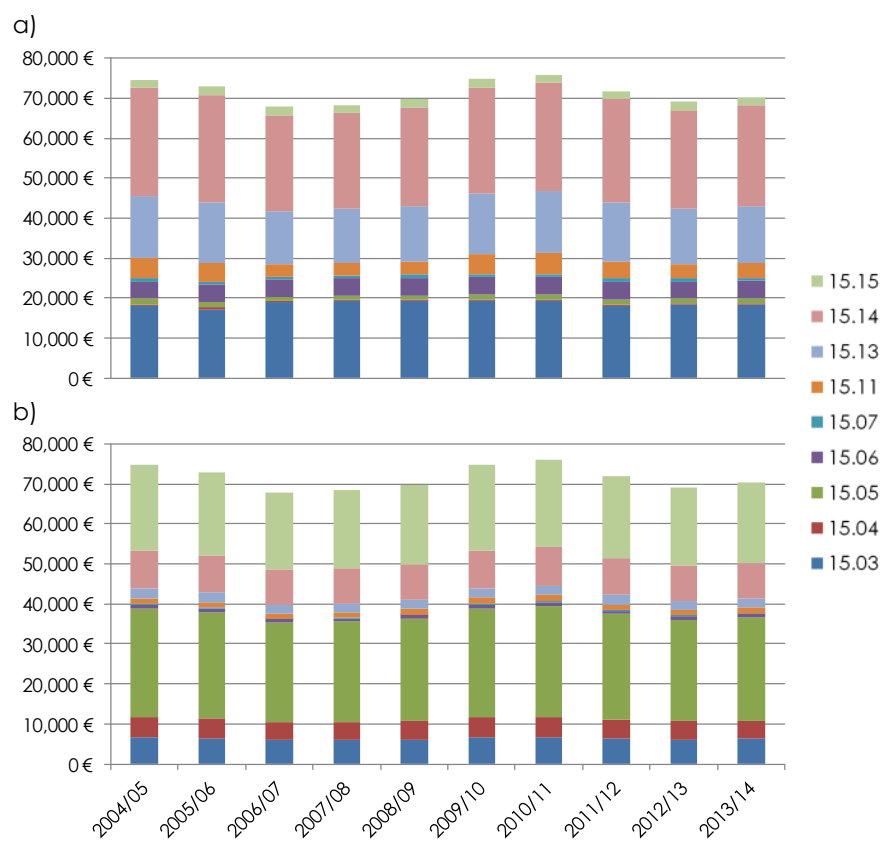

Figure 42. AHS annual benefit by water body considering biomass (a) and population (b) as distribution criteria in scenario 2.

Aggregating the partial outputs for the final mapping of the AHS, the results show a general melioration in all the simulated period, except for the hydrological year 2010/2011 that slightly reduces its benefit (Figure 43). This can be explained by the general decrease of reserves in Benagéber and Loriguilla reservoirs with the new management strategy (Figure 44), which forces the saving of water after the drought period, and prevents the release of water downstream the reservoirs in average and humid years. Due to the depletion of water reserves, it is possible to fully satisfy the water demands and improve the habitat conditions in some water bodies. Moreover, the hydropower demands increase the total volume turbined in almost $500 \mathrm{Mm}^{3}$. However, this cannot be a long term solution in water scarce river basins, since it increases the vulnerability of the system in front of future drought episodes. 


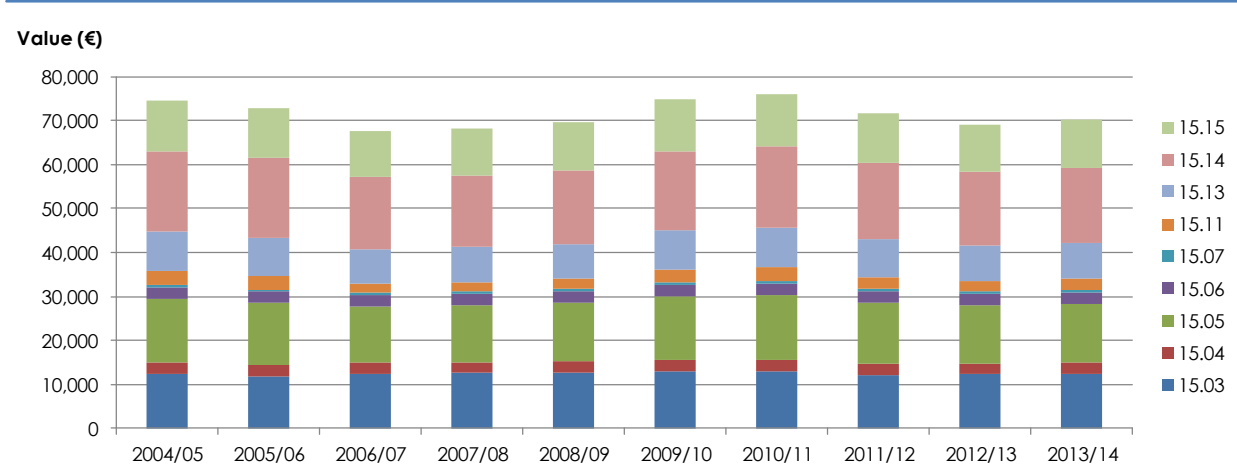

Figure 43. Annual provision of the AHS by the different water bodies in the TURB in scenario 2.

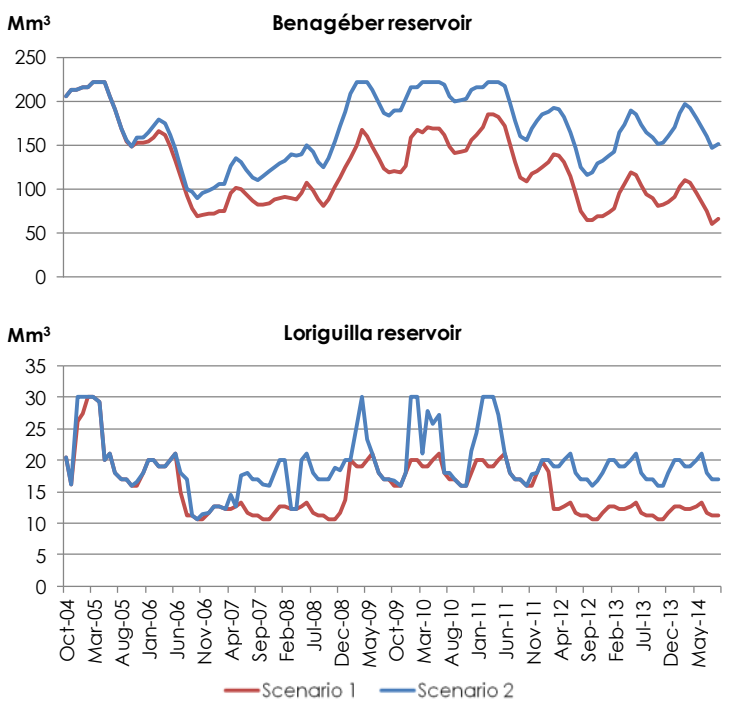

Figure 44. Comparison of the volumes stored in the Benagéber and Loriguilla reservoir in scenarios 1 and 2.

\subsubsection{Discussion}

The application of the proposed methodology enables identifying the most profitable water bodies in terms of fish production, linked to habitat availability. This information can be used to define the critical sites for environmental flows implementation. In the case of the TURB, the Arquillo reservoir (15.03), the water body downstream the confluence of the Guadalaviar and Alfambra Rivers (15.05), and the water bodies downstream 
Assessment of Ecosystem Services and Water Accounting Methodologies for Integrated Water Resources Management in water scarce basins

the Loriguilla reservoir until the intake of Valencia City $(15.13,15.14$ and 15.15) are the most relevant. By means of applying different water management scenarios, it has been demonstrated that water management can improve the provision of the AHS, by establishing minimum flows and volumes in key rivers stretches and reservoirs, respectively, in order to maximize the WUA. The effects of the management changes in the TURB are significant, but do not change the relative importance of the diverse water bodies in the provision of the service.

As in the previous applications of FES, the monthly scale allows observing the temporal variability inherent to natural and regulated flows in water scarce river basins. Furthermore, results can always be aggregated at larger time scales for the sake of clarity in the analysis. In the case of the definition of environmental flow regimes, the proposed methodology only covers one part of the problem which are minimum flows. Even so, there are other relevant aspects regarding habitat suitability that should be considered, such as maximum flows or flow rate changes. The analysis of these environmental flows regime components require daily or even hourly time scales that cannot be simulated with the AQUATOOL models at the moment.

For the assessment of the AHS in the TURB, most of the required information was public and available online, such as the cost of fishing licenses, the fishing areas, species, sizes, and periods. The WUA - flow curves are produced as part of the River Basin Management Plans in Spain. They do not cover all water bodies and harvestable aquatic species, but provide the information on the endemic species which presumably are the most valued by fishermen. On top of that, it is important to note that the use of WUA - flow curves represent the capacity of the habitat to be home of certain fish species, what does not necessarily mean that these species are present (Hudson et al., 2003). Nonetheless, they are the most reliable way up to date to determine the influence of flow rate variation on aquatic populations (Gore and Nestler, 1988; Payne, 2003). The specific information to convert WUA or stored volume units into fish biomass has been the most difficult to find. Eventually, it has been necessary to transfer data from comparable case studies in order to apply the methodology.

Another complex aspect for the assessment of the service is the selection of the mapping criteria and the weights to assign to each of them. Certainly, 
fishermen have information sources that orient them about the best fishing sites regarding captures (e.g. fishermen associations, personal blogs, etc.), but this information is based on observation and historical records that can be subjective. It is logical to think that the closeness and accessibility of the fishing sites also determine their use, but it is difficult to know to what extent in comparison with the amount of potential captures. Probably, there are other factors that have not been considered, such as the preference for free fishing sites against reserves or vice versa. Besides, assuming that the attendance of fishermen to a water body is related to the population living in the corresponding subbasin is quite simplistic, but no statistics as regard to fishermen preferences have been found. 



\section{Chapter 5: \\ General discussion}



This chapter includes a discussion about the potential of the ES and WA methodologies to support IWRM in water scarce river basins in the light of the analysis of the state of the art, the adaptation of the methodologies and the implementations presented in the previous sections.

\subsection{Key findings and recommendations}

The present research contributes to bridge the gap between theory and practice in the implementation of IWRM in water scarce river basins. It is done by proposing adapted WA and ES methodologies that take into account the specific needs and complexity of water management in this type of river basins, as demonstrated in the application cases.

On one hand, the AWAS have been selected as the most suitable WA methodology to serve the objectives of the research. The benefits that the AWAS approach brings compared to other WA methodologies are the representation of the commitments that the entity has towards its users through the water allocations, which in water scarce river basins could differ greatly with respect to the real water supply, and that it provides a measure of the global accounting error (Momblanch et al., 2014). Like the other reviewed WA methodologies, the AWAS applies the perspective of describing the hydrological cycle in which many accounting concepts are not controllable by water managers. Since the water accounts in their simplest form are perceived as the best way to transmit information (Tello et al., 2016), the approach in this work has been to modify the hydrological perspective to a water management perspective. This has implied the simplification of the content of the accounts to the essential information related to water resources management (Momblanch et al., 2014). To do so, especial attention should be paid to keep the water balance validity. Not only has this change improved the informative usefulness of the WA, but it has also demonstrated that the total accounting error is smaller because only well controlled concepts are considered. A small accounting error means that the water accounts are more accurate and more credible. Therefore, they can be used to support transparency towards the general public and control over water resources management, contributing to better water governance. 
Assessment of Ecosystem Services and Water Accounting Methodologies for Integrated Water Resources Management in water scarce basins

From the application of the improved WA methodology, the information about storages and flows along the reporting period is summarised. As opposed to what the Blueprint and the SEEA-Water framework claim, this static image does not supply sufficient information to take water management decisions (Momblanch et al., 2014), at least in water scarce river basins where the accordance between water availability and supply are not evident. For that purpose, there are other tools such as IWRM models which are much more suitable.

On the other hand, the ES assessment is generally acknowledged as one of the most suitable methodologies to introduce the environmental aspects into IWRM (Liv et al., 2013; Momblanch et al., 2016). The present research has proposed using IWRM tools such as RRM, WAM, WQM and HSM, and has tailored assessment methodologies for the most significant FES impacted by water management according to Momblanch et al. (2016). The application of these methodologies has confirmed some initial assumptions. In first place, the intense regulation and complex water management rules applied in water scarce river basins strongly affect the provision of FES. Moreover, if the tradeoffs between human uses and environmental aspects are to be analysed to make informed decisions, it is necessary to use modelling tools that provide detailed results for both types of water uses. In this sense, ES tools fall short to provide such complete and accurate information. Thus, the linked IWRM tools arise as the solution, because they are the only types of models that provide sound estimations of water supply reliability and vulnerability to human demands, while consider additional aspects such as water quality and habitat. Secondly, the monthly scale has revealed as sufficient for the assessment of the analysed FES. This is another clear advantage of IWRM tools against ES tools, as a more detailed temporal resolution provides better estimations of the FES. Moreover, given that most IWRM tools use this time scale, this means that the proposed methodologies can be implemented in river basins that are already using modelling platforms or DSS other than AQUATOOL, without having to migrate all their models. In the third place, one of the main drawbacks for the practical application of the methodologies is the lack of data, mostly for economic valuation but also for some environmental processes. The demand curves, WTP for improved water quality in recreational bathing sites or fish densities are some examples of data requirements which are not easy to find at local 
scale, and have to be transferred from other case studies or adapted from broader scales.

As regard to the results of the ES assessments the variability between the economic benefits is significant. In most of the cases it is just due to the differences in magnitude in the provision of various ES. Oppositely, in other cases, a single ES provides diverse benefits which are valued with very disparate magnitudes. It is the case of the benefit for urban uses and bathing uses in the WPS. The former benefit is calculated using a cost-based valuation technique, while the latter is estimated from stated preferences. The stated preference valuation results are criticised for presenting many possible shortfalls, such as survey-induced biases (Chee, 2004) and a weak connection between economic value and the actual ecological conditions (La Notte et al., 2015). Even so, this methodology is the only way to obtain an economic value for some benefits. Thus, it cannot be excluded from the set of valuation methodologies, but should be used with caution if it gets to be decisive for decision making.

Even though the different methodologies have not been tested in a single case study, their combined applicability to support the IWRM in a water scarce river basin can be outlined. Figure 45 presents the ideal IWRM application framework which involves all the topics included in the IWRM definition, as well as the tools and results necessary to operationalise it.

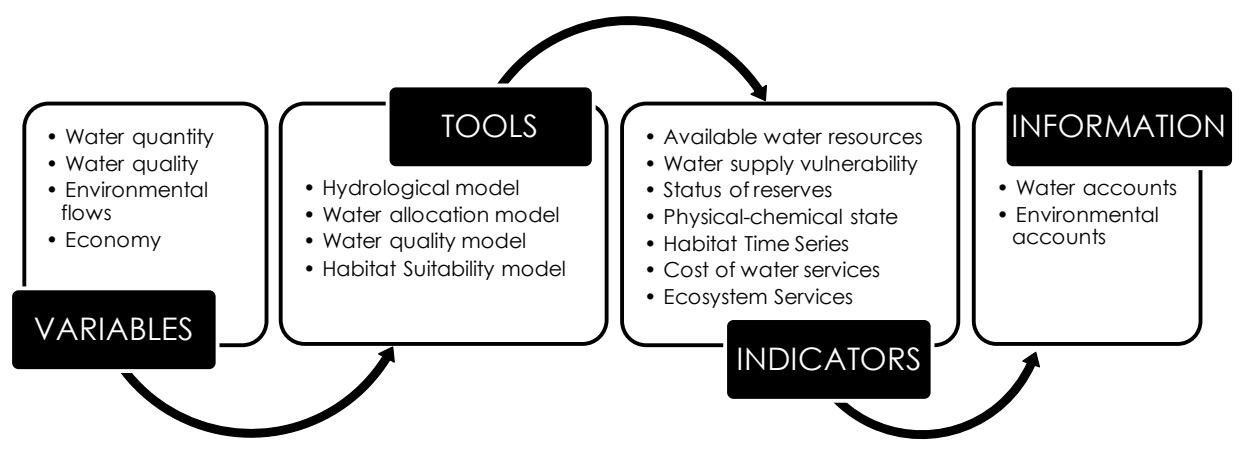

Figure 45. IWRM components and application diagram.

From the figure, it can be seen that WA usefulness is limited to provide information at the end of the IWRM process. This does not diminish the importance of this type of methodology to provide synthesised and clear 
Assessment of Ecosystem Services and Water Accounting Methodologies for Integrated Water Resources Management in water scarce basins

information to the general public and stakeholders enabling high-quality public participation and improved governance (Momblanch et al., 2014). Regarding the contribution of FES assessment for the analysis of water management there are many different possibilities depending on the management practices in the river basin and the purpose of the analysis. In most water scarce river basins, water allocation and other management strategies are based on water rights and priorities of use. In this case, the outputs from the ES assessment can be used as complementary information which does not determine directly the water sharing, but it can be used to choose among different alternatives in a multi-criteria analysis (Hearnshaw et al., 2011; Fontana et al., 2013; Favretto et al., 2016), as well as in a cost benefit analysis (Grossmann and Dietrich, 2012; Terrado et al., 2016a). Actually, there are many examples of multi-criteria analyses which include environmental variables without translating them into ES values (Divakar et al., 2013; Paredes-Arquiola et al., 2013; Yang and Yang, 2013; Momblanch et al., 2015; Roozbahani et al., 2015). Nevertheless, the contribution of ES in this sense is showing that both human and environmental uses contribute to society, and, consequently, investments in environmental protection have revenues like other investments in drinking water or hydroelectricity uses (Loomis, 2000). In case that the water allocation is analysed aiming at identifying the optimal solution in economic terms, the ES assessment results could be incorporated as decision variables in the target function of hydroeconomic models (Wainger et al., 2010; Bagdon et al., 2016).

From all the possible analyses with the ES approach, the tradeoffs amongst the diverse water users emerge. Inevitably, when a decision regarding water management is made, there are always uses which are more benefited than others. In order to find consensus and to adopt more equitable solutions for the sake of water governance, it is possible to apply the so-called payment for ES. This practice can be defined as a contractual transaction between a buyer and a seller for an ES or a management practice to secure the service (United Nations, 2007). By means of this payment scheme the beneficiaries of the water management measures partially compensate the losers with the gains they receive in terms of ES (Grima et al., 2016; Sun et al., 2016).

As a final recommendation, considering the numerous and diverse outputs that IWRM models provide, it is essential to carefully select the performance 
criteria, results presentation and decision analysis in order to identify possible tradeoffs and effectively support decision making (Loucks and van Beek, 2005).

\subsection{Limitations}

In addition to the previous discussion on the case study results and the general applicability of the proposed methodologies, the present research has revealed several caveats and limitations that need to be acknowledged. In the first place, the main limitation of the WA as a standard methodology is the lack of definition about the integration scale, which has a strong impact on the final quality of the accounts (Momblanch et al., 2014). Moreover, the level of detail to apply the WA should be better defined in order to allow comparability between different case studies. The application presented here proposes a sequence of actions to guide the implementation of WA which could minimise this handicap. An important limitation in order to represent the real water management in some river basins is the inability of the framework to represent water flows between the same type of water resources (surface or groundwater), since it only considers flows that get in or out of the entity boundaries, or that are transferred between different types of water resources. Nonetheless, this problem is common to all WA frameworks and not only for the AWAS.

On the other hand, the AWAS does not consider water quality and economic aspects. Considering its application in water scarce regions, quantitative information about water is the most relevant facet to regard. In fact, it seems logical for countries facing severe water scarcity to start with the compilation of basic information on the hydrological water balance which feeds into the quantitative accounts; in contrast, countries whose main problems are related to water pollution must account for pollution and the economic aspects which allow for the formulation of policies aimed at reducing the emission to water resources (United Nations Statistics Division, 2012).

As regard to the assessment of ES using IWRM tools, the main limitation is the difficulty to capture the critical thresholds that determine the behaviour of most ecological processes (Folke et al., 2004; Spangenberg et al., 2014; Momblanch et al., 2016). The origin of the problem, however, are not the 
Assessment of Ecosystem Services and Water Accounting Methodologies for Integrated Water Resources Management in water scarce basins

IWRM tools themselves, but the lack of knowledge about the critical thresholds and the effect that crossing them would have on the ecosystem integrity and the services it provides. Once this burden is overcome, the IWRM tools could be calibrated for different situations in relation to the existing thresholds in order to make them sensitive to them.

The second most important limitation for the use of ES assessment in decision making is the uncertainty that still exists in the economic data, the valuation techniques (Bateman et al., 2006), the number of ES benefits considered in the assessment (Boithias et al., 2016) and the changes in the physical parameters of the models to represent some management actions (Momblanch et al., under review). The only way to solve these issues is encouraging more research and specific studies to generate good quality data, being systematic in the application of valuation methods, and incorporating uncertainty analyses into ES valuation, including assessments of the implications of uncertainty in decision making (Cai et al., 2002).

As regard to the proposed ES assessment methodologies, the methodology to assess the AHS lacks realism since it does not incorporate the influence of barriers on the habitat suitability. Moreover, when it interacts with the WPS, the impact of water quality can be introduced by means of critical thresholds that reflect species intolerance but there is not any function that reflects the sensitivity of species presence to the water quality levels (Momblanch, 2013). Finally, there are some FES which have not been covered by the present research, such as flood protection or carbon sequestration by riparian vegetation, that should be considered in order to have a broad perspective of the environmental impacts of water planning and management. 


\section{Chapter 6: Conclusions}





\subsection{Summary}

This Thesis has addressed and identified a mismatch between practical water resources planning and management in water scarce river basins and IWRM. In light of the WFD and other European Policies related to water and sustainability, the focus has been put on ES assessment and WA methodologies as tools that can help approaching IWRM. However, these methodologies are disconnected from the real requirements of water resources planning and management in complex river basins such as the ones suffering from water scarcity. Thus, the objective of the Thesis has been proposing suitable ES assessment and WA methodologies to be implemented in water scarce river basins in line with IWRM.

After the motivation and contextualisation of the research, a review of the state of the art of the existing WA and ES assessment methods has been presented, followed by a critical analysis regarding their capacity to serve IWRM implementation in water scarce river basins. From this analysis, the AWAS for WA and the IWRM tools for ES assessment have been identified as the tools with more potential to reach the objectives of the research.

The next step has been proposing improved methodological frameworks that fit the requirements identified for water river basins. In the case of WA, simplicity and clarity have prevailed over exhaustive accounting for the sake of accuracy and transparency of the presented information. An improved version of the AWAS has been fully designed, as well as some criteria to guide its implementation at river basin scale with the purpose of improving public information and governance. In reference to ES assessment, the influence of water management, as well as the temporal and spatial variability of water resources and demands has been the milestone for the design of the assessment methodologies. The results provided by the RRM EVALHID, the WAM SIMGES, the WQM GESCAL and the HSM CAUDECO, which belong to the Decision Support System AQUATOOL, combined with economic information have been tailored to provide the benefits of the FPS, the WPS and the AHS.

Subsequently, the proposed WA and ES assessment methodologies have been tested in several river basins in Spain, covering drought periods as well as average years. Each methodology has been applied to a different river 
Assessment of Ecosystem Services and Water Accounting Methodologies for Integrated Water Resources Management in water scarce basins

basin in order to show the versatility of the tools to adapt to diverse features and management rules. The cases of study have shown the relevance of water management and time scale in order to capture all the complexity of water scarce river basins in the results, so that they are useful for informed decision making. ES assessment results have revealed helpful to classify water bodies or watersheds according to their capacity to provide environmental benefits, and to analyse the tradeoffs between the traditional demands and the ES beneficiaries. On the other hand, WA discloses synthesised and relevant information for water users and other stakeholders about the state of water resources and their allocation and supply during the analysed period.

Finally, the methodologies have been put into context inside the IWRM process that covers the target variables to consider, the tools that allow analysing the influence of management actions on them, the indicators that are more informative to water managers, and the ways to transmit the information to the general public. Furthermore, the types of analyses which can be conducted with the proposed methodologies have been detailed, and illustrated with examples in scientific literature.

The above summarised research is based on published work, which has been expanded or detailed, and includes other non published material. The result is a Thesis that provides improved results and conclusions with respect to the stand-alone papers.

\subsection{General conclusions}

This research contributes to harmonise the quantity-oriented water resources planning and management in water scarce regions to a more holistic approach in line with IWRM definition. The research is backed on the use of water management perspective and tools to shape the WA and ES assessment methodologies. This makes them more likely to be adopted as part of the real water resources management process, since they are in accordance with the current knowledge and practices.

Adopting WA methodologies into the water resources planning and management process brings us closer to achieving the objectives established by A Blueprint to Safeguard Europe's Water Resources (European 
Commission, 2012a) in order to gather and report water information in Europe, and to the WFD because it facilitates high-quality public participation (Momblanch et al., 2014). However, the financial accounting perspective of WA may prevent its use for real water resources planning and management. As stated by Momblanch et al. (2014), a simplification of reality is always necessary in the water accounts. The present research proposes limiting the accounting concepts to the essential information on the water resources, flows and commitments of a water entity. Moreover, differences in water management in each river basin require the adaptation of the WA concepts to be able to faithfully reproduce the relevant information of water users. Besides, the accounting domain, the integration scale and the detail of the accounted concepts have a relevant influence on the accuracy of the results.

The present research concludes that the AWAS with the improvements proposed in this Thesis, which lead to small errors in the global water balance, is the most recommendable WA methodology to support water management control and use efficiency in IWRM. If the accounts are detailed enough, they show the level of satisfaction of the diverse demands as well as the changes in the water storages on which they rely. Even though the AWAS does not consider water quality and economic aspects, quantitative water information is the most relevant aspect in water scarce regions. Moreover, other WA methodologies that include water quality and economic information like the SEEA-Water are difficult to be implemented at river basin scale, since the information about costs of water services for users and producers are usually compiled at administrative scale.

Apart from its contribution to transparency and control, WA provides more gains. The process of prioritising and selecting the elements to include in the accounts according to their importance for water management is a good exercise for water managers to think over strategic aspects of the water resources system. Furthermore, the process of filling out the accounts is useful to reveal monitoring deficiencies, while the periodical implementation of the WA shows the evolution of water resources and demands.

In relation to the assessment of ES, it is considered a thorough way to analyse the relevant environmental impacts of water management using the environment-economy connection (Momblanch et al., 2016). On this regard, 
Assessment of Ecosystem Services and Water Accounting Methodologies for Integrated Water Resources Management in water scarce basins

IWRM tools include the main processes involved in the provision of FES with accurateness, reflecting the effects of management actions and providing temporally and spatially detailed results (Momblanch et al., under review). Considering that the ES assessment is not meant to solve water planning and management problems for itself but that it should be added to a previously existing way of managing water, the fact that the designed methodologies make use of tools that are usually applied for water planning and management in water scarce river basins simplifies the task of adopting the ES approach. Moreover, the IWRM tools commonly work at monthly scale, which seems appropriate for the representation of the FES analysed, and presumably for many others, because is at the mid-way point between the accuracy needed to represent ecological processes and water movement along river networks, and the simplicity and aggregation required for decision making.

The scenario analysis demonstrates the high influence that water management has on FES, and reinforces the argument that water management cannot be omitted from the analysis. Another important conclusion that is drawn out from the applications is the importance of bouncing off the value of the service from the beneficiaries to the element providing it in order to prioritise management actions or protect certain areas of the river basin. Additionally, the use of ES assessment results in multicriteria or cost-benefit analyses contributes to more informed decision making that balances human and environmental aspects, and that allows solving the identified tradeoffs through the application of payment for ES schemes.

The main difficulties for the application of the FES methodologies come from data acquisition, mostly regarding economic information that is scarce and usually not specific for the case study. Moreover, when economic data is available, it has been obtained using diverse valuation techniques which provide very disparate ES benefits in order of magnitude. Finally, the lack of knowledge about some ecological processes and critical thresholds may also distort the results. All this, adds uncertainty to the analysis and should be clearly recognised in the presentation of the results so that they are used with the corresponding caution. 
Overall, the assimilation of these methodologies will imply a trans-disciplinary approach which can be challenging. Furthermore, if water managers are to use them for decision making, the limitations regarding data availability and uncertainty described above should be addressed. However, the gains derived from a more balanced water management that involves stakeholders to decide on the best tradeoffs and accounts for the environmental benefits are significant at least as regard to the compliance with European Policies.

\subsection{Future research}

The future research lines arise from the limitations presented in the previous chapter. In relation to WA, future research should look for possible ways of including additional information that completes the picture of quantitative management, such as water quality or economic benefits. Besides, the water flows between the same type of water resources should be represented somehow in the water accounts. However, the challenge relies on maintaining the synthetic and clear presentation of results so that they can effectively inform non-expert public. Another future research line could focus on advancing in geophysical monitoring for data acquisition regarding groundwater stocks and flows, which would prevent the use of models for the implementation of water accounts.

As regard to ES assessment, the main challenges are the current limits to understanding of ecological functions, which relate physical, ecological and economic values and critical environmental thresholds; and to account for all types of uncertainty that exist in the analysis. Specifically for the AHS, the effect of water quality on the existence/conservation of aquatic species diversity should be further investigated, as well as the way of translating the impact of barriers such as dams on the habitat suitability models. Furthermore, the economic valuation techniques (e.g. stated preferences) should be refined in order to avoid large disparities in the orders of magnitude of the values of the ES. If this was not possible, another option would be weighting the more disparate benefits to make them more realistic and in line with the rest of benefits.

Finally, some applications of the ES assessment have been investigated and applied, but there is need for including other FES to complete the analysis. 
Assessment of Ecosystem Services and Water Accounting Methodologies for Integrated Water Resources Management in water scarce basins

Perhaps, the point of view adopted in this work can be transferred to the assessment of ES related to other disciplines in which the use of models commonly used by decision makers can be linked and adapted. In general, there is still much room for research in order to identify other ways to use the results and fully exploit this still evolving discipline. 


\section{References}



AHMAD, R. A. R., TOWER, G., PLUMMER, J. and ARIPIN, N., 2010. Transparency and clarity of water accounting reporting. Journal of the Asia-Pacific Centre for Environmental Accountability. 16, 4-1.

AHMADI, A., KARAMOUZ, M., MORIDI, A. and HAN, D., 2012. Integrated Planning of Land Use and Water Allocation on a Watershed Scale Considering Social and Water Quality Issues. Journal of Water Resources Planning and Management. 138, 671-681.

ALCARAZ-HERNÁNDEZ, J. D., MUÑOZ-MAS, R., MARTíNEZ-CAPEL, F., GARÓFANOGÓMEZ, V. and VEZZA, P., 2016. Generalized additive models to predict adult and young brown trout (Salmo trutta Linnaeus, 1758) densities in Mediterranean rivers. Journal of Applied Ichthyology. 32, 217-228.

ALCOFORADO DE MORAES, M. M., CAI, X., RINGLER, C., ALBURQUERQUE, B. E., VIEIRA DA ROCHA, S. P. and AMORIM, C. A., 2010. Joint Water QuantityQuality Management in a Biofuel Production Area-Integrated Economic-Hydrologic Modeling Analysis. Journal of Water Resources Planning and Management. 136, 502-511.

ALMEIDA REAL, D. 2009. Ecología y conservación de la fauna fluvial en el Parque Nacional de Cabañeros: efectos de la degradación del hábitat y de la introducción de especies exóticas. PhD, Universidad Complutense de Madrid.

ALVAREZ, S., LARKIN, S. L., WHITEHEAD, J. C. and HAAB, T., 2014. A revealed preference approach to valuing non-market recreational fishing losses from the Deepwater Horizon oil spill. Journal of Environmental Management. 145, 199-209.

ANDREU, J., CAPILLA, J. and SANCHIS, E., 1996. AQUATOOL, a generalized decision-support system for water-resources planning and operational management. Journal of Hydrology. 177, 269-291.

ANDREU, J., MOMBLANCH, A., PAREDES, J., PÉREZ, M. Á. and SOlERA, A., 2012. Potential role of standardized water accounting in Spanish basins, in: GODFREY, J. M. and CHALMERS, K. (eds.), Water Accounting. International Approaches to Policy and Decision-making. Edward Elgar, Cheltenham

ANDREU, J., PÉREZ, M. Á., PAREDES-ARQUIOLA, J. and SOlERA, A. Year. Participatory analysis of the Jucar-Vinalopo (Spain) water conflict using a Decision Support System. In: ANDERSSEN, R. S., BRADDOCK, R. D. and NEWHAM, L. T. H., eds. 18th World IMACS Congress and MODSIM09 International Congress on Modelling and Simulation, July 20092009 Cairns, Australia. 3230-3236.

ANDREU, J., SOlERA, A., PAREDES, J., PÉREZ, M. Á. and PULIDO, M. Year. Decision support tools for policy making. In: European Water Research Day Review of EC- funded water research and future perspectives, 2008 Zaragoza. 
Assessment of Ecosystem Services and Water Accounting Methodologies for Integrated Water Resources Management in water scarce basins

ARNOLD, J. G., SRINIVASAN, R., MUTTIAH, R. S. and WILLIAMS, J. R., 1998. Large area hydrologic modeling and assessment. Part I: Model development. JAWRA Journal of the American Water Resources Association. 34, 73-89.

ASSIMACOPOULOS, D., BARRAQUE, D., BERLAND, J. M., FEINERMAN, E., KATSIARDI, $P$. and MANOLI, E. Year. Estimation of the level of cost recovery of different scenarios of water allocation in arid areas. An easy-toimplement approach. In: Second International Workshop on Implementing economic analysis in the Water Framework Directive, February 20052005 Paris, France.

AUSTRALIAN ACCOUNTING STANDARD BOARD 2004. Framework for the Preparation and Presentation of Financial Statements. Melbourne: Commonwealth of Australia.

AUSTRALIAN ACCOUNTING STANDARD BOARD and BUREAU OF METEOROLOGY 2012. Australian Water Accounting Standard 2: Assurance Engagements on General Purpose Water Accounting Reports. Melbourne: Commonwealth of Australia.

BABEL, M. S., DAS GUPTA, A. and NAYAK, D. K., 2005. A Model for Optimal Allocation of Water to Competing Demands. Water Resources Management. 19, 693-712.

BAGDON, B. A., HUANG, C.-H. and DEWHURST, S., 2016. Managing for ecosystem services in northern Arizona ponderosa pine forests using a novel simulation-to-optimization methodology. Ecological Modelling. 324, 1127.

BAGSTAD, K. J., SEMMENS, D. J., WAAGE, S. and WINTHROP, R., 2013a. A comparative assessment of decision-support tools for ecosystem services quantification and valuation. Ecosystem Services. 5, 27-39.

BAGSTAD, K. J., SEMMENS, D. J. and WINTHROP, R., 2013b. Comparing approaches to spatially explicit ecosystem service modeling: A case study from the San Pedro River, Arizona. Ecosystem Services. 5, 40-50.

BAGSTAD, K. J., VILLA, F., JOHNSON, G. W. and VOIGT, B. 2011. Artificial Intelligence for Ecosystem Services: A guide to models and data, version 1.0 .

BAKKER, K., 2012. Water Security: Research Challenges and Opportunities. Science. 337, 914-915.

BANERJEE, O., BARK, R., CONNOR, J. and CROSSMAN, N. D., 2013. An ecosystem services approach to estimating economic losses associated with drought. Ecological economics. 91, 19-27.

BAO, C. and FANG, C.-L., 2007. Water resources constraint force on urbanization in water deficient regions: A case study of the Hexi Corridor, arid area of NW China. Ecological economics. 62, 508-517.

BASTIAANSSEN, W. G. M., HA, L. T. and FENN, M. 2015. Water Accounting Plus (WA+) for Reporting Water Resources Conditions and Management: A Case Study in the Ca River Basin, Vietnam. 
BATEMAN, I. J., BROUWER, R., DAVIES, H., DAY, B. H., DEFLANDRE, A., FALCO, S. D., GEORGIOU, S., HADLEY, D., HUTCHINS, M., JONES, A. P., KAY, D., LEEKS, G., LEWIS, M., LOVETT, A. A., NEAL, C., POSEN, P., RIGBY, D. and KERRY TURNER, R., 2006. Analysing the Agricultural Costs and Non-market Benefits of Implementing the Water Framework Directive. Journal of Agricultural Economics. 57, 221-237.

BEKCHANOV, M., BHADURI, A. and RINGLER, C., 2015a. Potential gains from water rights trading in the Aral Sea Basin. Agricultural Water Management. 152, 41-56.

BEKCHANOV, M., RINGLER, C. and BHADURI, A., 2015b. A Water Rights Trading Approach to Increasing Inflows to the Aral Sea. Land Degradation \& Development. n/a-n/a.

BEKCHANOV, M., RINGLER, C., BHADURI, A. and JEULAND, M., 2015c. How would the Rogun Dam affect water and energy scarcity in Central Asia? Water International. 40, 856-876.

BERGSTRÖM, S., 1995. The HBV model, in: SINGH, V. P. (ed.) Computer Models of Watershed Hydrology. Water Resources Publications, LLC, Highlands Ranch

BIELSA, J. and DUARTE, R., 2001. An Economic Model for Water Allocation in North Eastern Spain. International Journal of Water Resources Development. 17, 397-408.

BLANCO-GUTIÉRREZ, I., VARELA-ORTEGA, C. and PURKEY, D. R., 2013. Integrated assessment of policy interventions for promoting sustainable irrigation in semi-arid environments: A hydro-economic modeling approach. Journal of Environmental Management. 128, 144-160.

BOITHIAS, L., TERRADO, M., COROMINAS, L., ZIV, G., KUMAR, V., MARQUÉS, M., SCHUHMACHER, M. and ACUÑA, V., 2016. Analysis of the uncertainty in the monetary valuation of ecosystem services - A case study at the river basin scale. Science of the Total Environment. 543, Part A, 683-690.

BOOKER, J. F., 1995. Hydrologic and economic impacts of drought under alternative policy responses. Journal of the American Water Resources Association. 31, 889-906.

BOOKER, J. F., HOWITT, R. E., MICHELSEN, A. M. and YOUNG, R. A., 2012. ECONOMICS AND THE MODELING OF WATER RESOURCES AND POLICIES. Natural Resource Modeling. 25, 168-218.

BOOKER, J. F., MICHELSEN, A. M. and WARD, F. A., 2005. Economic impact of alternative policy responses to prolonged and severe drought in the Rio Grande Basin. Water Resources Research. 41, n/a-n/a.

BOOKER, J. F. and YOUNG, R. A. 1991. Economic Impacts of Alternative Water Allocation Institutions in the Colorado River Basin. Completion Report. Colorado Water Resources Institute, Colorado State University.

BOOKER, J. F. and YOUNG, R. A., 1994. Modeling Intrastate and Interstate Markets for Colorado River Water Resources. Journal of Environmental Economics and Management. 26, 66-87. 
Assessment of Ecosystem Services and Water Accounting Methodologies for Integrated Water Resources Management in water scarce basins

BORAH, D. K., ARNOLD, J. G., BERA, M., KRUG, E. C. and LIANG, X.-Z., 2007. Storm Event and Continuous Hydrologic Modeling for Comprehensive and Efficient Watershed Simulations. Journal of Hydrologic Engineering. 12, 605-616.

BORREGO-MARÍN, M. M., GUTIÉRREZ-MARTíN, C. and BERBEL, J., 2016. Estimation of Cost Recovery Ratio for Water Services Based on the System of Environmental-Economic Accounting for Water. Water Resources Management. 30, 767-783.

BOVEE, K. D., 1982. A guide to stream habitat analysis using the Instream Flow Incremental Methodology [microform] / by Ken D. Bovee. Western Energy and Land Use Team, Office of Biological Services, Fish and Wildlife Service, U.S. Dept. of the Interior : [Supt. of Docs., U.S. G.P.O., distributor], Washington, D.C. :

BOYD, J. and BANZHAF, S., 2007. What are ecosystem services? The need for standardized environmental accounting units. Ecological economics. 63, 616-626.

BRAUMAN, K. A., DAILY, G. C., DUARTE, T. K. E. and MOONEY, H. A., 2007. The Nature and Value of Ecosystem Services: An Overview Highlighting Hydrologic Services, in: ANNUAL REVIEWS (ed.) Annual review of Environment and Resources. 67-98.

BRINK, C., VAN GRINSVEN, H., JACOBSEN, B. H., RABL, A., GREN, I.-M., HOLLAND, M., KLIMONT, Z., HICKS, K., BROUWER, R., DICKENS, R., WILLEMS, J., TERMANSEN, M., VELTHOF, G., ALKEMADE, R., VAN OORSCHOT, M. and WEBB, J., 2011. Costs and benefits of nitrogen in the environment, in: SUTTON, M. A., HOWARD, C. M., ERISMAN, J. W., BILLEN, G., BLEEKER, A., GRENNFELT, P., GRINSVEN, H. V. and GRIZZETTI, B. (eds.), The European nitrogen assessment. Cambridge University Press,

BROUWER, R. and HOFKES, M., 2008. Integrated hydro-economic modelling: Approaches, key issues and future research directions. Ecological economics. 66, 16-22.

BROWN, T. C., HARDING, B. L. and PAYTON, E. A., 1990. Marginal Economic Value of Streamflow: A Case Study for the Colorado River Basin. Water Resources Research. 26, 2845-2859.

BRYAN, B. A., HIGGINS, A., OVERTON, I. C., HOLLAND, K., LESTER, R. E., KING, D., NOLAN, M., MACDONALD, D. H., CONNOR, J. D., BJORNSSON, T. and KIRBY, M., 2013. Ecohydrological and socioeconomic integration for the operational management of environmental flows. Ecological Applications. 23, 999-1016.

BRYAN, B. A., NOLAN, M., HARWOOD, T. D., CONNOR, J. D., NAVARRO-GARCIA, J., KING, D., SUMMERS, D. M., NEWTH, D., CAI, Y., GRIGG, N., HARMAN, I., CROSSMAN, N. D., GRUNDY, M. J., FINNIGAN, J. J., FERRIER, S., WILLIAMS, K. J., WILSON, K. A., LAW, E. A. and HATFIELD-DODDS, S., 2014. Supply of carbon sequestration and biodiversity services from Australia's 
agricultural land under global change. Global Environmental Change. 28, 166-181.

BUREAU OF METEOROLOGY 2012. Australian Water Accounting Standard 1: Preparation and Presentation of General Purpose Water Accounting Reports. Canberra: Commonwealth of Australia.

BUREAU OF METEOROLOGY. 2016. http://www.bom.gov.au/water/nwa/2015/ [Online]. [Accessed 11 August 2016].

BURKE, S. M., ADAMS, R. M. and WALLENDER, W. W., 2004. Water banks and environmental water demands: Case of the Klamath Project. Water Resources Research. 40, n/a-n/a.

BURNASH, R. J. C., FERRAL, R. L. and MCGUIRE, R. A. 1973. A generalized streamflow simulation system - Conceptual modeling for digital computers. In: CENTER, J. F. A. S. R. F., SERVICE, U. N. W. and RESOURCES, C. D. O. W. (eds.). Sacramento.

CAI, X., MCKINNEY, D. C. and LASDON, L. S., 2002. A framework for sustainability analysis in water resources management and application to the Syr Darya Basin. Water Resources Research. 38, 21-1-21-14.

CAI, X., MCKINNEY, D. C. and ROSEGRANT, M. W., 2003a. Sustainability analysis for irrigation water management in the Aral Sea region. Agricultural Systems. 76, 1043-1066.

CAI, X., RINGLER, C. and YOU, J.-Y., 2008. Substitution between water and other agricultural inputs: Implications for water conservation in a River Basin context. Ecological economics. 66, 38-50.

CAI, X., ROSEGRANT, M. W. and RINGLER, C., 2003b. Physical and economic efficiency of water use in the river basin: Implications for efficient water management. Water Resources Research. 39, n/a-n/a.

CAO, Y. S. 2006. Evolution of Integrated Approaches to Water Resource Management in Europe and the United States. Some Lessons from Experience. In: WARFORD, J. (ed.) World Bank Analytical and Advisory Assistance Program China: Addressing Water Scarcity. World Bank.

CIRILO, J. A., 2008. Public Water Resources Policy for the Semi-Arid Region. Estudos Avançados. 22, 61-82.

CONNOR, J., 2008. The economics of time delayed salinity impact management in the River Murray. Water Resources Research. 44, n/a-n/a.

CONNOR, J. D., FRANKLIN, B., LOCH, A., KIRBY, M. and WHEELER, S. A., 2013. Trading water to improve environmental flow outcomes. Water Resources Research. 49, 4265-4276.

CONSELLERÍA DE AGRICULTURA MEDIO AMBIENTE CAMBIO CLIMÁTICO Y DESARROLLO RURAL. 2015. Cotos de pesca, http://www.habitatge.gva.es/web/medio-natural/cotos-de-pesca

[Online]. [Accessed 17.06.2016].

CONSELLERÍA DE INFRAESTRUCTURAS TERRITORIO Y MEDIO AMBIENTE 2015. ORDEN 2/2015, de 12 de febrero, de la Consellería de Infraestructuras, Territorio y Medio Ambiente por la que se fijan los periodos hábiles y las normas 
Assessment of Ecosystem Services and Water Accounting Methodologies for Integrated Water Resources Management in water scarce basins

generales relacionadas con la pesca deportiva y de entretenimiento en aguas continentales de la Comunitat Valenciana. Diari Oficial de la Comunitat Valenciana.

COOK, B. R. and SPRAY, C. J., 2012. Ecosystem services and integrated water resource management: Different paths to the same end? Journal of Environmental Management. 109, 93-100.

COPELAND, C. 2010. Clean Water Act: A Summary of the Law. US: Congressional Research Service.

COSTANZA, R., 2008. Ecosystem services: Multiple classification systems are needed. Biological Conservation. 141, 350-352.

COSTANZA, R., D'ARGE, R., GROOT, R. D., FARBER, S., GRASSO, M., HANNON, B., LIMBURG, K., NAEEM, S., O'NEILL, R. V., PERUELO, J., RASKIN, R. G., SUTTON, P. and BELT, M. V. D., 1997. The value of the world's ecosystem services and natural capital. Nature. 387, 253-260.

COSTANZA, R., KUBISZEWSKI, I., ERVIN, D., BLUFFSTONE, R., BOYD, J., BROWN, D., CHANG, H., DUJON, V., GRANEK, E., POLASKY, S., SHANDAS, V. and YEAKLEY, A., 2011. Valuing ecological systems and services. F1000 Biology Reports. 3, 14.

CROSSMAN, N. D., BARK, R. H., COLLOFF, M. J., MACDONALD, D. H. and POLINO, C. A., 2015. Using an ecosystem services-based approach to measure the benefits of reducing diversions of freshwater: a case study in the in the Murray-Darling Basin, Australia, in: MARTIN-ORTEGA, J., FERRIER, R. C., GORDON, I. J. and KHAN, S. (eds.), UNESCO Global Dialogue on Water Ecosystem Services. Cambridge University Press, United Kingdom, 82-89.

CSIRO 2012. Assessment of the ecological and economic benefits of environmental water in the Murray-Darling Basin. Australia: CSIRO Water for a Healthy Country National Research Flagship.

CHALMERS, K., GODFREY, J. M. and POTTER, B., 2009. More than a trickle. Charter. 80, 68.

CHEE, Y. E., 2004a. An ecological perspective on the valuation of ecosystem services. Biological Conservation. 120, 549-565.

CHEE, Y. E., 2004b. An ecological perspective on the valuation of ecosystem services. Biological Conservation. 120, 549-565.

DAILY, G. C. (ed.) 1997. Nature's Services: Societal dependence on natural ecosystems. Island Press.

DANDY, G., GANJI, A., KANDULU, J. M., HATTON MACDONALD, D., MARCHI, A., MAIER, H., MANKAD, A. and SCHMIDT, C. E. 2013. Managed Aquifer Recharge and Stormwater Use Options: Net Benefits Report. In: GOYDER INSTITUTE FOR WATER RESEARCH (ed.). Adelaide.

DANESHMAND, F., KARIMI, A., NIKOO, M., BAZARGAN-LARI, M. and ADAMOWSKI, J., 2014. Mitigating Socio-Economic-Environmental Impacts During Drought Periods by Optimizing the Conjunctive Management of Water Resources. Water Resources Management. 28, 1517-1529. 
DAVIDSON, B., MALANO, H., NAWARATHNA, B. and MAHESHWARI, B., 2013a. The hydrological and economic impacts of changing water allocation in political regions within the peri-urban South Creek catchment in Western Sydney I: Model development. Journal of Hydrology. 499, 339-348.

DAVIDSON, B., MALANO, H., NAWARATHNA, B. and MAHESHWARI, B., 2013b. The hydrological and economic impacts of changing water allocations in political regions within the peri-urban South Creek catchment in Western Sydney II: Scenarios. Journal of Hydrology. 499, 349-359.

DAVIES, E. G. G. and SIMONOVIC, S. P., 2011. Global water resources modelling with an integrated model of the social-economic-environmental system. Advances in Water Resources. 34, 684-700.

DE GROOT, R. S., WILSON, M. A. and BOUMANS, R. M. J., 2002. A typology for the classification, description and valuation of ecosystem functions, goods and services. Ecological economics. 41, 393-408.

DEBNATH, D., 2014. Integrating economic and hydrologic interdependence in reservoir management. Lakes and Reservoirs: Research and Management. 19, 211-224.

DEBNATH, D., BOYER, T. A., STOECKER, A. L. and SANDERS, L. D., 2015. Nonlinear Reservoir Optimization Model with Stochastic Inflows: Case Study of Lake Tenkiller. Journal of Water Resources Planning and Management. 141, 04014046.

DENNEDY-FRANK, P. J., MUENICH, R. L., CHAUBEY, I. and ZIV, G., 2016. Comparing two tools for ecosystem service assessments regarding water resources decisions. Journal of Environmental Management. 177, 331-340.

DIAZ, G. E., BROWN, T. C. and MOREL-SEYTOUX, H. J. Year. The marginal economic value of streamflows: a systems approach. In: MORELSEYTOUX, H. J., ed. American Geophysical Union Twelfth Annual Hydrology Days, March 31-April 31992 Colorado State University. Fort Collins, CO. Hydrology Days Publications. Atherton, CA, 419.

DIMOVA, G., TZANOV, E., NINOV, P., RIBAROVA, I. and KOSSIDA, M. 2014. Complementary Use of the WEAP Model to Underpin the Development of SEEAW Physical Water Use and Supply Tables. In: PROCEDIA ENGINEERING (ed.) 12th International Conference on Computing and Control for the Water Industry, CCWI2013.

DIVAKAR, L., BABEL, M. S., PERRET, S. R. and DAS GUPTA, A., 2011. Optimal allocation of bulk water supplies to competing use sectors based on economic criterion - An application to the Chao Phraya River Basin, Thailand. Journal of Hydrology. 401, 22-35.

DIVAKAR, L., BABEL, M. S., PERRET, S. R. and DAS GUPTA, A., 2013. Optimal water allocation model based on satisfaction and economic benefits. International Journal of Water. 7, 363-381.

DRAPER, A., JENKINS, M. W., KIRBY, K. W., LUND, J. R. and HOWITT, R. E., 2003. Economic-Engineering Optimization for California Water Management. Journal of Water Resources Planning and Management. 129, 155-164. 
Assessment of Ecosystem Services and Water Accounting Methodologies for Integrated Water Resources Management in water scarce basins

DROOGERS, P., SIMONS, G., BASTIAANSSEN, W. G. M. and HOOGEVEEN, J. 2010. Water Accounting Okavango. Coping with Water Scarcity - Developing National Water Audits Africa. FAO, Land and Water Division.

DU, J., QIAN, L., RUI, H., ZUO, T., ZHENG, D., XU, Y. and XU, C. Y., 2012. Assessing the effects of urbanization on annual runoff and flood events using an integrated hydrological modeling system for Qinhuai River basin, China. Journal of Hydrology. 464-465, 127-139.

ECOHYDROS S.L. 2009. Estudios censales de peces en los embalses de Albiña, Urrúnaga y Ullivarri de la cuenca del Ebro para la futura incorporación de este indicador biológico a la evaluación del potencial ecológico. Tomo 2: Embalse de Urrúnaga. Ministerio de Medio Ambiente y Medio Rural y Marino.

EIGENBROD, F., ARMSWORTH, P. R., ANDERSON, B. J., HEINEMEYER, A., GILLINGS, S., ROY, D. B., THOMAS, C. D. and GASTON, K. J., 2010. The impact of proxy-based methods on mapping the distribution of ecosystem services. Journal of Applied Ecology. 47, 377-385.

EMBID, A., 2003. The transfer from the Ebro basin to the Mediterranean basins as a decision of the 2001 national hydrological plan: The main problems posed. International Journal of Water Resources Development. 19, 399411.

ENVIRONMENT DIRECTORATE-GENERAL 2014. Mapping and Assessment of Ecosystems and their Services. Indicators for ecosystem assessments under Action 5 of the EU Biodiversity Strategy to 2020. European Commission.

ENVIRONMENT DIRECTORATE-GENERAL 2015a. Guidance Document No 31: Ecological flows in the implementation of the Water Framework Directive. Common Implementation Strategy for the Water Framework Directive (2000/60/EC). European Commission.

ENVIRONMENT DIRECTORATE-GENERAL 2015b. Guidance Document No 34 on the application of water balances for supporting the implementation of the WFD. Common Implementation Strategy for the Water Framework Directive (2000/60/EC). European Commission.

ERFANI, T., BINIONS, O. and HAROU, J. J., 2014. Simulating water markets with transaction costs. Water Resources Research. 50, 4726-4745.

ERFANI, T., BINIONS, O. and HAROU, J. J., 2015. Protecting environmental flows through enhanced water licensing and water markets. Hydrology Earth System Science. 19, 675-689.

ESTRELA, T., MARCUELLO, C. and IGLESIAS, A. 1996. Water resources problemsin Southern Europe. An overview report. In: THYSSEN, N. (ed.). European Environmental Agency.

EUROPEAN COMMISSION 2010. Communication from the Commission: Europe 2020. A strategy for smart, sustainable and inclusive growth. COM(2010) 2020. Brussels. 
EUROPEAN COMMISSION 2011. Communication from the Commission to the European Parliament, the Council, the Economic and Social Committee and the Committee of the Regions. Our life insurance, our natural capitar: an EU biodiversity strategy to 2020. COM(2011) 244 final.

EUROPEAN COMMISSION 2012a. Communication from the Commission to the European Parliament, the Council, the European Economic and Social Committee and the Committee of the Regions. A Blueprint to Safeguard Europe's Water Resources. COM(2012) 673 final. Brussels.

EUROPEAN COMMISSION 2012b. Communication from the Commission to the European Parliament, the Council, the European Economic and Social Committee and the Committee of the Regions. Report on the Review of the European Water Scarcity and Droughts Policy. COM(2012) 672 final. Brussels.

EUROPEAN COMMISSION, INTERNATIONAL MONETARY FUND, ORGANISATION FOR ECONOMIC CO-OPERATION AND DEVELOPMENT, UNITED NATIONS and WORLD BANK 1993. System of National Accounts 1993. United Nations Statistic Division.

EUROPEAN COUNCIL 1980. Council Directive 80/778/CEE, of 15 July 1980, on the quality of water intended for human consumption. Brussels: Official Journal of the European Communities.

EUROPEAN COUNCIL 1991. Council Directive 91/271/EEC of 21 May 1991 concerning urban waste-water treatment. Brussels: Official Journal of the European Communities.

EUROPEAN COUNCIL 1992. Council Directive 92/43/ECC of 21 May 1992 on the conservation of natural habitats and of wild fauna and flora. Official Journal of European Communities.

EUROPEAN COUNCIL 1998. Council Directive 98/83/EC, of 3 November 1998, on the quality of water intended for human consumption. Brussels: Official Journal of the European Communities.

EUROPEAN PARLIAMENT and COUNCIL 2000. Directive 2000/60/EC of the European Parliament and of the Council, of 23 October 2000, establishing a framework for Community action in the field of water policy. Brussels: Official Journal of the European Commission.

EUROPEAN PARLIAMENT and COUNCIL 2009. Directive 2009/147/EC of the European Parliament and of the Council of 30 November 2009 on the conservation of wild birds. Official Jorunal of the European union.

EVERARD, M., 2014. Integrating integrated water management. Proceedings of the Institution of Civil Engineers - Water Management. 167, 512-522.

FAVRETTO, N., STRINGER, L. C., DOUGILL, A. J., DALLIMER, M., PERKINS, J. S., REED, M. S., ATLHOPHENG, J. R. and MULALE, K., 2016. Multi-Criteria Decision Analysis to identify dryland ecosystem service trade-offs under different rangeland land uses. Ecosystem Services. 17, 142-151.

FISHER, B., TURNER, K., ZYLSTRA, M., BROUWER, R., GROOT, R. D., FARBER, S., FERRARO, P., GREEN, R., HADLEY, D., HARLOW, J., JEFFERISS, P., KIRKBY, C., 
Assessment of Ecosystem Services and Water Accounting Methodologies for Integrated Water Resources Management in water scarce basins

MORLING, P., MOWATT, S., NAIDOO, R., PAAVOLA, J., STRASSBURG, B., YU, D. and BALMFORD, A., 2008. Ecosystem services and economic theory: Integration for policy-relevant research. Ecological Applications. 18, 2050-2067.

FISHER, B. and TURNER, R. K., 2008. Ecosystem services: Classification for valuation. Biological Conservation. 141, 1167-1169.

FISHER, B., TURNER, R. K. and MORLING, P., 2009. Defining and classifying ecosystem services for decision making. Ecological economics. 68, 643653.

FISHER, F. M., ARLOSOROFF, S., ECKSTEIN, Z., HADDADIN, M., HAMATI, S. G., HUBERLEE, A., JARRAR, A., JAYYOUSI, A., SHAMIR, U. and WESSELING, H., 2002. Optimal water management and conflict resolution: The Middle East Water Project. Water Resources Research. 38, 25-1-25-17.

FOLKE, C., CARPENTER, S., ELMQVIST, T., GUNDERSON, L., HOLLING, C. S. and WALKER, B., 2002. Resilience and Sustainable Development: Building Adaptive Capacity in a World of Transformations. AMBIO: A Journal of the Human Environment. 31, 437-440.

FOLKE, C., CARPENTER, S., WALKER, B., SCHEFFER, M., ELMQVIST, T., GUNDERSON, L. and HOLLING, C. S., 2004. Regime Shifts, Resilience, and Biodiversity in Ecosystem Management. Annual Review of Ecology, Evolution, and Systematics. 35, 557-581.

FONTANA, V., RADTKE, A., BOSSI FEDRIGOTTI, V., TAPPEINER, U., TASSER, E., ZERBE, S. and BUCHHOLZ, T., 2013. Comparing land-use alternatives: Using the ecosystem services concept to define a multi-criteria decision analysis. Ecological economics. 93, 128-136.

GAN, H., WANG, Y., LU, Q., VARDON, M. and CHANGHAI, Q., 2012. Development and application of the System of Environmental-Economic Accounting for Water in China, in: GODFREY, J. M. and CHALMERS, K. (eds.), Water Accounting. International Approaches to Policy and Decision-making. Edward Elgar,

GAO, L., BRYAN, B. A., NOLAN, M., CONNOR, J. D., SONG, X. and ZHAO, G., 2016. Robust global sensitivity analysis under deep uncertainty via scenario analysis. Environmental Modelling \& Software. 76, 154-166.

GARCÍA-DELGADO, J. L., 1976. A propósito de "La agricultura en el desarrollo capitalista español (1940-1970), in: GARCíA-DELGADO, J. L. (ed.) La cuestión agraria en la España contemporánea. EDICUSA, Madrid

GARROTE, L., GRANADOS, A. and IGLESIAS, A., 2016. Strategies to reduce water stress in Euro-Mediterranean river basins. Science of the Total Environment. 543, Part B, 997-1009.

GENERALITAT VALENCIANA 1997. LEY 12/1997, de 23 de diciembre, de Tasas de la Generalitat Valenciana. Diari Oficial de la Comunitat Valenciana.

GENERALITAT VALENCIANA 2013. LEY 5/2013, de 23 de diciembre, de Medidas Fiscales, de Gestión Administrativa y Financiera, y de Organización de la Generalitat. Diari Oficial de la Generalitat Valenciana. 
GENG, G. and WARDLAW, R., 2013. Application of Multi-Criterion Decision Making Analysis to Integrated Water Resources Management. Water Resources Management. 27, 3191-3207.

GEORGE, B., MALANO, H., DAVIDSON, B., HELLEGERS, P., BHARATI, L. and MASSUEL, S., 2011 a. An integrated hydro-economic modelling framework to evaluate water allocation strategies I: Model development. Agricultural Water Management. 98, 733-746.

GEORGE, B., MALANO, H., DAVIDSON, B., HELLEGERS, P., BHARATI, L. and MASSUEL, S., $2011 \mathrm{~b}$. An integrated hydro-economic modelling framework to evaluate water allocation strategies II: Scenario assessment. Agricultural Water Management. 98, 747-758.

GIRARD, C., RINAUDO, J.-D., PULIDO-VELAZQUEZ, M. and CABALLERO, Y., 2015. An interdisciplinary modelling framework for selecting adaptation measures at the river basin scale in a global change scenario. Environmental Modelling \& Software. 69, 42-54.

GLOBAL WATER PARTNERSHIP 2000. Integrated Water Resources Management. Background report 4.

GOLDSTEIN, J. H., CALDARONE, G., DUARTE, T. K., ENNAANAY, D., HANNAHS, N., MENDOZA, G., POLASKY, S., WOLNY, S. and DAILY, G. C., 2012. Integrating ecosystem-service tradeoffs into land-use decisions. Proceedings of the National Academy of Sciences of the United States of America. 109, 7565-7570.

GORE, J. A. and NESTLER, J. M., 1988. Instream flow studies in perspective. Regulated Rivers: Research \& Management. 2, 93-101.

GRAFTON, R. Q., CHU, H. L., STEWARDSON, M. and KOMPAS, T., 2011. Optimal dynamic water allocation: Irrigation extractions and environmental tradeoffs in the Murray River, Australia. Water Resources Research. 47, n/a-n/a.

GRAFTON, R. Q., PITTOCK, J., DAVIS, R., WILLIAMS, J., FU, G., WARBURTON, M., UDALL, B., MCKENZIE, R., YU, X., CHE, N., CONNELL, D., JIANG, Q., KOMPAS, T., LYNCH, A., NORRIS, R., POSSINGHAM, H. and QUIGGIN, J., 2013. Global insights into water resources, climate change and governance. Nature Clim. Change. 3, 315-321.

GRIEBLER, C. and AVRAMOV, M., 2015. Groundwater ecosystem services: a review. Freshwater Science. 34, 355-367.

GRIFFIN, R. C. and HSU, S.-H., 1993. The Potential for Water Market Efficiency When Instream Flows Have Value. American Journal of Agricultural Economics. 75, 292-303.

GRIMA, N., SINGH, S. J., SMETSCHKA, B. and RINGHOFER, L., 2016. Payment for Ecosystem Services (PES) in Latin America: Analysing the performance of 40 case studies. Ecosystem Services. 17, 24-32.

GROSSMANN, M. and DIETRICH, O., 2012. Integrated Economic-Hydrologic Assessment of Water Management Options for Regulated Wetlands 
Assessment of Ecosystem Services and Water Accounting Methodologies for Integrated Water Resources Management in water scarce basins

Under Conditions of Climate Change: A Case Study from the Spreewald (Germany). Water Resources Management. 26, 2081-2108.

HAINES-YOUNG, R. and POTSCHIN, M. 2009. Methodologies for defining and assessing ecosystem services. Final report. CEM Report. Joint Nature Conservation Committee.

HAINES-YOUNG, R. and POTSCHIN, M., 2010. The links between biodiversity, ecosystem services and human well-being, in: RAFFAELLI, D. G. and FRID, C. L. J. (eds.), Ecosystem Ecology. A New Sythesis. Cambridge Univsetity Press,

HAINES-YOUNG, R. and POTSCHIN, M. 2013. Common International Classification of Ecosystem Services (CICES): Consultation of Version 4, AugustDecember 2012. EEA Framework Contract No EEA/IEA/09/003.

HAROU, J. J. and LUND, J. R., 2008. Ending groundwater overdraft in hydrologiceconomic systems. Hydrogeology Journal. 16, 1039-1055.

HAROU, J. J., MEDELLÍN-AZUARA, J., ZHU, T., TANAKA, S. K., LUND, J. R., STINE, S., OLIVARES, M. A. and JENKINS, M. W., 2010. Economic consequences of optimized water management for a prolonged, severe drought in California. Water Resources Research. 46, n/a-n/a.

HAROU, J. J., PULIDO-VELAZQUEZ, M., ROSENBERG, D. E., MEDELLín-AZUARA, J., LUND, J. R. and HOWITT, R. E., 2009. Hydro-economic models: Concepts, design, applications, and future prospects. Journal of Hydrology. 375, 627-643.

HASLER, B., SMART, J. C. R., FONNESBECH-WULFF, A., ANDERSEN, H. E., THODSEN, H., BLICHER MATHIESEN, G., SMEDBERG, E., GÖKE, C., CZAJKOWSKI, M., WAS, A., ELOFSSON, K., HUMBORG, C., WOLFSBERG, A. and WULFF, F., 2014. Hydro-economic modelling of cost-effective transboundary water quality management in the Baltic Sea. Water Resources and Economics. 5, 1-23.

HEARNSHAW, E. J. S., TOMPKINS, J. M. and CULLEN, R. 2011. Addressing the wicked problem of water resource management: An ecosystem services approach. 55th Annual AARES National Conference. Melbourne.

HEINZ, I., PULIDO-VELAZQUEZ, M., LUND, J. R. and ANDREU, J., 2007. Hydroeconomic Modeling in River Basin Management: Implications and Applications for the European Water Framework Directive. Water Resources Management. 21, 1103-1125.

HERNÁNDEZ-SANCHO, F., MOLINOS-SENANTE, M. and SALA-GARRIDO, R., 2010. Economic valuation of environmental benefits from wastewater treatment processes: An empirical approach for Spain. Science of the Total Environment. 408, 953-957.

HERNÁNDEZ, J. M., 1994. La planificación hidrológica en España. Revista de Estudios Agrosociales. 167.

HERRERA, S., GUtIÉRREZ, J. M., ANCELL, R., PONS, M. R., FRÍAS, M. D. and FERNÁNDEZ, J., 2012. Development and analysis of a 50-year high- 
resolution daily gridded precipitation dataset over Spain (Spain02). International Journal of Climatology. 32, 74-85.

HOEKSTRA, A. Y. and HUNG, P. Q. 2002. Virtual Water Trade. International Expert Meeting on Virtual Water Trade. In: IHE DELFT (ed.). Delft.

HONEY-ROSÉS, J., ACUÑA, V., BARDINA, M., BROZOVIĆ, N., MARCÉ, R., MUNNÉ, A., SABATER, S., TERMES, M., VALERO, F., VEGA, À. and SCHNEIDER, D. W., 2013. Examining the Demand for Ecosystem Services: The Value of Stream Restoration for Drinking Water Treatment Managers in the Llobregat River, Spain. Ecological economics. 90, 196-205.

HOUK, E. E., FRASIER, M. and TAYLOR, R. G., 2007. Evaluating Water Transfers from Agriculture for Reducing Critical Habitat Water Shortages in the Platte Basin. Journal of Water Resources Planning and Management. 133, 320328.

HUDSON, H. R., BYROM, A. E. and CHADDERTON, W. L. 2003. A critique of IFIM instream habitat simulation in the New Zealand context. Science for Conservation. New Zealand Department of Conservation.

HUGHES, D. A., CORRAL, E. and MULLER, N. W. J., 2012. Potential for the application of General Purpose Water Accounting in South Africa, in: J.M. GODFREY and K. CHALMERS (eds.), Water Accounting. International Approaches to Policy and Decision-making. Edward Elgar, Cheltenham

HURD, B., CALLAWAY, M., SMITH, J. B. and KIRSHEN, P., 1999. Economic effects of climate change on US water resources. The Impact of Climate Change on the United States Economy. Cambridge University Press.

IDESCAT. 2012. Recomptes de població, http://www.idescat.cat/cat/poblacio/poblrecomptes.html [Online]. Institut d'Estadística de Catalunya. [Accessed April 15, 2013].

INTERGOVERNMENTAL PANEL ON CLIMATE CHANGE 2014. Climate Change 2014: Sythesis Report. Contribution of Working Groups I, II and III to the Fifth Assessment Reoprt of the Intergovernmental Panel on Climate Change. In: PACHAURI, R. K. and MEYER, L. A. (eds.). Geneva.

JACKSON, E. L., REES, S. E., WILDING, C. and ATTRILL, M. J., 2015. Use of a seagrass residency index to apportion commercial fishery landing values and recreation fisheries expenditure to seagrass habitat service. Conservation Biology. 29, 899-909.

JAKEMAN, A. J. and LETCHER, R. A., 2003. Integrated assessment and modelling: features, principles and examples for catchment management. Environmental Modelling \& Software. 18, 491-501.

JEFATURA DEL ESTADO 1985. Ley 29/1985 de 2 de agosto, de Aguas. Madrid: Boletín Oficial del Estado.

JEFATURA DEL ESTADO 2001. Ley 10/2001, de 5 de julio, del Plan Hidrológico Nacional. Madrid: Boletín Oficial del Estado.

JEFATURA DEL ESTADO 2005. Ley 11/2005, de 22 de junio, por la que se modifica la ley 10/2001, de 5 de julio, del Plan Hidrológico Nacional. Madrid: Boletín Oficial del Estado. 
Assessment of Ecosystem Services and Water Accounting Methodologies for Integrated Water Resources Management in water scarce basins

JENKINS, M. W. and LUND, J. R., 2000. Integrating Yield and Shortage Management under Multiple Uncertainties. Journal of Water Resources Planning and Management. 126, 288-297.

JENKINS, M. W., LUND, J. R., HOWITT, R. E., DRAPER, A., MSANGI, S., TANAKA, S., RITZEMA, R. S. and MARQUES, G., 2004. Optimization of California's Water Supply System: Results and Insights. Journal of Water Resources Planning and Management. 130, 271-280.

KAHIL, M. T., DINAR, A. and ALBIAC, J., 2015. Modeling water scarcity and droughts for policy adaptation to climate change in arid and semiarid regions. Journal of Hydrology. 522, 95-109.

KANDULU, J. M., CONNOR, J. D. and MACDONALD, D. H., 2014. Ecosystem services in urban water investment. Journal of Environmental Management. 145, 43-53.

KARIMI, P. and BASTIAANSSEN, W. G. M., 2015. Spatial evapotranspiration, rainfall and land use data in water accounting - Part 1: Review of the accuracy of the remote sensing data. Hydrol. Earth Syst. Sci. 19, 507-532.

KARIMI, P., BASTIAANSSEN, W. G. M. and MOLDEN, D., 2013a. Water Accounting Plus (WA+) - a water accounting procedure for complex river basins based on satellite measurements. Hydrol. Earth Syst. Sci. 17, 2459-2472.

KARIMI, P., BASTIAANSSEN, W. G. M., MOLDEN, D. and CHEEMA, M. J. M., 2013b. Basin-wide water accounting based on remote sensing data: an application for the Indus Basin. Hydrol. Earth Syst. Sci. 17, 2473-2486.

KARIMI, P., BASTIAANSSEN, W. G. M., SOOD, A., HOOGEVEEN, J., PEISER, L., BASTIDAS-OBANDO, E. and DOST, R. J., 2015. Spatial evapotranspiration, rainfall and land use data in water accounting - Part 2: Reliability of water acounting results for policy decisions in the Awash Basin. Hydrol. Earth Syst. Sci. 19, 533-550.

KEELER, B. L., POLASKY, S., BRAUMAN, K. A., JOHNSON, K. A., FINLAY, J. C., O'NEILL, A., KOVACS, K. and DALZELL, B., 2012. Linking water quality and wellbeing for improved assessment and valuation of ecosystem services. Proceedings of the National Academy of Sciences. 109, 18619-18624.

KEUNING, S. J. and DE HAAN, M. 1996. What's in a NAMEA? Recent results of the NAMEA-Approach to Environmental Accounting. Occasional Papers Statistics Netherlands.

KNAPP, K. C., WEINBERG, M., HOWITT, R. and POSNIKOFF, J. F., 2003. Water transfers, agriculture, and groundwater management: a dynamic economic analysis. Journal of Environmental Management. 67, 291-301.

KOVACS, K. F., 2012. Integrating property value and local recreation models to value ecosystem services from regional parks. Landscape and Urban Planning. 108, 79-90.

KRAGT, M. E., 2013. Hydro-economic modelling in an uncertain world: Integrating costs and benefits of water quality management. Water Resources and Economics. 4, 1-21. 
LA NOTTE, A., LIQUETE, C., GRIZZETTI, B., MAES, J., EGOH, B. N. and PARACCHINI, M. L., 2015. An ecological-economic approach to the valuation of ecosystem services to support biodiversity policy. A case study for nitrogen retention by Mediterranean rivers and lakes. Ecological Indicators. 48, 292-302.

LA NOTTE, A., MAES, J., GRIZZETTI, B., BOURAOUI, F. and ZULIAN, G., 2012. Spatially explicit monetary valuation of water purification services in the Mediterranean bio-geographical region. International Journal of Biodiversity Science, Ecosystem Services \& Management. 8, 26-34.

LANGE, G.-M., MUNGATANA, E. and HASSAN, R., 2007. Water accounting for the Orange River Basin: An economic perspective on managing a transboundary resource. Ecological economics. 61, 660-670.

LEFKOFF, L. J. and GORELICK, S. M., 1990. Benefits of an irrigation water rental market in a saline stream-aquifer system. Water Resources Research. 26, 1371-1381.

LETCHER, R. A., JAKEMAN, A. J. and CROKE, B. F. W., 2004. Model development for integrated assessment of water allocation options. Water Resources Research. 40, n/a-n/a.

LI, Y. P., HUANG, G. H. and CHEN, X., 2009. Multistage scenario-based intervalstochastic programming for planning water resources allocation. Stochastic Environmental Research and Risk Assessment. 23, 781-792.

LIANG, X., LETTENMAIER, D. P., WOOD, E. F. and BURGES, S. J., 1994. A simple hydrologically based model of land surface water and energy fluxes for general circulation models. Journal of Geophysical Research: Atmospheres. 99, 14415-14428.

LIQUETE, C., CID, N., LANZANOVA, D., GRIZZETTI, B. and REYNAUD, A., 2016. Perspectives on the link between ecosystem services and biodiversity: The assessment of the nursery function. Ecological Indicators. 63, 249-257.

LIU, S., CROSSMAN, N. D., NOLAN, M. and GHIRMAY, H., 2013. Bringing ecosystem services into integrated water resources management. Journal of Environmental Management. 129, 92-102.

LONSDORF, E., KREMEN, C., RICKETTS, T., WINFREE, R., WILLIAMS, N. and GREENLEAF, S., 2009. Modelling pollination services across agricultural landscapes. Annals of Botany. 103, 1589-1600.

LOOMIS, J. B., 2000. Environmental Valuation Techniques in Water Resource Decision Making. Journal of Water Resources Planning and Management. 126, 339-344.

LOUCKS, D. P. and VAN BEEK, E., 2005. Water Resources Systems Planning and Management. An Introduction to Methods, Models and Applications. Unated Nations Educational, Paris.

LUND, J., 2012. Water accounting issues in California, in: GODFREY, J. M. and CHALMERS, K. (eds.), Water Accounting. International Approaches to Policy and Decision-making. Edward Elgar, Cheltenham 
Assessment of Ecosystem Services and Water Accounting Methodologies for Integrated Water Resources Management in water scarce basins

LUND, R. J. and FERREIRA, I., 1996. Operating Rule Optimization for Missouri River Reservoir System. Journal of Water Resources Planning and Management. 122, 287-295.

MAES, J., PARACCHINI, M. L. and ZULIAN, G. 2011. A European assessment of the provision of ecosystem services. Towards and atlas of ecosystem services. In: SUSTAINABILITY, J. R. C.-I. F. E. A. (ed.). European Union.

MAINUDDIN, M., KIRBY, M. and QURESHI, M. E., 2007. Integrated hydrologiceconomic modelling for analyzing water acquisition strategies in the Murray River Basin. Agricultural Water Management. 93, 123-135.

MALTBY, E. and BARKER, T. (eds.) 2009. The wetlands handbook. John Wiley \& Sons Ltd.

MARGAT, J. 1983. Compte des eaux continentales. Nomenclature, organisation et mode d'emploi des tableaux comptables (quantité). Orleáns: Commission Interministérielle des Comptes du Patrimoine Naturel.

MARQUES, G. F., LUND, J. R., LEU, M. R., JENKINS, M. W., HOWITT, R., HARTER, T., HATCHETT, S., RUUD, N. and BURKE, S. M., 2006. Economically Driven Simulation of Regional Water Systems: Friant-Kern, California. Journal of Water Resources Planning and Management. 132, 468-479.

MARTÍNEZ-CAPEL, F., GARCÍA DE JALÓN, D., WERENITZKY, D., BAEZA, D. and RODILLA-ALAMÁ, M., 2009. Microhabitat use by three endemic Iberian cyprinids in Mediterranean rivers (Tagus River Basin, Spain). Fisheries Management and Ecology. 16, 52-60.

MAZZANTI, B., BONAMINI, I., CHECCUCCI, G., FIUMI, L., CONSUMI, F., BARTALESI, S. and MONTINI, G., 2014. The UN System for Environmental-Economic Accounts for Water (SEEA-W) and groundwater management: the experience of the Arno River Basin Authority within the PAWA project. Italian Journal of Groundwater. 137, 73-77.

MCINTOSH, B. S., GIUPPONI, C., VOINOV, A. A., SMITH, C., MATTHEWS, K. B., MONTICINO, M., KOLKMAN, M. J., CROSSMAN, N., VAN ITTERSUM, M. HAASE, D., HAASE, A., MYSIAK, J., GROOT, J. C. J., SIEBER, S., VERWEIJ, P., QUINN, N., WAEGER, P., GABER, N., HEPTING, D., SCHOLTEN, H., SULIS, A., VAN DELDEN, H., GADDIS, E. and ASSAF, H., 2008. Bridging the Gaps Between Design and Use: Developing Tools to Support Environmental Management and Policy, in: JAKEMAN, A. J., VOINOV, A. A., RIZZOLI, A. E. and CHEN, S. H. (eds.), Developments in Integrated Environmental Assessment. Elsevier, 33-48.

MEDELLÍN-AZUARA, J., HAROU, J. J., OlIVARES, M. A., MADANI, K., LUND, J. R., HOWITT, R. E., TANAKA, S. K., JENKINS, M. W. and ZHU, T., 2008a. Adaptability and adaptations of California's water supply system to dry climate warming. Climatic Change. 87, 75-90.

MEDELLÍN-AZUARA, J., LUND, J. R. and HOWITT, R. E., 2007. Water Supply Analysis for Restoring the Colorado River Delta, Mexico. Journal of Water Resources Planning and Management. 133, 462-471. 
MEDELLÍN-AZUARA, J., MENDOZA-ESPINOSA, L. G., LUND, J. R., HAROU, J. J. and HOWITT, R. E., 2009. Virtues of simple hydro-economic optimization: Baja California, Mexico. Journal of Environmental Management. 90, 34703478.

MEDELLÍN-AZUARA, J., MENDOZA-ESPINOSA, L. G., LUND, J. R. and HOWITT, R. E., 2008b. Hydro-economic analysis of water supply for the binational transboundary region of Baja California, Mexico. Water Science and Technology: Water Supply. 8, 189-196.

MILHOUS, R. T. Year. Instream flow values as a factor in water management. In: AMERICAN WATER RESOURCES ASSOCIATION, ed. Symposium on Regional and State Water Resources Planning and Management, 1983 Washington.

MILLENNIUM ECOSYSTEM ASSESSMENT 2003. Ecosystems and human well-being: A framework for assessment. Ecosystems and human well-being. World Resources Institute,.

MILLENNIUM ECOSYSTEM ASSESSMENT 2005. Ecosystems and human well-being. Synthesis. In: ISLAND PRESS (ed.) Ecosystems and human well-being. World Resources Institute.

MINISTERIO DE OBRAS PÚBLICAS Y URBANISMO 1980. Real Decreto 3029/1979, de 7 de diciembre, por el que se regula la realización de estudios previos para la planificación hidrológica. Madrid: Boletìn Oficial del Estado.

MINISTERIO DE OBRAS PÚBLICAS Y URBANISMO 1988. Real Decreto 927/1988, de 29 de julio, por el que se aprueba el Reglamento de la Administración Oública del Agua y de la Planificación Hidrológica, en desarrollo de los títulos II y III de la Ley de Aguas. Madrid: Boletín Oficial del Estado.

MITCHELL, M., VANBERG, J. and SIPPONEN, M. 2010. Commercial inland fishing in member countries of the European Inland Fisheries Advisory Commission (EIFAC): Operational environments, property rights regimes and socioeconomic indicators. In: FOOD AND AGRICULTURE ORGANIZATION OF THE UNITED NATIONS (ed.).

MOLDEN, D. 1997. Accounting for Water Use and Productivity. SWIM paper 1. Sri Lanka: International Irrigation Management Institute.

MOMBLANCH, A. 2013. Integrated water resources management for Ecosystem Services assessment. Máster en Ingeniería Hidráulica y Medio Ambiente Master Thesis, Universitat Politècnica de València.

MOMBLANCH, A., ANDREU, J., PAREDES-ARQUIOLA, J., SOLERA, A. and PEDROMONZONÍS, M., 2014. Adapting water accounting for integrated water resource management. The Júcar Water Resource System (Spain). Journal of Hydrology. 519, Part D, 3369-3385.

MOMBLANCH, A., CONNOR, J. D., CROSSMAN, N. D., PAREDES-ARQUIOLA, J. and ANDREU, J., 2016. Using ecosystem services to represent the environment in hydro-economic models. Journal of Hydrology. 538, 293-303.

Momblanch, A., Paredes-Arquiola, J., Andreu, J., under review. Improved modelling of the freshwater provisioning ecosystem service in water scarce 
Assessment of Ecosystem Services and Water Accounting Methodologies for Integrated Water Resources Management in water scarce basins

river basins. Environ. Model. Softw.

MOMBLANCH, A., PAREDES-ARQUIOLA, J., MUNNÉ, A., MANZANO, A., ARNAU, J. and ANDREU, J., 2015. Managing water quality under drought conditions in the Llobregat River Basin. Science of the Total Environment. 503-504, 300-318.

MULLICK, R. A., BABEL, M. S. and PERRET, S. R., 2013. Marginal benefit based optimal water allocation: Case of Teesta River, Bangladesh. Water Policy. 15, 126-146.

MUNGATANA, E. and HASSAN, R., 2012. Two prespectives of water resource accounting: comparing the Australian and the United Nations approaches, in: GODFREY, J. M. and CHALMERS, K. (eds.), Water Accounting. International Approaches to Policy and Decision-making. Edward Elgar, Cheltenham

MUNNS, W. R., REA, A. W., MAZZOTTA, M. J., WAINGER, L. A. and SATERSON, K. 2015. Toward a standard lexicon for ecosystem services. Integrated Environmental Assessment and Management. 11, 666-673.

MUNOZ-HERNÁNDEZ, A., MAYER, A. S. and WATKINS JR, D. W., 2011. Integrated Hydrologic-Economic-Institutional Model of Environmental Flow Strategies for Rio Yaqui Basin, Sonora, Mexico. Journal of Water Resources Planning and Management. 137, 227-237.

NAIFER, A., AL-RAWAHY, S. A. and ZEKRI, S., 2011. Economic Impact of Salinity: The Case of Al-Batinah in Oman. International Journal of Agricultural Research. 6, 134-142.

NEARY, B., CASH, K., HÉBERT, S., KHAN, H., SAFFRAN, K., SWAIN, L. and WILLIAMSON, D. 2001. Canadian water quality guidelines for the protection of aquatic life. CCME Water Quality Index 1.0, Technical Report. Canadian Council of Ministers of the Environment.

NELSON, E., MENDOZA, G., REGETZ, J., POLASKY, S., TALLIS, H., CAMERON, D., CHAN, K. M. A., DAILY, G. C., GOLDSTEIN, J., KAREIVA, P. M., LONSDORF, E., NAIDOO, R., RICKETTS, T. H. and SHAW, M., 2009. Modeling multiple ecosystem services, biodiversity conservation, commodity production, and tradeoffs at landscape scales. Frontiers in Ecology and the Environment. 7, 4-11.

NEWLIN, B. D., JENKINS, M. W., LUND, J. R. and HOWITT, R. E., 2002. Southern California Water Markets: Potential and Limitations. Journal of Water Resources Planning and Management. 128, 21-32.

NULL, S. E. and LUND, J. R., 2006. REASSEMBLING HETCH HETCHY: WATER SUPPLY WITHOUT O'SHAUGHNESSY DAMI. JAWRA Journal of the American Water Resources Association. 42, 395-408.

OLAYA MARÍN, E., MARTINEZ-CAPEL, F., GARCÍA BARTUAL, R. and VEZZA, P., 2016. Modelling critical factors affecting the distribution of the vulnerable endemic Eastern Iberian barbel (Luciobarbus guiraonis) in Mediterranean rivers. Mediterranean Marine Science. 17, 264-279. 
OSTROUMOV, S. A., 2005. On Some Issues of Maintaining Water Quality and SelfPurification. Water Resources. 32, 305-313.

PAPADOPOULOS, C. E. and YEUNG, H., 2001. Uncertainty estimation and Monte Carlo simulation method. Flow Measurement and Instrumentation. 12, 291-298.

PAREDES-ARQUIOLA, J., ANDREU-ÁLVAREZ, J., MARTíN-MONERRIS, M. and SOLERA, A., 2010. Water Quantity and Quality Models Applied to the Jucar River Basin, Spain. Water Resources Management. 24, 2759-2779.

PAREDES-ARQUIOLA, J., MARTINEZ-CAPEL, F., SOLERA, A. and AGUILELLA, V., 2013. Implementing environmental flows in complex water resources systems Case study: the Duero River Basin, Spain. River Research and Applications. 29, 451-468.

PAREDES-ARQUIOLA, J., SOLERA, A., ANDREU, J. and LERMA, N. 2014 a. Herramienta EvalHid para la evaluación de recussos hídricos. Grupo de Ingeniería de Recursos Hídricos. Universitat Politècnica de València.

PAREDES-ARQUIOLA, J., SOLERA, A., MARTINEZ-CAPEL, F., MOMBLANCH, A. and ANDREU, J., 2014b. Integrating water management, habitat modelling and water quality at the basin scale and environmental flow assessment: case study of the Tormes River, Spain. Hydrological Sciences Journal. 59, 878-889.

PAYNE, T. 2003. The concept of weighted usable area as relative sustainability index. IFIM Users Workshop. Fort Collins.

PEARCE, D., MARKANDYA, A. and BARBIER, E. B. (eds.) 1989. Blueprint for a green economy. Earthscan, London.

PEDRO-MONZONÍS, M., JIMÉNEZ-FERNÁNDEZ, P., SOLERA, A. and JIMÉNEZGAVILÁN, P., 2016a. The use of AQUATOOL DSS applied to the System of Environmental-Economic Accounting for Water (SEEAW). Journal of Hydrology. 533, 1-14.

PEDRO-MONZONÍS, M., SOLERA, A., FERRER, J., ANDREU, J. and ESTRELA, T., $2016 \mathrm{~b}$. Water accounting for stressed river basins based on water resources management models. Science of the Total Environment. 565, 181-190.

PEDRO-MONZONÍS, M., SOLERA, A., FERRER, J., ESTRELA, T. and PAREDESARQUIOLA, J., 2015. A review of water scarcity and drought indexes in water resources planning and management. Journal of Hydrology. 527, 482-493.

PERANGINANGIN, N., SAKTHIVADIVEL, R., SCOTT, N. R., KENDY, E. and STEENHUIS, T. S., 2004. Water accounting for conjunctive groundwater/surface water management: case of the Singkarak-Ombilin River basin, Indonesia. Journal of Hydrology. 292, 1-22.

PLUMMER, M. L., 2009. Assessing benefit transfer for the valuation of ecosystem services. Frontiers in Ecology and the Environment. 7, 38-45.

POTSCHIN, M. B. and HAINES-YOUNG, R. H., 2011. Ecosystem services: Exploring a geographical perspective. Progress in Physical Geography. 35, 575-594. 
Assessment of Ecosystem Services and Water Accounting Methodologies for Integrated Water Resources Management in water scarce basins

PULIDO-VELAZQUEZ, M., ALVAREZ-MENDIOLA, E. and ANDREU, J., 2013. Design of Efficient Water Pricing Policies Integrating Basinwide Resource Opportunity Costs. Journal of Water Resources Planning and Management. 139, 583-592.

PULIDO-VELAZQUEZ, M., ANDREU, J. and SAHUQUILLO, A., 2006. Economic Optimization of Conjunctive Use of Surface Water and Groundwater at the Basin Scale. Journal of Water Resources Planning and Management. $132,454-467$.

PULIDO-VELAZQUEZ, M., ANDREU, J., SAHUQUILLO, A. and PULIDO-VELAZQUEZ, D., 2008a. Hydro-economic river basin modelling: The application of a holistic surface-groundwater model to assess opportunity costs of water use in Spain. Ecological economics. 66, 51-65.

PULIDO-VELAZQUEZ, M., ANDREU, J., SAHUQUILLO, A. and PULIDO-VELAZQUEZ, D., 2008b. Hydro-economic river basin modelling: The application of a holistic surface-groundwater model to assess opportunity costs of water use in Spain. Ecological Economics. 66, 51-65.

PULIDO-VELAZQUEZ, M., JENKINS, M. W. and LUND, J. R., 2004. Economic values for conjunctive use and water banking in southern California. Water Resources Research. 40, n/a-n/a.

QURESHI, M. E., CONNOR, J., KIRBY, M. and MAINUDDIN, M., 2007. Economic assessment of acquiring water for environmental flows in the Murray Basin*. Australian Journal of Agricultural and Resource Economics. 51, 283-303.

RAHAMAN, M. and VARIS, O., 2005. Integrated water resources management: evolution, prospects and future challenges. Sustainability: Science, Practice, \& Policy. 1, 15-21.

REYNAUD, A. and LEENHARDT, D. Year. MoGIRE: A Model for IntegratedWater Management. In: International Congress on Environmental Modelling and Software, 2008 Barcelona, Spain.

RICHTER, B. D. and THOMAS, G. A., 2007. Restoring environmental flows by modifying dam operations. Ecology and Society. 12, 12.

RIEGELS, N., JENSEN, R., BENSASSON, L., BANOU, S., MØLLER, F. and BAUERGOTTWEIN, P., 2011. Estimating resource costs of compliance with EU WFD ecological status requirements at the river basin scale. Journal of Hydrology. 396, 197-214.

RIEGELS, N., PULIDO-VELAZQUEZ, M., DOULGERIS, C., STURM, V., JENSEN, R., MOLLER, F. and BAUER-GOTTWEIN, P., 2013. Systems Analysis Approach to the Design of Efficient Water Pricing Policies under the EU Water Framework Directive. Journal of Water Resources Planning and Management. 139, 574-582.

RINGLER, C. and CAI, X., 2006. Valuing Fisheries and Wetlands Using Integrated Economic-Hydrologic Modeling-Mekong River Basin. Journal of Water Resources Planning and Management. 132, 480-487. 
RINGLER, C., VON BRAUN, J. and ROSEGRANT, M. W., 2004. Water Policy Analysis for the Mekong River Basin. Water International. 29, 30-42.

ROOST, N., MOLDEN, D., ZHU, Z. and LOEVE, R. Year. Identifying Water Saving Opportunities: Examples from Three Irrigation Districts in China's Yellow River and Yangtze Basins In: 1st International Yellow River Forum on River Basin Management, 2003 Zhengzhou, China.

ROOZBAHANI, R., SCHREIDER, S. and ABBASI, B., 2013. Economic Sharing of Basin Water Resources between Competing Stakeholders. Water Resources Management. 27, 2965-2988.

ROOZBAHANI, R., SCHREIDER, S. and ABBASI, B., 2015. Optimal water allocation through a multi-objective compromise between environmental, social, and economic preferences. Environmental Modelling \& Software. 64, 1830.

ROSEGRANT, M. W., RINGLER, C., MCKINNEY, D. C., CAI, X., KELLER, A. and DONOSO, G., 2000. Integrated economic-hydrologic water modeling at the basin scale: the Maipo river basin. Agricultural Economics. 24, 33-46.

ROSSUM, M., VAN GELOOF, I. and SCHENAU, S. 2010. NAMWA 2010 Water in de nationale rekeningen (2007). Den Haag: Statistics Netherlands.

ROY, D., BARR, J. and VENEMA, H. D. 2011. Ecosystem Approaches in Integrated Water Resources Management (IWRM): A Review of Transboundary River Basins. United Nations Environment Programme and the International Institute for Sustainable Development.

RUHRVERBAND 2014. Ruhrwassermenge 2014. Essen: Ruhrverband.

SAFFRAN, K., CASH, K., HALLARD, K., NEARY, B. and WRIGHT, R. 2001. Canadian Water Quality Guidelines for the Protection of Aquatic Life. CCME WATER QUALITY INDEX 1.0 User's Manual. Canadian Council of Ministers of the Environment.

SCHEFFER, M., CARPENTER, S., FOLEY, J. A., FOLKE, C. and WALKER, B., 2001. Catastrophic shifts in ecosystems. Nature. 413, 591-596.

SCHMEDTJE, U., KREMER, F., GRIMEAUD, D., NOTARO, N., NYLUND, L., RODRIGUEZ ROMERO, J., RUBIN, A., VERHEIJ, M. and WEGERDT, P. 2011. Links between the Water Frameworkd Directive and Nature Directives. Frequently Asked Questions. European Commission.

SCHOUPS, G., ADDAMS, C. L., MINJARES, J. L. and GORELICK, S. M., 2006. Sustainable conjunctive water management in irrigated agriculture: Model formulation and application to the Yaqui Valley, Mexico. Water Resources Research. 42, n/a-n/a.

SCHWABE, K., ALBIAC, J., ANDREU, J., AYERS, J., CAIOLA, N., HAYMAN, P. and IBANEZ, C., 2013. Summaries and Considerations, in: SCHWABE, K., ALBIAC, J., CONNOR, J. D., HASSAN, R. M. and MEZA GONZÁLEZ, L. (eds.), Drought in Arid and Semi-Arid Regions. A Multi-Disciplinary and CrossCountry Perspective. Springer, 471-507.

SEPPELT, R., DORMANN, C. F., EPPINK, F. V., LAUTENBACH, S. and SCHMIDT, S., 2011. A quantitative review of ecosystem service studies: approaches, 
Assessment of Ecosystem Services and Water Accounting Methodologies for Integrated Water Resources Management in water scarce basins

shortcomings and the road ahead. Journal of Applied Ecology. 48, 630636.

SHAMA, P., 2004. Population Growth and Sustainable Development. Economic and Political Weekly. 39, 629-633.

SHILPAKAR, R. L., BASTIAANSSEN, W. G. M. and MOLDEN, D., 2011. A remote sensing-based approach for water accounting in the East Rapti River Basin, Nepal. Himalayan Journal of Sciences. 7, 15-30.

SHRESTHA, R. K., SEIDL, A. F. and MORAES, A. S., 2002. Value of recreational fishing in the Brazilian Pantanal: a travel cost analysis using count data models. Ecological economics. 42, 289-299.

SLOMP, H. J. 2004. La despoblación del medio rural español. Human Geography, Groningen University.

SPANGENBERG, J. H., VON HAAREN, C. and SETTELE, J., 2014. The ecosystem service cascade: Further developing the metaphor. Integrating societal processes to accommodate social processes and planning, and the case of bioenergy. Ecological economics. 104, 22-32.

STEMPEL, J. M. 1990. Conversion of weighted usable area to potential fish production in the Yakima River Basin. In: PARK, D. L. (ed.) Status and Future of Spring Chinook Salmon in the Columbia River BasinConservation and Enhancement.

SUN, J., DANG, Z. and ZHENG, S., 2016. Development of payment standards for ecosystem services in the largest interbasin water transfer projects in the world. Agricultural Water Management.

TALLIS, H. T., RICKETTS, T., GUERRY, A. D., WOOD, S. A., SHARP, R., NELSON, E., ENNAANAY, D., WOLNY, S., OLWERO, N., VIGERSTOL, K., PENNINGTON, D., MENDOZA, G., AUKEMA, J., FOSTER, J., FORREST, J., CAMERON, D., ARKEMA, K., LONSDORF, E., KENNEDY, C., VERUTES, G., KIM, C. K., GUANNEL, G., PAPENFUS, M., TOFT, J., MARSIK, M., BERNHARDT, J. and GRIFFIN, R. 2013. InVEST 2.5.4 User's Guide. In: PROJECT, T. N. C. (ed.). Stanford.

TANAKA, S. K., ZHU, T., LUND, J. R., HOWITT, R. E., JENKINS, M. W., PULIDO, M. A., TAUBER, M., RITZEMA, R. S. and FERREIRA, I. C., 2006. Climate Warming and Water Management Adaptation for California. Climatic Change. 76, 361-387.

TELLO, E., HAZELTON, J. and CUMMINGS, L., 2016. Potential users' perceptions of general purpose water accounting reports. Accounting, Auditing \& Accountability Journal. 29, 80-110.

TÉMEZ, J. R. 1977. Modelo matemático de transformación "precipitaciónescorrentía". Madrid: Asociación de Investigación Industrial Eléctrica.

TERRADO, M., ACUÑA, V., ENNAANAY, D., TALlIS, H. and SABATER, S., 2014. Impact of climate extremes on hydrological ecosystem services in a heavily humanized Mediterranean basin. Ecological Indicators. 37, 199209. 
TERRADO, M., MOMBLANCH, A., BARDINA, M., BOITHIAS, L., MUNNÉ, A., SABATER, S., SOLERA, A. and ACUÑA, V., 2016a. Integrating ecosystem services in river basin management plans. Journal of Applied Ecology. n/a-n/a.

TERRADO, M., SABATER, S., CHAPLIN-KRAMER, B., MANDLE, L., ZIV, G. and ACUÑA, V., 2016b. Model development for the assessment of terrestrial and aquatic habitat quality in conservation planning. Science of the Total Environment. 540, 63-70.

THE ECONOMICS OF ECOSYSTEMS \& BIODIVERSITY 2008. The economics of ecosystems and biodiversity: An interim report. European Communities.

THE ECONOMICS OF ECOSYSTEMS \& BIODIVERSITY, 2010. The Economics of Ecosystems and Biodiversity Ecological and Economic Foundations, in: KUMAR, P. (ed.). Earthscan, London and Washington

TIETENBERG, T. and LEWIS, L., 2009. Environmental \& Natural Resource Economics. Pearson Addison Wesley, Boston.

TISDELL, J. G., 2001. The environmental impact of water markets: An Australian case-study. Journal of Environmental Management. 62, 113-120.

TURNER, R. K., GEORGIOU, S. and FISHER, B. (eds.) 2008. Valuing Ecosystem Services: The Case of Multi-functional Wetlands. Taylor and Francis, London.

TUYA, F., HAROUN, R. and ESPINO, F., 2014. Economic assessment of ecosystem services: Monetary value of seagrass meadows for coastal fisheries. Ocean \& Coastal Management. 96, 181-187.

TYAGI, S., SHARMA, B., SINGH, P. and DOBHAL, R., 2013. Water Quality Assessment in Terms of Water Quality Index. American Journal of Water Resources. 1, 34-38.

U.S. DEPARTMENT OF THE INTERIOR, BUREAU OF RECLAMATION, LOWER COLORADO REGIONAL OFFICE and BOULDER CANYON OPERATIONS OFFICE 2016. Colorado River Accounting and Water User Report: Arizona, California, and Nevada. Calendar Year 2015. Reclamation. Managing water in the West.

UK NATIONAL ECOSYSTEM ASSESSMENT 2011. The UK National Ecosystem Assessment: Technical Report. In: UNAP-WCMC (ed.). Cambridge.

UNITED NATIONS - DEPARMENT OF ECONOMIC AND SOCIAL AFFAIRS POPULATION DIVISION 2015. World Population Prospects: The 2015 Revision, Key Findings and Advance Tables. Working Paper No. ESA/P/WP.241.

UNITED NATIONS 2007. Recommendations on Payments for Ecosystem Services in Integrated Water Resources Management. New York and Geneva.

UNITED NATIONS 2008. International Standard Industrial Classification of All Economic Activities. Revision 4. New York: United Nations Statistic Division.

UNITED NATIONS STATISTICS DIVISION 2012. System of Environmental-Economic Accounting for Water. New York: United Nations.

VAN HOUTVEN, G., POWERS, J. and PATTANAYAK, S. K., 2007. Valuing water quality improvements in the United States using meta-analysis: Is the glass 
Assessment of Ecosystem Services and Water Accounting Methodologies for Integrated Water Resources Management in water scarce basins

half-full or half-empty for national policy analysis? Resource and Energy Economics. 29, 206-228.

VARDON, M., LENZEN, M., PEEVOR, S. and CREASER, M., 2007. Water accounting in Australia. Ecological economics. 61, 650-659.

VARELA-ORTEGA, C., BLANCO-GUTIÉRREZ, I., SWARTZ, C. H. and DOWNING, T. E., 2011. Balancing groundwater conservation and rural livelihoods under water and climate uncertainties: An integrated hydro-economic modeling framework. Global Environmental Change. 21, 604-619.

VAUX, H. J. and HOWITT, R. E., 1984. Managing Water Scarcity: An Evaluation of Interregional Transfers. Water Resources Research. 20, 785-792.

VICENTE, D. J., RODRÍGUEZ-SINOBAS, L., GARROTE, L. and SÁNCHEZ, R., 2016. Application of the system of environmental economic accounting for water SEEAW to the Spanish part of the Duero basin: Lessons learned. Science of the Total Environment. 563-564, 611-622.

VIGERSTOL, K. L. and AUKEMA, J. E., 2011. A comparison of tools for modeling freshwater ecosystem services. Journal of Environmental Management. 92, 2403-2409.

VILLA, F., BAGSTAD, K. J., VOIGT, B., JOHNSON, G. W., PORTELA, R., HONZÁK, M. and BATKER, D., 2014. A Methodology for Adaptable and Robust Ecosystem Services Assessment. PLoS ONE. 9, e91001.

VLACHOPOULOU, M., COUGHLIN, D., FORROW, D., KIRK, S., LOGAN, P. and VOULVOULIS, N., 2014. The potential of using the Ecosystem Approach in the implementation of the EU Water Framework Directive. Science of the Total Environment. 470-471, 684-694.

VOLK, M., HIRSCHFELD, J., DEHNHARDT, A., SCHMIDT, G., BOHN, C., LIERSCH, S. and GASSMAN, P. W., 2008. Integrated ecological-economic modelling of water pollution abatement management options in the Upper Ems River Basin. Ecological economics. 66, 66-76.

WADDLE, T. Year. Integrating microhabitat and macrohabitat. In: BLAZKOVA, S., STALNAKER, C. and NOVICKY, O., eds. Hydroecological modelling: research, practice, legislation and decision-making, 1998 Prague. Masaryk Water Research Institute.

WAGNER, P. D., KUMAR, S. and SCHNEIDER, K., 2013. An assessment of land use change impacts on the water resources of the Mula and Mutha Rivers catchment upstream of Pune, India. Hydrol. Earth Syst. Sci. 17, 2233-2246.

WAINGER, L. A., KING, D. M., MACK, R. N., PRICE, E. W. and MASLIN, T., 2010. Can the concept of ecosystem services be practically applied to improve natural resource managment decisions? Ecological Economics. 69, 978987.

WALLACE, K., 2008. Ecosystem services: Multiple classifications or confusion? Biological Conservation. 141, 353-354.

WALLACE, K. J., 2007. Classification of ecosystem services: Problems and solutions. Biological Conservation. 139, 235-246. 
WAN, J., YANG, Y.-C. E., LIN, Y.-F. and WANG, J., 2013. Groundwater Resource Planning to Preserve Streamflow: Where Environmental Amenity Meets Economic Welfare Loss. Journal of Water Resources Planning and Management. 139, 440-448.

WARD, F. A., 2009. Economics in integrated water management. Environmental Modelling \& Software. 24, 948-958.

WARD, F. A., BOOKER, J. F. and MICHELSEN, A. M., 2006. Integrated Economic, Hydrologic, and Institutional Analysis of Policy Responses to Mitigate Drought Impacts in Rio Grande Basin. Journal of Water Resources Planning and Management. 132, 488-502.

WARD, F. A. and LYNCH, T. P., 1996. INTEGRATED RIVER BASIN OPTIMIZATION: MODELING ECONOMIC AND HYDROLOGIC INTERDEPENDENCE. JAWRA Journal of the American Water Resources Association. 32, 1127-1138.

WARD, F. A. and LYNCH, T. P., 1997. Is dominant use management compatible with basin-wide economic efficiency? Water Resources Research. 33, $1165-1170$.

WARD, F. A. and PULIDO-VELAZQUEZ, M., 2008. Water conservation in irrigation can increase water use. Proceedings of the National Academy of Sciences of the United States of America. 105, 18215-18220.

WARD, F. A. and PULIDO-VELAZQUEZ, M., 2009. Incentive pricing and cost recovery at the basin scale. Journal of Environmental Management. 90, 293-313.

WARD, F. A. and PULIDO-VELAZQUEZ, M., 2012. Economic Costs of Sustaining Water Supplies: Findings from the Rio Grande. Water Resources Management. 26, 2883-2909.

WARD, F. A. and PULIDO-VELÁZQUEZ, M., 2008. Efficiency, equity, and sustainability in a water quantity-quality optimization model in the Rio Grande basin. Ecological economics. 66, 23-37.

WATER ACCOUNTING+. 2016. http://www.wateraccounting.org/ [Online]. [Accessed 11 August 2016].

WATKINS JR, D. W. and MCKINNEY, D. C., 1999. Screening Water Supply Options for the Edwards Aquifer Region in Central Texas. Journal of Water Resources Planning and Management. 125, 14-24.

WEBER, J. L. 1984. L'articulation des comptes du patrimoine naturel et de la comptabilité économique nationale. L'example du compte des eaux continentales. Paris: Institut National de la Statistique et des Etudes Economiques.

WILCHFORT, O. and LUND, J. R., 1997. Shortage Management Modeling for Urban Water Supply Systems. Journal of Water Resources Planning and Management. 123, 250-258.

WORKING GROUP 2.1 - IMPRESS 2003. Guidance Document No 3: Analysis of Pressures and Impacts. Common Implementation Strategy for the Water Framework Directive (2000/60/EC). European Commission. 
Assessment of Ecosystem Services and Water Accounting Methodologies for Integrated Water Resources Management in water scarce basins

WORKING GROUP 2.6 - WATECO 2003. Guidance Document No 1: Economics and the environment. The implementaton challenge of the Water Framework Directive. Common Implementation Strategy for the Water Framework Directive (2000/60/EC). European Commission.

WORLD BANK. 2016. Water Resources Management [Online]. [Accessed 10 August 2016].

YANG, W. and YANG, Z., 2013. Development of a Long-term, Ecologically Oriented Dam Release Plan for the Lake Baiyangdian Sub-basin, Northern China. Water Resources Management. 27, 485-506.

YANG, W. and YANG, Z., 2014. Analyzing Hydrological Regime Variability and Optimizing Environmental Flow Allocation to Lake Ecosystems in a Sustainable Water Management Framework: Model Development and a Case Study for China's Baiyangdian Watershed. Journal of Hydrologic Engineering. 19, 993-1005.

YANG, X., REN, L., SINGH, V. P., LIU, X., YUAN, F., JIANG, S. and YONG, B., 2012a. Impacts of land use and land cover changes on evapotranspiration and runoff at Shalamulun River watershed, China. Hydrology Research. 43, 23-37.

YANG, Y.-C. E. and CAI, X., 2011. Reservoir Reoperation for Fish Ecosystem Restoration Using Daily Inflows-Case Study of Lake Shelbyville. Journal of Water Resources Planning and Management. 137, 470-480.

YANG, Y.-C. E., ZHAO, J. and CAI, X., 2012b. Decentralized Optimization Method for Water Allocation Management in the Yellow River Basin. Journal of Water Resources Planning and Management. 138, 313-325.

YATES, D., SIEBER, J., PURKEY, D. and HUBER-LEE, A., 2005. WEAP21-A Demand-, Priority-, and Preference-Driven Water Planning Model. Water International. 30, 487-500.

ZOLTAY, V. I., VOGEL, R. M., KIRSHEN, P. H. and WESTPHAL, K., 2010. Integrated Watershed Management Modeling: Generic Optimization Model Applied to the Ipswich River Basin. Journal of Water Resources Planning and Management. 136, 566-575. 
Annexes 

A1. Adapting water accounting for integrated water resource management. The Júcar Water Resource System (Spain)

\section{Abstract}

An increase in water demands, exacerbated by climate change and the tightening of environmental requirements, leads to a reduction in available water resources for economic uses. This situation poses challenges for water resource planning and management. Water accounting has emerged as an appropriate tool to improve transparency and control in water management. There are multiple water accounting approaches, but they generally involve a very exhaustive list of accounted concepts. According to our findings in this research, one of the best water accounting methodologies is the Australian Water Accounting Standard. However, its implementation for integrated water resource planning and management purposes calls into questioning the amount of information and level of detail necessary for the users of water accounts. In this paper, we present a different method of applying the Australian Water Accounting Standard in relation to water resource management, which improves its utility. In order to compare the original approach and that proposed here, we present and discuss an application to the Júcar Water Resource System, in eastern Spain.

\section{Keywords}

Water accounting; Transparency; Australian Water Accounting Standard; Water resource management; Water balance.

\section{Introduction}

Following several years of implementing River Basin Management Plans based on the European Water Framework Directive (WFD) (EP, 2000), the European Commission published A Blueprint to Safeguard Europe's Water Resources (EC, 2012), in response to the diverse problems in water resource management that need to be addressed in the various member states. This blueprint highlights key aspects, such as water use efficiency and improved water management governance. Furthermore, it states that there are information gaps and errors in the dissemination and integration of the data necessary for decision-making. It recognises water accounting as a good tool to provide basic information in order to support decision-making in water resource management, in line with other proposed future actions to 
Assessment of Ecosystem Services and Water Accounting Methodologies for Integrated Water Resources Management in water scarce basins

address these problems. In a broad sense, water accounting can be defined as the development of water balances in a territory which includes elements related with water use (country, river basin, etc.), reported in a certain format.

There are several water accounting methodologies developed by states and international organisations, with various purposes, physical domains and presentation formats (BoM, 2011; Chalmers and Godfrey, 2012). Many of these focus on the relationship between water use and economy in order to evaluate the costs associated with water services (Ward and PulidoVelazquez, 2009), the productivity of water, and the environmental costs. Currently, the System of Environmental-Economic Accounting for Water (UNSD, 2007; Vardon et al., 2012) is the most widespread hybrid accounting approach and it is applied in many countries, such as China (Gan et al., 2012), South Africa (Lange et al., 2007) and Australia (Vardon et al., 2007). Other water accounting approaches refer only to physical magnitudes, in this case water volume. Some of these accounts show the state and quantity of water resources for the purpose of achieving better control over them and resolve conflicts between co-riparian regions (Allan, 2012). The International Water Management Institute proposed a water accounting framework (WA) that classifies water consumption and water use to assess water productivity (Karimi et al., 2012). It has recently developed an improved version (WA+) that provides explicit spatial information (Karimi et al., 2013a). Alternatively, the Australian Water Accounting Standard (AWAS) (WASB, 2010; BoM, 2012) governs the implementation of reports that provide specific information to water users for them to make and evaluate decisions on the allocation of water resources.

All the above water accounting methodologies have diverse viewpoints and features. However, they all tend to be very exhaustive in terms of the accounted concepts. This makes them very useful for describing the hydrological processes taking place in the landscape, but it could represent a limitation as regards water resource management transparency and supervision. Water management analysis is performed at a water resource system scale, which is conceptually different to the river basin scale. Some authors define a water resource system as a physical environment comprised of independent water bodies and infrastructures, which is 
inseparable from a cultural environment with social, political and economic constraints (White et al. 1992; Karamouz et al. 2003). To serve the interests of water users (urban, agricultural and industrial water demands) and society, the information in the water accounts should include elements from both environments (physical and cultural) and be limited to the essential figures, clearly and intuitively presented so that it is readily understandable. What is more, some authors maintain that there are insufficient reliable information sources available in order to complete the various kinds of water accounting methodologies (Hughes et al., 2012). Furthermore, if the values presented are not accurate enough, this thorough accounting of every water volume and flow record in a basin may even have a detrimental effect on the primary purpose of water accounting, transmitting uncertainty about the presented figures rather than assurance.

From a water management perspective, the water accounting methodologies should be applicable at a river basin scale or at a water resource system scale as these are the scales established by the WFD for integrated water resource management. The water accounts should contain complete information about relevant water flows and storages for water users in the accounting domain. Finally, in order to facilitate generalised use, along with information comparison and transfer, the water accounting methodologies should set up standard procedures for calculating and presenting the water accounts. According to these criteria, the WA+ and AWAS are the most useful water accounting methodologies for integrated water resource management, among all those analysed. As the WA+ accounting methodology has already been analysed in depth in scientific literature (Karimi et al., 2013a; Karimi et al., 2013b), we find investigating the AWAS and its explicitly developed conceptual framework (WASB, 2009; Chalmers and Godfrey, 2012) much more convenient.

In this paper we analyse the suitability of the AWAS to improve transparency in water management towards water users, leading to higher efficiency and governance in water resource management. Based on this assessment, we propose a new conceptual approach for the implementation of the AWAS, using it to improve water resource management in terms of accuracy and understanding of the data. Finally, we present an application of both 
Assessment of Ecosystem Services and Water Accounting Methodologies for Integrated Water Resources Management in water scarce basins

accounting approaches to the Júcar Water Resource System in order to make a clearer comparison of the approaches.

\section{Material and methods}

\subsection{The Australian Water Accounting Standard. Original version.}

As a result of the serious drought that occurred in Australia between 1997 and 2010, known as Australia's Millennium Drought (Kirono et al., 2011; Banerjee et al., 2013), the government brought about extensive reforms related to water management. A key objective of these reforms was the establishment of efficient water markets for the reallocation of scarce water resources. In order to have better control of the evolving markets, they identified the need to create a standard water accounting system. The AWAS is based on a series of documents that define the contents and format of the General Purpose Water Accounting Reports (GPWARs). These reports should be published regularly by the Water Report Entities (WREs). These entities hold and transfer water or water rights, they have other direct or indirect claims to water, or they have inflows and/or outflows of water. Additionally, they have a responsibility to inform their users about the state and variation of the water resources of which they are in charge.

The resulting products of the Australian methodology are not limited to the water accounts. Moreover, the GPWARs include a detailed description of the WRE context; information about the origin and processes used to obtain every value in the accounts and the associated error; other relevant aspects for the water management; and an assurance statement that the report is presented fairly in accordance with the standard (AASB and BoM, 2012). GPWARs have to be presented annually by the WREs and put at public availability, making it possible to analyse the evolution of water management, demands and resources. This information can also be a very useful support in the monitoring of River Basin Management Plans. The water accounts proposed in the AWAS were designed based on the Framework for the Preparation and Presentation of Financial Statements (AASB, 2004). Due to this, there are significant similarities between the terminology and format used in the Australian water accounts and those seen in financial accounts. There are three water accounting statements: Water Assets and Water Liabilities (A1), Changes in Water Assets and Water Liabilities (A2), and 
Physical Water Flows (A3). Table 1 presents the structure and examples of these water accounting statements.

Table 1. Structure and examples of accounting concepts in the AWAS water accounting statements.

\begin{tabular}{|c|c|c|}
\hline $\begin{array}{l}\text { Water Assets and } \\
\text { Water Liabilities (A1) }\end{array}$ & $\begin{array}{l}\text { Changes in Water Assets and } \\
\text { Water Liabilities (A2) }\end{array}$ & Physical Water Flows (A3) \\
\hline $\begin{array}{l}\text { Water assets } \\
\text { Landscape } \\
\text { Reservoirs } \\
\text { Aquifers } \\
\text { Rivers } \\
\text { Canals } \\
\text { Inter-region claim } \\
\text { on water of } \\
\text { another entity } \\
\text { Water liabilities } \\
\text { Water allocation } \\
\text { remaining } \\
\text { Inter-region claim } \\
\text { on water of the } \\
\text { entity } \\
\text { Opening net water } \\
\text { assets } \\
\text { Closing net water } \\
\text { assets } \\
\text { Changes in net water } \\
\text { resources } \\
\text { Opening water } \\
\text { storage } \\
\text { Closing water storage } \\
\text { Changes in net water } \\
\text { storage }\end{array}$ & $\begin{array}{l}\text { Water asset increases } \\
\text { River inflow to region } \\
\text { Returns from demands } \\
\text { Transfer of inter-region claim } \\
\text { on water of another entity } \\
\text { Precipitation into } \\
\text { landscape, reservoirs, rivers } \\
\text { and canals } \\
\text { Groundwater recharge } \\
\text { from landscape } \\
\text { Increase of inter-region } \\
\text { claim on water of another } \\
\text { entity } \\
\text { Water liability decreases } \\
\text { Adjustment of water } \\
\text { allocation } \\
\text { Decrease of inter-region } \\
\text { claim on water of the entity } \\
\text { Water asset decreases } \\
\text { River \& groundwater } \\
\text { outflow from region } \\
\text { Transfer of inter-region claim } \\
\text { on water of the entity } \\
\text { Evapotranspiration from } \\
\text { landscape, reservoirs, rivers } \\
\text { and canals } \\
\text { Deep leakages from } \\
\text { reservoirs and canals } \\
\text { Decrease of inter-region } \\
\text { claim on water of another } \\
\text { entity } \\
\text { Water liability increases } \\
\text { Water allocation } \\
\text { announcements } \\
\text { Increase of inter-region } \\
\text { claim on water of the entity } \\
\text { Changes in net water resources } \\
\text { Unaccounted-for difference } 1 \\
\end{array}$ & $\begin{array}{l}\text { Water inflows } \\
\text { River inflow to region } \\
\text { Returns from demands } \\
\text { Transfer of inter-region claim } \\
\text { on water of another entity } \\
\text { Precipitation into } \\
\text { landscape, reservoirs, rivers } \\
\text { and canals } \\
\text { Groundwater recharge } \\
\text { from landscape } \\
\text { Water outflows } \\
\text { River \& groundwater } \\
\text { outflow from region } \\
\text { Transfer of inter-region claim } \\
\text { on water of the entity } \\
\text { Evapotranspiration from } \\
\text { landscape, reservoirs, rivers } \\
\text { and canals } \\
\text { Deep leakages from } \\
\text { reservoirs and canals } \\
\text { Water allocation diversion } \\
\text { Changes in net water storage } \\
\text { Unaccounted-for difference } 2 \\
\end{array}$ \\
\hline
\end{tabular}


Assessment of Ecosystem Services and Water Accounting Methodologies for Integrated Water Resources Management in water scarce basins

The equations that relate the different concepts in the accounts, which are based on financial balances, are the following:

Changes in net water resources $=$ Finalnet waterresources - Initiahet water resources

Changes innet waterstorage $=$ Finalstorage- Initialstorage

Changes in net water resources $=$

= Totalincrease in waterresources-Totaldecreaseinwaterresources

Unaccounted for difference l= (1)-(3)

Changes in net waterstorage $=$ Total inf lows - Total outflows

Unaccounted for difference 2= (2)-(5)

Unaccounted for difference l= Unaccounted for difference 2

Al is equivalent to the so-called Statement of Financial Position of a company. This is an accounting document that shows the assets and financial situation of a company at a certain time, usually at the end of the reported period. It consists of two parts: assets and liabilities. The assets in this case would be the water resources owned by a water entity, physically or for vested right. The financial liabilities correspond to the current obligations of the entity, and these debts must be settled on or before the due date. In the water accounts, liabilities refer to water supply duties contracted during the reported period that are to be supplied in the following period. From the assets and the liabilities, the net equity can be deduced as the difference between these two concepts. Similarly, the net water resources are obtained by subtracting the water liabilities from the water assets, which represent the available water resources not compromised by supply duties.

A2 is equivalent to the Financial Performance, which summarises the financial activity of a company, showing the profit or loss obtained in a certain period. In financial accounting, the profit is calculated as the difference between income and expenditure, considering the accrual basis of financial accounting. In the water accounts the accrual basis means that the effects of water transactions and transformations are recognised when the decisions or commitments that give rise to them occur. This may not be the time at which water is physically transacted, consumed or subject to some other event (BoM 2012). Hence, the increase or decrease in water resources refers to the water acquired or lost, physically or for vested right. 
The changes in net water resources calculated in A2 (3) must be equal to those obtained in A1 (1). However, these values do not usually match due to errors in measurements and records or the omission of certain water resources or flows in the accounts. In order to better quantify the global error, an unaccounted-for difference value is computed (4), providing an estimate of the reliability of the water accounts. Thus, a high value denotes lack of control over the water resources and flows.

Finally, A3 is analogous to the Cash Flows account in financial accounting, which provides information about the changes in the cash and equivalents of an entity during the reported period. Similarly, the AWAS considers the water inflows and outflows of a WRE. This account refers to the water resources physically owned and managed by the water entity, permitting the calculation of the net water storage as the difference between water inflows and outflows. The resulting variation in the net water storage in A3 (5) must coincide with the one obtained in Al (2). Nevertheless, for the abovementioned reasons, it does not usually happen this way. Therefore, in order to quantify the error in this account, a second unaccounted-for difference item is introduced (6). This figure must be equal to the unaccounted-for difference in A2 (7), otherwise there is a conceptual error in the global water balance.

\subsection{Proposal for the modification of Australian Water Accounts}

As it has been mentioned previously, the water accounting proposed by the Australian government takes its inspiration from financial accounting, which deals with an easily measurable unit: currency. That is why the AWAS is very exhaustive in the accounting of all the water storage and flow records inside the accounting domain. In contrast, this is not a common practice in water management reports, which mainly focus on water management concepts.

The Australian water accounts are meant to extend the water accounting domain to the physical boundary of the basin, in an attempt to cover all the elements involved in the hydrological cycle. When considering water accounting as a support for water management transparency and supervision, the usefulness of its application to the territorial domain and the hydrological cycle as a whole may be uncertain. In fact, what water users need to know, in order to make decisions or judge water managers' 
Assessment of Ecosystem Services and Water Accounting Methodologies for Integrated Water Resources Management in water scarce basins

solutions, is the exploitable water stocks and their allocation and diversion to the different demands, in a simple and reliable way. Therefore, a balance is needed between the maximisation of the elements regarded inside the accounting domain and the rigorousness of the accounting (Andreu et al., 2012). A key issue is to define the WRE in terms of the information required to satisfy its users' needs, and the boundaries of water accounting (Chalmers and Godfrey, 2012). Note that the order of this process is also important.

The original water accounts proposed by the AWAS cover such different terms as: water storage in the landscape, water storage in rivers, leakages from canals or evaporation from rivers and canals (see Table). It is likely that most part of the errors committed, in absolute terms, come from concepts with much bigger order of magnitude than the other accounted terms. For instance, the infiltration and the evapotranspiration from the landscape reach very high values $(6,448.83 \mathrm{Mm} 3$ and $6,373.36 \mathrm{Mm} 3$, respectively, in the Júcar Water Resource System during the hydrological year 2007/2008), while the supply to demands has relatively low figures in comparison $1114.30 \mathrm{Mm} 3$ to urban demands, $549.25 \mathrm{Mm} 3$ to agriculture and $32.24 \mathrm{Mm} 3$ to industrial demands, in the Júcar Water Resource System during the hydrological year 2007/2008). Certainly, new technologies, like earth observation, substantially improve the accuracy of hydrological and related data (Karimi and Bastiaanssen, 2014) and hydrological models benefit from these data for calibration and simulation. However, small errors of $5 \%$ in these large figures may reach the same order of magnitude as water demands in the accounting domain. This poses a problem when we are applying water accounting for water management purposes, as the quantification of large terms may increase the unaccounted-for difference balance term, distorting other variables that are smaller in magnitude but more decisive or interesting to the water users. On the other hand, there are concepts such as water storage in rivers or canals that are simply insignificant compared to other water assets. Besides, there are no specific data to obtain them and their calculation has to be based on many assumptions.

Under the above premises, we propose to change the focus of the Australian water accounting. We think that the significance and clarity of information, and unaccounted-for difference terms, can be improved by adjusting the accounting domain to the elements of importance for each 
water resource system. Therefore, with the aim of supporting water management, we defend that the water accounts should only include the information that refers to the manageable elements (e.g. reservoirs, aquifers, and demands) that can be controlled by water managers and which are essential for the water users.

As a general rule for water accounting in a water resource system, we propose that the assets included in the Al account encompass only the aquifers and reservoirs, and exclude the landscape of the basin, rivers and canals. Consequently, in A2 and A3 all the accounting terms that refer to increases or decreases in these water assets should also be removed (precipitation, evaporation, leakages, etc.). This way, we maintain the water balance of the river basin. By doing this, the accounts are simplified to show only the relevant information for the users and the accounted terms have higher reliability.

Another feature of the original Australian water accounts is that A2 and A3 are identical except for the application of the accrual basis of the financial accounting. That is, A2 includes the water liabilities and inter-region claims variation, as well as the allocations to the different demands and their adjustments. In contrast, A3 does not contain information about water liabilities and inter-region claims variation, while it reveals the real water supply to the demands. However, the balance of the demands is preserved and the information in $\mathrm{A} 3$ can be deduced from the information in $\mathrm{Al}$ and A2 (8). In order to avoid data redundancies, we propose to remove account A3 and maintain the relevant information on the demands, liabilities and commitments contracted by the WRE during the reporting period in A2. In accordance with the above considerations, Table shows the structure and content of the new proposed water accounting statements. Additionally, it also includes the concepts removed from the original version, coloured in grey, to facilitate comparison between the two versions.

Initialallocation(A2) - Adjustment of water allocation(A2) + Water allocation announc. $(A 2)=$ = Water allocation diversion(A3) + Water allocation remaining(Al)

(8) 
Assessment of Ecosystem Services and Water Accounting Methodologies for Integrated Water Resources Management in water scarce basins

Table 2. Structure and examples of accounting concepts in the new proposed water accounting statements. To facilitate the comparison with the original version, the removed terms are coloured in grey.

\begin{tabular}{|c|c|c|}
\hline $\begin{array}{l}\text { Water Assets and } \\
\text { Water Liabilities (A1) }\end{array}$ & $\begin{array}{l}\text { Changes in Water Assets and } \\
\text { Water Liabilities (A2) }\end{array}$ & Physical Water Flows (A3) \\
\hline $\begin{array}{l}\text { Water assets } \\
\text { Landscape } \\
\text { Reservoirs } \\
\text { Aquifers } \\
\text { Rivers } \\
\text { Canals } \\
\text { Inter-region claim } \\
\text { on water of } \\
\text { another entity } \\
\text { Water liabilities } \\
\text { Water allocation } \\
\text { remaining } \\
\text { Inter-region claim } \\
\text { on water of the } \\
\text { entity } \\
\text { Opening net water } \\
\text { assets } \\
\text { Closing net water } \\
\text { assets } \\
\text { Changes in net water } \\
\text { resources } \\
\text { Opening water } \\
\text { storage } \\
\text { Closing water storage } \\
\text { Changes in net water } \\
\text { storage }\end{array}$ & $\begin{array}{l}\text { Water asset increases } \\
\text { River inflow to region } \\
\text { Returns from demands } \\
\text { Transfer of inter-region claim } \\
\text { on water of another entity } \\
\text { Precipitation into } \\
\text { Iandscape, reservoirs, rivers } \\
\text { and canals } \\
\text { Groundwater recharge } \\
\text { from landscape } \\
\text { Increase of inter-region } \\
\text { claim on water of another } \\
\text { entity } \\
\text { Water liability decreases } \\
\text { Adjustment of water } \\
\text { allocation } \\
\text { Decrease of inter-region } \\
\text { claim on water of the entity } \\
\text { Water asset decreases } \\
\text { River \& groundwater } \\
\text { outflow from region } \\
\text { Transfer of inter-region claim } \\
\text { on water of the entity } \\
\text { Evapotranspiration from } \\
\text { landscape, reservoirs, rivers } \\
\text { and canals } \\
\text { Deep leakages from } \\
\text { reservoirs and canals } \\
\text { Decrease of inter-region } \\
\text { claim on water of another } \\
\text { entity } \\
\text { Water liability increases } \\
\text { Water allocation } \\
\text { announcements } \\
\text { Increase of inter-region } \\
\text { claim on water of the entity } \\
\text { Changes in net water resources } \\
\text { Unaccounted-for difference } 1\end{array}$ & $\begin{array}{l}\text { Water inflows } \\
\text { River inflow to region } \\
\text { Returns from demands } \\
\text { Transfer of inter-region claim } \\
\text { on water of another entity } \\
\text { Precipitation into } \\
\text { landscape, reservoirs, rivers } \\
\text { and canals } \\
\text { Groundwater recharge } \\
\text { from landscape } \\
\text { Water outflows } \\
\text { River \& groundwater } \\
\text { outflow from region } \\
\text { Transfer of inter-region claim } \\
\text { on water of the entity } \\
\text { Evapotranspiration from } \\
\text { landscape, reservoirs, rivers } \\
\text { and canals } \\
\text { Deep leakages from } \\
\text { reservoirs and canals } \\
\text { Water allocation diversion } \\
\text { Changes in net water storage } \\
\text { Unaccounted-for difference } 2\end{array}$ \\
\hline
\end{tabular}

Finally, with the aim of summarising the most relevant information for the users of the water accounts, we propose to add an outline table for the 
water demands. This new table includes water allocations, supplies, returns and deficits or surpluses in the supply to each demand. In this way, the water resources consumed by water demands can also be explicitly shown in the new version of the water accounts. This figure was not presented in the original water accounts, though it shows important data for the water managers and water users of the WREs. This new version of the water accounts is closer to the water management perspective than the original version, which has a financial accounting approach.

\subsection{Study area: Júcar Water Resource System}

The Júcar Water Resource System (Júcar System from now on), the biggest system in the Júcar River Basin District (see Figure 1), is a complex river system with a huge variety of uses with different supply priorities, and with an intense relationship between surface and groundwater. The total area of the system is $22,378.51 \mathrm{~km}^{2}$. Figure 2 shows the most relevant rivers: Júcar, Cabriel, Magro and Albaida, and the most important aquifers: Mancha Oriental and Plana de Valencia Sur. The Júcar System includes the Albufera wetland, classified as Natural Park, Special Protection Area, RAMSAR and site of Community Importance. It receives water resources from the Júcar System and the neighbouring system (Turia), and it is hydraulically connected to the Plana de Valencia Sur aquifer. The Júcar System presents a ratio of 0.84 between total water demands and mean renewable water resources. This value (close to 1) denotes that the water resource exploitation, and therefore water scarcity, is very high. Surface water is mainly used by the cities of Valencia, Sagunto and Albacete (123 Mm³/year for 1,203,617 inhabitants) and for traditional irrigation demands in the lower part of the system. The remaining urban demands and the majority of agricultural demands are met with groundwater. The total irrigation demand reaches $995 \mathrm{Mm}^{3} /$ year $(158,500 \mathrm{ha})$. For more information about the Júcar System, consult the web page of the Júcar River Basin District Agency (www.chj.es). 
Assessment of Ecosystem Services and Water Accounting Methodologies for Integrated Water Resources Management in water scarce basins

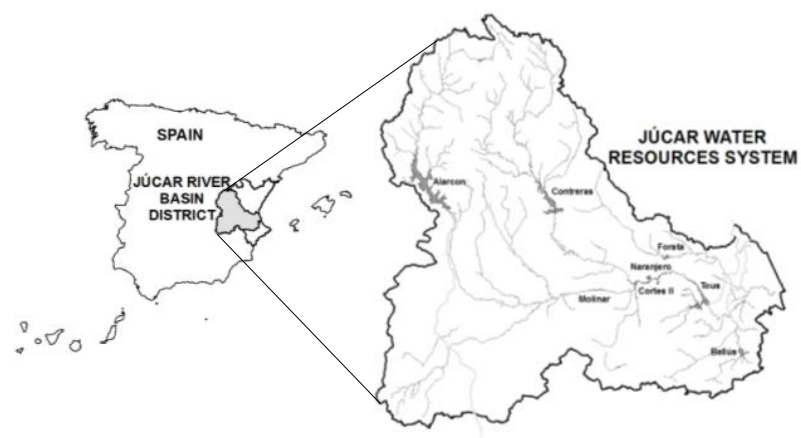

Figure 1. Location of the study area.

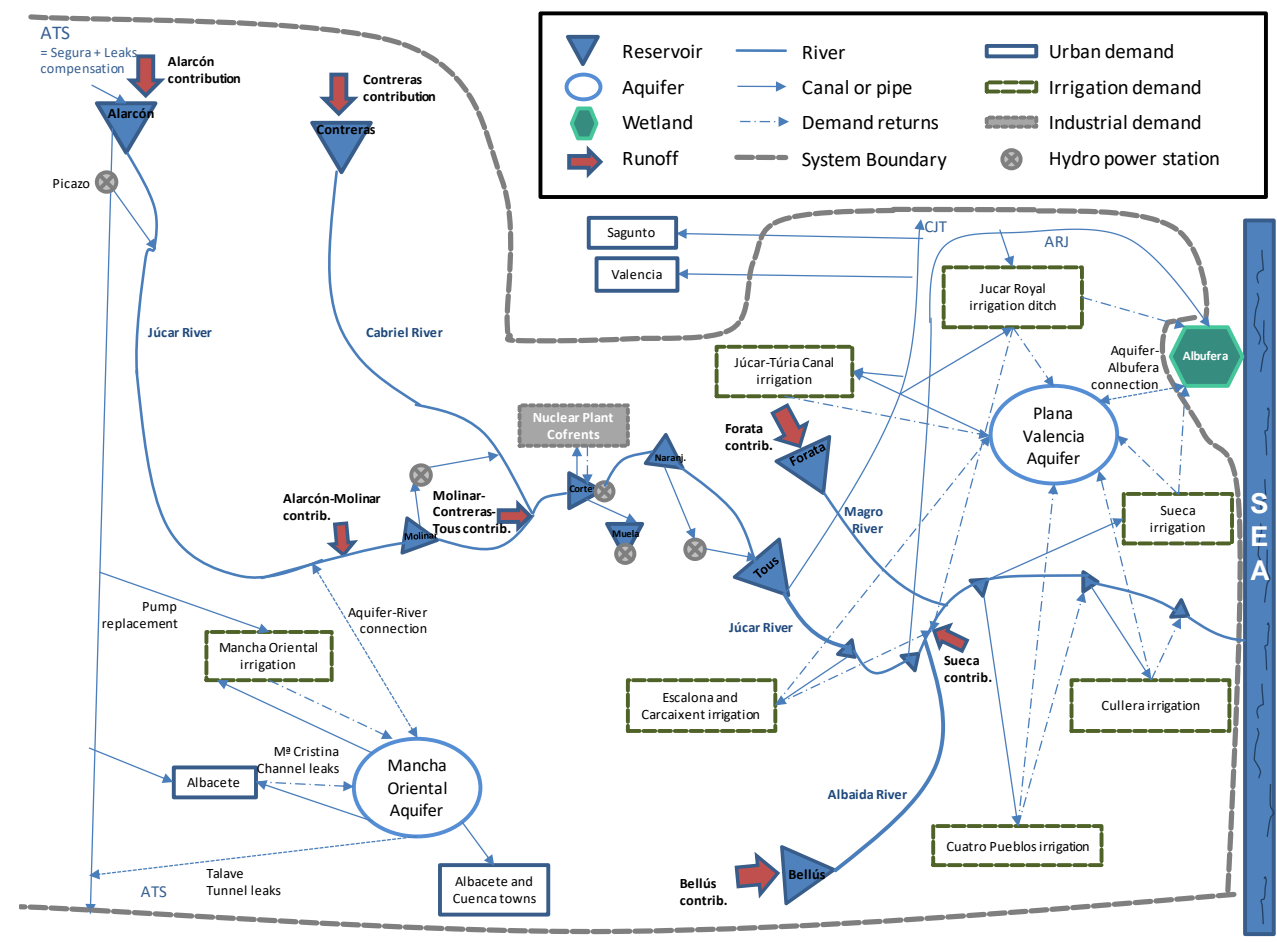

Figure 2. Diagram of the Júcar Water Resource System with the most relevant elements for water management. 


\section{Application to the Júcar Water Resource System}

\section{1 Implementation process}

In the case that the WRE is River Basin Agency and the accounting domain is a water resource system, the first thing to take into account in order to apply any water accounting approach is determining the end users of the reports and defining the boundaries of the water accounting to make them compatible with the users' requirements. In the case of a water resource system, not only do the hydrographical boundaries have to be taken into account, but also the availability and reliability of the data and the interaction of the system with its neighbours. The users of the reports should be the stakeholders of the water management authority: urban, agricultural and industrial demands and water-related civil organisations (e.g. NGOs, cultural associations). Through the water accounting, each of them is informed about the water allocated according to their water rights, the state of the reservoirs and aquifers and the water really received from each water source. Apart from this, they can also observe the same data referred to the other water uses and water services, and understand the global functioning of the water resource system.

Secondly, the concepts to be included in the water accounts should be selected. It is important to keep in mind that the aim of water accounting for water management purposes is to describe the allocation and diversion of water to the different users by means of the existing infrastructures; these are the relevant manageable elements of the system. Consequently, the information about demands should be broken down into real water users' associations, and the water sources serving them should also be shown separately. The rest of the concepts included (water resources entering or leaving of the system, river-aquifer relationships, etc.) have to ensure that the global water balance is maintained. Furthermore, the water accounts have to be adapted to the special features of the water management in the region. It is important to highlight that there are no universally standard water accounting approaches, as there are always different management practices and concepts that need to be reflected on the water accounts. For instance, the greatest difference between Australian and Spanish water management is that, in Australia, the fraction of the volume allocated to the demands which is not supplied during the period is considered a carryover, 
Assessment of Ecosystem Services and Water Accounting Methodologies for Integrated Water Resources Management in water scarce basins

and it is extended to the next period to be used by the same demand (Water allocation remaining in Table 2). By contrast, in Spain, non-supplied water is considered a saving and contributes to the assets for the next period without being linked to any specific demand. Therefore, the accounting concept referred to water allocation remaining in Al should not be shown in the Spanish versions of the water accounts.

Finally, the different terms of the water accounts have to be quantified. The ideal situation would be having extremely accurate records for each of the accounted terms, enabling genuinely detailed accounting. But, this is not possible in practice. In a real water resource system, the majority of values are not directly known and they have to be indirectly estimated, or obtained from models. For instance, the water stored in aquifers, the groundwater transfers, or the flows between rivers and aquifers are commonly modelled. Other concepts like pumped water are calculated as the pumped flow multiplied by the pumping time, which is derived from electricity bills; and the evaporation and leakages in reservoirs are obtained from balance equations. Whether directly or indirectly calculated, all this information is generated and validated, and stored in different reports and databases by the Júcar River Basin District Agency. Table 3 presents the different data used to fill out the original water accounting and the new proposed version. Note that, depending on the accounting concept, it is presented as a punctual value or an accumulated value throughout the period; hence it requires a different estimation strategy. These examples demonstrate the wide quantity of data sources that need to be used in order to complete all the accounting concepts. Obviously, the variety of data sources could go against the final quality of the water accounting, so that special care has to be taken to ensure that all the information is consistent.

Table 3. Data sources and estimation strategies employed to fill out the water accounts for the Júcar System.

\begin{tabular}{|l|l|c|}
\hline Data source & Water accounting concept & $\begin{array}{c}\text { Estimation } \\
\text { strategy }\end{array}$ \\
\hline \multirow{3}{*}{ Direct measurement } & - Demands supply from surface water bodies. & $\mathrm{A}$ \\
\cline { 2 - 3 } & - Surface outflows to the sea: gauged flows. & $\mathrm{A}$ \\
\cline { 2 - 3 } & - Surface outflows through canals and ditches. & $\mathrm{A}$ \\
\hline Mixed estimation: & - Demands supply from groundwater bodies: & $\mathrm{A}$ \\
\hline
\end{tabular}




\begin{tabular}{|c|c|c|}
\hline Data source & Water accounting concept & $\begin{array}{l}\text { Estimation } \\
\text { strategy }\end{array}$ \\
\hline \multirow[t]{4}{*}{ direct + indirect } & pumped flow + pumping time (electricity bills). & \\
\hline & $\begin{array}{l}\text { - Water stored in reservoirs: water level + } \\
\text { bathymetric curves. }\end{array}$ & B \\
\hline & $\begin{array}{l}\text { - Precipitation on the landscape, reservoirs, etc.: } \\
\text { interpolation of rainfall measurements. }\end{array}$ & A \\
\hline & $\begin{array}{l}\text { - Surface runoff entering the water resources system: } \\
\text { gauged flows + natural regime restitution. }\end{array}$ & A \\
\hline \multirow{3}{*}{ Indirect estimation } & $\begin{array}{l}\text { - Return flows from water demands: theoretical } \\
\text { return coefficients from water management models. }\end{array}$ & A \\
\hline & $\begin{array}{l}\text { - Water storage in rivers and canals: Average flow + } \\
\text { simplified geometry. }\end{array}$ & B \\
\hline & $\begin{array}{l}\text { - Leakages from canals to aquifers: theoretical } \\
\text { coefficients from water management models. }\end{array}$ & A \\
\hline \multirow{6}{*}{$\begin{array}{l}\text { From hydrological } \\
\text { models }\end{array}$} & - Water stored in the landscape. & B \\
\hline & - Water stored in aquifers. & $\mathrm{B}$ \\
\hline & - Percolation from the landscape to aquifers. & A \\
\hline & - Water exchange between rivers and aquifers. & A \\
\hline & - Water transfers between aquifers. & A \\
\hline & $\begin{array}{l}\text { - Evaporation and evapotranspiration from the } \\
\text { landscape, reservoirs, etc. }\end{array}$ & A \\
\hline
\end{tabular}

A: Periodically along the studied period. The value is accumulated.

B: At the beginning and at the end of the studied period. The value is punctual.

\subsection{Results and discussion}

At this point, we present the comparison between both versions of the water accounts through their application to the Júcar System. The assessment is based on the accuracy of the water balance, reflected on the unaccounted-for difference terms. Additionally, other criteria are considered, such as the relevance of the presented information for water resource management control purposes and the clarity of its presentation.

First, we apply the AWAS to the whole Júcar System as a territory. Therefore, the water accounts include all the elements proposed by the standard (Table 1), as can be seen in the Statement of Water Assets and Water Liabilities, A1, in Figure 3. The other two accounts, A2 and A3, contain the information about water demands, flows and commitments occurring in the Júcar System, which are related to the water assets in the first account; these 
accounts are included in Appendix A1. Table 4 shows the unaccounted-for difference and its percentage over the total water supplied and over the total water resources of the entity for the Júcar System, together with some examples of the Australian National Account 2010 (BoM, 2013). We consider that the most representative percentage is that calculated with respect to the supplied water (the water diverted to demands), as the entity is responsible for its efficient management and supervision. As can be seen in Table 4, the unaccounted-for difference figures obtained in the Australian National Account 2010 and in our application to the Júcar System are too high to be accepted in official documents. Thus, it seems that these exhaustive water accounts do not produce satisfactory results, at least for the purpose of achieving transparency in the water resource management.

TOTAL SURFACE WATER ASSETS

\section{Landscape Water Storage}

Soil moisture - unsaturated zone

Surface water storage - unregulated

Unregulated river channel storage

Unregulated major storages (>1 $\left.\mathrm{Mm}^{3}\right)$

Surface water storage - regulated

Regulated river channel storage

Regulated major storages (>1 $\left.\mathrm{Mm}^{3}\right)$

Regulated minor storages $\left(<1 \mathrm{Mm}^{3}\right)$

Water transport system storage

Distribution network carrier storage

Within transport system storage

Other surface water assets

Groundwater assets

TOTAL GROUNDWATER ASSETS

\section{Groundwater storages \\ Unconfined aquifer}

TOTAL WATER STORAGE (1)

14552.39

Other water assets

TOTAL OTHER WATER ASSETS

TOTAL WATER ASSETS (2) 
LIABILITIES

Allocation remaining

Other water liabilities

TOTAL LIABILITIES (3)

Net water assets

Opening net water assets (5)

Changes in net water resources $(6)=(4)-(5)$

Closing net water assets $(4)=(2)-(3)$

140.87

14552.39

\section{Net water storage}

Opening water storage (7)

Changes in net water storage (8) $=(1)-(7)$

Closing water storage $=(1)$

Figure 3. Statement of Water Assets and Water Liabilities for the Júcar System. Hydrological year $2007 / 08$.

Table 4. Unaccounted-for difference terms for the Australian National Water Account 2010 and the application to the Júcar System 2007/08.

\begin{tabular}{|l|r|rr|rr|}
\cline { 2 - 6 } \multicolumn{1}{c|}{ Mm $^{3}$} & $\begin{array}{r}\text { Unaccounted } \\
\text {-for difference 2 }\end{array}$ & $\begin{array}{r}\text { Diversion to } \\
\text { demands }\end{array}$ & \% Error & $\begin{array}{r}\text { Total water } \\
\text { assets }\end{array}$ & $\begin{array}{r}\text { \% } \\
\text { Error }\end{array}$ \\
\hline Júcar System & 325.78 & $1,903.74$ & $\mathbf{1 7 . 1 1}$ & $14,552.39$ & $\mathbf{2 . 2 4}$ \\
\hline Murray-Darling & $1,085,123.00$ & $4,832,677.00$ & $\mathbf{2 2 . 4 5}$ & $10,889,737.00$ & $\mathbf{9 . 9 6}$ \\
Ord & $4,352,385.00$ & $168,987.00$ & $\mathbf{2 , 5 7 5 . 5 7}$ & $8,780,762.00$ & $\mathbf{4 9 . 5 7}$ \\
Perth & $125,812.00$ & $645,123.00$ & $\mathbf{1 9 . 5 0}$ & $261,576.00$ & $\mathbf{4 8 . 1 0}$ \\
\hline
\end{tabular}

In an attempt to improve the above results, we build the water accounts according to the new approach proposed in section 2.2. Now, we implement the water accounts in a simplified domain that contains only the relevant manageable elements of the system (see Figure 2), instead of the whole territory. The first water accounting statement (Figure 4) presents the major reservoirs and aquifers, the most relevant demand units (in priority and magnitude) depending on them, and the flows through the boundaries of the entity. The other accounts of this improved version are presented in Appendix A2. In the new version, the unaccounted-for difference term is significantly smaller than in the previous application. The percentage of error referring to the water supplied to demands is $3.29 \%$ instead of $17.11 \%$. However, this new value can be misleading. If we obtain the error for the surface and ground water resources separately, we observe that one figure is positive and the other is negative (see Table 5 and Table 6). Thus, it is necessary to analyse the surface and groundwater errors independently for 
Assessment of Ecosystem Services and Water Accounting Methodologies for Integrated Water Resources Management in water scarce basins

an adequate analysis. If we aggregate both unaccounted-for difference terms in absolute values, the resulting total error is still lower than the value obtained in the original version of the accounts; $12.12 \%$ versus $17.11 \%$.

\section{STATEMENT OF WATER ASSETS AND WATER LIABILITIES}

WATER ASSETS

Surface water assets

TOTAL SURFACE WATER ASSETS

Groundwater assets

TOTAL GROUNDWATER ASSETS

TOTAL WATER STORAGE (1)

Other water assets

TOTAL OTHER WATER ASSETS

TOTAL WATER ASSETS (2)

LIABILITIES

Allocation remaining

Other water liabilities

TOTAL LIABILITIES (3)

Net water assets

Opening net water assets (5)

Changes in net water resources $(6)=(4)-(5)$

Closing net water assets (4) $=(2)-(3)$

\section{Groundwater storages \\ Unconfined aquifer}

5271.13

5271.13

5565.04

Water rights

0.00

$\mathbf{0 . 0 0}$

5564.04

0.00

5509.52

54.53

5564.04

Opening water storage (7)

Changes in net water storage (8) $=(1)-(7)$

Closing water storage $=(1)$
5509.52

54.53

5564.04

Figure 4. New proposed Statement of Water Assets and Water Liabilities for the Júcar System. Hydrological year 2007/08. 
Table 5. Unaccounted-for difference term in the Statement of Physical Flows, for the Júcar System surface water resources.

Initial surface water resources

Surface water resources increase

Surface water resources decrease

Theoretical final surface water resources

Table 6. Unaccounted-for difference term in the Statement of Physical Flows, for the Júcar System groundwater resources.

\begin{tabular}{lr|}
\hline Initial groundwater resources & $5,333.36$ \\
Groundwater resources increase & 495.34 \\
Groundwater resources decrease & 690.90 \\
& \\
Theoretical final groundwater resources & $5,137.80$ \\
Final groundwater resources & $5,270.13$ \\
\hline Unaccounted-for difference for groundwater resources $\left(\mathrm{Mm}^{3}\right)$ & 132.34 \\
Unaccounted-for difference for groundwater resources & $\mathbf{2 6 . 8 8 \%}$ \\
(\% with respect to the surface water supply) &
\end{tabular}

The analysis of the presented results demonstrates that the adjustment of the accounting domain and the elimination of the non-manageable elements enable the use of data with comparable orders of magnitude and accuracy, to provide more faithful results. It is true that the difference between the unaccounted-for difference terms of the two approaches is not very significant $(17.11 \%-12.12 \%=4.99 \%)$. Nevertheless, the improvement in the values related to surface water is more relevant. It decreases from $14.19 \%$ in the original version to $6.19 \%$ in the proposed version of the water accounts. This means that the main part of the error is due to the groundwater estimations, with error values of around $25 \%$ in both versions of the accounts. This fact is reasonably logical given the well-known difficulties in measuring and controlling groundwater stocks and flows.

It should also be discussed whether the terms removed from the original version of water accounts are important enough to cause under- or overestimation in the water balance. Actually, none of the terms omitted from the accounts has an impact on the validity of the final water balance. 
Assessment of Ecosystem Services and Water Accounting Methodologies for Integrated Water Resources Management in water scarce basins

In the case of those concepts with very low values, the effect is absorbed by the errors in other concepts. In fact, the water balances cannot be more precise than the available records and observations in the basin (Andreu et al., 2012). For the removed concepts that have higher magnitudes, the situation is different. In this case, it is crucial to ensure that they are represented by other elements in the accounts, keeping the global water balance. This is the case of precipitation and evapotranspiration from the landscape, whose effect on the water balance of the landscape is considered in the water accounts by means of the total runoff (surface and groundwater). As a result, we consider that the modification of the Australian water accounts produces acceptable unaccounted-for difference results, which ensure the reliability of the water accounting reports. Moreover, the reduction in the volume of information provided enhances its understanding, and highlights key data for better control and evaluation of the WRE by its users.

Regardless of the kind of information managed in the water accounts, they represent balances that show the state of water resources and water flows during a period; this is the water cycle. This means that they provide a static image of what happened in the region studied. Nevertheless, compared with other tools (such as water resource management models), water accounts do not supply adequate information with the required temporal and spatial resolution to optimise water allocation or perform scenario analyses. On the other hand, the positive aspect of implementing any water accounting methodology in a river basin or water resource system is that it forces the water managers to focus on the most significant management elements. This exercise is positive because it can contribute to a better knowledge of the physical reality of the water entity, to detect scarce or bad data measurements, and to rethink the managed elements. Finally, it should be highlighted that water accounting, periodically applied, reveals the evolution and trends of water assets and demands. This can help small water entities, such as municipalities or irrigation associations, to come up with better ways of managing their water resources by learning from the data. 


\section{Conclusions}

A deep knowledge of existent water accounting methodologies brings us closer to achieving the objectives established by A Blveprint to Safeguard Europe's Water Resources, in order to gather and report water information in Europe. In general, even though water accounting has its pros and cons, it can help to improve transparency in water management towards water users and other stakeholders. This facilitates high-quality public participation, as the stakeholders are aware of the global problems of the water resource system and the existing tradeoffs among the different water uses. Furthermore, the information provided is of use to make a broad evaluation of the water management performed during a given period, and to support coordination between water entities in cases like inter-basin transfers, or coriparian countries.

Some problems arising from the utilisation of water accounting in real water resource management have been identified. Firstly, given the complexity of the water cycle, a simplification of reality is always necessary in the water accounts. Some criteria have been stated to guide the selection of the accounting concepts. Secondly, there are always differences in water management in each country or river basin, which require the adaptation of the water accounting concepts. Finally, it has been proved that the accounting domain, the integration scale and the detail of the accounted concepts have a relevant influence on the final result.

To conclude, we recommend the utilisation of the Australian Water Accounting Standard for water management purposes, with the modified water accounts and scope proposed in section 2.2. Contrary to the original, complete version, which is more useful for a hydrological analysis of water resource systems, the new approach of the accounting methodology contains only the essential information on the water resources, flows and commitments of a water entity, in an easily comprehensible way. All this contributes to clarifying the presented data and facilitates its subsequent use for water management evaluation. The Australian water accounting also includes information on the origin of the data, the methodology, the accuracy, and the final errors. Hence, it is important to consider the potential of water accounting as a support for integrated water resource 
Assessment of Ecosystem Services and Water Accounting Methodologies for Integrated Water Resources Management in water scarce basins

management, for the purpose of achieving transparency and control over water resource management.

\section{Acknowledgments}

Authors would like to thank Universitat Politècnica de València for its Support Programme for Research and Development, and the Spanish Ministry of Economy and Competitiveness for its financial support through the projects SCARCE (Consolider-Ingenio 2010 CSD2009-00065) and NUTEGES (CGL201234978). We also value the support provided by the European Community's Seventh Framework Program in financing the projects SIRIUS (FP7-SPACE2010-1, 262902), DROUGHT-R\&SPI (FP7-ENV-2011, 282769) and ENHANCE (FP7ENV-2012, 308438). We would also like to express our gratitude to the Júcar River Basin District Agency (Spanish Ministry of Environment) for the data provided to develop this study. Finally, thanks to the Commonwealth Scientific and Industrial Research Organisation in Adelaide, Australia, for hosting one of the authors for a research stay. This paper reflects only the authors' viewpoints and the mentioned institutions are not liable for any use that may be made of the information herein contained.

\section{Appendix}

A1. Original Statements of Changes in Water Assets and Water Liabilities and Physical Water Flows.

STATEMENT OF CHANGES IN WATER ASSETS AND WATER LIABILITIES

$2007 / 2008$

WATER RESOURCES INCREASES

$\left(\mathrm{Mm}^{3}\right)$

In surface water

\begin{tabular}{|c|c|}
\hline \multicolumn{2}{|l|}{ Precipitation } \\
\hline Into landscape & \\
\hline \multicolumn{2}{|l|}{ Into surface water - unregulated } \\
\hline River channel & 0.32 \\
\hline Major storages & 3.79 \\
\hline \multicolumn{2}{|l|}{ Into surface water - regulated } \\
\hline River channel & 3.36 \\
\hline Major storages & 56.78 \\
\hline Minor storages & 0.70 \\
\hline \multicolumn{2}{|l|}{ Into other } \\
\hline Transport system & 1.23 \\
\hline $\begin{array}{l}\text { Transfer of inter-region claim on water of another entity } \\
\text { River inflow to region }\end{array}$ & 242.97 \\
\hline To unregulated water storage & 786.74 \\
\hline $\begin{array}{l}\text { To regulated water } \\
\text { storage }\end{array}$ & 363.28 \\
\hline $\begin{array}{l}\text { Surface water returns from irrigation demands } \\
\text { Groundwater discharges to surface water }\end{array}$ & 124.12 \\
\hline
\end{tabular}


To soil moisture - unsaturated zone $\quad 0.00$

To surface water storage - unregulated $\quad 0.00$

To surface water storage - regulated $\quad 77.25$

To transport system 6.50

Groundwater extraction for surface water storage
Surface returns from urban demands

Surface returns from industrial demands $\quad 539.19$

Desalinated water

Increase of inter-region claim on water of another entity

In groundwater

Recharge from surface water

From landscape

Precipitation $\quad 471.73$

Irrigation demands returns $\quad 252.16$

From surface water storage - unregulated 12.87

From surface water storage - regulated $\quad 0.00$

From transport system $\quad 13.15$

Entries of external groundwater $\quad 0.00$

$\begin{array}{ll}\text { Artificial recharge } & 0.00\end{array}$

WATER LIABILITIES DECREASES

In surface water

Allocations adjustment

Urban allocations $\quad 9.71$

Irrigation allocations $\quad 187.61$

Industrial allocations $\quad 0.00$

Environmental flows adjustment

Decrease of inter-region claim on water of the entity

In groundwater

Allocations adjustment

Urban allocations

Irrigation allocations

TOTAL INCREASE IN WATER RESOURCES (1)

WATER RESOURCES DECREASES

In surface water

Evapotranspiration

From landscape

6373.36

From surface water storage - unregulated $\quad 7.00$

From surface water storage - regulated $\quad 33.65$

From transport system 2.59

Groundwater recharges from surface water

From landscape

471.73

From surface water storage - unregulated $\quad 12.87$

From surface water storage - regulated $\quad 0.00$

From transport system

13.15

Environmental flows allocation

Artificial recharge

Outflows from region 
Assessment of Ecosystem Services and Water Accounting Methodologies for Integrated Water Resources Management in water scarce basins

$\begin{array}{lc}\text { Transfer of inter-region claim on water of the entity } & 245.29 \\ \text { Treated waste water } & 30.57 \\ \text { To the sea } & 253.47 \\ \text { To wetlands } & 37.67 \\ \text { To external surface bodies } & 24.54\end{array}$

In groundwater

Groundwater discharges to surface water

To soil moisture - unsaturated zone

To surface water storage - unregulated $\quad 0.00$

To surface water storage - regulated $\quad 77.25$

To transport system 6.50

Groundwater extraction for surface water storage

Evapotranspiration from aquifers

Outflows from region

To wetlands

83.82

To the sea $\quad 26.34$

To other aquifers $\quad 43.44$

In surface water

WATER LIABILITIES INCREASES
Allocation to demands
Urban allocations
124.01
Irrigation allocations
736.86
Industrial allocations
24.00
Allocations increase
Urban allocations
0.00
Irrigation allocations
0.00
Industrial allocations
537.75
Environmental flows adjustment
Decrease of inter-region claim on water of the entity
Allocation to demands
Urban allocations
69.04
Irrigation allocations
648.07
Allocations adjustment
Urban allocations
0.00
Irrigation allocations

In groundwater

TOTAL DECREASE IN WATER RESOURCES (2)

9882.99

Changes in net water resources (3) $=(1)-(2)$

Unaccounted - for difference $1=(6)$ in Figure 3 - (3)

325.78

Figure A1. Statement of Changes in Water Assets and Water Liabilities for the Júcar System.

Hydrological year 2007/08. 
WATER INFLOWS

To surface water

\author{
Precipitation \\ Into landscape \\ Into surface water - unregulated
}

Into surface water - regulated

Into other
6448.83

0.32

3.79

3.36

56.78

0.70

1.23

242.97

786.74

363.28

124.12

0.00

0.00

77.25

6.50

57.10

539.19

To groundwater

\section{Recharge from surface water \\ From landscape}

Precipitation

Irrigation demands returns

From surface water storage - unregulated

From surface water storage - regulated

From transport system

Entries of external groundwater

Artificial recharge
471.73

252.16

12.87

0.00

13.15

0.00

0.00

9462.08

TOTAL INFLOWS (1)

WATER OUTFLOWS

From surface water
Evapotranspiration
From landscape
From surface water storage - unregulated
From surface water storage - regulated
Groundwater recharges from surface water
From landscape

6373.36

7.00

33.65

2.59

471.73 
Assessment of Ecosystem Services and Water Accounting Methodologies for Integrated Water Resources Management in water scarce basins

$\begin{array}{lc}\text { From surface water storage - unregulated } & 12.87 \\ \text { From surface water storage - regulated } & 0.00 \\ \text { From transport system } & 13.15 \\ \text { Supply to demands } & \\ \text { Urban allocations } & 114.30 \\ \text { Irrigation allocations } & 549.25 \\ \text { Industrial allocations } & 561.75 \\ \text { Environmental flows allocation } & \\ \text { Artificial recharge } & \\ \text { Outflows from region } & 245.29 \\ \text { Transfer of inter-region claim on water of the entity } & 30.57 \\ \text { Treated waste water } & 253.47 \\ \text { To the sea } & 37.67 \\ \text { To wetlands } & 24.54 \\ \text { To external surface bodies } & \end{array}$

From groundwater

Groundwater discharges to surface water

To soil moisture - unsaturated zone

To surface water storage - unregulated $\quad 0.00$

To surface water storage - regulated $\quad 77.25$

To transport system $\quad 6.50$

Groundwater extraction for surface water storage

Evapotranspiration from aquifers

Supply to demands

Urban allocations $\quad 68.80$

Irrigation allocations $\quad 609.65$

Outflows from region

To wetlands $\quad 83.82$

To the sea $\quad 26.34$

To other aquifers $\quad 43.44$

TOTAL OUTFLOWS (2)

9646.99

Changes in net water storage (3) = (1) - (2) $\quad-184.91$

Unaccounted - for difference 2 = (8) in Figure 3 - (3) 325.78

Figure A2. Statement of Physical Water Flows for the Júcar System. Hydrological year $2007 / 08$.

STATEMENT OF CHANGES IN WATER ASSETS AND WATER LIABILITIES 2007/2008

$\left(\mathrm{Mm}^{3}\right)$

WATER ASSETS INCREASES

In surface water

$\begin{array}{llc}\begin{array}{l}\text { Precipitation } \\ \text { Into surface water - unregulated }\end{array} & \\ & \text { Major storages } & 3.79 \\ \text { Into surface water - regulated } & \text { Major storages } & 56.78 \\ & 242.97 \\ \begin{array}{l}\text { Transfer of inter-region claim on water of another entity } \\ \text { River inflow to region }\end{array} & 624.05 \\ \quad \text { To unregulated water storage } & \end{array}$ 
To regulated water storage

Surface water returns from irrigation demands

Groundwater discharges to surface water

To surface water storage - unregulated

To surface water storage - regulated

To transport system

Groundwater extraction for surface water storage

Surface returns from urban demands

Surface returns from industrial demands

Desalinated water

Increase of inter-region claim on water of another entity

In groundwater
363.28

124.12

0.00

49.20

6.50

37.85

539.19

204.02

155.28

12.87

0.00

90.47

0.00

WATER LIABILITIES DECREASES

In surface water

Allocations adjustment

Urban allocations

Irrigation allocations

Industrial allocations

Environmental flows adjustment

Decrease of inter-region claim on water of the entity

In groundwater

\author{
Allocations adjustment \\ Urban allocations \\ Irrigation allocations
}

TOTAL INCREASE IN WATER RESOURCES (1)

WATER ASSETS DECREASES

In surface water

$\begin{array}{lc}\text { Evapotranspiration } & \\ \quad \text { From surface water storage - unregulated } & 6.29 \\ \text { From surface water storage - regulated } & 26.06 \\ \text { Groundwater recharges from surface water } & \\ \quad \text { From surface water storage - unregulated } & 12.87 \\ \quad \text { From surface water storage - regulated } & 0.00 \\ \text { Environmental flows allocation } & \\ \text { Artificial recharge } & \\ \text { Outflows from region } & \\ \quad \text { Transfer of inter-region claim on water of the entity } & 245.29 \\ \text { Treated waste water } & 22.60 \\ \text { To the sea } & 253.47\end{array}$


Assessment of Ecosystem Services and Water Accounting Methodologies for Integrated Water Resources Management in water scarce basins

$\begin{array}{ll}\text { To wetlands } & 37.67 \\ \text { To external surface bodies } & 24.54\end{array}$

In groundwater

Groundwater discharges to surface water

To surface water storage - regulated $\quad 49.20$

To transport system $\quad 6.50$

Groundwater extraction for surface water storage

Evapotranspiration from aquifers

Outflows from region

To wetlands $\quad 83.82$

To the sea $\quad 26.34$

To other aquifers $\quad 0.00$

WATER LIABILITIES INCREASES

In surface water

$\begin{array}{lc}\text { Allocation to demands } & \\ \text { Urban allocations } & 124.01 \\ \text { Irrigation allocations } & 736.86 \\ \text { Industrial allocations } & 24.00 \\ \text { Allocations increase } & \\ \text { Urban allocations } & 0.00 \\ \text { Irrigation allocations } & 0.00 \\ \text { Industrial allocations } & 537.75\end{array}$

Environmental flows ajdustment

Decrease of inter-region claim on water of the entity

In groundwater
Allocation to demands
Urban allocations
42.69
Irrigation allocations
482.35
Allocations adjustment
Urban allocations
0.00
Irrigation allocations

TOTAL DECREASE IN WATER RESOURCES (2)

Changes in net water resources (3) = (1) - (2)

Unaccounted - for difference $1=(6)$ in Figure 4 - (3)

56.45

Figure A3. New proposed Statement of Changes in Water Assets and Water Liabilities for the Júcar System. Hydrological year 2007/08. 
A2. Improved Statement of Changes in Water Assets and Water Liabilities and Demands outline table.

Table A1. New proposed outline of water allocation, supply, return flow and supply deficit or surplus for each water demand.

\begin{tabular}{|l|c|c|c|c|c|c|}
\hline Demand & $\begin{array}{c}\text { Allocati } \\
\text { on } \\
\left(\mathbf{M m}^{3}\right)\end{array}$ & $\begin{array}{c}\text { Supply } \\
\left(\mathbf{M m}^{3}\right)\end{array}$ & $\begin{array}{c}\text { Supply } \\
\text { deficit } \\
\left(\mathbf{M m}^{3}\right)\end{array}$ & $\begin{array}{c}\text { Supply } \\
\text { surplus } \\
\left(\mathbf{M m}^{3}\right)\end{array}$ & $\begin{array}{c}\text { Return } \\
\text { flows } \\
\left(\mathbf{M m}^{3}\right)\end{array}$ & $\begin{array}{c}\text { Consum } \\
\text { ption } \\
\left(\mathbf{M m}^{3}\right)\end{array}$ \\
\hline Albacete & 15.00 & 15.70 & 0.00 & 0.70 & 7.85 & 7.85 \\
\hline Valencia & 94.61 & 84.10 & 10.51 & 0.00 & 0.00 & 84.10 \\
\hline Sagunto & 7.00 & 7.00 & 0.00 & 0.00 & 0.00 & 7.00 \\
\hline La Ribera towns & 20.58 & 20.58 & 0.00 & 0.00 & 14.40 & 6.18 \\
\hline Albacete and Cuenca towns & 29.51 & 29.61 & 0.00 & 0.10 & 15.60 & 14.01 \\
\hline Total urban demands & $\mathbf{1 6 6 . 7 0}$ & $\mathbf{1 5 6 . 9 9}$ & $\mathbf{1 0 . 5 1}$ & $\mathbf{0 . 8 0}$ & $\mathbf{3 7 . 8 5}$ & $\mathbf{1 1 9 . 1 4}$ \\
\hline Mancha Oriental & 384.95 & 381.00 & 3.95 & 0.00 & 57.15 & 323.85 \\
\hline Júcar-Turia Canal & 89.74 & 26.07 & 63.67 & 0.00 & 0.60 & 25.47 \\
\hline Escalona and Carcaixent & 37.50 & 20.08 & 17.42 & 0.00 & 4.29 & 15.79 \\
\hline Júcar Royal Ditch & 213.12 & 128.69 & 84.43 & 0.00 & 28.51 & 100.18 \\
\hline Cuatro Pueblos & 21.94 & 12.67 & 9.27 & 0.00 & 3.39 & 9.28 \\
\hline Sueca & 146.17 & 153.23 & 0.00 & 7.06 & 38.31 & 114.92 \\
\hline Cullera & 85.40 & 86.02 & 0.00 & 0.62 & 29.51 & 56.51 \\
\hline Other irrigation demands & 240.39 & 191.14 & 49.25 & 0.00 & 117.64 & 73.50 \\
\hline Total irrigation demands & $\mathbf{1 , 2 1 9 . 2 1}$ & $\mathbf{9 9 8 . 9 0}$ & $\mathbf{2 2 7 . 9 9}$ & $\mathbf{7 . 6 8}$ & $\mathbf{2 7 9 . 4 0}$ & $\mathbf{7 1 9 . 5 0}$ \\
\hline Nuclear Plant Cofrents & 24.00 & 32.24 & 0.00 & 8.24 & 13.79 & 18.45 \\
\hline Hydro power station Cofrents & 0.00 & 44.77 & 0.00 & 44.77 & 44.74 & 0.03 \\
\hline $\begin{array}{l}\text { Hydro power station Cortes- } \\
\text { La Muela }\end{array}$ & 0.00 & 225.56 & 0.00 & 225.56 & 221.83 & 3.73 \\
\hline Hydro power station Millars & 0.00 & 259.18 & 0.00 & 259.18 & 258.83 & 0.35 \\
\hline Total industrial demands & $\mathbf{2 4 . 0 0}$ & $\mathbf{5 6 1 . 7 5}$ & $\mathbf{0 . 0 0}$ & $\mathbf{5 3 7 . 7 5}$ & $\mathbf{5 3 9 . 1 9}$ & $\mathbf{2 2 . 5 6}$ \\
\hline
\end{tabular}

\section{References}

Allan, A., 2012. Is there a role for water accounting in the avoidance and resolution of international water disputes?, in: Godfrey, J., Chalmers, K. (Eds.), International Water Accounting: Effective Management of a Scarce Resource. Edward Elgar Publishing Inc., New York, pp 236-254.

Andreu, J., Momblanch, A., Paredes, J., Pérez, M.A., Solera, A., 2012. Potential role of standardized water accounting in Spanish basins, in: Godfrey, J., Chalmers, K. (Eds.), International Water Accounting: Effective Management of a Scarce Resource. Edward Elgar Publishing Inc., New York, pp 123-138. 
Assessment of Ecosystem Services and Water Accounting Methodologies for Integrated Water Resources Management in water scarce basins

AASB (Australian Accounting Standard Board), 2004. Framework for the Preparation and Presentation of Financial Statements. Commonwealth of Australia, Melbourne.

AASB and BOM (Australian Accounting Standard Board and Bureau of Meteorology), 2012. Australian Water Accounting Standard 2: Assurance Engagements on General Purpose Water Accounting Reports. Commonwealth of Australia, Melbourne.

Banerjee, O., Bark, R., Connor, J., Crossman, N.D., 2013. An ecosystem services approach to estimating economic losses associated with drought. Ecol. Econ. 91, 19-27.

BoM (Bureau of Meteorology), 2011. International water accounting: Current practice and potential development. Commonwealth of Australia, Melbourne.

BoM (Bureau of Meteorology), 2012. Australian Water Accounting Standard 1: Preparation and Presentation of General Purpose Water Accounting Reports. Commonwealth of Australia, Melbourne.

BoM (Bureau of Meteorology), 2013. National Water Account. http://www.bom.gov.au/water/nwa/.

Chalmers, K. and Godfrey, J., 2012. Conclusion, in: Godfrey, J., Chalmers, K. (Eds.), International Water Accounting: Effective Management of a Scarce Resource. Edward Elgar Publishing Inc., New York, pp 291-308.

EC (European Commission), 2012. A Blueprint to Safeguard Europe's Water Resources. European Commission, 14.11.2012 COM(2012) 673 final, Brussels.

EP (European Parliament), 2000. Directive 2000/60/EC of the European Parliament and of the Council of 23 October 2000 establishing a framework for Community action in the field of water policy. Official Journal L 327, 2212-2000, Brussels.

Gan, H., Wang, Y., LU, Q., Vardon, M., Chanchai, A., 2012. Development and application of the System of Environmental-Economic Accounting for Water in China, in: Godfrey, J., Chalmers, K. (Eds.), International Water Accounting: 
Effective Management of a Scarce Resource. Edward Elgar Publishing Inc., New York, pp 139-161.

Hughes, D.A., Corral, E., Muller, N.W.J., 2012. Potential for the application of General Purpose Water Accounting in South Africa, in: Godfrey, J., Chalmers, K. (Eds.), International Water Accounting: Effective Management of a Scarce Resource. Edward Elgar Publishing Inc., New York, pp 106-122.

Karamouz, M., Szidarovszky, F., Zahraie, B., 2003. Water resources systems analysis. Lewis Publishers, Boca Raton.

Karimi, P., Molden, D., Bastiaanssen, W., Xueliang, C., 2012. Water accounting to Assess Use and Productivity of Water-Evolution of a Concept and New frontiers, in: Godfrey, J., Chalmers, K. (Eds.), International Water Accounting: Effective Management of a Scarce Resource. Edward Elgar Publishing Inc., New York, pp 76-90.

Karimi, P., Bastiaanssen, W.G.M., Molden, D., and Cheema, M.J.M., 2013 (a). Basin-wide water accounting based on remote sensing data: an application for the Indus Basin. Hydrol. Earth Syst. Sc. 17, 2473-2486.

Karimi, P., Bastiaanssen, W.G.M., and Molden, D., 2013 (b). Water Accounting Plus (WA+) - a water accounting procedure for complex river basins based on satellite measurements. Hydrol. Earth Syst. Sc. 17, 2459-2472.

Karimi, P. and Bastiaanssen, W.G.M., 2014. Spatial evapotranspiration, rainfall and land use data in water accounting - Part 1: Review of the accuracy of the remote sensing data. Hydrol. Earth Syst. Sc. Discussion. 11, 1073-1123.

Kirono, D.G.C., Kent, D.M., Hennessy, K.J., Mpelasoka, F., 2011. Characteristics of Australian droughts under enhanced greenhouse conditions: Results from 14 global climate models. J. Arid Environ. 75, 566-575.

Lange, G.M., Mungatana, E., Hassan, R., 2007. Water accounting for the Orange River Basin: An economic perspective on managing a transboundary resource. Ecol. Econ. 61, 660-670.

UNSD (United Nations Statistic Division), 2007. System of EnvironmentalEconomic Accounting for Water. United Nations Statistic Division, New York. 
Assessment of Ecosystem Services and Water Accounting Methodologies for Integrated Water Resources Management in water scarce basins

Vardon, M., Lenzen, M., Peevor, S., Creaser, M., 2007. Water Accounting in Australia. Ecol. Econ. 61, 650-659.

Vardon, M., Martinez-Lagunas, R., Gan, H., Nagy, M., 2012. The System of Environmental-Economic Accounting for Water: Development, Implementation and Use, in: Godfrey, J., Chalmers, K. (Eds.), International Water Accounting: Effective Management of a Scarce Resource. Edward Elgar Publishing Inc., New York, pp 32-57.

Ward, F.A., Pulido-Velázquez, M., 2009. Incentive pricing and cost recovery at the basin scale. J. Environ. Manage. 90, 293-313.

WASB (Water Accounting Standards Board), 2009. Water Accounting Conceptual Framework for the Preparation and Presentation of General Purpose Water Accounting Reports. Commonwealth of Australia, Melbourne.

WASB (Water Accounting Standards Board), 2010. Exposure Draft of Australian Water Accounting Standard 1: Preparation and Presentation of General Purpose Water Accounting Reports. Commonwealth of Australia, Melbourne.

White, I.D., Mottershead, D.N., Harrison, S.J., 1992. Environmental Systems: An Introductory Text, second ed. Chapman \& Hall, New York. 
A.2 Using ecosystem services to represent the environment in hydroeconomic models

\section{Abstract}

Demand for water is expected to grow in line with global human population growth, but opportunities to augment supply are limited in many places due to resource limits and expected impacts of climate change. Hydroeconomic models are often used to evaluate water resources management options, commonly with a goal of understanding how to maximise water use value and reduce conflicts among competing uses. The environment is now an important factor in decision making, which has resulted in its inclusion in hydro-economic models. We reviewed 95 studies applying hydro-economic models, and documented how the environment is represented in them and the methods they use to value environmental costs and benefits. We also sought out key gaps and inconsistencies in the treatment of the environment in hydro-economic models. We found that representation of environmental values of water is patchy in most applications, and there should be systematic consideration of the scope of environmental values to include and how they should be valued. We argue that the ecosystem services framework offers a systematic approach to identify the full range of environmental costs and benefits. The main challenges to more holistic representation of the environment in hydro-economic models are the current limits to understanding of ecological functions which relate physical, ecological and economic values and critical environmental thresholds; and the treatment of uncertainty.

\section{Keywords}

Water resources management; Hydro-economic models; Environmental impacts; Ecosystem Services Framework.

\section{Introduction}

Adequate flows of fresh water in rivers support food and energy production, other economic activities such as river navigation and productive fisheries, as well as clean water provision through processes such as dilution and biological degradation (Momblanch et al., 2015). All these uses compete for water resources with diverse use rights (Babel et al., 2005), and different 
Assessment of Ecosystem Services and Water Accounting Methodologies for Integrated Water Resources Management in water scarce basins

opportunities and costs associated with adapting to less water availability (Booker, 1995).

The 1972 amendment to the US Clean Water Act established national water quality standard to preserve aquatic life, recreational uses, and their values (Copeland, 2010). Since then, there has been an increased focus on understanding the environmental and socio-economic benefits of leaving water in streams, rivers and aquifers rather than extracting it for consumptive use. For example, in the Murray-Darling Basin in Australia, Connor (2008) found that additional flows in the river could significantly reduce costs of salinity damage through dilution, and Crossman et al. (2015) documented substantial carbon sequestration, tourism, and freshwater quality values, among others, from reducing water extraction. Grossmann and Dietrich (2012) assessed carbon sequestration, boating, habitat and biodiversity values of different water management options for the Spreewald Wetland in Germany. These studies used the ecosystem services (ES) concept to report on the benefits. The core ES notion is that a wide range of natural ecosystem processes help sustain and fulfil human life (Daily et al., 1997), and that these services can be translated into economic values. Many ES are only substitutable at high economic costs, and in some cases cannot be replaced (Costanza et al., 1997; Brauman et al., 2007). For example, wetlands have the capacity to purify water by means of biochemical processes (Turner et al., 2008) with capacity being a function of wetland condition and health. The degradation of wetland ecosystems could increase treatment costs of the water extracted for consumptive use (Maltby and Barker, 2009) and/or a reduce the recreation potential (Kahil et al., 2015) leading to loss of income for the tourism industry.

According to the 5th assessment report of the Intergovernmental Panel on Climate Change (2014), renewable fresh water resources are likely to decrease over the 21st century, most significantly in arid and semi-arid regions where increased frequency of drought occurrence is expected (Schwabe et al., 2013). Additionally, water demand is expected to grow with global population growth (UN 2015), resulting in more waste generation, pollution and land use expansion, which increases the pressure on land and water resources (Shama, 2004). Less water availability and lower quality, together with larger water demands, has led to increasing conflicts among 
water uses. Examples include conflicts between hydropower production and fisheries in the Mekong River in China (Ringler et al., 2004); irrigation and urban water uses in the Jucar and Vinalopó rivers in Spain (Andreu et al., 2009); and environmental and irrigation water uses in the Murray Darling Basin in Australia (Qureshi et al., 2007) and the Colorado River Basin in the United States (Booker and Young, 1991).

Integrated water resources management, defined as the coordinated development and management of water, land and related resources to maximise economic and social welfare without compromising the sustainability of vital ecosystems (GWP 2000), can inform decisions about water sharing in the face of competing water demands and increasing scarcity (Booker et al., 2012). Hydro-economic models (HEMs) are one of the main tools used for integrated water resources management (Harou et al., 2009; Booker et al., 2012). HEMs combine hydrological and water infrastructure representation of water resources systems with economic demand functions for key water uses in order to allocate water subject to physical and institutional constraints (Heinz et al., 2007). HEMs typically use a node network structure with nodes representing points of diversion, inflow, outflow, storage or treatment and links between nodes representing river reach processes (Harou et al., 2009). HEMs can use optimisation or simulation approaches, but typically have the goal of allocating water among multiple uses to optimize economic value (Brouwer and Hofkes, 2008). HEMs have been used to solve water management problems for more than 50 years, and have evolved from analysing single-water use problems at water supply scale (Lefkoff and Gorelick, 1990; Wilchfort and Lund, 1997) to integrated multiple-demand and multiple-source problems at single river basin scale (Divakar et al., 2011; Davidson et al., 2013b) and multi-basin scale (Fisher et al., 2002; Bekchanov et al., 2015c). Groundwater representation and its connection to the surface water system have also featured in HEMs (PulidoVelazquez et al., 2006; Pulido-Velazquez et al., 2008b; Daneshmand et al., 2014).

Several studies have reviewed HEMs. For example, Harou et al. (2009) focus on methodological aspects of HEMs, such as model formulation and design, economic valuation methods for the different water uses, and major applications. Heinz et al. (2007) discuss the role of economic approaches in 
Assessment of Ecosystem Services and Water Accounting Methodologies for Integrated Water Resources Management in water scarce basins

water management to address the European Water Framework Directive (EC 2000) objectives, analysing diverse assessment and performance criterion, water policies and management options. Booker et al. (2012) review the advances in economic representation, policy objectives and water institutions, and level of integration and complexity of HEMs.

Consistent across reviews of HEMs is the conclusion that representation of environmental costs and benefits in HEMs is patchy and limited. For example, Harou et al. (2009) conclude that environmental water uses are rarely represented with economic value functions in HEMs, although minimum-flow constraints are included more often. They also highlight the importance of incorporating water quality processes and values which are mostly lacking in HEMs. Booker et al. (2012) argue for the expansion of HEMs to jointly tackle environmental, economic, hydrologic and institutional water resources management problems. Other reviews highlight the limited representation of environmental in-stream uses and processes in HEMs (Ringler and Cai, 2006; Ward and Pulido-Velázquez, 2008; Ward and Pulido-Velazquez, 2009), and the dearth of HEMs which account for water management changes on nonmarket values provided by ecosystems (Griffin and Hsu, 1993; Kragt, 2013).

There has not yet been any attempt at systematic cataloguing and critical assessment of the range of environmental impacts and values included in HEMs. Here we address this gap by: i) reviewing the range of environmental impacts included in HEMs; ii) documenting the methods used to represent the economic value of environmental impacts in HEMs, and; iii) making recommendations to improve the inclusion of environmental impacts and values in HEMs.

We use ES as an organising framework because it offers a systematic way to analyse the potential environmental impacts of changes to water management using the environment-economy connection. This connection is best demonstrated by the ES cascade (Potschin and Haines-Young, 2011) which shows the causal links from a change in biophysical state as a result of altered management, to the ecosystem change and then the change to ES, economic values and human well-being (Figure 1). In recent years there has been a proliferation of ES frameworks (MA 2005; TEEB 2008; UK NEA 2011; Haines-Young and Potschin, 2013). Common to all ES frameworks is the provisioning category, which are directly consumed ES products. An 
example is fish production in rivers that people value as food. All ES frameworks also include the regulating category for ES that arise from maintenance and moderation of environmental conditions. The capacity of wetlands to purify water by means of biochemical processes (Turner et al., 2008 ) is an example. Also common to ES frameworks is a category for nonconsumptive values such as recreational, educational, aesthetic and spiritual. The major difference between ES frameworks is how intermediate ecosystem processes are treated. Some frameworks only include endproducts or services consumed or valued directly by humans (MA 2005; Wallace, 2007), while other frameworks include environmental processes which only indirectly contribute to human welfare, such as decomposition and nutrient cycling (Boyd and Banzhaf, 2007; Costanza, 2008; Fisher and Turner, 2008). We use the Common International Classification of Ecosystem Services (CICES) (Haines-Young and Potschin, 2013) as the reference framework to classify the environmental impacts addressed by our reviewed studies. CICES supports the System of Environmental-Economic Accounting (United Nations Statistics Division, 2012) and includes only final ES (HainesYoung and Potschin, 2013) which leads to clear environment-economy links consistent with the need of HEMs to include economic demand functions.

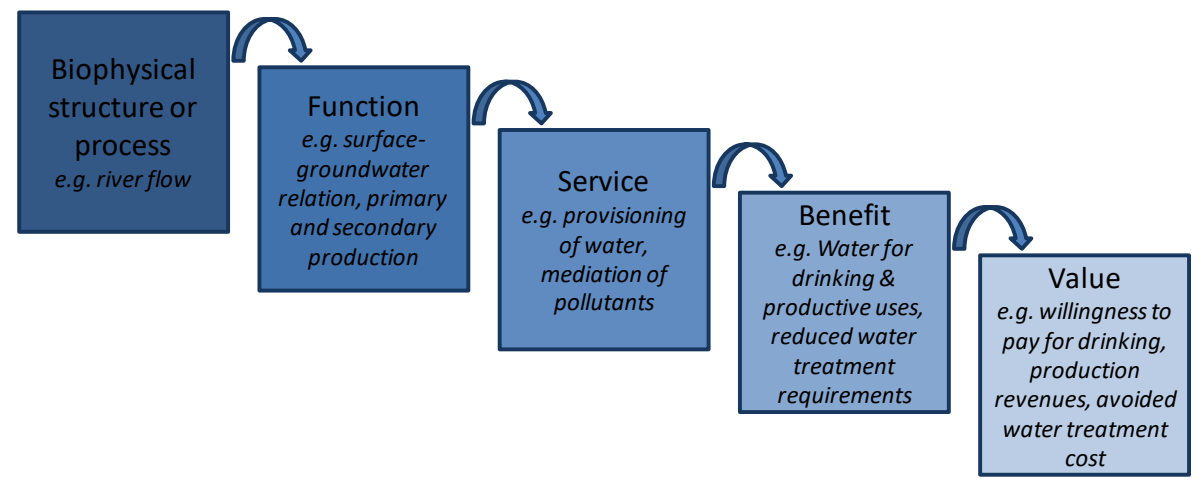

Figure 1. Ecosystem services cascade exemplifying some effects of river flow change due to water management.

\section{Methods}

\subsection{Literature search and selection}

We started with the set of papers reviewed by Heinz et al. (2007), Brouwer and Hofkes (2008) and Harou et al. (2009) ( $n=124)$. These were 
Assessment of Ecosystem Services and Water Accounting Methodologies for Integrated Water Resources Management in water scarce basins

supplemented with papers from 2009 to the present using a SCOPUS search containing the key words 'hydro-economic model', 'water management', 'optimization', and 'network flow' ( $n=877)$. We then refined the scope to case studies dealing with economic analysis of water management, including environmental aspects, at river basin scale ( $n=144)$. For environmental aspects we considered environmental flows, water quality in water bodies, nature related recreation activities, flood control, and broader concepts such as habitat or vegetation. We screened the titles, abstracts and journals to remove irrelevant papers ( $n=135$ ), and then downloaded and read the full papers in order to select the final collection of papers ( $n=$ 95).

We classified all papers by year of publication and identified the water use sector to which each HEM was applied. We also documented the spatial scale of analysis, the major water management problem addressed based on the categories established in Harou et al. (2009), the assessment criteria used according to the proposal by Heinz et al. (2007), and how uncertainty was treated. We assessed whether the environment was considered as a constraint or valued in economic terms. For the papers in the latter group, we extended the review as described in sections 2.2 and 2.3.

\subsection{Classifying representation of the environment}

We used CICES to classify the representation of the environment in the reviewed studies. CICES uses the three main ES categories of provisioning, regulating and maintenance, and cultural services. Each of these broad ES types is successively split into divisions, groups and classes, following a hierarchical structure. The elements within a level of hierarchy are conceptually similar to one another according to the ways they are used by people (Haines-Young and Potschin, 2013). We identified which ES in CICES are potentially provided by freshwater bodies (Table 1). 
Table 1. CICES framework for ecosystem accounting (v4.3) modified with the inclusion of the potential services provided by water bodies.

\begin{tabular}{|c|c|c|c|c|}
\hline Section & Division & Group & Class & $\begin{array}{l}\text { Water } \\
\text { bodie } \\
\mathrm{s}^{*}\end{array}$ \\
\hline \multirow{16}{*}{$\begin{array}{l}\text { Provisionin } \\
g\end{array}$} & \multirow[t]{8}{*}{ Nutrition } & \multirow[t]{6}{*}{ Biomass } & Cultivated crops & \\
\hline & & & Reared animals and their outputs & \\
\hline & & & Wild plants, algae and their outputs & $\sqrt{ }$ \\
\hline & & & Wild animals and their outputs & $\sqrt{ }$ \\
\hline & & & $\begin{array}{l}\text { Plants and algae from in-situ } \\
\text { aquaculture }\end{array}$ & $\sqrt{ }$ \\
\hline & & & Animals from in-situ aquaculture & $\sqrt{ }$ \\
\hline & & \multirow[t]{2}{*}{ Water } & Surface water for drinking & $\sqrt{ }$ \\
\hline & & & Ground water for drinking & $\sqrt{ }$ \\
\hline & \multirow[t]{5}{*}{ Materials } & \multirow[t]{3}{*}{ Biomass } & $\begin{array}{l}\text { Fibres and other materials from plants, } \\
\text { algae and animals for direct use or } \\
\text { processing }\end{array}$ & $\sqrt{ }$ \\
\hline & & & $\begin{array}{l}\text { Materials from plants, algae and } \\
\text { animals for agricultural use }\end{array}$ & $\sqrt{ }$ \\
\hline & & & Genetic materials from all biota & $\sqrt{ }$ \\
\hline & & \multirow[t]{2}{*}{ Water } & $\begin{array}{l}\text { Surface water for non-drinking } \\
\text { purposes }\end{array}$ & $\sqrt{ }$ \\
\hline & & & $\begin{array}{l}\text { Ground water for non-drinking } \\
\text { purposes }\end{array}$ & $\sqrt{ }$ \\
\hline & \multirow[t]{3}{*}{ Energy } & \multirow{2}{*}{$\begin{array}{l}\text { Biomass- } \\
\text { based } \\
\text { energy } \\
\text { sources }\end{array}$} & Plant-based resources & \\
\hline & & & Animal-based resources & \\
\hline & & $\begin{array}{l}\text { Mechanical } \\
\text { energy }\end{array}$ & Animal-based energy & \\
\hline \multirow{12}{*}{$\begin{array}{l}\text { Regulation } \\
\& \\
\text { Maintenan } \\
\text { ce }\end{array}$} & \multirow{5}{*}{$\begin{array}{l}\text { Mediation } \\
\text { of waste, } \\
\text { toxics and } \\
\text { other } \\
\text { nuisances }\end{array}$} & \multirow[t]{2}{*}{$\begin{array}{l}\text { Mediation } \\
\text { by biota }\end{array}$} & $\begin{array}{l}\text { Bio-remediation by micro-organisms, } \\
\text { algae, plants, and animals }\end{array}$ & $\sqrt{ }$ \\
\hline & & & $\begin{array}{l}\text { Filtration/sequestration/storage/accu } \\
\text { mulation by micro-organisms, algae, } \\
\text { plants, and animals }\end{array}$ & $\sqrt{ }$ \\
\hline & & \multirow{3}{*}{$\begin{array}{l}\text { Mediation } \\
\text { by } \\
\text { ecosystems }\end{array}$} & $\begin{array}{l}\text { Filtration/sequestration/storage/accu } \\
\text { mulation by ecosystems }\end{array}$ & $\sqrt{ }$ \\
\hline & & & $\begin{array}{l}\text { Dilution by atmosphere, freshwater } \\
\text { and marine ecosystems }\end{array}$ & $\sqrt{ }$ \\
\hline & & & $\begin{array}{l}\text { Mediation of smell/noise/visual } \\
\text { impacts }\end{array}$ & \\
\hline & \multirow[t]{6}{*}{$\begin{array}{l}\text { Mediation } \\
\text { of flows }\end{array}$} & \multirow[t]{2}{*}{ Mass flows } & $\begin{array}{l}\text { Mass stabilisation and control of } \\
\text { erosion rates }\end{array}$ & $\sqrt{ }$ \\
\hline & & & $\begin{array}{l}\text { Buffering and attenuation of mass } \\
\text { flows }\end{array}$ & $\sqrt{ }$ \\
\hline & & \multirow[t]{2}{*}{ Liquid flows } & $\begin{array}{l}\text { Hydrological cycle and water flow } \\
\text { maintenance }\end{array}$ & $\sqrt{ }$ \\
\hline & & & Flood protection & $\sqrt{ }$ \\
\hline & & \multirow{2}{*}{$\begin{array}{l}\text { Gaseous / } \\
\text { air flows }\end{array}$} & Storm protection & \\
\hline & & & Ventilation and transpiration & \\
\hline & Maintenan & Lifecycle & Pollination and seed dispersal & $\sqrt{ }$ \\
\hline
\end{tabular}


Assessment of Ecosystem Services and Water Accounting Methodologies for Integrated Water Resources Management in water scarce basins

\begin{tabular}{|c|c|c|c|c|}
\hline Section & Division & Group & Class & $\begin{array}{l}\text { Water } \\
\text { bodie } \\
\mathbf{s}^{*}\end{array}$ \\
\hline & \multirow{9}{*}{$\begin{array}{l}\text { ce of } \\
\text { physical, } \\
\text { chemical, } \\
\text { biological } \\
\text { conditions }\end{array}$} & $\begin{array}{l}\text { maintenan } \\
\text { ce, habitat } \\
\text { and gene } \\
\text { pool }\end{array}$ & $\begin{array}{l}\text { Maintaining nursery populations and } \\
\text { habitats }\end{array}$ & $\sqrt{ }$ \\
\hline & & \multirow{2}{*}{$\begin{array}{l}\text { Pest and } \\
\text { disease } \\
\text { control }\end{array}$} & Pest control & \\
\hline & & & Disease control & \\
\hline & & \multirow{2}{*}{$\begin{array}{l}\text { Soil } \\
\text { formation } \\
\text { and } \\
\text { compositio } \\
n\end{array}$} & Weathering processes & \\
\hline & & & Decomposition and fixing processes & \\
\hline & & \multirow{2}{*}{$\begin{array}{l}\text { Water } \\
\text { conditions }\end{array}$} & Chemical condition of freshwaters & \\
\hline & & & Chemical condition of salt waters & \\
\hline & & \multirow{2}{*}{$\begin{array}{l}\text { Atmospheri } \\
\mathrm{C} \\
\text { compositio } \\
\mathrm{n} \text { and } \\
\text { climate } \\
\text { regulation }\end{array}$} & $\begin{array}{l}\text { Global climate regulation by } \\
\text { reduction of greenhouse gas } \\
\text { concentrations }\end{array}$ & $\sqrt{ }$ \\
\hline & & & Micro and regional climate regulation & $\sqrt{ }$ \\
\hline \multirow[t]{11}{*}{ Cultural } & \multirow{7}{*}{$\begin{array}{l}\text { Physical } \\
\text { and } \\
\text { intellectual } \\
\text { interaction } \\
\mathrm{s}\end{array}$} & \multirow{2}{*}{$\begin{array}{l}\text { Physical } \\
\text { and } \\
\text { experiential } \\
\text { interactions }\end{array}$} & $\begin{array}{l}\text { Experiential use of plants, animals and } \\
\text { land-/seascapes }\end{array}$ & $\sqrt{ }$ \\
\hline & & & Physical use of land-/seascapes & $\sqrt{ }$ \\
\hline & & \multirow{5}{*}{$\begin{array}{l}\text { Intellectual } \\
\text { and } \\
\text { representati } \\
\text { ve } \\
\text { interactions }\end{array}$} & Scientific & $\sqrt{1}$ \\
\hline & & & Educational & $\sqrt{ }$ \\
\hline & & & Heritage, cultural & $\sqrt{ }$ \\
\hline & & & Entertainment & $\sqrt{ }$ \\
\hline & & & Aesthetic & $\sqrt{ }$ \\
\hline & \multirow{4}{*}{$\begin{array}{l}\text { Spiritual, } \\
\text { symbolic } \\
\text { and other } \\
\text { interaction } \\
\text { s }\end{array}$} & \multirow{2}{*}{$\begin{array}{l}\text { Spiritual } \\
\text { and/or } \\
\text { emblemati } \\
\text { c }\end{array}$} & Symbolic & $\sqrt{ }$ \\
\hline & & & Sacred and/or religious & $\sqrt{ }$ \\
\hline & & \multirow{2}{*}{$\begin{array}{l}\text { Other } \\
\text { cultural } \\
\text { outputs }\end{array}$} & Existence & $\sqrt{ }$ \\
\hline & & & Bequest & $\sqrt{ }$ \\
\hline
\end{tabular}

* They comprise all the river basin elements that can be affected by water management (quantity and quality): rivers including riverbed and riverbanks; wetlands considering the different types (e.g. US Hydrogeomorphic classification or the simplification proposed by Turner et al. (2008); aquifers; and reservoirs.

\subsection{Economic valuation methods}

The next step was to identify the economic valuation methods used to estimate environmental values included in the HEMs. We classified valuation methods into the standard typologies common throughout the literature (de 
Groot et al., 2002; Chee, 2004a; Tietenberg and Lewis, 2009; TEEB 2010; Costanza et al., 2011). The typologies we used are:

- Market value: Used when the valued ES is a good that has a market price, e.g. cultivated crop. However, for the ES whose price does not include the impact of abstraction/use on their availability for other users and the environment, e.g. drinking water, the value is derived from the marginal willingness-to-pay using econometric approaches.

- Production-based: Used when the valued ES is a factor of production for a good or service traded on the market, e.g. Water for agricultural production. Value is estimated as the contribution to the net revenues obtained from the produced good or service in the market.

- Cost-based: This method approximates the value of the ES based on the costs of replacing it (replacement cost method). This approach is applicable to ES such as mediation of waste. The method can also consider the avoided damages given the presence of the ES (avoided cost method), e.g. flood protection.

- Revealed preference: Often used to value recreation and amenity values of water. The travel cost method assumes that the value of an ES can be approximated with the expenses incurred to enjoy it. This method is applicable to ES such as aquatic recreation by considering transportation expenses, on site spending and protected area entrance fees. The hedonic price method relates the value of an ES with the price variation of associated goods for different production levels or quality of the ES. A common example is the difference in market prices for real estate with more and less aesthetic water related amenity, assuming all other variables influencing real estate sales are equal.

- Stated preference: Surveys designed to elicit the values people ascribe to an ES. Respondents are usually asked how much they would be willing to pay for a specific improvement in the ES (contingent valuation method), or they are asked to select one among a number of alternatives for improvement of the ES, where price or cost required to pay for improved ES condition is a key 
Assessment of Ecosystem Services and Water Accounting Methodologies for Integrated Water Resources Management in water scarce basins

attribute (choice experiment method). This method is applicable to non-consumptive ES such as aquatic biodiversity.

- Benefit transfer (or meta-analysis). Takes estimates of ES value from one site and applies them to another site.

In HEMs, these valuation methods are used to produce a value function for the different water uses and environmental benefits and costs, given the variation in the physical variables such as water flow or volume. In the studies we assessed, these functions are estimated using econometric or statistical methods, or by combining mathematical representations of an ecological production function with a unit production value obtained with one of the valuation approaches.

\section{Results}

\subsection{General features of the studies}

As a result of the literature search and selection, 95 papers were reviewed. Table 2 cites the final set of papers which was assigned unique ID numbers for easy citation.

Table 2. Final selection of papers reviewed.

\begin{tabular}{|c|c|c|c|c|c|}
\hline ID & Citation & ID & Citation & ID & Citation \\
\hline 1 & $\begin{array}{l}\text { (Vaux and Howitt, } \\
\text { 1984) }\end{array}$ & 33 & $\begin{array}{l}\text { (Pulido-Velazquez et al., } \\
\text { 2006) }\end{array}$ & 65 & (Yang and Cai, 2011) \\
\hline 2 & (Brown et al., 1990) & 34 & (Ringler and Cai, 2006) & 66 & (Ahmadi et al., 2012) \\
\hline 3 & $\begin{array}{l}\text { (Booker and Young, } \\
\text { 1991) }\end{array}$ & 35 & (Schoups et al., 2006) & 67 & $\begin{array}{l}\text { (Grossmann and Dietrich, } \\
2012 \text { ) }\end{array}$ \\
\hline 4 & (Diaz et al., 1992) & 36 & (Tanaka et al., 2006) & 68 & $\begin{array}{l}\text { (Ward and Pulido- } \\
\text { Velazquez, 2012) }\end{array}$ \\
\hline 5 & $\begin{array}{l}\text { (Booker and Young, } \\
\text { 1994) }\end{array}$ & 37 & (Ward et al., 2006) & 69 & (Yang et al., 2012b) \\
\hline 6 & (Booker, 1995) & 38 & (Houk et al., 2007) & 70 & $\begin{array}{l}\text { (Blanco-Gutiérrez et al., } \\
2013 \text { ) }\end{array}$ \\
\hline 7 & $\begin{array}{l}\text { (Lund and Ferreira, } \\
\text { 1996) }\end{array}$ & 39 & (Mainuddin et al., 2007) & 71 & (Bryan et al., 2013) \\
\hline 8 & $\begin{array}{l}\text { (Ward and Lynch, } \\
\text { 1996) }\end{array}$ & 40 & $\begin{array}{l}\text { (Medellín-Azuara et al., } \\
\text { 2007) }\end{array}$ & 72 & (Connor et al., 2013) \\
\hline 9 & $\begin{array}{l}\text { (Ward and Lynch, } \\
\text { 1997) }\end{array}$ & 41 & (Qureshi et al., 2007) & 73 & (Davidson et al., 2013a) \\
\hline 10 & (Hurd et al., 1999) & 42 & (Cai et al., 2008) & 74 & (Davidson et al., 2013b) \\
\hline 11 & $\begin{array}{l}\text { (Watkins Jr and } \\
\text { McKinney, 1999) }\end{array}$ & 43 & (Harou and Lund, 2008) & 75 & (Divakar et al., 2013) \\
\hline 12 & $\begin{array}{l}\text { (Jenkins and Lund, } \\
\text { 2000) }\end{array}$ & 44 & $\begin{array}{l}\text { (Medellín-Azuara et al., } \\
\text { 2008a) }\end{array}$ & 76 & $\begin{array}{l}\text { (Geng and Wardlaw, } \\
\text { 2013) }\end{array}$ \\
\hline
\end{tabular}


Annexes

\begin{tabular}{|c|c|c|c|c|c|}
\hline ID & Citation & ID & Citation & ID & Citation \\
\hline 13 & (Rosegrant et al., 2000) & 45 & $\begin{array}{l}\text { (Medellín-Azuara et al., } \\
\text { 2008b) }\end{array}$ & 77 & (Mullick et al., 2013) \\
\hline 14 & $\begin{array}{l}\text { (Bielsa and Duarte, } \\
\text { 2001) } \\
\end{array}$ & 46 & $\begin{array}{l}\text { (Pulido-Velazquez et al., } \\
\text { 2008a) } \\
\end{array}$ & 78 & $\begin{array}{l}\text { (Pulido-Velazquez et al., } \\
2013) \\
\end{array}$ \\
\hline 15 & (Tisdell, 2001) & 47 & $\begin{array}{l}\text { (Reynaud and } \\
\text { Leenhardt, 2008) }\end{array}$ & 79 & (Riegels et al., 2013) \\
\hline 16 & (Cai et al., 2002) & 48 & (Volk et al., 2008) & 80 & (Roozbahani et al., 2013) \\
\hline 17 & (Fisher et al., 2002) & 49 & $\begin{array}{l}\text { (Ward and Pulido- } \\
\text { Velázquez, 2008) }\end{array}$ & 81 & (Wan et al., 2013) \\
\hline 18 & (Newlin et al., 2002) & 50 & (Li et al., 2009) & 82 & (Yang and Yang, 2013) \\
\hline 19 & (Cai et al., 2003a) & 51 & $\begin{array}{l}\text { (Medellín-Azuara et al., } \\
\text { 2009) }\end{array}$ & 83 & $\begin{array}{l}\text { (Daneshmand et al., } \\
\text { 2014) }\end{array}$ \\
\hline 20 & (Cai et al., 2003b) & 52 & (Ward, 2009) & 84 & (Debnath, 2014) \\
\hline 21 & (Draper et al., 2003) & 53 & $\begin{array}{l}\text { (Ward and Pulido- } \\
\text { Velazquez, 2009) }\end{array}$ & 85 & (Erfani et al., 2014) \\
\hline 22 & (Knapp et al., 2003) & 54 & $\begin{array}{l}\text { (Alcoforado de Moraes } \\
\text { et al., 2010) }\end{array}$ & 86 & (Hasler et al., 2014) \\
\hline 23 & (Burke et al., 2004) & 55 & (Harou et al., 2010) & 87 & (Yang and Yang, 2014) \\
\hline 24 & (Jenkins et al., 2004) & 56 & (Zoltay et al., 2010) & 88 & (Bekchanov et al., 2015b) \\
\hline 25 & (Letcher et al., 2004) & 57 & (Divakar et al., 2011) & 89 & (Bekchanov et al., 2015c) \\
\hline 26 & $\begin{array}{l}\text { (Pulido-Velazquez et } \\
\text { al., 2004) } \\
\end{array}$ & 58 & (George et al., 201 la) & 90 & (Bekchanov et al., 2015a) \\
\hline 27 & (Ringler et al., 2004) & 59 & (George et al., 201 1b) & 91 & (Debnath et al., 2015) \\
\hline 28 & $\begin{array}{l}\text { (Assimacopoulos et al., } \\
2005 \text { ) }\end{array}$ & 60 & (Grafton et al., 2011) & 92 & (Erfani et al., 2015) \\
\hline 29 & (Babel et al., 2005) & 61 & $\begin{array}{l}\text { (Munoz-Hernández et al., } \\
2011 \text { ) }\end{array}$ & 93 & (Girard et al., 2015) \\
\hline 30 & (Booker et al., 2005) & 62 & (Grafton et al., 2011) & 94 & (Kahil et al., 2015) \\
\hline 31 & (Marques et al., 2006) & 63 & (Riegels et al., 2011) & 95 & (Roozbahani et al., 2015) \\
\hline 32 & (Null and Lund, 2006) & 64 & $\begin{array}{l}\text { (Varela-Ortega et al., } \\
2011 \text { ) }\end{array}$ & & \\
\hline
\end{tabular}

The 95 papers covered the period 1984 to 2015, with less than 2 papers published per year on average prior to 2002 (Figure 2). About 6 papers were published per year on average after 2002, with the most studies in 2013 ( $n=$ 13).

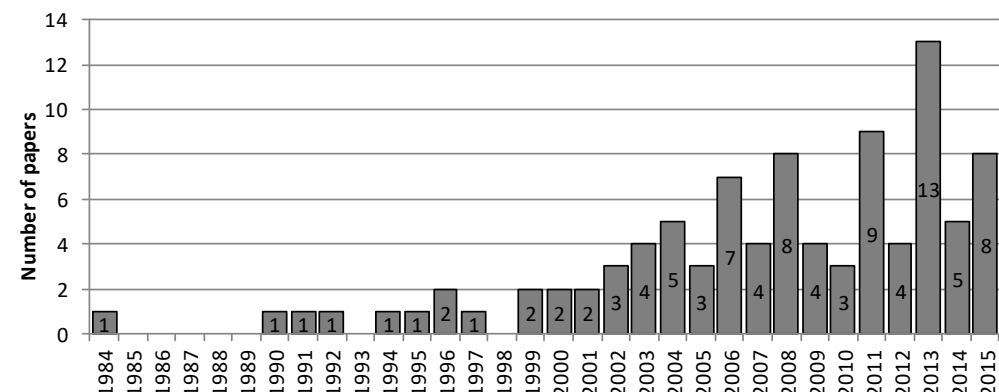

Figure 2. Number of papers published per year which suit the review scope. 
Assessment of Ecosystem Services and Water Accounting Methodologies for Integrated Water Resources Management in water scarce basins

We found that the water use sectors most represented by HEMs were urban, agricultural, industrial, and hydropower sectors (Table 3). Other sectors such as livestock, tourism, navigation, and industry were rarely included except within the twelve studies that included five or more sectors. The river basin was the most common spatial scale of the papers we reviewed. We also found that HEMs have been applied to administrative regions (15 papers: 1 , $18,21,22,24,26,28,32,35,36,44,45,51,55$, and 81 ), water supply systems (7 papers: $11,12,29,31,65,84$, and 91), and international regions (5 papers: 17 , $86,88,89$, and 90 ).

Table 3. Water use sectors considered in the reviewed HEM studies indicating the number of papers and their ID.

\begin{tabular}{|c|c|c|c|}
\hline \multicolumn{2}{|l|}{ Sectors } & \multirow{2}{*}{$\begin{array}{c}\text { Num. } \\
\text { papers } \\
2\end{array}$} & \multirow{2}{*}{\begin{tabular}{|l} 
ID papers \\
65,71
\end{tabular}} \\
\hline $\begin{array}{l}\text { Single } \\
\text { sector }\end{array}$ & Environmental & & \\
\hline \multirow{3}{*}{$\begin{array}{l}\text { Two } \\
\text { sectors }\end{array}$} & Environmental and agricultural & 23 & $\begin{array}{l}15,22,23,25,31,35,38,39,41 \\
48,60,61,62,64,66,67,70,72 \\
76,80,88,90,92\end{array}$ \\
\hline & Environmental and hydropower & 2 & 8,9 \\
\hline & Environmental and urban & 3 & $12,50,81$ \\
\hline \multirow{5}{*}{$\begin{array}{l}\text { Three } \\
\text { sectors }\end{array}$} & $\begin{array}{l}\text { Environmental, agricultural and } \\
\text { hydropower }\end{array}$ & 2 & 14,89 \\
\hline & $\begin{array}{l}\text { Environmental, agricultural and } \\
\text { industrial }\end{array}$ & 3 & $82,85,86$ \\
\hline & $\begin{array}{l}\text { Environmental, agricultural and } \\
\text { navigation }\end{array}$ & 1 & 77 \\
\hline & Environmental, urban and agricultural & 23 & $\begin{array}{l}1,18,21,24,26,28,33,37,40 \\
43,45,46,47,49,51,52,53,55 \\
68,69,78,93,94\end{array}$ \\
\hline & $\begin{array}{l}\text { Environmental, urban and } \\
\text { hydropower }\end{array}$ & 2 & 84,91 \\
\hline \multirow{2}{*}{$\begin{array}{l}\text { Four } \\
\text { sectors }\end{array}$} & $\begin{array}{l}\text { Environmental, urban, agricultural and } \\
\text { hydropower }\end{array}$ & 13 & $\begin{array}{l}2,6,13,16,19,20,27,32,36 \\
42,44,58,59\end{array}$ \\
\hline & $\begin{array}{l}\text { Environmental, urban, agricultural and } \\
\text { industrial }\end{array}$ & 9 & $5,17,30,73,74,79,83,87,95$ \\
\hline \multicolumn{2}{|c|}{ Five or more sectors } & 12 & $\begin{array}{l}3,4,7,10,11,29,34,54,56,57 \\
63,75\end{array}$ \\
\hline
\end{tabular}

The major water management problems tackled by the HEMs we reviewed were resource allocation, with emphases on inter-sectoral allocation $(n=48)$, water institutions ( $n=13)$, and water supply infrastructure $(n=13)$. Other water issues such as drought or climate change management, transboundary water management, conjunctive surface-groundwater use, and 
land use management were less common. The HEMs used different types of assessment criteria to design and test water management solutions. We identified 58 papers which used a net benefit maximisation approach. Table 4 presents the number of papers addressing each major issue and the type of assessment used.

Table 4. Cross relationship between major issues and assessment criteria in the reviewed papers indicating the number of papers and their ID.

\begin{tabular}{|c|c|c|c|c|c|c|c|}
\hline $\begin{array}{l}\begin{array}{r}\text { Assessment } \\
\text { criteria }\end{array} \\
\text { Major water } \\
\text { management } \\
\text { problems }\end{array}$ & 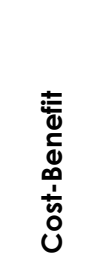 & 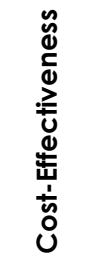 & 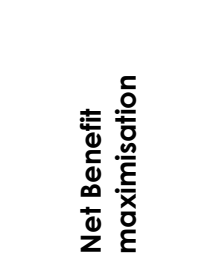 & 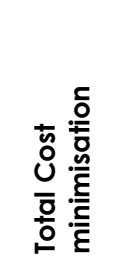 & 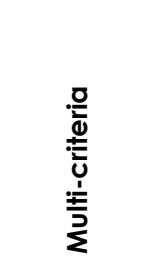 & 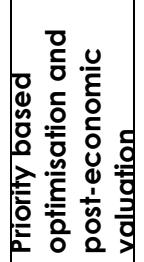 & $\overline{0}$ \\
\hline $\begin{array}{l}\text { Conjunctive use } \\
\text { of surface and } \\
\text { groundwater }\end{array}$ & 0 & 0 & $\begin{array}{c}4(26,31,35 \\
83)\end{array}$ & $1(33)$ & 0 & 0 & 5 \\
\hline $\begin{array}{l}\text { Drought/climate } \\
\text { change } \\
\text { management }\end{array}$ & 0 & 0 & $\begin{array}{c}4(10,30,37 \\
94)\end{array}$ & $\begin{array}{l}3(36 \\
44,55)\end{array}$ & 0 & $1(6)$ & 8 \\
\hline $\begin{array}{l}\text { Inter-sectoral } \\
\text { water allocation }\end{array}$ & $\begin{array}{l}4(52 \\
58,59 \\
67)\end{array}$ & $\begin{array}{l}3(38 \\
64 \\
93)\end{array}$ & $\begin{array}{l}28(3,4,8,9 \\
13,14,15,20 \\
25,39,41,42 \\
47,50,54,56 \\
57,60,61,62 \\
69,70,77,79 \\
84,89,90,91) \\
\end{array}$ & $1(46)$ & $\begin{array}{l}11(29,65 \\
66,71,75 \\
76,80,81 \\
82,87,95)\end{array}$ & $1(28)$ & 48 \\
\hline $\begin{array}{l}\text { Land use } \\
\text { management }\end{array}$ & 0 & $1(48)$ & 0 & 0 & 0 & 0 & 1 \\
\hline $\begin{array}{l}\text { Trans-boundary } \\
\text { management } \\
\text { and conflict } \\
\text { resolution }\end{array}$ & 0 & $1(86)$ & $\begin{array}{c}5(16,17,19 \\
27,34)\end{array}$ & $1(40)$ & 0 & 0 & 7 \\
\hline $\begin{array}{l}\text { Water institutions } \\
\text { (prices, markets, } \\
\text { rights) }\end{array}$ & 0 & 0 & $\begin{array}{c}12(1,5,18,22 \\
23,49,53,63 \\
78,85,88,92)\end{array}$ & 0 & 0 & $1(72)$ & 13 \\
\hline $\begin{array}{l}\text { Water supply, } \\
\text { engineering } \\
\text { infrastructures } \\
\text { and capacity } \\
\text { expansion }\end{array}$ & $1(45)$ & 0 & $\begin{array}{c}5(24,43,68 \\
73,74)\end{array}$ & $\begin{array}{l}6(7,11 \\
12,21 \\
32,51)\end{array}$ & 0 & $1(2)$ & 13 \\
\hline Total & 5 & 5 & 58 & 12 & 11 & 4 & 95 \\
\hline
\end{tabular}

We found that there were very few studies that treated uncertainty in physical variables and parameters. Uncertainty was analysed by means of 
Assessment of Ecosystem Services and Water Accounting Methodologies for Integrated Water Resources Management in water scarce basins

probabilistic approaches (2 and 11) and sensitivity analyses in deterministic models (17 and 77). Only two studies (6 and 34) assessed uncertainty of economic parameters.

We distinguished between HEMs that included economic valuation of the environment versus those that accounted for the environment using only biophysical units. We found that 61 papers considered environmental uses as constraints (e.g. 12, 33 and 93) or as decision variables in the optimisation function via ecological functions (e.g. 66 and 72). These studies mainly included minimum flows and, occasionally, water quality as environmental aspects. Some calculated the opportunity costs of environmental constraints, which provided useful economic information for decision making but did not allow comparison of environmental and other water use values.

\subsection{Environmental impacts classification}

Among the reviewed studies, 34 defined environmental benefits and costs and used economic functions to value these within water management analysis $(2,3,5,6,7,8,9,10,11,16,27,28,29,30,34,37,49,53,57,60,65,67$, $68,71,73,74,75,77,84,88,89,90,91$, and 94). The aspects of the environment considered were diverse and broadly covered vegetation and fauna, water quality and flood control. Most studies analysed only one $(2,3$, $5,8,9,16,30,37,49,53,57,60,68,73,74,75,77,84$, and 91) or two (i.e. 6,7 , $11,27,28,29,34,65,71$, and 94) environmental aspects, and only five papers covered more than three $(10,67,88,89$, and 90$)$. Table 5 uses the CICES framework to summarise the environmental impacts included in the HEMs we reviewed. Some HEMs included components of ecosystems which could not readily be allocated to the CICES framework, such as wetlands and environmental flows $(16,27,28,29,34,60,73,74,88,89,90$, and 94). 
Table 5. Classification of environmental and non-environmental impacts included in HEM studies (and papers ID) according to the CICES framework.

\begin{tabular}{|c|c|c|}
\hline Section & Class & Number of papers \\
\hline \multirow[b]{5}{*}{ Provisioning } & Wild animals and their outputs & $\begin{array}{l}\text { Commercial fishing }(11,27 \text {, } \\
34,77,88,89 \text {, and } 90)\end{array}$ \\
\hline & \begin{tabular}{|l|} 
Surface water for drinking \\
\end{tabular} & \multirow{2}{*}{$\begin{array}{l}\text { Urban demands }(2,3,5,6, \\
7,10,11,16,27,28,29,30 \\
34,37,49,53,57,68,73,74, \\
75,84,91, \text { and } 94)\end{array}$} \\
\hline & Ground water for drinking & \\
\hline & Surface water for non-drinking purposes & \multirow[b]{2}{*}{$\begin{array}{l}\text { Agricultural and/or } \\
\text { Hydropower and/or } \\
\text { Industrial and/or Navigation } \\
\text { and/or Livestock and/or } \\
\text { Commercial }(2,3,5,6,7,8, \\
9,10,11,16,27,28,29,30, \\
34,37,49,53,57,60,67,68, \\
74,75,77,84,88,89,90,91, \\
\text { and 94) }\end{array}$} \\
\hline & Ground water for non-drinking purposes & \\
\hline \multirow{5}{*}{$\begin{array}{l}\text { Regulation \& } \\
\text { Maintenance }\end{array}$} & $\begin{array}{l}\text { Filtration/sequestration/storage/accumulation } \\
\text { by micro-organisms, algae, plants, and } \\
\text { animals }\end{array}$ & \multirow{2}{*}{$\begin{array}{l}\text { Water quality (28) + } \\
\text { Wastewater treatment (10) }\end{array}$} \\
\hline & $\begin{array}{l}\text { Filtration/sequestration/storage/accumulation } \\
\text { by ecosystems }\end{array}$ & \\
\hline & $\begin{array}{l}\text { Dilution by atmosphere, freshwater and } \\
\text { marine ecosystems }\end{array}$ & $\begin{array}{l}\text { Salt dilution }(2,3,5,6,10 \\
57, \text { and } 75)+ \text { Waste heat } \\
\text { (10) }\end{array}$ \\
\hline & Flood protection & Flood control $(7,10$, and 65$)$ \\
\hline & $\begin{array}{l}\text { Global climate regulation by reduction of } \\
\text { greenhouse gas concentrations }\end{array}$ & Carbon sequestration (67) \\
\hline \multirow{3}{*}{ Cultural } & $\begin{array}{l}\text { Experiential use of plants, animals and land- } \\
\text { /seascapes }\end{array}$ & Tourism $(88,89,90$, and 94$)$ \\
\hline & Physical use of land-/seascapes & $\begin{array}{l}\text { Recreation }(6,10,11,29,30, \\
65,84, \text { and } 91)+ \\
\text { Recreational fishing }(8,9, \\
37,49,53 \text {, and } 68)+ \text { Boating } \\
(67)\end{array}$ \\
\hline & Symbolic & $\begin{array}{l}\text { Habitat (67) + Biodiversity } \\
\text { (67) + Natural vegetation } \\
\text { (71) + Native animals (71) }\end{array}$ \\
\hline
\end{tabular}

We found no systematic approaches to valuation of the environment and ecosystems in HEMs although there were some recurring methods (Table 6). Production-based valuation methods were more commonly applied for provisioning ES such as commercial fishing. Water quality improvement (e.g. salt dilution and nutrients abatement) was most often valued using costbased methods (e.g. agricultural production losses due to salinity, and treatment for drinking water). Flood control and carbon sequestration 
Assessment of Ecosystem Services and Water Accounting Methodologies for Integrated Water Resources Management in water scarce basins

valuation were also valued with cost-based methods. Recreation activity related values were mainly estimated using the travel cost method. When valuing impacts on habitat and biodiversity, in general, or for specific natural vegetation types and native animals, stated preferences techniques were used, but in some cases results were obtained through the benefit transfer method rather than with case specific studies. Among the impacts which cannot be categorised according to CICES, benefit transfer was the main valuation technique for wetlands, and other non-specified or bespoke valuation methods were used for the environment as a general concept. The greatest diversity in valuation methods was found for environmental flows in rivers or volumes in aquifers.

HEMs require demand functions which relate the value of the impacts to water supply. For most in-stream use studies, the values were dependent on river flows $(3,10,27,34,77,88,89$, and 90), whilst for uses in lakes and reservoirs values relied on the water level or the stored volume $(49,65,84$, and 91). Finally, there were few examples of more complex demand functions which captured the relationship between the value and the ecological response using more than one hydrological variable $(67,71$, and 94).

Table 6. Valuation methods used in HEM studies for the considered environmental and nonenvironmental impacts. The most used method on which the calculation was based is indicated with +++, the second most with ++, and the third most with +; empty values mean that the method was not used. Based on de Groot et al. (2002).

\begin{tabular}{|c|c|c|c|c|c|c|c|c|}
\hline & & $\begin{array}{l}\text { Consu } \\
\text { mer } \\
\text { Surplus }\end{array}$ & $\begin{array}{l}\text { Produ } \\
\text { ction- } \\
\text { based }\end{array}$ & $\begin{array}{l}\text { Cost- } \\
\text { base } \\
\text { d }\end{array}$ & $\begin{array}{l}\text { Reveale } \\
\text { d } \\
\text { preferen } \\
\text { ces }\end{array}$ & $\begin{array}{c}\text { State } \\
d \\
\text { prefer } \\
\text { ences }\end{array}$ & $\begin{array}{c}\text { Benefit } \\
\text { transfe } \\
\mathbf{r}\end{array}$ & $\begin{array}{l}\text { Oth } \\
\text { er }\end{array}$ \\
\hline \multirow{7}{*}{ 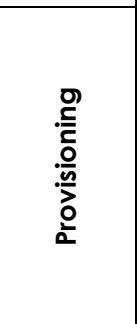 } & Commercial fishing & & +++ & & & & & \\
\hline & Urban demands & +++ & & & & & & \\
\hline & $\begin{array}{l}\text { Agricultural } \\
\text { demands }\end{array}$ & ++ & +++ & & & & & \\
\hline & $\begin{array}{l}\text { Hydropower } \\
\text { demands }\end{array}$ & & +++ & & & & & \\
\hline & Industrial demands & +++ & ++ & + & & & & \\
\hline & Navigation demands & & +++ & & & & & ++ \\
\hline & Livestock demands & & +++ & & & & & \\
\hline \multirow{4}{*}{ 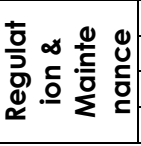 } & Water quality & & & +++ & & & & \\
\hline & Wastewater treat. & & & +++ & & & & \\
\hline & Salt dilution & & & +++ & & & & \\
\hline & Waste heat & & & +++ & & & & \\
\hline
\end{tabular}


Annexes

\begin{tabular}{|c|c|c|c|c|c|c|c|c|}
\hline & & $\begin{array}{l}\text { Consu } \\
\text { mer } \\
\text { Surplus }\end{array}$ & $\begin{array}{l}\text { Produ } \\
\text { ction- } \\
\text { based }\end{array}$ & $\begin{array}{l}\text { Cost- } \\
\text { base } \\
\text { d }\end{array}$ & $\begin{array}{c}\text { Reveale } \\
\text { d } \\
\text { preferen } \\
\text { ces }\end{array}$ & $\begin{array}{l}\text { State } \\
\text { d } \\
\text { prefer } \\
\text { ences }\end{array}$ & $\begin{array}{c}\text { Benefit } \\
\text { transfe } \\
r\end{array}$ & $\begin{array}{l}\text { Oth } \\
\text { er }\end{array}$ \\
\hline & Flood control & & & +++ & & & & ++ \\
\hline & $\begin{array}{l}\text { Carbon } \\
\text { sequestration }\end{array}$ & & & +++ & & & & \\
\hline \multirow{8}{*}{$\begin{array}{l}\bar{\sigma} \\
\frac{5}{3} \\
\text { U }\end{array}$} & Tourism & & ++ & & +++ & & & \\
\hline & Recreation & & & & +++ & & + & ++ \\
\hline & Recreational fishing & & & & +++ & & & \\
\hline & Boating & & & & +++ & & & \\
\hline & Habitat & & & & & & +++ & \\
\hline & Biodiversity & & & & & & +++ & \\
\hline & Natural vegetation & & & & & +++ & & \\
\hline & Native animals & & & & & +++ & & \\
\hline \multirow{3}{*}{$\begin{array}{l}. \cong \\
\frac{0}{0} \\
z\end{array}$} & Wetlands & & ++ & & & & +++ & \\
\hline & Environmental flows & & & +++ & & +++ & +++ & $\begin{array}{c}++ \\
+\end{array}$ \\
\hline & Environment & & & & & & & $\begin{array}{c}++ \\
+\end{array}$ \\
\hline
\end{tabular}

\section{Discussion}

We selected 95 HEM studies which cover environmental aspects of water management at river basin or comparable scales. The majority of HEMs analysed inter-sectoral water allocation between two or three water use sectors, including environmental, agricultural and urban uses, with the aim of maximising net benefits. The consideration of uncertainty issues was rare. From the initial 95 studies, about two thirds considered environmental aspects in physical terms, mostly as constraints to realising other use values. The third which valued at least one environmental impact in economic terms were mostly limited to a single environmental aspect, or included very broad or vague environmental aspects. Recreation, commercial fishing and salt dilution were the most frequently valued in HEMs. We also found that established and traditional valuation methods were used to assign economic value to the environment, with little deviation from methods recommended in the ES literature (de Groot et al., 2002; TEEB 2010; Banerjee et al., 2013).

We found that the use of the ES framework to identify the aspects of the environment likely affected by alternative water management actions is a systematic and thorough way to select relevant impacts and values. The ES framework should more comprehensively capture the ecological processes, values and interactions in HEMs. To some extent, the ES approach is already 
Assessment of Ecosystem Services and Water Accounting Methodologies for Integrated Water Resources Management in water scarce basins

influencing the inclusion of environmental and economic values in HEMs. For example, Bryan et al. (2013) selected environmental impacts based on the main water demands and the important river ecological and ES components were identified using river basin mapping.

A reason for the poor representation of the environment, especially in economic terms, in many HEMs is the limited availability of data and models characterising relevant environmental processes and associated economic values (Dandy et al., 2013). Although good quality information is complex and costly to obtain, we think that in well studied river basins omissions may be a result of the single issue focus of many studies. Many river basins have a good knowledge base which can be used to include more environmental values. For example, water quality processes related to flow are reasonably well understood and they are not difficult to value using cost-based methods (Keeler et al., 2012; La Notte et al., 2015; Terrado et al., 2016a). Similarly, it is possible to estimate values of recreational opportunities related to flow or water level (Hurd et al., 1999; Grossmann and Dietrich, 2012), and obtain values of provisioning services such as fisheries using production functions and market values (Ringler and Cai, 2006; Mullick et al., 2013), although for these ES the difficulty relies on having reliable data about underlying biophysical processes for water bodies in the basin. Environmental impacts can be valued with more than one method and, in agreement with de Groot et al. (2002), we suggest that following a rank ordering of valuation methods for each type of ES adds rigour and value comparability. Selection of the appropriate method depends on the data available and on the type of ES. Market valuation methods are generally more suited to provisioning ES or use values, cost-based methods to regulating ES, and revealed and stated preferences methods to cultural ES (Turner et al., 2008; TEEB 2010).

Uncertainty in ES values can be a consequence of the valuation approach and of the quality of the economic data. For instance, revealed and stated preference valuation methods have been criticised for their subjectivity and bias (Chee, 2004a; Bateman et al., 2006; La Notte et al., 2015), while market value, production and cost based valuation techniques are more objective. Benefit transfer can increase the range of values included in HEMs when local valuation studies are absent. However, transferring values introduces additional uncertainty if there is inadequate correspondence between the 
original and new studies (Plummer, 2009). This uncertainty may lead to highly variable results that would prevent decision makers from using HEMs to support decisions.

Expanding the representation of the environment and its values in HEMs will likely increase model uncertainties. Since the number of ES values associated with environmental impacts can be the greatest source of uncertainty (Boithias et al., 2016), there will need to be more systematic incorporation of uncertainty analyses into HEMs, including assessment of implications of uncertainty in decision making (Cai et al., 2002). We show that very few HEMs currently treat uncertainty, a conclusion drawn by a number of other studies (Lund and Ferreira, 1996; Bateman et al., 2006; La Notte et al., 2015). We suggest that Monte Carlo based analysis, an approach used more often in integrated analysis such as integrated assessment of global climate change impacts and adaptation (Gao et al., 2016), be also used to assess uncertainty in HEMs. Monte Carlo analyses consider non-linearities and are probabilistic, which is in line with actual measurement processes (Papadopoulos and Yeung, 2001).

Although there are arguments for expanding the number of monetised environmental values in HEMs, not all the potential environmental values impacted by water management need to be included to support good decisions. It may be the case that inclusion of additional environmental values does not influence the decision path. For example, in the case of a decision that has high net benefit based on the social, economic and environmental benefit values that are already quantified, quantifying additional benefits in monetary terms may add little to the conclusion (Kandulu et al., 2014). It may also be the case that monetised environmental values, such as those characterising productivity of wetlands or environmental flows (e.g. $€ /$ ha and $€ / m 3$, respectively), disguise the diverse pluralistic values of the environmental assets. These aggregated values are incompatible with ES classification and valuation, though in some cases they may provide information that could be unpacked into distinct components that could be valued in an ES framework.

Something that is rarely dealt with explicitly in HEMs, despite many studies noting its importance, is the role of critical thresholds and system irreversibilities in the ecosystems response functions (Scheffer et al., 2001; 
Assessment of Ecosystem Services and Water Accounting Methodologies for Integrated Water Resources Management in water scarce basins

Folke et al., 2002; Folke et al., 2004; Spangenberg et al., 2014). An exception is Kahil et al. (2015) who use a piecewise function to consider the shifts in the benefits provided by a wetland depending on inflow critical thresholds. Another aspect, not often considered in valuation functions in HEMs, is the correlation between ecological functions and other biophysical variables apart from water flows and volumes. Water quality has an important bearing on environmental aspects such as fauna and flora, and so water quality should be represented with environmental processes and linked to valuation functions. Although none of our reviewed studies consider the impact of water quality on environmental uses of water, some studies do consider impacts on traditional uses. For instance, Hurd et al. (1999) account for the impact of salinity on agricultural, urban and industrial uses. We suggest water quality variables (e.g. salinity, temperature) should be sufficiently detailed in HEMs to assess environmental impacts.

\section{Conclusion}

We used an ES framework to catalogue how HEMs have represented and valued the environment. Even though water management affects many environmental values, the HEMs we reviewed did not apply any systematic approaches to identify potential environmental impacts. This unsystematic approach to inclusion of the environment in HEMs risks over-looking potential trade-offs (between environment and economy) and unintended ecosystem impacts from water management decisions. The ES framework can be used to screen many environmental impacts that could be more widely applied in setting scope of analysis for water management actions.

Some important challenges remain. Firstly, the biophysical variables impacted by water management should be better understood in order to undertake a proper impact assessment and valuation. Aggregated environmental indexes which lose information about relevant detailed environmental impact values should then be avoided. Secondly, environmental functions which capture non-linearities and thresholds in ecological processes should be better defined, as should the role that water quality plays in broader aspects of environmental quality. Finally, uncertainty in both biophysical and economic variables should be more often addressed to improve the decision-support capabilities of HEMs. 


\section{Acknowledgments}

The authors acknowledge the backing of Universitat Politècnica de València through its Support Programme for Research and Development. Support by the CSIRO for an internship visit by the lead author is also acknowledged. We also wish to thank the European Commission for financing the Seventh Framework Program project ENHANCE (FP7-ENV-2012, 308438) and the H2020 project IMPREX (H2020-WATER-2014-2015, 641811), and the Spanish Ministry of Economy and Competitiveness for granting the project NUTEGES (VI Plan Nacional de I+D+i 2008-2011, CGL2012-34978).

\section{References}

AHMADI, A., KARAMOUZ, M., MORIDI, A. \& HAN, D., 2012. Integrated Planning of Land Use and Water Allocation on a Watershed Scale Considering Social and Water Quality Issues. Journal of Water Resources Planning and Management. 138, 671-681.

ALCOFORADO DE MORAES, M. M., CAI, X., RINGLER, C., ALBURQUERQUE, B. E., VIEIRA DA ROCHA, S. P. \& AMORIM, C. A., 2010. Joint Water QuantityQuality Management in a Biofuel Production Area-Integrated EconomicHydrologic Modeling Analysis. Journal of Water Resources Planning and Management. 136, 502-511.

ANDREU, J., PÉREZ, M. Á., PAREDES-ARQUIOLA, J. \& SOLERA, A. Year. Participatory analysis of the Jucar-Vinalopo (Spain) water conflict using a Decision Support System, in: ANDERSSEN, R. S., BRADDOCK, R. D. \& NEWHAM, L. T. H., (eds.) 18th World IMACS Congress and MODSIM09 International Congress on Modelling and Simulation, July 20092009 Cairns, Australia. 32303236.

ASSIMACOPOULOS, D., BARRAQUE, D., BERLAND, J. M., FEINERMAN, E., KATSIARDI, P. \& MANOLI, E. Year. Estimation of the level of cost recovery of different scenarios of water allocation in arid areas. An easy-to-implement approach, in: Second International Workshop on Implementing economic analysis in the Water Framework Directive, February 20052005 Paris, France.

BABEL, M. S., DAS GUPTA, A. \& NAYAK, D. K., 2005. A Model for Optimal Allocation of Water to Competing Demands. Water Resources Management. 19, 693-712. 
Assessment of Ecosystem Services and Water Accounting Methodologies for Integrated Water Resources Management in water scarce basins

BANERJEE, O., BARK, R., CONNOR, J. \& CROSSMAN, N. D., 2013. An ecosystem services approach to estimating economic losses associated with drought. Ecological economics. 91, 19-27.

BATEMAN, I. J., BROUWER, R., DAVIES, H., DAY, B. H., DEFLANDRE, A., FALCO, S. D., GEORGIOU, S., HADLEY, D., HUTCHINS, M., JONES, A. P., KAY, D., LEEKS, G., LEWIS, M., LOVETT, A. A., NEAL, C., POSEN, P., RIGBY, D. \& KERRY TURNER, R., 2006. Analysing the Agricultural Costs and Non-market Benefits of Implementing the Water Framework Directive. Journal of Agricultural Economics. 57, 221-237.

BEKCHANOV, M., BHADURI, A. \& RINGLER, C., 2015a. Potential gains from water rights trading in the Aral Sea Basin. Agricultural Water Management. $152,41-56$.

BEKCHANOV, M., RINGLER, C. \& BHADURI, A., 2015b. A Water Rights Trading Approach to Increasing Inflows to the Aral Sea. Land Degradation \& Development. n/a-n/a.

BEKCHANOV, M., RINGLER, C., BHADURI, A. \& JEULAND, M., 2015c. How would the Rogun Dam affect water and energy scarcity in Central Asia? Water International. 40, 856-876.

BIELSA, J. \& DUARTE, R., 2001. An Economic Model for Water Allocation in North Eastern Spain. International Journal of Water Resources Development. 17, 397-408.

BLANCO-GUTIÉRREZ, I., VARELA-ORTEGA, C. \& PURKEY, D. R., 2013. Integrated assessment of policy interventions for promoting sustainable irrigation in semiarid environments: A hydro-economic modeling approach. Journal of Environmental Management. 128, 144-160.

BOITHIAS, L., TERRADO, M., COROMINAS, L., ZIV, G., KUMAR, V., MARQUÉS, M., SCHUHMACHER, M. \& ACUÑA, V., 2016. Analysis of the uncertainty in the monetary valuation of ecosystem services - A case study at the river basin scale. Science of the Total Environment. 543, Part A, 683-690. 
BOOKER, J. F., 1995. Hydrologic and economic impacts of drought under alternative policy responses. Journal of the American Water Resources Association. 31, 889-906.

BOOKER, J. F., HOWITT, R. E., MICHELSEN, A. M. \& YOUNG, R. A., 2012. ECONOMICS AND THE MODELING OF WATER RESOURCES AND POLICIES. Natural Resource Modeling. 25, 168-218.

BOOKER, J. F., MICHELSEN, A. M. \& WARD, F. A., 2005. Economic impact of alternative policy responses to prolonged and severe drought in the Rio Grande Basin. Water Resources Research. 41, n/a-n/a.

BOOKER, J. F. \& YOUNG, R. A. 1991. Economic Impacts of Alternative Water Allocation Institutions in the Colorado River Basin. Completion Report. Colorado Water Resources Institute, Colorado State University.

BOOKER, J. F. \& YOUNG, R. A., 1994. Modeling Intrastate and Interstate Markets for Colorado River Water Resources. Journal of Environmental Economics and Management. 26, 66-87.

BOYD, J. \& BANZHAF, S., 2007. What are ecosystem services? The need for standardized environmental accounting units. Ecological economics. 63, 616-626.

BRAUMAN, K. A., DAILY, G. C., DUARTE, T. K. E. \& MOONEY, H. A., 2007. The Nature and Value of Ecosystem Services: An Overview Highlighting Hydrologic Services, in: ANNUAL REVIEWS (ed.) Annual review of Environment and Resources. 67-98.

BROUWER, R. \& HOFKES, M., 2008. Integrated hydro-economic modelling: Approaches, key issues and future research directions. Ecological economics. 66, 16-22.

BROWN, T. C., HARDING, B. L. \& PAYTON, E. A., 1990. Marginal Economic Value of Streamflow: A Case Study for the Colorado River Basin. Water Resources Research. 26, 2845-2859.

BRYAN, B. A., HIGGINS, A., OVERTON, I. C., HOLLAND, K., LESTER, R. E., KING, D., NOLAN, M., MACDONALD, D. H., CONNOR, J. D., BJORNSSON, T. \& KIRBY, M., 2013. Ecohydrological and socioeconomic integration for the 
Assessment of Ecosystem Services and Water Accounting Methodologies for Integrated Water Resources Management in water scarce basins

operational management of environmental flows. Ecological Applications. 23, 999-1016.

BURKE, S. M., ADAMS, R. M. \& WALLENDER, W. W., 2004. Water banks and environmental water demands: Case of the Klamath Project. Water Resources Research. 40, n/a-n/a.

CAI, X., MCKINNEY, D. C. \& LASDON, L. S., 2002. A framework for sustainability analysis in water resources management and application to the Syr Darya Basin. Water Resources Research. 38, 21-1-21-14.

CAI, X., MCKINNEY, D. C. \& ROSEGRANT, M. W., 2003a. Sustainability analysis for irrigation water management in the Aral Sea region. Agricultural Systems. 76, 1043-1066.

CAI, X., RINGLER, C. \& YOU, J.-Y., 2008. Substitution between water and other agricultural inputs: Implications for water conservation in a River Basin context. Ecological economics. 66, 38-50.

CAl, X., ROSEGRANT, M. W. \& RINGLER, C., 2003b. Physical and economic efficiency of water use in the river basin: Implications for efficient water management. Water Resources Research. 39, n/a-n/a.

CONNOR, J., 2008. The economics of time delayed salinity impact management in the River Murray. Water Resources Research. 44, n/a-n/a.

CONNOR, J. D., FRANKLIN, B., LOCH, A., KIRBY, M. \& WHEELER, S. A., 2013. Trading water to improve environmental flow outcomes. Water Resources Research. 49, 4265-4276.

COPELAND, C. 2010. Clean Water Act: A Summary of the Law. US: Congressional Research Service.

COSTANZA, R., 2008. Ecosystem services: Multiple classification systems are needed. Biological Conservation. 141, 350-352.

COSTANZA, R., D'ARGE, R., GROOT, R. D., FARBER, S., GRASSO, M., HANNON, B., LIMBURG, K., NAEEM, S., O'NEILL, R. V., PERUELO, J., RASKIN, R. G., SUTTON, P. \& BELT, M. V. D., 1997. The value of the world's ecosystem services and natural capital. Nature. 387, 253-260. 
COSTANZA, R., KUBISZEWSKI, I., ERVIN, D., BLUFFSTONE, R., BOYD, J., BROWN, D., CHANG, H., DUJON, V., GRANEK, E., POLASKY, S., SHANDAS, V. \& YEAKLEY, A., 2011. Valuing ecological systems and services. F1000 Biology Reports. 3, 14.

CROSSMAN, N. D., BARK, R. H., COLLOFF, M. J., MACDONALD, D. H. \& POLINO, C. A., 2015. Using an ecosystem services-based approach to measure the benefits of reducing diversions of freshwater: a case study in the in the Murray-Darling Basin, Australia, in: MARTIN-ORTEGA, J., FERRIER, R. C., GORDON, I. J. \& KHAN, S. (eds.), UNESCO Global Dialogue on Water Ecosystem Services. Cambridge University Press, United Kingdom, 82-89.

CHEE, Y. E., 2004. An ecological perspective on the valuation of ecosystem services. Biological Conservation. 120, 549-565.

DANDY, G., GANJI, A., KANDULU, J. M., HATTON MACDONALD, D., MARCHI, A., MAIER, H., MANKAD, A. \& SCHMIDT, C. E. 2013. Managed Aquifer Recharge and Stormwater Use Options: Net Benefits Report. In: GOYDER INSTITUTE FOR WATER RESEARCH (ed.). Adelaide.

DANESHMAND, F., KARIMI, A., NIKOO, M., BAZARGAN-LARI, M. \& ADAMOWSKI, J., 2014. Mitigating Socio-Economic-Environmental Impacts During Drought Periods by Optimizing the Conjunctive Management of Water Resources. Water Resources Management. 28, 1517-1529.

DAVIDSON, B., MALANO, H., NAWARATHNA, B. \& MAHESHWARI, B., 2013a. The hydrological and economic impacts of changing water allocation in political regions within the peri-urban South Creek catchment in Western Sydney I: Model development. Journal of Hydrology. 499, 339-348.

DAVIDSON, B., MALANO, H., NAWARATHNA, B. \& MAHESHWARI, B., 2013b. The hydrological and economic impacts of changing water allocations in political regions within the peri-urban South Creek catchment in Western Sydney II: Scenarios. Journal of Hydrology. 499, 349-359.

DE GROOT, R. S., WILSON, M. A. \& BOUMANS, R. M. J., 2002. A typology for the classification, description and valuation of ecosystem functions, goods and services. Ecological economics. 41, 393-408. 
Assessment of Ecosystem Services and Water Accounting Methodologies for Integrated Water Resources Management in water scarce basins

DEBNATH, D., 2014. Integrating economic and hydrologic interdependence in reservoir management. Lakes and Reservoirs: Research and Management. $19,211-224$.

DEBNATH, D., BOYER, T. A., STOECKER, A. L. \& SANDERS, L. D., 2015. Nonlinear Reservoir Optimization Model with Stochastic Inflows: Case Study of Lake Tenkiller. Journal of Water Resources Planning and Management. 141, 04014046.

DIAZ, G. E., BROWN, T. C. \& MOREL-SEYTOUX, H. J. Year. The marginal economic value of streamflows: a systems approach, in: MOREL-SEYTOUX, H. J., (ed.) American Geophysical Union Twelfth Annual Hydrology Days, March 31-April 31992 Colorado State University. Fort Collins, CO. Hydrology Days Publications. Atherton, CA, 419.

DIVAKAR, L., BABEL, M. S., PERRET, S. R. \& DAS GUPTA, A., 2011. Optimal allocation of bulk water supplies to competing use sectors based on economic criterion - An application to the Chao Phraya River Basin, Thailand. Journal of Hydrology. 401, 22-35.

DIVAKAR, L., BABEL, M. S., PERRET, S. R. \& DAS GUPTA, A., 2013. Optimal water allocation model based on satisfaction and economic benefits. International Journal of Water. 7, 363-381.

DRAPER, A., JENKINS, M. W., KIRBY, K. W., LUND, J. R. \& HOWITT, R. E., 2003. Economic-Engineering Optimization for California Water Management. Journal of Water Resources Planning and Management. 129, 155-164.

ERFANI, T., BINIONS, O. \& HAROU, J. J., 2014. Simulating water markets with transaction costs. Water Resources Research. 50, 4726-4745.

ERFANI, T., BINIONS, O. \& HAROU, J. J., 2015. Protecting environmental flows through enhanced water licensing and water markets. Hydrology Earth System Science. 19, 675-689.

EUROPEAN COMMISSION 2000. Directive 2000/60/EC of the European Parliament and of the Council, of 23 October 2000, establishing a framework for Community action in the field of water policy. Brussels: Official Journal of the European Commission. 
FISHER, B. \& TURNER, R. K., 2008. Ecosystem services: Classification for valuation. Biological Conservation. 141, 1167-1169.

FISHER, F. M., ARLOSOROFF, S., ECKSTEIN, Z., HADDADIN, M., HAMATI, S. G., HUBER-LEE, A., JARRAR, A., JAYYOUSI, A., SHAMIR, U. \& WESSELING, H., 2002. Optimal water management and conflict resolution: The Middle East Water Project. Water Resources Research. 38, 25-1-25-17.

FOLKE, C., CARPENTER, S., ELMQVIST, T., GUNDERSON, L., HOLLING, C. S. \& WALKER, B., 2002. Resilience and Sustainable Development: Building Adaptive Capacity in a World of Transformations. AMBIO: A Journal of the Human Environment. 31, 437-440.

FOLKE, C., CARPENTER, S., WALKER, B., SCHEFFER, M., ELMQVIST, T., GUNDERSON, L. \& HOLLING, C. S., 2004. Regime Shifts, Resilience, and Biodiversity in Ecosystem Management. Annual Review of Ecology, Evolution, and Systematics. 35, 557-581.

GAO, L., BRYAN, B. A., NOLAN, M., CONNOR, J. D., SONG, X. \& ZHAO, G., 2016. Robust global sensitivity analysis under deep uncertainty via scenario analysis. Environmental Modelling \& Software. 76, 154-166.

GENG, G. \& WARDLAW, R., 2013. Application of Multi-Criterion Decision Making Analysis to Integrated Water Resources Management. Water Resources Management. 27, 3191-3207.

GEORGE, B., MALANO, H., DAVIDSON, B., HELLEGERS, P., BHARATI, L. \& MASSUEL, S., 2011 a. An integrated hydro-economic modelling framework to evaluate water allocation strategies I: Model development. Agricultural Water Management. 98, 733-746.

GEORGE, B., MALANO, H., DAVIDSON, B., HELLEGERS, P., BHARATI, L. \& MASSUEL, S., $2011 \mathrm{~b}$. An integrated hydro-economic modelling framework to evaluate water allocation strategies II: Scenario assessment. Agricultural Water Management. 98, 747-758.

GIRARD, C., RINAUDO, J.-D., PULIDO-VELAZQUEZ, M. \& CABALLERO, Y., 2015. An interdisciplinary modelling framework for selecting adaptation measures 
Assessment of Ecosystem Services and Water Accounting Methodologies for Integrated Water Resources Management in water scarce basins

at the river basin scale in a global change scenario. Environmental Modelling \& Software. 69, 42-54.

GLOBAL WATER PARTNERSHIP 2000. Integrated Water Resources Management. Background report 4.

GRAFTON, R. Q., CHU, H. L., STEWARDSON, M. \& KOMPAS, T., 2011. Optimal dynamic water allocation: Irrigation extractions and environmental tradeoffs in the Murray River, Australia. Water Resources Research. 47, n/a-n/a.

GRAFTON, R. Q. \& JIANG, Q., 2011. Economic effects of water recovery on irrigated agriculture in the Murray-Darling Basin. Australian Journal of Agricultural and Resource Economics. 55, 487-499.

GRIFFIN, R. C. \& HSU, S.-H., 1993. The Potential for Water Market Efficiency When Instream Flows Have Value. American Journal of Agricultural Economics. 75, 292-303.

GROSSMANN, M. \& DIETRICH, O., 2012. Integrated Economic-Hydrologic Assessment of Water Management Options for Regulated Wetlands Under Conditions of Climate Change: A Case Study from the Spreewald (Germany). Water Resources Management. 26, 2081-2108.

HAINES-YOUNG, R. \& POTSCHIN, M. 2013. Common International Classification of Ecosystem Services (CICES): Consultation of Version 4, August-December 2012. EEA Framework Contract No EEA/IEA/09/003.

HAROU, J. J. \& LUND, J. R., 2008. Ending groundwater overdraft in hydrologiceconomic systems. Hydrogeology Journal. 16, 1039-1055.

HAROU, J. J., MEDELLÍN-AZUARA, J., ZHU, T., TANAKA, S. K., LUND, J. R., STINE, S., OLIVARES, M. A. \& JENKINS, M. W., 2010. Economic consequences of optimized water management for a prolonged, severe drought in California. Water Resources Research. 46, n/a-n/a.

HAROU, J. J., PULIDO-VELAZQUEZ, M., ROSENBERG, D. E., MEDELLÍN-AZUARA, J., LUND, J. R. \& HOWITT, R. E., 2009. Hydro-economic models: Concepts, design, applications, and future prospects. Journal of Hydrology. 375, 627643. 
HASLER, B., SMART, J. C. R., FONNESBECH-WULFF, A., ANDERSEN, H. E., THODSEN, H., BLICHER MATHIESEN, G., SMEDBERG, E., GÖKE, C., CZAJKOWSKI, M., WAS, A., ELOFSSON, K., HUMBORG, C., WOLFSBERG, A. \& WULFF, F., 2014. Hydro-economic modelling of cost-effective transboundary water quality management in the Baltic Sea. Water Resources and Economics. 5, 1-23.

HEINZ, I., PULIDO-VELAZQUEZ, M., LUND, J. R. \& ANDREU, J., 2007. Hydroeconomic Modeling in River Basin Management: Implications and Applications for the European Water Framework Directive. Water Resources Management. 21, 1103-1125.

HOUK, E. E., FRASIER, M. \& TAYLOR, R. G., 2007. Evaluating Water Transfers from Agriculture for Reducing Critical Habitat Water Shortages in the Platte Basin. Journal of Water Resources Planning and Management. 133, 320-328.

HURD, B., CALLAWAY, M., SMITH, J. B. \& KIRSHEN, P., 1999. Economic effects of climate change on US water resources. The Impact of Climate Change on the United States Economy. Cambridge University Press.

INTERGOVERNMENTAL PANEL ON CLIMATE CHANGE 2014. Climate Change 2014: Sythesis Report. Contribution of Working Groups I, II and III to the Fifth Assessment Reoprt of the Intergovernmental Panel on Climate Change. In: PACHAURI, R. K. \& MEYER, L. A. (eds.). Geneva.

JENKINS, M. W. \& LUND, J. R., 2000. Integrating Yield and Shortage Management under Multiple Uncertainties. Journal of Water Resources Planning and Management. 126, 288-297.

JENKINS, M. W., LUND, J. R., HOWITT, R. E., DRAPER, A., MSANGI, S., TANAKA, S., RITZEMA, R. S. \& MARQUES, G., 2004. Optimization of California's Water Supply System: Results and Insights. Journal of Water Resources Planning and Management. 130, 271-280.

KAHIL, M. T., DINAR, A. \& ALBIAC, J., 2015. Modeling water scarcity and droughts for policy adaptation to climate change in arid and semiarid regions. Journal of Hydrology. 522, 95-109. 
Assessment of Ecosystem Services and Water Accounting Methodologies for Integrated Water Resources Management in water scarce basins

KANDULU, J. M., CONNOR, J. D. \& MACDONALD, D. H., 2014. Ecosystem services in urban water investment. Journal of Environmental Management. $145,43-53$.

KEELER, B. L., POLASKY, S., BRAUMAN, K. A., JOHNSON, K. A., FINLAY, J. C., O'NEILL, A., KOVACS, K. \& DALZELL, B., 2012. Linking water quality and wellbeing for improved assessment and valuation of ecosystem services. Proceedings of the National Academy of Sciences. 109, 18619-18624.

KNAPP, K. C., WEINBERG, M., HOWITT, R. \& POSNIKOFF, J. F., 2003. Water transfers, agriculture, and groundwater management: a dynamic economic analysis. Journal of Environmental Management. 67, 291-301.

KRAGT, M. E., 2013. Hydro-economic modelling in an uncertain world: Integrating costs and benefits of water quality management. Water Resources and Economics. 4, 1-21.

LA NOTTE, A., LIQUETE, C., GRIZZETTI, B., MAES, J., EGOH, B. N. \& PARACCHINI, M. L., 2015. An ecological-economic approach to the valuation of ecosystem services to support biodiversity policy. A case study for nitrogen retention by Mediterranean rivers and lakes. Ecological Indicators. 48, 292302.

LEFKOFF, L. J. \& GORELICK, S. M., 1990. Benefits of an irrigation water rental market in a saline stream-aquifer system. Water Resources Research. 26, 1371-1381.

LETCHER, R. A., JAKEMAN, A. J. \& CROKE, B. F. W., 2004. Model development for integrated assessment of water allocation options. Water Resources Research. 40, n/a-n/a.

LI, Y. P., HUANG, G. H. \& CHEN, X., 2009. Multistage scenario-based intervalstochastic programming for planning water resources allocation. Stochastic Environmental Research and Risk Assessment. 23, 781-792.

LUND, R. J. \& FERREIRA, I., 1996. Operating Rule Optimization for Missouri River Reservoir System. Journal of Water Resources Planning and Management. $122,287-295$. 
MAINUDDIN, M., KIRBY, M. \& QURESHI, M. E., 2007. Integrated hydrologiceconomic modelling for analyzing water acquisition strategies in the Murray River Basin. Agricultural Water Management. 93, 123-135.

MALTBY, E. \& BARKER, T. (eds.) 2009. The wetlands handbook. John Wiley \& Sons Ltd.

MARQUES, G. F., LUND, J. R., LEU, M. R., JENKINS, M. W., HOWITT, R., HARTER, T., HATCHETT, S., RUUD, N. \& BURKE, S. M., 2006. Economically Driven Simulation of Regional Water Systems: Friant-Kern, California. Journal of Water Resources Planning and Management. 132, 468-479.

MEDELLÍN-AZUARA, J., HAROU, J. J., OLIVARES, M. A., MADANI, K., LUND, J. R., HOWITT, R. E., TANAKA, S. K., JENKINS, M. W. \& ZHU, T., 2008a. Adaptability and adaptations of California's water supply system to dry climate warming. Climatic Change. 87, 75-90.

MEDELLÍN-AZUARA, J., LUND, J. R. \& HOWITT, R. E., 2007. Water Supply Analysis for Restoring the Colorado River Delta, Mexico. Journal of Water Resources Planning and Management. 133, 462-471.

MEDELLÍN-AZUARA, J., MENDOZA-ESPINOSA, L. G., LUND, J. R., HAROU, J. J. \& HOWITT, R. E., 2009. Virtues of simple hydro-economic optimization: Baja California, Mexico. Journal of Environmental Management. 90, 3470-3478.

MEDELLÍN-AZUARA, J., MENDOZA-ESPINOSA, L. G., LUND, J. R. \& HOWITT, R. E., 2008b. Hydro-economic analysis of water supply for the binational transboundary region of Baja California, Mexico. Water Science and Technology: Water Supply. 8, 189-196.

MILLENNIUM ECOSYSTEM ASSESSMENT 2005. Ecosystems and human wellbeing. Systhesis. In: ISLAND PRESS (ed.) Ecosystems and human well-being. World Resources Institute.

MOMBLANCH, A., PAREDES-ARQUIOLA, J., MUNNÉ, A., MANZANO, A., ARNAU, J. \& ANDREU, J., 2015. Managing water quality under drought conditions in the Llobregat River Basin. Science of the Total Environment. 503-504, 300-318. 
Assessment of Ecosystem Services and Water Accounting Methodologies for Integrated Water Resources Management in water scarce basins

MULLICK, R. A., BABEL, M. S. \& PERRET, S. R., 2013. Marginal benefit based optimal water allocation: Case of Teesta River, Bangladesh. Water Policy. 15, 126-146.

MUNOZ-HERNÁNDEZ, A., MAYER, A. S. \& WATKINS JR, D. W., 2011. Integrated Hydrologic-Economic-Institutional Model of Environmental Flow Strategies for Rio Yaqui Basin, Sonora, Mexico. Journal of Water Resources Planning and Management. 137, 227-237.

NEWLIN, B. D., JENKINS, M. W., LUND, J. R. \& HOWITT, R. E., 2002. Southern California Water Markets: Potential and Limitations. Journal of Water Resources Planning and Management. 128, 21-32.

NULL, S. E. \& LUND, J. R., 2006. REASSEMBLING HETCH HETCHY: WATER SUPPLY WITHOUT O'SHAUGHNESSY DAM1. JAWRA Journal of the American Water Resources Association. 42, 395-408.

PAPADOPOULOS, C. E. \& YEUNG, H., 2001. Uncertainty estimation and Monte Carlo simulation method. Flow Measurement and Instrumentation. 12, 291298.

PLUMMER, M. L., 2009. Assessing benefit transfer for the valuation of ecosystem services. Frontiers in Ecology and the Environment. 7, 38-45.

POTSCHIN, M. B. \& HAINES-YOUNG, R. H., 2011 . Ecosystem services: Exploring a geographical perspective. Progress in Physical Geography. 35, 575-594.

PULIDO-VELAZQUEZ, M., ALVAREZ-MENDIOLA, E. \& ANDREU, J., 2013. Design of Efficient Water Pricing Policies Integrating Basinwide Resource Opportunity Costs. Journal of Water Resources Planning and Management. 139, 583-592.

PULIDO-VELAZQUEZ, M., ANDREU, J. \& SAHUQUILLO, A., 2006. Economic Optimization of Conjunctive Use of Surface Water and Groundwater at the Basin Scale. Journal of Water Resources Planning and Management. 132, 454-467.

PULIDO-VELAZQUEZ, M., ANDREU, J., SAHUQUILLO, A. \& PULIDO-VELAZQUEZ, D., 2008a. Hydro-economic river basin modelling: The application of a holistic surface-groundwater model to assess opportunity costs of water use in Spain. Ecological Economics. 66, 51-65. 
PULIDO-VELAZQUEZ, M., ANDREU, J., SAHUQUILLO, A. \& PULIDO-VELAZQUEZ, D., 2008b. Hydro-economic river basin modelling: The application of a holistic surface-groundwater model to assess opportunity costs of water use in Spain. Ecological economics. 66, 51-65.

PULIDO-VELAZQUEZ, M., JENKINS, M. W. \& LUND, J. R., 2004. Economic values for conjunctive use and water banking in southern California. Water Resources Research. 40, n/a-n/a.

QURESHI, M. E., CONNOR, J., KIRBY, M. \& MAINUDDIN, M., 2007. Economic assessment of acquiring water for environmental flows in the Murray Basin*. Australian Journal of Agricultural and Resource Economics. 51, 283-303.

REYNAUD, A. \& LEENHARDT, D. Year. MoGIRE: A Model for IntegratedWater Management, in: International Congress on Environmental Modelling and Software, 2008 Barcelona, Spain.

RIEGELS, N., JENSEN, R., BENSASSON, L., BANOU, S., MØLLER, F. \& BAUERGOTTWEIN, P., 2011. Estimating resource costs of compliance with EU WFD ecological status requirements at the river basin scale. Journal of Hydrology. $396,197-214$.

RIEGElS, N., PULIDO-VELAZQUEZ, M., DOULGERIS, C., STURM, V., JENSEN, R., MOLLER, F. \& BAUER-GOTTWEIN, P., 2013. Systems Analysis Approach to the Design of Efficient Water Pricing Policies under the EU Water Framework Directive. Journal of Water Resources Planning and Management. 139, 574582.

RINGLER, C. \& CAI, X., 2006. Valuing Fisheries and Wetlands Using Integrated Economic-Hydrologic Modeling-Mekong River Basin. Journal of Water Resources Planning and Management. 132, 480-487.

RINGLER, C., VON BRAUN, J. \& ROSEGRANT, M. W., 2004. Water Policy Analysis for the Mekong River Basin. Water International. 29, 30-42.

ROOZBAHANI, R., SCHREIDER, S. \& ABBASI, B., 2013. Economic Sharing of Basin Water Resources between Competing Stakeholders. Water Resources Management. 27, 2965-2988. 
Assessment of Ecosystem Services and Water Accounting Methodologies for Integrated Water Resources Management in water scarce basins

ROOZBAHANI, R., SCHREIDER, S. \& ABBASI, B., 2015. Optimal water allocation through a multi-objective compromise between environmental, social, and economic preferences. Environmental Modelling \& Software. 64, 18-30.

ROSEGRANT, M. W., RINGLER, C., MCKINNEY, D. C., CAI, X., KELLER, A. \& DONOSO, G., 2000. Integrated economic-hydrologic water modeling at the basin scale: the Maipo river basin. Agricultural Economics. 24, 33-46.

SCHEFFER, M., CARPENTER, S., FOLEY, J. A., FOLKE, C. \& WALKER, B., 2001. Catastrophic shifts in ecosystems. Nature. 413, 591-596.

SCHOUPS, G., ADDAMS, C. L., MINJARES, J. L. \& GORELICK, S. M., 2006. Sustainable conjunctive water management in irrigated agriculture: Model formulation and application to the Yaqui Valley, Mexico. Water Resources Research. 42, n/a-n/a.

SCHWABE, K., ALBIAC, J., ANDREU, J., AYERS, J., CAIOLA, N., HAYMAN, P. \& IBANEZ, C., 2013. Summaries and Considerations, in: SCHWABE, K., ALBIAC, J., CONNOR, J. D., HASSAN, R. M. \& MEZA GONZÁLEZ, L. (eds.), Drought in Arid and Semi-Arid Regions. A Multi-Disciplinary and Cross-Country Perspective. Springer, 471-507.

SHAMA, P., 2004. Population Growth and Sustainable Development. Economic and Political Weekly. 39, 629-633.

SPANGENBERG, J. H., VON HAAREN, C. \& SETtELE, J., 2014. The ecosystem service cascade: Further developing the metaphor. Integrating societal processes to accommodate social processes and planning, and the case of bioenergy. Ecological economics. 104, 22-32.

TANAKA, S. K., ZHU, T., LUND, J. R., HOWITT, R. E., JENKINS, M. W., PULIDO, M. A., TAUBER, M., RITZEMA, R. S. \& FERREIRA, I. C., 2006. Climate Warming and Water Management Adaptation for California. Climatic Change. 76, 361387.

TERRADO, M., MOMBLANCH, A., BARDINA, M., BOITHIAS, L., MUNNÉ, A., SABATER, S., SOLERA, A. \& ACUÑA, V., 2016. Integrating ecosystem services in river basin management plans. Journal of Applied Ecology. n/a-n/a. 
THE ECONOMICS OF ECOSYSTEMS \& BIODIVERSITY 2008. The economics of ecosystems and biodiversity: An interim report. European Communities.

THE ECONOMICS OF ECOSYSTEMS \& BIODIVERSITY, 2010. The Economics of Ecosystems and Biodiversity Ecological and Economic Foundations, in: KUMAR, P. (ed.). Earthscan, London and Washington

TIETENBERG, T. \& LEWIS, L., 2009. Environmental \& Natural Resource Economics. Pearson Addison Wesley, Boston.

TISDELL, J. G., 2001. The environmental impact of water markets: An Australian case-study. Journal of Environmental Management. 62, 113-120.

TURNER, R. K., GEORGIOU, S. \& FISHER, B. (eds.) 2008. Valuing Ecosystem Services: The Case of Multi-functional Wetlands. Taylor and Francis, London.

UK NATIONAL ECOSYSTEM ASSESSMENT 2011. The UK National Ecosystem Assessment: Synthesis of the Key Findings. In: UNAP-WCMC (ed.). Cambridge.

UNITED NATIONS - DEPARMENT OF ECONOMIC AND SOCIAL AFFAIRS POPULATION DIVISION 2015. World Population Prospects: The 2015 Revision, Key Findings and Advance Tables. Working Paper No. ESA/P/WP.241.

UNITED NATIONS, EUROPEAN COMMISSION, FOOD AND AGRICULTURE ORGANIZATION OF THE UNITED NATIONS, INTERNATIONAL MONETARY FUND, ORGANISATION FOR ECONOMIC CO-OPERATION AND DEVELOPMENT \& WORLD BANK 2012. System of Environmental-Economic Accounting 2012. Central Framework. In: NATIONS, U. (ed.). New York.

VARELA-ORTEGA, C., BLANCO-GUTIÉRREZ, I., SWARTZ, C. H. \& DOWNING, T. E., 2011. Balancing groundwater conservation and rural livelihoods under water and climate uncertainties: An integrated hydro-economic modeling framework. Global Environmental Change. 21, 604-619.

VAUX, H. J. \& HOWITT, R. E., 1984. Managing Water Scarcity: An Evaluation of Interregional Transfers. Water Resources Research. 20, 785-792.

VOLK, M., HIRSCHFELD, J., DEHNHARDT, A., SCHMIDT, G., BOHN, C., LIERSCH, S. \& GASSMAN, P. W., 2008. Integrated ecological-economic modelling of 
Assessment of Ecosystem Services and Water Accounting Methodologies for Integrated Water Resources Management in water scarce basins

water pollution abatement management options in the Upper Ems River Basin. Ecological economics. 66, 66-76.

WALLACE, K. J., 2007. Classification of ecosystem services: Problems and solutions. Biological Conservation. 139, 235-246.

WAN, J., YANG, Y.-C. E., LIN, Y.-F. \& WANG, J., 2013. Groundwater Resource Planning to Preserve Streamflow: Where Environmental Amenity Meets Economic Welfare Loss. Journal of Water Resources Planning and Management. 139, 440-448.

WARD, F. A., 2009. Economics in integrated water management. Environmental Modelling \& Software. 24, 948-958.

WARD, F. A., BOOKER, J. F. \& MICHELSEN, A. M., 2006. Integrated Economic, Hydrologic, and Institutional Analysis of Policy Responses to Mitigate Drought Impacts in Rio Grande Basin. Journal of Water Resources Planning and Management. 132, 488-502.

WARD, F. A. \& LYNCH, T. P., 1996. INTEGRATED RIVER BASIN OPTIMIZATION: MODELING ECONOMIC AND HYDROLOGIC INTERDEPENDENCE. JAWRA Journal of the American Water Resources Association. 32, 1127-1138.

WARD, F. A. \& LYNCH, T. P., 1997. Is dominant use management compatible with basin-wide economic efficiency? Water Resources Research. 33, 1165 1170.

WARD, F. A. \& PULIDO-VELAZQUEZ, M., 2009. Incentive pricing and cost recovery at the basin scale. Journal of Environmental Management. 90, 293313.

WARD, F. A. \& PULIDO-VELAZQUEZ, M., 2012. Economic Costs of Sustaining Water Supplies: Findings from the Rio Grande. Water Resources Management. 26, 2883-2909.

WARD, F. A. \& PULIDO-VELÁZZUEZ, M., 2008. Efficiency, equity, and sustainability in a water quantity-quality optimization model in the Rio Grande basin. Ecological economics. 66, 23-37. 
WATKINS JR, D. W. \& MCKINNEY, D. C., 1999. Screening Water Supply Options for the Edwards Aquifer Region in Central Texas. Journal of Water Resources Planning and Management. 125, 14-24.

WILCHFORT, O. \& LUND, J. R., 1997. Shortage Management Modeling for Urban Water Supply Systems. Journal of Water Resources Planning and Management. 123, 250-258.

YANG, W. \& YANG, Z., 2013. Development of a Long-term, Ecologically Oriented Dam Release Plan for the Lake Baiyangdian Sub-basin, Northern China. Water Resources Management. 27, 485-506.

YANG, W. \& YANG, Z., 2014. Analyzing Hydrological Regime Variability and Optimizing Environmental Flow Allocation to Lake Ecosystems in a Sustainable Water Management Framework: Model Development and a Case Study for China's Baiyangdian Watershed. Journal of Hydrologic Engineering. 19, 993-1005.

YANG, Y.-C. E. \& CAI, X., 2011. Reservoir Reoperation for Fish Ecosystem Restoration Using Daily Inflows-Case Study of Lake Shelbyville. Journal of Water Resources Planning and Management. 137, 470-480.

YANG, Y.-C. E., ZHAO, J. \& CAI, X., 2012. Decentralized Optimization Method for Water Allocation Management in the Yellow River Basin. Journal of Water Resources Planning and Management. 138, 313-325.

ZOLTAY, V. I., VOGEL, R. M., KIRSHEN, P. H. \& WESTPHAL, K., 2010. Integrated Watershed Management Modeling: Generic Optimization Model Applied to the Ipswich River Basin. Journal of Water Resources Planning and Management. 136, 566-575. 
Assessment of Ecosystem Services and Water Accounting Methodologies for Integrated Water Resources Management in water scarce basins

\section{A.3 Integrating ecosystem services in river basin management plans}

\section{Summary}

1. According to the European Union Water Framework Directive, river basin management plans must include a programme of measures, with a series of management actions aiming to achieve good ecosystem status of all water bodies within the basin. The design and later prioritization of these management actions is, in theory, done through cost-effectiveness analysis (CEA), which compares management action costs with expected improvements in ecosystem status. However, such an approach does not consider the effects of management actions on human well-being resulting from changes in the provision of ecosystem services.

2. We propose to complement the current CEA approach with a costbenefit analysis (CBA) integrating the effects of management actions on the provision of ecosystem services, therefore moving from a single-objective to a multiobjective approach. We propose a flexible methodological framework based on a combination of CEA and CBA that can be easily adapted to different case studies.

3. To test the applicability of our approach, we applied it to an impaired basin, the Llobregat River basin (north-eastern Iberian Peninsula). The analysis considers management actions selected from the programme of measures under implementation: establishment of environmental river flows, improvement of river connectivity, treatment of urban wastewater and reduction in saline pollution; and the effects on a series of ecosystem services: water provisioning, waste treatment and habitat for species.

4. Results revealed that management actions designed to improve ecosystem status do not necessarily improve human well-being through changes in the provision of ecosystem services.

5. The implementation of the CEA and CBA allowed the identification of management actions providing the best trade-offs between improvements of ecosystem status and human well-being. For example, the establishment of environmental river flows in the upper Llobregat River was the management action that maximized the balance between gains in ecosystem status and human well-being. 
6. Synthesis and applications. Overall, the combination of cost-effectiveness analysis and cost-benefit analysis supports a more informed and transparent decision-making in the implementation of river basin management plans, better assisting stakeholders to prioritize those management actions providing the optimal win-win results.

\section{Key-words}

Cost-benefit analysis, cost-effectiveness analysis, decision-making, ecosystem services, ecosystem status, human well-being, programme of measures, river basin management plan, Water Framework Directive.

\section{Introduction}

The management of river basins plays a key role in the conservation and improvement of the general state of water bodies world-wide because it allows for the consideration of resource protection while meeting social and ecological needs. In the European Union, river basin management is implemented through river basin management plans (RBMPs) defined in the context of the Water Framework Directive (WFD, 2000/60/EC). The core of these RBMPs is the programme of measures, which includes a series of management actions designed to achieve good ecosystem status of all water bodies within the basin. The design and later prioritization of the management actions of the programme of measures is sometimes done through cost-effectiveness analysis (CEA) (Balana, Vinten \& Slee 2011; Berbel, Martin-Ortega \& Mesa 2011). CEA compares management action costs with expected improvements in ecosystem status aiming to identify those measures allowing the achievement of environmental objectives at the minimum cost. However, it has been suggested that CEA might not be the most appropriate decision-making approach (Berbel, Martin-Ortega \& Mesa 2011 ), as it does not consider the effects of management actions on human well-being resulting from changes in the provision of ecosystem services. In fact, CEA is a single- rather than a multiobjective approach, and it does not reflect trade-offs between environmental and social objectives (Berbel, Martin-Ortega \& Mesa 2011; Martin-Ortega 2012). Thus, the consideration of improvement of the ecosystem status as the unique objective in the design and prioritization of management actions may lead to undesired negative consequences for human well-being as a result of a decrease in the level of 
Assessment of Ecosystem Services and Water Accounting Methodologies for Integrated Water Resources Management in water scarce basins

certain ecosystem services.

Given this background, we believe that the integration of ecosystem services into the design and prioritization of management actions within the programme of measures might allow to better address multibenefit goals (Everard 2014), although the practical application of the ecosystem services concept requires focusing on stakeholder needs and counting on their collaboration (Böck et al. 2015). In fact, the consideration of costs and benefits of measures has been progressively included in the decision-making process (Adams 2014), reinforcing the idea of nature being incorporated as an economic value in environmental decisions. Some authors have argued against the use of monetary values to weight non-market ecosystem services and biodiversity (McCauley 2006). Others have argued that intrinsic valuation of nature (i.e. that nature should be protected for its own sake) and instrumental valuation of nature (i.e. that valuation should be used in contexts where support for conservation is essential) are compatible approaches; these approaches have been proposed to comprise a unified and diverse conservation ethic (Tallis et al. 2014). The assessment of the effects of management actions on human well-being through the changes in the provision of ecosystem services allows the comparison of the management action costs with the economic benefits related to their implementation. Specifically, a cost-benefit analysis (CBA), performed comparing management action costs with the marginal benefits resulting from the implementation of the management actions, allows for a direct comparison of alternative management actions and provides planners more information than a CEA alone (Alcon et al. 2012). Although in an ambiguous way, CBA is one of the instruments that the WFD suggests to determine whether the costs of reaching certain environmental objectives are disproportionate (i.e. costs to implement management actions are too high compared to the obtained improvement in ecological status) or an extension of a deadline should be granted because environmental objectives cannot be attained by the date established in the WFD (MolinosSenante, Hernández-Sancho \& Sala-Garrido 2011). Still, numerous questions remain regarding the CBA approach. In particular, whether CBA represents society's collective well-being rather than particular interests (Turner 2007), whether economic valuation can adequately capture the complexity of people's preferences or whether CBA considers the appropriate factors 
when considering public benefits, including social justice (Norgaard 2010). Even acknowledging its limitations, CBA can be useful for clarifying certain trade-offs, and this has favoured its growing use by government agencies interested in quantifying the outcomes of proposed management actions. The progressive integration of economic theory and the ecosystem services concept to inform decision-making has crystallized in estimations of proportionality between the costs of implementing particular actions and the obtained benefits in the specific context of the WFD (Birch et al. 2010; Laurans et al. 2013; Vlachopoulou et al. 2014). The use of CBA to assess the effect of management actions has included the establishment of environmental flows or the treatment of wastewater on ecosystem services at the basin scale (Del Saz-Salazar, Hernández-Sancho \& Sala-Garrido 2009; Martin-Ortega, Giannoccaro \& Berbel 2011; Honey-Roses et al. 2013). These studies have shown that benefits often overcome costs but also provide evidence of the large information gap between the ideal CBA and what is feasible in the context of each particular case.

In this study, we aimed to test whether the integration of ecosystem services into the design and prioritization of management actions through CBA allows for the accounting of trade-offs among different management actions and, when combined with CEA, could help prioritizing actions that provide winwin results for both human wellbeing and ecosystem status. Thus, we applied CEA and CBA for a series of management actions within the programme of measures of the Llobregat River basin (northeastern Iberian Peninsula). This river basin has a strong human influence and a complex management (Marce et al. 2012) and therefore provides a good setting to test the complementarity of both approaches. The management actions considered address some of the most striking problems in the basin, such as the establishment of environmental river flows (the minimum flow necessary to sustain freshwater ecosystems), improvement of river connectivity, treatment of urban wastewater and reduction in saline pollution. The ecosystem services considered include water provisioning, waste treatment and habitat provision for species. To our knowledge, few studies have relied on a combination of CBA and CEA within the framework of the WFD (Barton et al. 2008; Galioto et al. 2013), and only the latter related ecosystem services to the implementation of a programme of measures. We compared the results obtained by CBA and CEA for the selected management actions in the 
Assessment of Ecosystem Services and Water Accounting Methodologies for Integrated Water Resources Management in water scarce basins

Llobregat and assessed whether gains in terms of ecosystem services also correspond to improvement in ecosystem status. Furthermore, we also developed a framework to link management actions of a given programme of measures with a series of benefits and monetary values that could guide similar approaches in other basins.

\section{Materials and methods}

Study site

The Llobregat River flows from the Pyrenees Mountains to the Mediterranean Sea and is one of the main water sources for the city of Barcelona and its metropolitan area, with a population of more than 3 million people (Fig. 1). Covering an area of $4950 \mathrm{~km}^{2}$, the Llobregat basin is an example of a highly populated, severely exploited and highly impacted area in the Mediterranean region. More than 100 small hydropower plants are located in the basin (Fig. 1b), taking water from the river, routing it through derivation channels to the hydropower plants and returning it to the river after several metres (Marcé et al. 2012). The diverted water is not consumed, but repeated diversions leave river segments with residual flow. Residual flows, weirs from the hydropower plants, gauging stations and other obstacles located along the river channel disrupt river connectivity and constitute a barrier for fish movement upstream and downstream. The river also receives the discharge from several urban and industrial wastewater treatment plants (WWTPs), especially at its lower course, where these anthropogenic activities mainly concentrate (Fig. 1a). The mining activity existing in one of the Llobregat tributaries is responsible for high salinity concentrations in the river. A brine collector transporting mining waste directly to the Mediterranean was built (Marcé et al. 2012). Finally, two drinking water treatment plants (drinking WTPs) are located close to the outlet. 

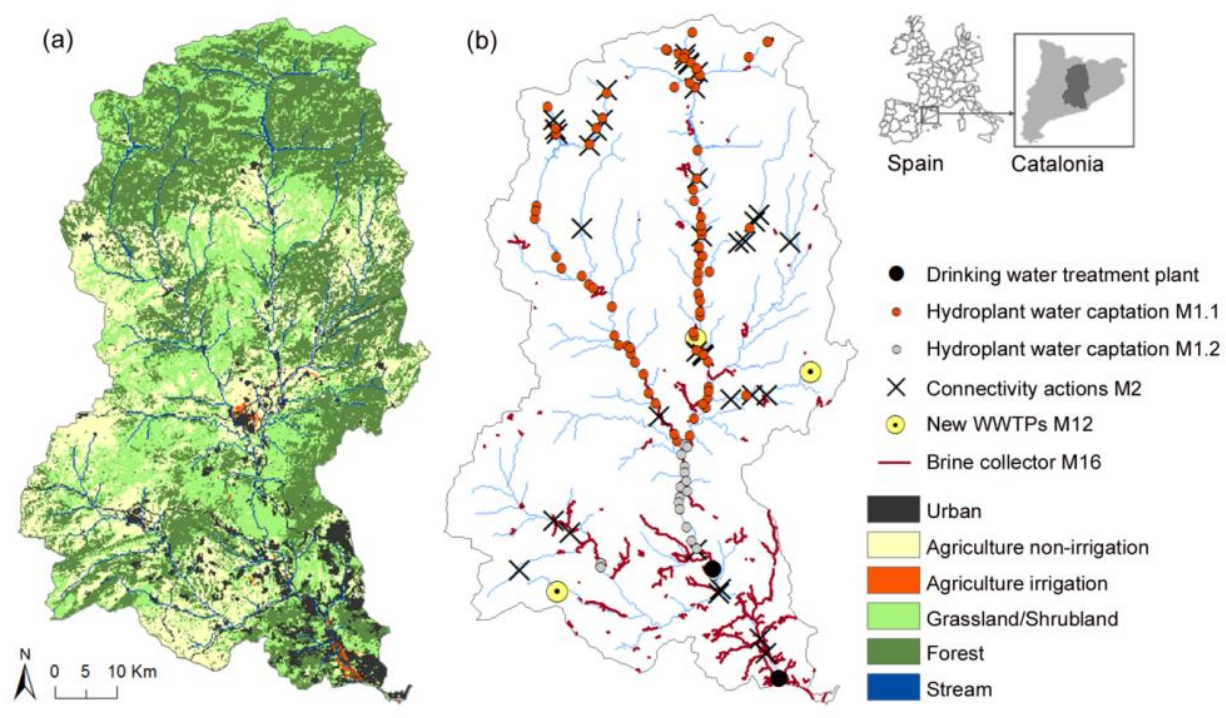

Figure 1. Llobregat River basin land uses (a) and spatial locations of the selected measures to be implemented (b). WWTP stands for wastewater treatment plant. Measures: establishment of environmental river flows in the upper Llobregat and Cardener rivers (M1.1) and in the lower Llobregat and Anoia rivers (M1.2), improvement of river connectivity (M2), treatment of urban wastewater (M12), reduction in saline pollution (M16).

\section{Selected measures}

Eighteen different types of measures were included by the regional water agency (the Catalan Water Agency) in the programme of measures for the Llobregat RBMP (ACA 2010a). Among those, we selected four types to perform the CEA and the CBA: implementation of environmental river flows (M1), improvement of river connectivity (M2), treatment of urban wastewater (M12) and reduction in saline pollution (M16). The rationale behind the selection of those four types of measures was to use some of the most commonly implemented management actions in Europe (EEA 2012), to show the usefulness of the proposed approach rather than to assess the impact of the implementation of all the programme of measures in that particular river basin. For each measure, we selected one or more actions depending on data availability regarding the expected effects of the action (Table 1). It is important to note that a single action can affect the provision of more than one ecosystem service and therefore it might accrue for multiple benefits. Although the efficacy of different actions varies when they 
Assessment of Ecosystem Services and Water Accounting Methodologies for Integrated Water Resources Management in water scarce basins

are implemented individually or in combination with other actions, we analysed the effect of each action individually for the sake of simplicity.

\begin{tabular}{|c|c|c|c|c|}
\hline Measure & Action & $\begin{array}{l}\text { Action code in } \\
\text { PoM }\end{array}$ & Description & $\begin{array}{c}\text { Representation of the } \\
\text { effect }\end{array}$ \\
\hline \multirow{2}{*}{ MI } & M1.1 & 01.0 .00 .0007 & $\begin{array}{l}\text { Establishment of environmental } \\
\text { flow rates in the upper Llobregat } \\
\text { and Cardener rivers }\end{array}$ & \multirow{2}{*}{$\begin{array}{l}\text { Increase of water in the } \\
\text { river and decrease of } \\
\text { the apportionment for } \\
\text { other uses }\end{array}$} \\
\hline & M1.2 & 01.0 .00 .0008 & $\begin{array}{l}\text { Establishment of environmental } \\
\text { flow rates in the lower Llobregat } \\
\text { and Anoia rivers }\end{array}$ & \\
\hline M2 & M2 & 02.0.00.0006 & $\begin{array}{l}\text { Improvement of river } \\
\text { connectivity }\end{array}$ & $\begin{array}{l}\text { Elimination/restoration } \\
\text { of particular obstacles } \\
\text { in the river channel } \\
\text { priority reaches (weirs, } \\
\text { gauge stations...) }\end{array}$ \\
\hline \multirow{3}{*}{ M12 } & M12.1 & 12.1 .01 .0065 & $\begin{array}{l}\text { New wastewater treatment plant } \\
\text { with nutrient reduction in } \\
\text { Mediona }\end{array}$ & \multirow{3}{*}{$\begin{array}{l}\text { Reduction efficiency } \\
\text { objectives for the } \\
\text { treatment of urban } \\
\text { wastewater (BOE 1996) }\end{array}$} \\
\hline & M12.2 & 12.1 .01 .0066 & $\begin{array}{l}\text { New wastewater treatment plant } \\
\text { with nutrient reduction in } \\
\text { Balsareny }\end{array}$ & \\
\hline & M12.3 & 12.1 .01 .0067 & $\begin{array}{l}\text { New wastewater treatment plant } \\
\text { with nutrient reduction in Moià }\end{array}$ & \\
\hline \multirow{4}{*}{ M16 } & M16.1 & $\begin{array}{l}16.1 .01 .0001 \\
16.1 .01 .0002 \\
16.1 .01 .0003 \\
16.1 .01 .0004 \\
\end{array}$ & $\begin{array}{l}\text { Reduction of saline pollution in } \\
\text { the medium-low Llobregat basin }\end{array}$ & \multirow{4}{*}{$\begin{array}{l}\text { Attainment of the } \\
\text { environmental } \\
\text { objectives (for } \\
\text { conductivity) for } \\
\text { chemical and } \\
\text { ecological status of } \\
\text { surface water bodies } \\
\text { (ACA 2010c) }\end{array}$} \\
\hline & M16.2 & $\begin{array}{l}16.2 .01 .0001 \\
16.2 .01 .0002 \\
\end{array}$ & $\begin{array}{l}\text { Reduction of saline pollution in } \\
\text { the medium-low Llobregat basin }\end{array}$ & \\
\hline & M16.3 & 16.2.02.0001 & $\begin{array}{l}\text { Minimization of the impact of salt } \\
\text { mines }\end{array}$ & \\
\hline & M16.4 & $\begin{array}{l}\text { 16.3.01.0001 } \\
16.3 .01 .0002\end{array}$ & $\begin{array}{l}\text { Minimization of the impact of salt } \\
\text { mines }\end{array}$ & \\
\hline
\end{tabular}

Table 1. Description of the actions selected in the Llobregat basin and expected effects in the model.

\section{Modelling approach}

Ecosystems and Biodiversity (TEEB 2010), which describes the pathway from ecosystems and biodiversity to human well-being (Fig. 2) in order to assign the relevant benefits to each considered ecosystem service. This approach clearly differentiates among ecological phenomena (functions), their direct and indirect contribution to human well-being (services) and the gains they generate in well-being (benefits). Thus, benefits correspond to the gains in well-being from each of the three considered services potentially affected 
by the selected management actions (Fig. 2). To quantify the effects of the management actions on these benefits, we used two different models: AQUATOOL (Andreu, Capilla \& Sanchis 1996) and InVEST (Integrated Valuation of Ecosystem Services and Tradeoffs) (Tallis et al. 2011), which can be complementary for issues that cannot be adequately assessed within a single model platform. AQUATOOL is a monthly Decision Support System Shell for integrated water resources management at the river basin scale, and we applied two of its modules: SIMGES and GESCAL. SIMGES is a simulationoptimization module based on a flow network algorithm that solves the water allocation of complex water resource systems with surface and groundwater storage, intake, transport, artificial recharge, use and consumption elements; GESCAL simulates the evolution of water quality in the river network. The water quality variables considered were temperature, dissolved oxygen, organic matter, nutrients and toxic pollutants, among others. InVEST is a spatially explicit ecosystem service tool consisting of a suite of models available to estimate levels of different benefits at the annual scale. Information about data requirements and outputs of the models applied is listed in Table S1 in Supporting Information.

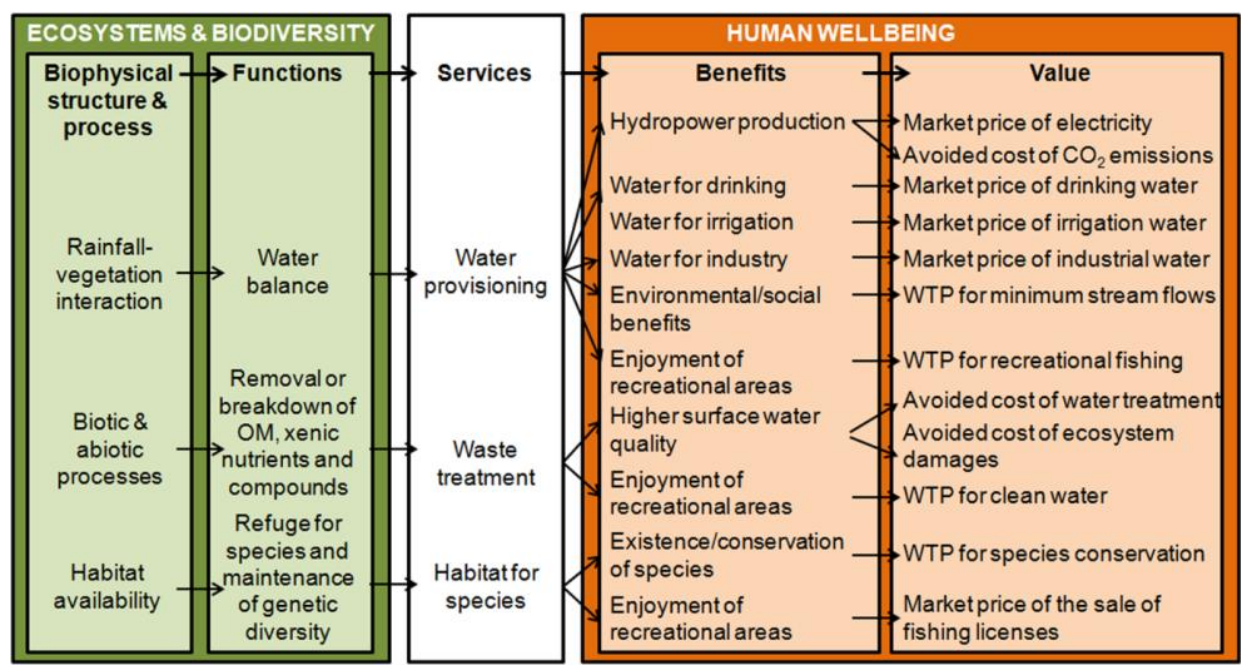

Figure 2. Pathways from biophysical structures and processes to human well-being for three freshwater-related ecosystem services. WTP stands for willingness to pay. 
Assessment of Ecosystem Services and Water Accounting Methodologies for Integrated Water Resources Management in water scarce basins

Given the selection of services, we considered in our study as many benefits as possible as long as we could maintain the possibility of applying at least one valuation metric to calculate its annual monetary value.

\section{Effect of management actions}

The effect of management actions was calculated as the change in ecosystem status (subsequently integrated in a CEA) and the change in the provision of benefits from ecosystem services (subsequently integrated in a (BA).

\section{Cost-effectiveness analysis}

The effects of management actions on the ecological status of water bodies were estimated from the induced changes in threat levels. The relationship between ecosystem status and threat level was based on a study performed by the regional water agency, which related the current 13 main threats in the Llobregat basin to the current ecosystem status (ACA 2014). Specifically, this study assigned a value between 0 (no pressure) and 3 (high pressure) to each of the 13 identified threats for each water body. The threat values were based on the threat's magnitude, the water bodies' vulnerability and the environmental objective defined for each threat. Environmental objectives corresponded to values from which a perturbation on the ecosystem was expected to occur. Thus, when the effect of the threat equalled the environmental objective, the threat was assigned a value of 1 (i.e. the risk of not meeting the environmental objective was low). In contrast, when the effect of the threat exceeded the objective, a value of 2 or 3 was assigned (i.e. the risk of not meeting the environmental objective was higher). To estimate the total threat level for the scenario previous to the implementation of the management action, we aggregated the threat values of the individual threats for the whole river basin (Table S2). The effects of management actions were estimated by assigning a threat level of ' 0 ' to those threats directly affected by the specific management actions: the establishment of environmental river flows minimized the threats posed by water abstraction; the improvement of river connectivity affected the threats posed by dams and weirs; the treatment of urban wastewater minimized the threats posed by urban discharge; and the reduction in saline pollution minimized the threats posed by salinization. To sum up, the threat 
level after the implementation of the management actions was calculated after aggregating the values of individual threats for the whole river basin (Table S2). The effect of each management action in terms of ecosystem status was calculated as the difference between the total threat level before and after the implementation of the management action. Then, this change in ecosystem status was compared with the net present value of costs. The considered costs included the implementation costs and the exploitation and maintenance costs of management actions.

\section{Cost-benefit analysis}

The considered benefits are listed in Table S3, and the equations applied to calculate the monetary value of each benefit are described in Table S4. When the same benefit was assessed using more than one valuation metric, an average result is reported. For each of the selected management actions, the benefits expected to be affected by the action were calculated (1) with the implementation of the action and (2) without the implementation of the action. The marginal value of the action was calculated as (1-2), accounting for the change in benefit provision after implementation of the action. Calculations were performed at the subbasin scale (sub-basins associated with each water body) and eventually aggregated to obtain a value for the whole basin. The obtained marginal values can be positive or negative; positive values mean that the implementation of the action increases gains in well-being (coherent to benefit gains in the economic analysis), whereas negative values imply the increase in well-being losses or 'dis-benefits' (TEEB 2010) (coherent to opportunity costs or benefit losses in the economic analysis).

The considered costs included the implementation costs, the exploitation and maintenance costs and the opportunity costs of foregone alternatives. Both marginal benefits and costs were expressed as net present values, calculated considering a period of 15 years and a discount rate of $5 \%$. Fifteen years is a commonly selected period because it often corresponds to the useful life span of certain measures (i.e. those involving wastewater treatment plants, although other life spans have also been considered elsewhere according to plant-specific technology) (Del Saz-Salazar, Hernandez-Sancho \& Sala-Garrido 2009; Molinos-Senante, HernandezSancho \& Sala-Garrido 2011). This timespan coincides approximately with 
Assessment of Ecosystem Services and Water Accounting Methodologies for Integrated Water Resources Management in water scarce basins

the time frame for the implementation of the WFD (by 2027). The $5 \%$ discount rate was selected based on the recommendation of the European Commission of this value as an indicative benchmark for public investment projects (EC 2006). However, lower discount rates (2\% and $3 \%$ ) also have been tried in order to assess the sensitivity of the results to this parameter.

\section{Results}

\section{Cost-effectiveness analysis}

The management action providing the highest gain in ecosystem status at the river basin scale was the establishment of environmental river flows, followed by the management actions for the reduction in saline pollution and the improvement of river connectivity (Fig. 3a; see Table S5 for more detail). The ranking of management actions differed when considering the costs, as the management action with the best cost-effectiveness was one of the actions for the reduction in saline pollution (M16.3). After that, actions for the treatment of urban wastewater held the second position in terms of cost-effectiveness. The management action with the lowest costeffectiveness was one of the actions for the reduction in salinity (M16.1), because it incurred a considerably higher cost than the other actions selected in this study. 


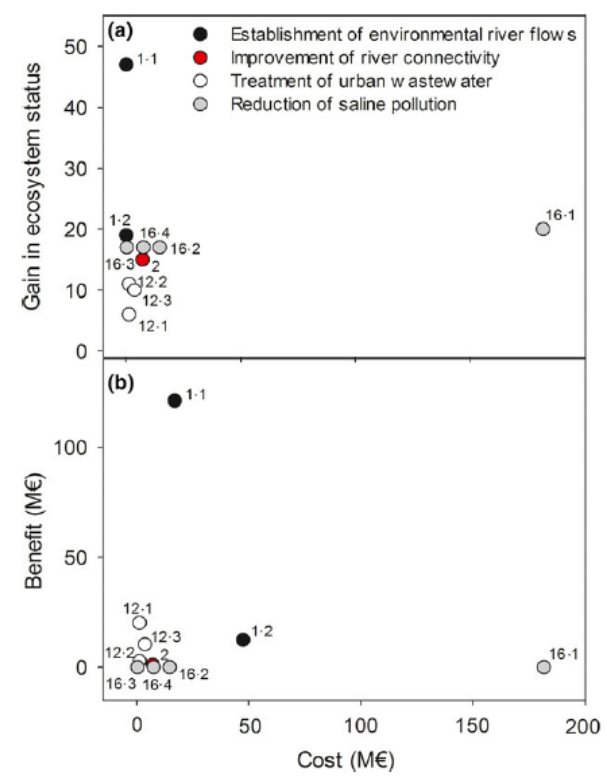

Figure 3. Cost-effectiveness analysis (a) and cost-benefit analysis (b) of the selected actions of the programme of measures in the Llobregat River basin. Cost in (a) refers to the cost of implementation + the cost of exploitation and maintenance. Cost in (b) is the cost of implementation + the cost of exploitation and maintenance + the cost of opportunity.

\section{Effects of management actions on benefits}

The management actions providing the highest gain in the benefits associated with the considered ecosystem services were actions for the establishment of environmental river flows (M1.1 and M1.2) (Table 2). Actually, the establishment of environmental flows in the upper Llobregat basin (M1.1) caused both benefit gains and losses, which were estimated to amount to $10.8 \mathrm{M} €$ and $-1.51 \mathrm{M} \epsilon$, respectively. The greatest losses were related to the hydropower production, followed by losses of water use by industry, drinking and irrigation. The highest gains were related to the enjoyment of recreational areas and environmental/social benefits. The assessment of hydropower production gave different economic estimations depending on the applied valuation metric (see Table S3 for a compilation of the applied metrics): a loss value of $-2.3 \mathrm{M} €$ year -1 was obtained using the market price of electricity, whereas $-0.048 \mathrm{M} €$ year -1 was obtained when the avoided cost of $\mathrm{CO}_{2}$ emissions was used instead. This difference is highly relevant and demonstrates that a different result is obtained 
Assessment of Ecosystem Services and Water Accounting Methodologies for Integrated Water Resources Management in water scarce basins

according to the valuation metrics applied in the calculation of the benefit. To reduce the overall uncertainty of results, the average value obtained with the different valuation metrics is reported in Table 2. Similarly, two different values were estimated for the enjoyment of recreational areas, one through contingent valuation and the other through the market price, and an average value of $5.46 \mathrm{M} €$ is reported in Table 2. The same benefits assessed for the establishment of environmental flows in the upper basin were also assessed in the lower basin (M1.2), except for environmental/social benefits, for which we lacked appropriate data since the lower Llobregat basin receives much higher urban and industrial pressures. The total annual gains and losses estimated by the implementation of environmental river flows in the lower Llobregat basin amounted to 1.1 M€ and -4.2 $\mathrm{M} €$, respectively. The highest losses corresponded to water for drinking, followed by hydropower production, water for irrigation and water for industry, whereas the highest gains corresponded to enjoyment of recreational areas. Unlike in the upper basin, the market price of fishing licences was not calculated in the lower basin because this metric was only applied to river reaches with trout fishing, which are only present in the upper part.

\begin{tabular}{|c|c|c|}
\hline Action & Benefits/Opportunity costs & Value $\left(€\right.$ basin $\left.^{-1} y^{-1}\right)$ \\
\hline \multirow{7}{*}{ M1.1 } & Hydropower production & -1173088 \\
\hline & Water for drinking & -85024 \\
\hline & Water for irrigation & -33855 \\
\hline & Water for industry & -221175 \\
\hline & Environmental/social benefits & 5334487 \\
\hline & Existence/conservation of species diversity & 97 \\
\hline & Enjoyment of recreational areas & 5468681 \\
\hline \multirow{6}{*}{ M1.2 } & Hydropower production & -371109 \\
\hline & Water for drinking & -3857581 \\
\hline & Water for irrigation & -2844 \\
\hline & Water for industry & 0 \\
\hline & Existence/conservation of species diversity & 752 \\
\hline & Enjoyment of recreational areas & 1097904 \\
\hline \multirow{3}{*}{ M2 } & Hydropower production & -70374 \\
\hline & Existence/conservation of species diversity & 109461 \\
\hline & Enjoyment of recreational areas & 0.4 \\
\hline \multirow[t]{2}{*}{ M12.1 } & Higher surface water quality & 23404 \\
\hline & Enjoyment of recreational areas & 1773261 \\
\hline \multirow[t]{2}{*}{ M12.2 } & Higher surface water quality & 37968 \\
\hline & Enjoyment of recreational areas & 209566 \\
\hline \multirow[t]{2}{*}{ M12.3 } & Higher surface water quality & 102709 \\
\hline & Enjoyment of recreational areas & 819933 \\
\hline M16.1 & Higher surface water quality & 0 \\
\hline M16.2 & Higher surface water quality & 0 \\
\hline
\end{tabular}




\begin{tabular}{ccc}
\hline Action & Benefits/Opportunity costs & Value $\left(\boldsymbol{\epsilon}\right.$ basin $\left.^{-1} \mathbf{y}^{-1}\right)$ \\
\hline M16.3 & Higher surface water quality & 0 \\
\hline M16.4 & Higher surface water quality & 0 \\
\hline
\end{tabular}

Table 2. Annual marginal benefits after the implementation of the selected actions in the entire Llobregat basin. Positive values refer to benefit gains, and negative values to benefit losses.

The management action for the improvement of river connectivity (M2) caused total annual gains estimated to amount to $0.1 \mathrm{M} €$ for the whole basin. The highest gains were obtained for existence/conservation of species diversity. Actions for the treatment of urban wastewater (M12.1 to M12.3) were responsible for total estimated annual gains of $1.8 \mathrm{M} €, 0.25 \mathrm{M} €$ and 0.9 $M €$, respectively. The highest gains were obtained for the enjoyment of recreational areas, followed by improvement in surface water quality. Improvement in water quality was valued both through the avoided cost of the treatment of water for drinking and through the avoided cost of ecosystem damages (see average in Table 2). In this case, the value of the avoided cost of drinking water treatment was zero because before the application of the measure the average annual concentrations of nutrients and organic matter at the two drinking WTPs were already below the legal threshold for drinking water (80/778/CEE and 98/83/EC). Thus, no further treatment was needed to reduce the concentration of nutrients and organic matter to meet legal specifications. Conversely, the valuation of the improvement of water quality through the avoided cost of ecosystem damages reported gains because nitrogen concentrations considered to have effects on ecosystems (which are not regulated) were exceeded in some water bodies affected by this management action. Thus, nitrogen reduction in these water bodies was needed in order to protect the quality of the ecosystem. We could only assess one benefit affected by actions for the reduction in saline pollution (M16.1 to M16.4). The benefit corresponded to a gain through the avoided cost of treating water for drinking purposes. In all cases, the annual gains were $0 €$ because the average annual conductivity at the two drinking WTPs already fulfilled the legal threshold before the application of the management actions, and therefore, no further salinity reduction was needed. 
Assessment of Ecosystem Services and Water Accounting Methodologies for Integrated Water Resources Management in water scarce basins

\section{Spatial distribution of marginal benefits}

The variation of benefits resulting from the application of actions was heterogeneously distributed across the basin. Figure 4 displays the marginal benefit gains (in blue) and losses (in red) after the establishment of environmental flows in the upper Llobregat (M1_1). The spatial distribution of marginal benefits affected by the other actions is detailed in Figs S1-S3. For all the benefits derived from action $\mathrm{Ml}_{-}$, the sub-basins in the lower Llobregat basin received zero marginal value because this action affected only the upper Llobregat River. Hydropower production was the only category with losses in all the sub-basins affected by the action (Fig. 4a). Losses were greater in headwaters and decreased downstream. When regarded at industry showed gains or losses depending on the region of the basin (Fig. 4b-d). The highest losses in all cases continued to be associated with the upper part of the basin, whereas gains were associated with areas downstream of those water bodies with implemented environmental flows and upstream of water demand intakes. This finding is related to the water resource production pattern and the defined water management strategy in the model, which aims to satisfy multiple objectives of supply to the various demands. The benefit categories experiencing gains presented a substantially different spatial distribution (Fig. 4e-g). Environmental/social benefits tended to be greater in areas of greater population concentration, benefits to the existence/conservation of species diversity were inversely related to the sites of water abstraction, and enjoyment of recreational areas had higher benefit values in headwaters, where the main water sources were found. 


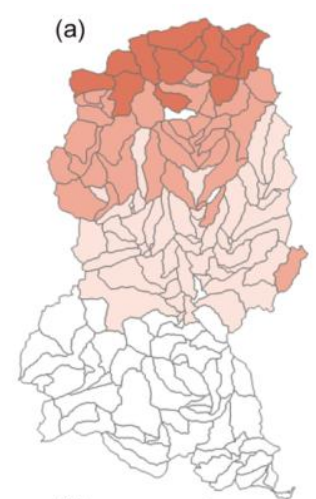

(e)

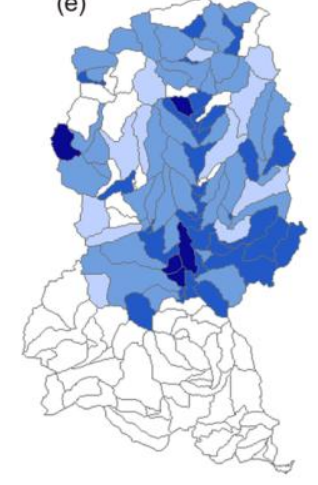

(b)

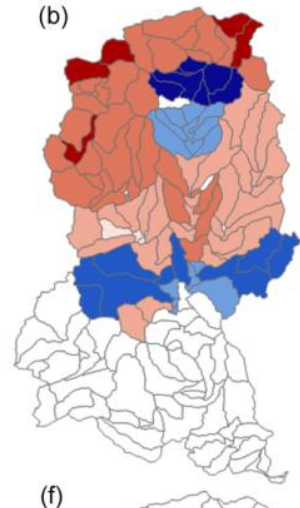

(f)

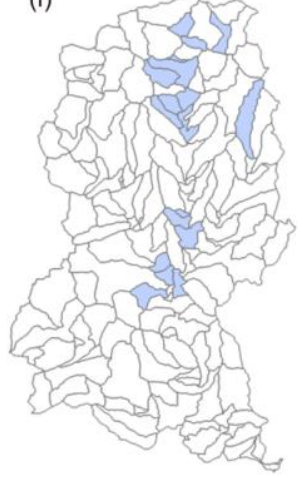

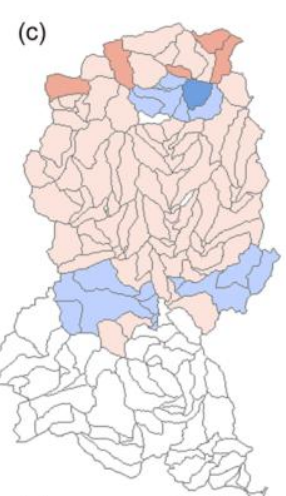

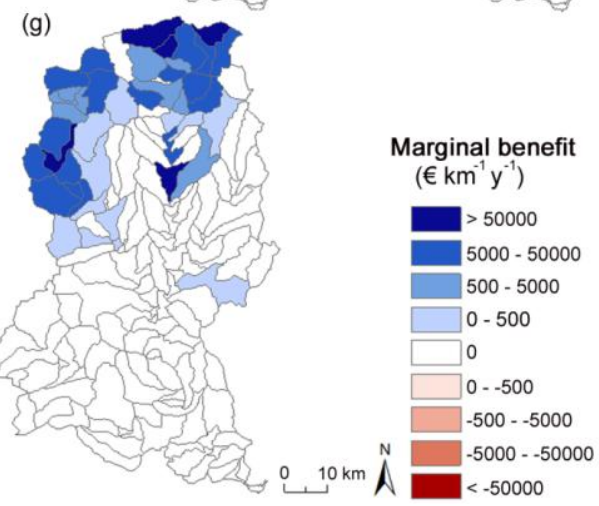

(d)

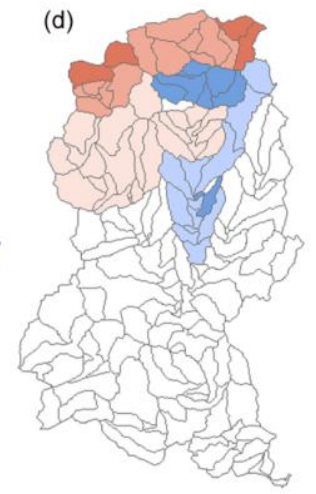

Figure 4. Effects of the establishment of environmental river flows in the upper Llobregat basin on the potential benefits for hydropower production (a), water for drinking (b), water for irrigation (c), water for industry (d), environmental/social benefits (e),

existence/conservation of species diversity $(f)$ and enjoyment of recreational areas $(g)$. Results are expressed as marginal values in $€$ per kilometre of river per year.

\section{Total marginal benefits of actions}

When the marginal values of all the benefits assessed for a particular action were aggregated, a map of the total marginal benefit of the action was obtained, corresponding to a change in the partial total economic value of the basin (Fig. 5). The upper part of the basin experienced the greatest total losses after the establishment of environmental river flows, whereas total gains were more heterogeneously distributed (Fig. 5a). The establishment of environmental river flows in the lower Llobregat basin resulted in net losses in the upper Llobregat (Fig. 5b), even though the action was only implemented in the lower part of the river. This effect occurred because for one of the assessed benefits (hydropower production), all subbasins located upstream 
Assessment of Ecosystem Services and Water Accounting Methodologies for Integrated Water Resources Management in water scarce basins

from the water demand intakes (hydropower plants) were affected and received a marginal value, which in this case corresponded to a loss of hydropower production. This connectivity between upstream and downstream areas did not apply in the case of the other benefits assessed for the establishment of environmental river flows in the lower basin (Fig. S1). The improvement of river connectivity got the greatest total gains in the middle part of the basin and downstream, where a larger population was concentrated (Fig. 5c). Actions for the treatment of urban wastewater resulted in net gains downstream from their implementation, that is downstream of the new WWTPs (Fig. 5d-f).
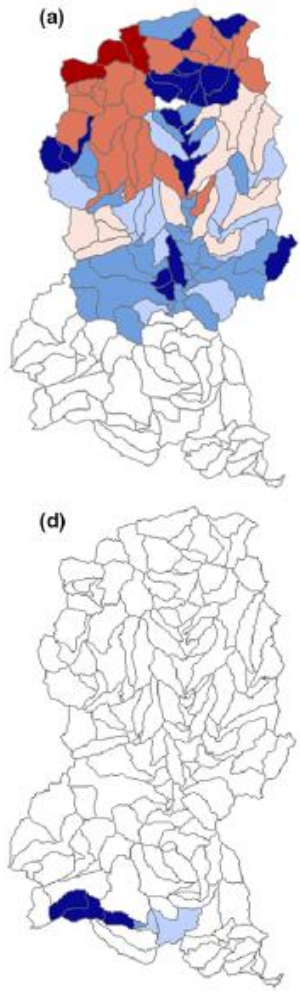
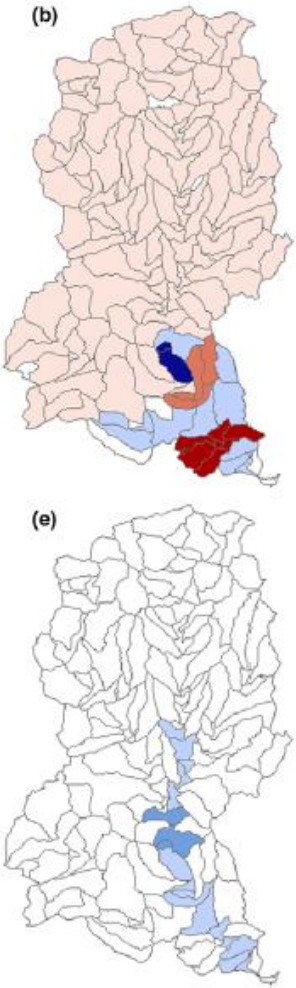
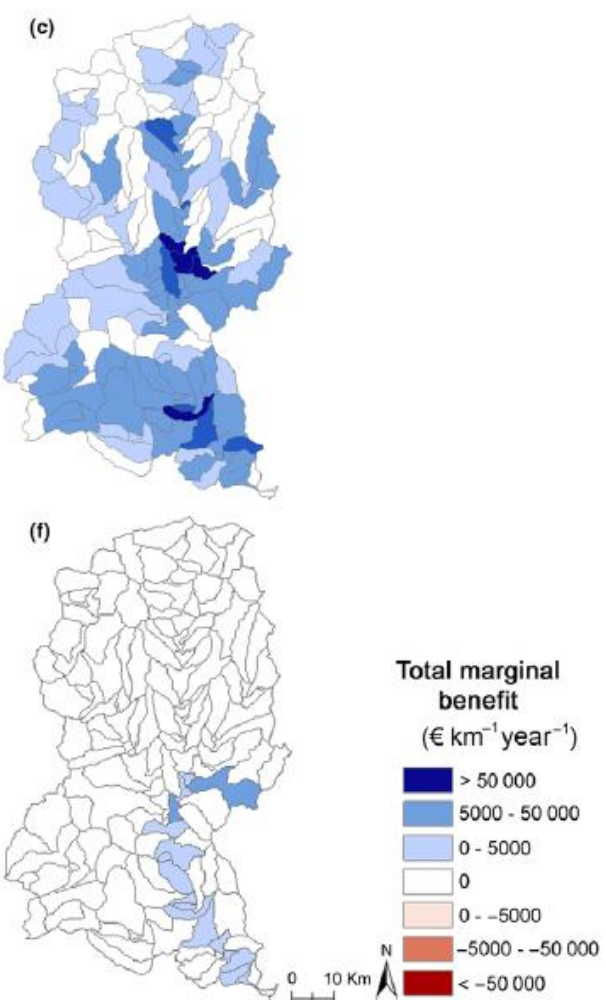

Figure 5. Total marginal benefit after the implementation of the selected actions in the Llobregat River basin: establishment of environmental river flows in the upper Llobregat basin (a), establishment of environmental river flows in the lower Llobregat basin (b), improvement of river connectivity (c), treatment of urban wastewater in Mediona (d), treatment of urban wastewater in Balsareny (e) and treatment of urban wastewater in Moi_a (f). Results are expressed as marginal values in $€$ per kilometre of river per year. 


\section{Cost-benefit analysis}

The action with the highest net balance (difference between the net present value of benefits and costs) was the establishment of environmental river flows in the upper Llobregat basin (see Table S6 for more detail) (Fig. 3b). Management actions for the treatment of urban wastewater also returned a positive net balance, with action M12.1 resulting in the highest value gain. All other management actions had a negative net balance, as costs were greater than the estimated benefits. The ranking slightly changed when analysing the benefit-to-cost ratio, as the action resulting in the highest benefit-to-cost ratio was the treatment of urban wastewater from action M12.1, followed by the establishment of environmental river flows in the upper basin, and the treatment of urban wastewater at the two other WWTPS (M12.2 and M12.3) (Fig. 3b). Actions for the establishment of environmental river flows in the lower Llobregat basin and the improvement of river connectivity resulted in a small benefit-to cost ratio, and the benefitto-cost ratio was zero for all actions devoted to the reduction in saline pollution because calculated benefits were zero in that case. The use of lower discount rates (2\% and $3 \%$ ) increased the benefits obtained for management actions more than the costs, although changes were not high (around $10 \%$ for benefits and around $4 \%$ for costs). Consequently, some actions received a different benefit-to-cost ratio, even though observed trends in the CBA remained the same.

\section{Discussion}

The ecosystem services approach presented here allows for a spatially explicit quantification of the marginal benefits of management actions proposed by river authorities in the programme of measures of RBMPs. Management actions identified as the most cost-effective in the CEA differed sometimes from those receiving the best benefit to-cost ratio according to the CBA, stressing that gains in ecosystem status do not necessarily involve gains in benefits derived from ecosystem services, or at least not those quantified here. Overall, CBA proved to be complementary to the CEA, and the integration of ecosystem services in the implementation of river basin management plans is therefore proposed to move from a single- to a multiobjective decision-making approach in the design and prioritization of management actions. 
Assessment of Ecosystem Services and Water Accounting Methodologies for Integrated Water Resources Management in water scarce basins

\section{Considerations about the approach}

Caution should be taken when analysing the results of the performed assessment of CBA for a series of management actions, as in our study only four types of management actions were considered, and not all the ecosystem services but a subset of them were included in the analysis. As a result, the estimates of environmental benefits have an associated uncertainty often combined with a lack of information that might compromise the informative capacity of the applied tools. Our assessment was performed considering a best-guess range of benefits based on a compilation of past cases and scientific literature that certainly excludes many potentially influenced benefits that may be important, among these the lack of a valuation technique converting benefits to a monetary value, or the impossibility of assessing ecosystem functions that entrain relevant services with the models applied in the context of the study. For example, the effect of the reduction in saline pollution on the enjoyment of recreational areas of the Llobregat basin (i.e. angling) could not be assessed because of the inability to find a relationship between individual willingness to pay and improvement in water quality caused by a reduction in water salinity. Similarly, the effect of the treatment of urban wastewater on the existence/ conservation of species diversity was not quantified because of the limitations of the applied habitat quality model, which was not sensitive enough to small changes in wastewater treatment plant performance. However, the inability to estimate some benefits in our work does not prevent their assessment in other case studies that do not show such limitations. Additional uncertainty can also be introduced in the analysis through the application of benefit transfer (i.e. to value environmental/social benefits derived from the establishment of environmental river flows), as this technique uses data obtained from other sites (Plummer 2009). Regardless of the constraints in the modelling approach, we should be aware that the value of the parameters used to assess the different benefits can also highly influence the outcome of CBA, and for this reason, the use of a range of possible values is preferred to account for uncertainty (Boithias et al. 2016). Likewise, caution should be taken when analysing CEA results, as the expected changes in ecosystem status of management actions are not based on models comparing the changes in the threat level to changes in the ecosystem status of water bodies. Instead, we applied an approach in 
which the threat directly affected by the management action was set to zero after the application of the action. Establishing this type of relationship would require a notable amount of work and was beyond the scope of our study.

\section{Cost-effectiveness and cost-benefit analyses in the llobregat case study}

The performed CBA and CEA indicate that the establishment of environmental river flows in the upper Llobregat River was the management action that maximizes the balance between the marginal increase in ecosystem services and the ecosystem status in the basin. The management actions for the treatment of urban wastewater were also identified as winwin, since they yield a positive balance for both ecosystem services and ecosystem status in the basin. However, the increase in ecosystem status was lower than that obtained with all the other selected management actions. This is because the actions for the treatment of urban wastewater are more locally focused; only involving particular wastewater treatment plants. When environmental river flows were implemented in the lower Llobregat River, the expected gain in ecosystem status was much lower than that obtained in the upper basin, and there was a marginal decrease in ecosystem services. The same happened with the management action for the improvement of river connectivity. In regard to the management actions for the reduction in saline pollution, they did not yield net gains for ecosystem services according to the assessed benefits, but were expected to result in ecological gains at the basin scale. The mismatch between gains in ecosystem status and human well-being was not an unexpected result, as other studies have stressed that the delivery of ecosystem services is not necessarily related to species richness (Adams 2014; Winfree et al. 2015). A clear example of this mismatch in the Llobregat is exemplified by dams and weirs, which certainly favour the benefits associated with hydropower production (Terrado et al. 2014), but constitute a threat to freshwater habitat quality (Terrado et al. 2016).

The results obtained from the CBA revealed the importance of considering opportunity costs together with benefits in the decision-making process, as opportunity costs for the assessed actions can range from $0 \%$ to $100 \%$ of the total costs. Those of $0 \%$ corresponded to measures for which no cost of opportunity could be assessed. Those of $100 \%$ corresponded to measures 
Assessment of Ecosystem Services and Water Accounting Methodologies for Integrated Water Resources Management in water scarce basins

with no implementation and exploitation/maintenance costs, or to those with implementation costs conceived as compensation to beneficiaries potentially negatively affected by the measure. One of these latter cases would be the establishment of environmental river flows, where negatively affected beneficiaries would be hydropower plants, farmers, industries, etc. Efficiency gains from including opportunity costs (not fully taken into account in a CEA) in the process of environmental planning have already been demonstrated in previous studies (Naidoo et al. 2006; Adams, Pressey \& Naidoo 2010).

\section{Integration of ecosystem services in river basin management plans}

The proposed assessment approach of the marginal benefits resulting from management actions in river basins can be used in CBA to identify the trade-offs among multiple benefits affected by different actions. More importantly, the CBA proved to be complementary to the CEA, and the integration of ecosystem services in the river basin management plans is therefore proposed to move from a single- to a multiobjective decisionmaking approach in the design and prioritization of management actions. In fact, this methodological approach addresses better multibenefit goals, allowing the identification of win-win management actions that maximize simultaneously ecosystem status and human well-being. The approach makes a contribution to already available management approaches and helps policymakers to gain insights and evaluate policy impacts comprehensively.

In summary, we provide a flexible and systematic framework to assess the effect of management actions proposed in the programme of measures for the fulfilment of the WFD objectives (see Table 54 for a list of ready to- use equations) that can be easily extended to the valuation of other benefits and services and adapted to other river basins. The implementation of the ecosystem service concept into existing frameworks such as the WFD and its consideration through CBA allows for the accounting of trade-offs among different management actions. However, although ecosystem services are obviously a strategic tool for conservation, caution should be taken in creating schemes based exclusively on the value of ecosystem services, since they may not parallel gains in ecosystem status. To prevent such an outcome, our approach is based on a combination of CEA and CBA, 
therefore allowing the selection of optimal management actions simultaneously maximizing the value of ecosystem services and the gains in ecosystem status of river basins. Although win-win outcomes may not always be possible in practice, adding a systematic basis to decision support that addresses interdependencies between human well-being and ecosystem status provides transparency and a more inclusive basis for decision-making.

\section{Acknowledgements}

This research was supported by the EC 7th Framework Programme GLOBAQUA; 603629-ENV-2013-6.2.1) and the Juan de la Cierva subprogramme from the MINECO. The authors acknowledge the support of the Polytechnic University of València through its Support Programme for Research and Development and the Economy and Knowledge Department of the Catalan Government (Consolidated Research Group 2014 SGR291ICRA).

\section{Data accessibility}

Threat level in the basin: ACA (2014).

Benefit definition, equations and parameter values: uploaded as online Supporting Information (Tables S3 and S4).

\section{References}

ACA (2010a) Programa de mesures del pla de gestió del districte de conca fluvial de Catalunya. Generalitat de Catalunya.

ACA (2010b) Pla de gestió del districte de conca fluvial de Catalunya. Apèndix Annex XVI. Objectius ambientals. Generalitat de Catalunya.

ACA (2014) IMPRESS 2013. Annex 8. Pressions identificades per massa d'aigua. Generalitat de Catalunya.

Adams, W.M. (2014) The value of valuing nature. Valuing nature in economic terms is not always beneficial for biodiversity conservation. Science, 346, 549551.

Adams, V.M., Pressey, R.L. \& Naidoo, R. (2010) Opportunity costs: who really pays for conservation? Biological Conservation, 143, 439-448. 
Assessment of Ecosystem Services and Water Accounting Methodologies for Integrated Water Resources Management in water scarce basins

Alcon, F., Martin-Ortega, J., Berbel, J. \& de Miguel, M.D. (2012) Environmental benefits of reclaimed water: an economic assessment in the context of the Water Framework Directive. Water Policy, 14, 148-159.

Andreu, J., Capilla, J. \& Sanchis, E. (1996) AQUATOOL: A generalized decision support system for water resources planning and operational management. Journal of Hydrology, 177, 269-291.

Balana, B.B., Vinten, A. \& Slee, B. (2011) A review on cost-effectiveness analysis of agri-environmental measures related to the EU WFD: key issues, methods, and applications. Ecological Economics, 70, 1021-1031.

Barton, D.N., Saloranta, T., Moe, S.J., Eggestad, H.O. \& Kuikka, S. (2008) Bayesian belief networks as a meta-modelling tool in integrated river basin management - Pros and cons in evaluating nutrient abatement decisions under uncertainty in a Norwegian river basin. Ecological Economics, 66, 91104.

Berbel, J., Martin-Ortega, J. \& Mesa, P. (2011) A cost-effectiveness analysis of water-saving measures for the Water Framework Directive: the case of the Guadalquivir River basin. Water Resources Management, 25, 623-640.

Birch, J.C., Newton, A.C., Aquino, C.A., Cantarello, E., Echeverr_Ia, C., Kitzberger, T., Schiappacasse, I. \& Tejedor-Garavito, N. (2010) Costeffectiveness of dryland forest restoration evaluated by spatial analysis of ecosystem services. Proceedings of the National Academy of Sciences, 107, 21925-21930.

Böck, K., Muhar, S., Muhar, A. \& Polt, R. (2015) The ecosystem services concept: gaps between science and practice in river landscape management. Gaia, 24, 32-40.

Boithias, L., Terrado, M., Corominas, L., Ziv, G., Kumar, V., Marqu_es, M., Schuhmacher, M. \& Acuña, V. (2016) Analysis of the uncertainty in the monetary valuation of ecosystem services - a case study at the river basin scale. Science of the Total Environment, 543, 683-690.

Del Saz-Salazar, S., Hernández-Sancho, F. \& Sala-Garrido, R. (2009) The social benefits of restoring water quality in the context of the Water Framework 
Directive: a comparison of willingness to pay and willingness to accept. Science of the Total Environment, 407, 4574-4583.

EC (2006) Guidance on the methodology for carrying out cost-benefit analysis. The new programming period 2007-2013, Methodological Working Document 4, European Commission, Brussels.

EEA (2012) European waters - Assessment of status and pressures. Report 8/2012, European Environment Agency, Copenhagen.

Everard, M. (2014) Integrating integrated water management. Water Management, 167, 512-522.

Galioto, F., Marconi, V., Raggi, M. \& Viaggi, D. (2013) An assessment of disproportionate costs in WFD: the experience of Emilia-Romagna. Water, 5, 1967-1995.

Honey-Rosés, J., Acuña, V., Bardina, M., Brozovic, N., Marc_e, R. \& Munn_e, A. et al. (2013) Examining the demand for ecosystem services: the value of stream restoration for drinking water treatment managers in the Llobregat River, Spain. Ecological Economics, 90, 196-205.

Laurans, Y., Rankovic, A., Billé, R., Pirard, R. \& Mermet, L. (2013) Use of ecosystem services economic valuation for decision making: questioning a literature blindspot. Journal of Environmental Management, 119, 208-219.

Marc_e, R., Honey-Rosés, J., Manzano, A., Moragas, L., Catllar, B. \& Sabater, S. (2012). The Llobregat River basin: a paradigm of impaired rivers under climate change threats. The Llobregat: The Story of a Polluted Mediterranean River (eds S. Sabater, A. Ginebreda \& D. Barcel_o). The Handbook of Environmental Chemistry, 21, pp. 1-26. Springer- Verlag, Berlin.

Martin-Ortega, J. (2012) Economic prescriptions and policy applications in the implementation of the European Water Framework Directive. Environmental Science and Policy, 24, 83-91.

Martin-Ortega, J., Giannoccaro, G. \& Berbel, J. (2011) Environmental and resource costs under water scarcity conditions: an estimation in the context of the European Water Framework Directive. Water Resources Management, 25, 1615-1633. 
Assessment of Ecosystem Services and Water Accounting Methodologies for Integrated Water Resources Management in water scarce basins

McCauley, D.J. (2006) Selling out on nature. Nature, 443, 27-28.

Molinos-Senante, M., Hernández-Sancho, F. \& Sala-Garrido, R. (2011) Assessing disproportionate costs to achieve good ecological status of water bodies in a Mediterranean river basin. Journal of Environmental Monitoring, 13, 2091-2101.

Naidoo, R., Balmford, A., Ferraro, P.J., Polasky, S., Ricketts, T.H. \& Rouget, M. (2006) Integrating economic costs into conservation planning. Trends in Ecology and Evolution, 21, 681-687.

Norgaard, R.B. (2010) Ecosystem services: from eye-opening metaphor to complexity blinder. Ecological Economics, 69, 1219-1227.

Plummer, M.L. (2009) Assessing benefit transfer for the valuation of ecosytem services. Frontiers in Ecology and the Environment, 7, 38- 45.

Tallis, H., Ricketts, T.H., Guerry, A.D., Wood, S.A., Sharp, R. \& Nelson, E. et al. (2011) InVEST 2.4.4 User's Guide. The Natural Capital Project, Stanford.

Tallis, H., Lubchenco, J., Adams, V.M., Adams-Hosking, C., Agostini, V.N. \& Andelman, S.J. et al. (2014) A call for inclusive conservation. Nature, 515, 2728.

TEEB (2010) The Economics of Ecosystems and Biodiversity: the Ecological and Economic Foundations. (ed. P. Kumar). Earthscan, London.

Terrado, M., Acuña, V., Ennaanay, D., Tallis, H. \& Sabater, S. (2014) Impact of climate extremes on hydrological ecosystem services in a heavily humanized Mediterranean basin. Ecological Indicators, 37, 199-209.

Terrado, M., Sabater, S., Chaplin-Kramer, B., Mandle, L., Ziv, G. \& Acuña, V. (2016) Model development for the assessment of terrestrial and aquatic biodiversity in conservation planning. Science of the Total Environment, 540 , 63-70.

Turner, R.K. (2007) Limits to CBA in UK and European environmental policy: retrospects and future prospects. Environmental and Resource Economics, 37, 253-269. 
Vlachopoulou, M., Coughlin, D., Forrow, D., Kirk, S., Logan, P. \& Voulvoulis, N. (2014) The potential of using the Ecosystem Approach in the implementation of the EU Water Framework Directive. Science of the Total Environment, 470471, 684-694.

Winfree, R., Fox, J.W., Williams, N.M., Reilly, J.R. \& Cariveau, D.P. (2015) Abundance of common species, not species richness, drives delivery of a real-world ecosystem service. Ecology Letters, 18, 626-635.

\section{Supporting information}

Additional Supporting Information may be found in the online version of this article.

Fig. S1. Effect of the establishment of environmental flows in the lower basin on the considered benefits.

Fig. S2. Effect of the improvement of river connectivity on the considered benefits.

Fig. S3. Effects of the treatment of urban wastewater on the considered benefits.

Table S1. Data requirements and outputs of the models applied.

Table S2. Threat level in the Llobregat basin before and after the application of the management actions.

Table S3. Benefits, beneficiaries and valuation of the management actions.

Table S4. Equations and parameters used for benefit valuation.

Table S5. Costs of the management actions and predicted gain in ecosystem status.

Table S6. Costs and benefits of the management actions. 
Assessment of Ecosystem Services and Water Accounting Methodologies for Integrated Water Resources Management in water scarce basins

\section{A.4 License agreement for Momblanch et al. 2014}

\section{ELSEVIER LICENSE TERMS AND CONDITIONS. Aug 21, 2016}

This Agreement between Andrea Momblanch ("You") and Elsevier ("Elsevier") consists of your license details and the terms and conditions provided by Elsevier and Copyright Clearance Center.

License Number 3920780096100

License date Aug 02, 2016

Licensed Content Publisher Elsevier

Licensed Content Publication Journal of Hydrology

Licensed Content Title Adapting water accounting for integrated water resource management. The Júcar Water Resource System (Spain)

Licensed Content Author Andrea Momblanch, Joaquín Andreu, Javier Paredes-Arquiola, Abel Solera,María Pedro-Monzonís

Licensed Content Date 27 November 2014

Licensed Content Volume Number 519

Licensed Content Issue Number n/a

Licensed Content Pages 17

Start Page 3369

End Page 3385

Type of Use reuse in a thesis/dissertation

Portion full article

Format both print and electronic

Are you the author of this Elsevier article? Yes

Will you be translating? No

Order reference number

Title of your thesis/dissertation Assessment of Ecosystem Services and Water Accounting methodologies for Integrated Water Resources Management in water scarce basins

Expected completion date Aug 2016

Estimated size (number of pages) 120

Elsevier VAT number GB 494627212

Requestor Location Andrea Momblanch, Plaza Horteta, 3-21, Alcasser, Valencia 46290, Spain. Attn: Andrea Momblanch

Total 0.00 EUR 
Terms and Conditions

INTRODUCTION

1. The publisher for this copyrighted material is Elsevier. By clicking "accept" in connection with completing this licensing transaction, you agree that the following terms and conditions apply to this transaction (along with the Billing and Payment terms and conditions established by Copyright Clearance Center, Inc. ("CCC"), at the time that you opened your Rightslink account and that are available at any time at http://myaccount.copyright.com).

\section{GENERAL TERMS}

2. Elsevier hereby grants you permission to reproduce the aforementioned material subject to the terms and conditions indicated.

3. Acknowledgement: If any part of the material to be used (for example, figures) has appeared in our publication with credit or acknowledgement to another source, permission must also be sought from that source. If such permission is not obtained then that material may not be included in your publication/copies. Suitable acknowledgement to the source must be made, either as a footnote or in a reference list at the end of your publication, as follows:

"Reprinted from Publication title, Vol /edition number, Author(s), Title of article I title of chapter, Pages No., Copyright (Year), with permission from Elsevier [OR APPLICABLE SOCIETY COPYRIGHT OWNER]." Also Lancet special credit "Reprinted from The Lancet, Vol. number, Author(s), Title of article, Pages No., Copyright (Year), with permission from Elsevier."

4. Reproduction of this material is confined to the purpose and/or media for which permission is hereby given.

5. Altering/Modifying Material: Not Permitted. However figures and illustrations may be altered/adapted minimally to serve your work. Any other abbreviations, additions, deletions and/or any other alterations shall be made only with prior written authorization of Elsevier Ltd. (Please contact Elsevier at permissions@elsevier.com)

6. If the permission fee for the requested use of our material is waived in this instance, please be advised that your future requests for Elsevier materials may attract a fee.

7. Reservation of Rights: Publisher reserves all rights not specifically granted in the combination of (i) the license details provided by you and accepted in the course of this licensing transaction, (ii) these terms and conditions and (iii) CCC's Billing and Payment terms and conditions.

8. License Contingent Upon Payment: While you may exercise the rights licensed immediately upon issuance of the license at the end of the licensing process for the transaction, provided that you have disclosed complete and accurate details of your proposed use, no license is finally effective unless and until full payment is received from you (either by publisher or by (CC) as provided in CCC's Billing and Payment terms and 
Assessment of Ecosystem Services and Water Accounting Methodologies for Integrated Water Resources Management in water scarce basins

conditions. If full payment is not received on a timely basis, then any license preliminarily granted shall be deemed automatically revoked and shall be void as if never granted. Further, in the event that you breach any of these terms and conditions or any of CCC's Billing and Payment terms and conditions, the license is automatically revoked and shall be void as if never granted. Use of materials as described in a revoked license, as well as any use of the materials beyond the scope of an unrevoked license, may constitute copyright infringement and publisher reserves the right to take any and all action to protect its copyright in the materials.

9. Warranties: Publisher makes no representations or warranties with respect to the licensed material.

10. Indemnity: You hereby indemnify and agree to hold harmless publisher and $\mathrm{CCC}$, and their respective officers, directors, employees and agents, from and against any and all claims arising out of your use of the licensed material other than as specifically authorized pursuant to this license.

11. No Transfer of License: This license is personal to you and may not be sublicensed, assigned, or transferred by you to any other person without publisher's written permission.

12. No Amendment Except in Writing: This license may not be amended except in a writing signed by both parties (or, in the case of publisher, by CCC on publisher's behalf).

13. Objection to Contrary Terms: Publisher hereby objects to any terms contained in any purchase order, acknowledgment, check endorsement or other writing prepared by you, which terms are inconsistent with these terms and conditions or CCC's Billing and Payment terms and conditions. These terms and conditions, together with CCC's Billing and Payment terms and conditions (which are incorporated herein), comprise the entire agreement between you and publisher (and CCC) concerning this licensing transaction. In the event of any conflict between your obligations established by these terms and conditions and those established by CCC's Billing and Payment terms and conditions, these terms and conditions shall control.

14. Revocation: Elsevier or Copyright Clearance Center may deny the permissions described in this License at their sole discretion, for any reason or no reason, with a full refund payable to you. Notice of such denial will be made using the contact information provided by you. Failure to receive such notice will not alter or invalidate the denial. In no event will Elsevier or Copyright Clearance Center be responsible or liable for any costs, expenses or damage incurred by you as a result of a denial of your permission request, other than a refund of the amount(s) paid by you to Elsevier and/or Copyright Clearance Center for denied permissions.

LIMITED LICENSE

The following terms and conditions apply only to specific license types: 
15. Translation: This permission is granted for non-exclusive world English rights only unless your license was granted for translation rights. If you licensed translation rights you may only translate this content into the languages you requested. A professional translator must perform all translations and reproduce the content word for word preserving the integrity of the article.

16. Posting licensed content on any Website: The following terms and conditions apply as follows: Licensing material from an Elsevier journal: All content posted to the web site must maintain the copyright information line on the bottom of each image; A hyper-text must be included to the Homepage of the journal from which you are licensing at http://www.sciencedirect.com/science/journal/xxxxx or the Elsevier homepage for books at http://www.elsevier.com; Central Storage: This license does not include permission for a scanned version of the material to be stored in a central repository such as that provided by Heron/XanEdu.

Licensing material from an Elsevier book: A hyper-text link must be included to the Elsevier homepage at http://www.elsevier.com . All content posted to the web site must maintain the copyright information line on the bottom of each image.

Posting licensed content on Electronic reserve: In addition to the above the following clauses are applicable: The web site must be password-protected and made available only to bona fide students registered on a relevant course. This permission is granted for 1 year only. You may obtain a new license for future website posting.

17. For journal authors: the following clauses are applicable in addition to the above:

Preprints:

A preprint is an author's own write-up of research results and analysis, it has not been peer-reviewed, nor has it had any other value added to it by a publisher (such as formatting, copyright, technical enhancement etc.).

Authors can share their preprints anywhere at any time. Preprints should not be added to or enhanced in any way in order to appear more like, or to substitute for, the final versions of articles however authors can update their preprints on arXiv or RePEc with their Accepted Author Manuscript (see below).

If accepted for publication, we encourage authors to link from the preprint to their formal publication via its DOI. Millions of researchers have access to the formal publications on ScienceDirect, and so links will help users to find, access, cite and use the best available version. Please note that Cell Press, The Lancet and some society-owned have different preprint policies. Information on these policies is available on the journal homepage.

Accepted Author Manuscripts: An accepted author manuscript is the manuscript of an article that has been accepted for publication and which 
Assessment of Ecosystem Services and Water Accounting Methodologies for Integrated Water Resources Management in water scarce basins

typically includes author-incorporated changes suggested during submission, peer review and editor-author communications.

Authors can share their accepted author manuscript:

- immediately

via their non-commercial person homepage or blog

by updating a preprint in arXiv or RePEc with the accepted manuscript

via their research institute or institutional repository for internal institutional uses or as part of an invitation-only research collaboration work-group

directly by providing copies to their students or to research collaborators for their personal use

for private scholarly sharing as part of an invitation-only work group on commercial sites with which Elsevier has an agreement

- $\quad$ after the embargo period

via non-commercial hosting platforms such as their institutional repository via commercial sites with which Elsevier has an agreement

In all cases accepted manuscripts should:

- $\quad$ link to the formal publication via its DOI

- bear a CC-BY-NC-ND license - this is easy to do

- if aggregated with other manuscripts, for example in a repository or other site, be shared in alignment with our hosting policy not be added to or enhanced in any way to appear more like, or to substitute for, the published journal article.

Published journal article (JPA): A published journal article (PJA) is the definitive final record of published research that appears or will appear in the journal and embodies all value-adding publishing activities including peer review co-ordination, copy-editing, formatting, (if relevant) pagination and online enrichment.

Policies for sharing publishing journal articles differ for subscription and gold open access articles:

Subscription Articles: If you are an author, please share a link to your article rather than the full-text. Millions of researchers have access to the formal publications on ScienceDirect, and so links will help your users to find, access, cite, and use the best available version.

Theses and dissertations which contain embedded PJAs as part of the formal submission can be posted publicly by the awarding institution with DOI links back to the formal publications on ScienceDirect.

If you are affiliated with a library that subscribes to ScienceDirect you have additional private sharing rights for others' research accessed under that agreement. This includes use for classroom teaching and internal training at the institution (including use in course packs and courseware programs), and inclusion of the article for grant funding purposes. 
Gold Open Access Articles: May be shared according to the authorselected end-user license and should contain a CrossMark logo, the end user license, and a DOI link to the formal publication on ScienceDirect.

Please refer to Elsevier's posting policy for further information.

18. For book authors the following clauses are applicable in addition to the above: Authors are permitted to place a brief summary of their work online only. You are not allowed to download and post the published electronic version of your chapter, nor may you scan the printed edition to create an electronic version. Posting to a repository: Authors are permitted to post a summary of their chapter only in their institution's repository.

19. Thesis/Dissertation: If your license is for use in a thesis/dissertation your thesis may be submitted to your institution in either print or electronic form. Should your thesis be published commercially, please reapply for permission. These requirements include permission for the Library and Archives of Canada to supply single copies, on demand, of the complete thesis and include permission for Proquest/UMI to supply single copies, on demand, of the complete thesis. Should your thesis be published commercially, please reapply for permission. Theses and dissertations which contain embedded PJAs as part of the formal submission can be posted publicly by the awarding institution with DOI links back to the formal publications on ScienceDirect.

20. Other Conditions: v1.8 
Assessment of Ecosystem Services and Water Accounting Methodologies for Integrated Water Resources Management in water scarce basins

\section{A.5 License agreement for Momblanch et al. 2016}

\section{ELSEVIER LICENSE TERMS AND CONDITIONS. Aug 21, 2016}

This Agreement between Andrea Momblanch ("You") and Elsevier ("Elsevier") consists of your license details and the terms and conditions provided by Elsevier and Copyright Clearance Center.

License Number 3921801402302

License date Aug 04, 2016

Licensed Content Publisher Elsevier

Licensed Content Publication Journal of Hydrology

Licensed Content Title Using ecosystem services to represent the environment in hydro-economic models

Licensed Content Author Andrea Momblanch, Jeffery D. Connor, Neville D. Crossman, Javier Paredes-Arquiola, Joaquín Andreu

Licensed Content Date July 2016

Licensed Content Volume Number 538

Licensed Content Issue Number n/a

Licensed Content Pages 11

Start Page 293

End Page 303

Type of Use reuse in a thesis/dissertation

Portion full article

Format both print and electronic

Are you the author of this Elsevier article? Yes

Will you be translating? No

Order reference number

Title of your thesis/dissertation Assessment of Ecosystem Services and Water Accounting methodologies for Integrated Water Resources Management in water scarce basins

Expected completion date Aug 2016

Estimated size (number of pages) 120

Elsevier VAT number GB 494627212

Requestor Location Andrea Momblanch, Plaza Horteta, 3-21, Alcasser, Valencia 46290, Spain. Attn: Andrea Momblanch

Total 0.00 EUR 
Terms and Conditions

INTRODUCTION

1. The publisher for this copyrighted material is Elsevier. By clicking "accept" in connection with completing this licensing transaction, you agree that the following terms and conditions apply to this transaction (along with the Billing and Payment terms and conditions established by Copyright Clearance Center, Inc. ("CCC"), at the time that you opened your Rightslink account and that are available at any time at http://myaccount.copyright.com).

\section{GENERAL TERMS}

2. Elsevier hereby grants you permission to reproduce the aforementioned material subject to the terms and conditions indicated.

3. Acknowledgement: If any part of the material to be used (for example, figures) has appeared in our publication with credit or acknowledgement to another source, permission must also be sought from that source. If such permission is not obtained then that material may not be included in your publication/copies. Suitable acknowledgement to the source must be made, either as a footnote or in a reference list at the end of your publication, as follows:

"Reprinted from Publication title, Vol /edition number, Author(s), Title of article I title of chapter, Pages No., Copyright (Year), with permission from Elsevier [OR APPLICABLE SOCIETY COPYRIGHT OWNER]." Also Lancet special credit "Reprinted from The Lancet, Vol. number, Author(s), Title of article, Pages No., Copyright (Year), with permission from Elsevier."

4. Reproduction of this material is confined to the purpose and/or media for which permission is hereby given.

5. Altering/Modifying Material: Not Permitted. However figures and illustrations may be altered/adapted minimally to serve your work. Any other abbreviations, additions, deletions and/or any other alterations shall be made only with prior written authorization of Elsevier Ltd. (Please contact Elsevier at permissions@elsevier.com)

6. If the permission fee for the requested use of our material is waived in this instance, please be advised that your future requests for Elsevier materials may attract a fee.

7. Reservation of Rights: Publisher reserves all rights not specifically granted in the combination of (i) the license details provided by you and accepted in the course of this licensing transaction, (ii) these terms and conditions and (iii) CCC's Billing and Payment terms and conditions.

8. License Contingent Upon Payment: While you may exercise the rights licensed immediately upon issuance of the license at the end of the licensing process for the transaction, provided that you have disclosed complete and accurate details of your proposed use, no license is finally effective unless and until full payment is received from you (either by publisher or by (CC) as provided in CCC's Billing and Payment terms and 
Assessment of Ecosystem Services and Water Accounting Methodologies for Integrated Water Resources Management in water scarce basins

conditions. If full payment is not received on a timely basis, then any license preliminarily granted shall be deemed automatically revoked and shall be void as if never granted. Further, in the event that you breach any of these terms and conditions or any of CCC's Billing and Payment terms and conditions, the license is automatically revoked and shall be void as if never granted. Use of materials as described in a revoked license, as well as any use of the materials beyond the scope of an unrevoked license, may constitute copyright infringement and publisher reserves the right to take any and all action to protect its copyright in the materials.

9. Warranties: Publisher makes no representations or warranties with respect to the licensed material.

10. Indemnity: You hereby indemnify and agree to hold harmless publisher and $\mathrm{CCC}$, and their respective officers, directors, employees and agents, from and against any and all claims arising out of your use of the licensed material other than as specifically authorized pursuant to this license.

11. No Transfer of License: This license is personal to you and may not be sublicensed, assigned, or transferred by you to any other person without publisher's written permission.

12. No Amendment Except in Writing: This license may not be amended except in a writing signed by both parties (or, in the case of publisher, by CCC on publisher's behalf).

13. Objection to Contrary Terms: Publisher hereby objects to any terms contained in any purchase order, acknowledgment, check endorsement or other writing prepared by you, which terms are inconsistent with these terms and conditions or CCC's Billing and Payment terms and conditions. These terms and conditions, together with CCC's Billing and Payment terms and conditions (which are incorporated herein), comprise the entire agreement between you and publisher (and CCC) concerning this licensing transaction. In the event of any conflict between your obligations established by these terms and conditions and those established by CCC's Billing and Payment terms and conditions, these terms and conditions shall control.

14. Revocation: Elsevier or Copyright Clearance Center may deny the permissions described in this License at their sole discretion, for any reason or no reason, with a full refund payable to you. Notice of such denial will be made using the contact information provided by you. Failure to receive such notice will not alter or invalidate the denial. In no event will Elsevier or Copyright Clearance Center be responsible or liable for any costs, expenses or damage incurred by you as a result of a denial of your permission request, other than a refund of the amount(s) paid by you to Elsevier and/or Copyright Clearance Center for denied permissions.

LIMITED LICENSE

The following terms and conditions apply only to specific license types: 
15. Translation: This permission is granted for non-exclusive world English rights only unless your license was granted for translation rights. If you licensed translation rights you may only translate this content into the languages you requested. A professional translator must perform all translations and reproduce the content word for word preserving the integrity of the article.

16. Posting licensed content on any Website: The following terms and conditions apply as follows: Licensing material from an Elsevier journal: All content posted to the web site must maintain the copyright information line on the bottom of each image; A hyper-text must be included to the Homepage of the journal from which you are licensing at http://www.sciencedirect.com/science/journal/xxxxx or the Elsevier homepage for books at http://www.elsevier.com; Central Storage: This license does not include permission for a scanned version of the material to be stored in a central repository such as that provided by Heron/XanEdu.

Licensing material from an Elsevier book: A hyper-text link must be included to the Elsevier homepage at http://www.elsevier.com . All content posted to the web site must maintain the copyright information line on the bottom of each image.

Posting licensed content on Electronic reserve: In addition to the above the following clauses are applicable: The web site must be password-protected and made available only to bona fide students registered on a relevant course. This permission is granted for 1 year only. You may obtain a new license for future website posting.

17. For journal authors: the following clauses are applicable in addition to the above:

Preprints:

A preprint is an author's own write-up of research results and analysis, it has not been peer-reviewed, nor has it had any other value added to it by a publisher (such as formatting, copyright, technical enhancement etc.).

Authors can share their preprints anywhere at any time. Preprints should not be added to or enhanced in any way in order to appear more like, or to substitute for, the final versions of articles however authors can update their preprints on arXiv or RePEc with their Accepted Author Manuscript (see below).

If accepted for publication, we encourage authors to link from the preprint to their formal publication via its DOI. Millions of researchers have access to the formal publications on ScienceDirect, and so links will help users to find, access, cite and use the best available version. Please note that Cell Press, The Lancet and some society-owned have different preprint policies. Information on these policies is available on the journal homepage.

Accepted Author Manuscripts: An accepted author manuscript is the manuscript of an article that has been accepted for publication and which 
Assessment of Ecosystem Services and Water Accounting Methodologies for Integrated Water Resources Management in water scarce basins

typically includes author-incorporated changes suggested during submission, peer review and editor-author communications.

Authors can share their accepted author manuscript:

- immediately

via their non-commercial person homepage or blog

by updating a preprint in arXiv or RePEc with the accepted manuscript

via their research institute or institutional repository for internal institutional uses or as part of an invitation-only research collaboration work-group

directly by providing copies to their students or to research collaborators for their personal use

for private scholarly sharing as part of an invitation-only work group on commercial sites with which Elsevier has an agreement

- $\quad$ after the embargo period

via non-commercial hosting platforms such as their institutional repository via commercial sites with which Elsevier has an agreement

In all cases accepted manuscripts should:

- $\quad$ link to the formal publication via its DOI

- bear a CC-BY-NC-ND license - this is easy to do

- if aggregated with other manuscripts, for example in a repository or other site, be shared in alignment with our hosting policy not be added to or enhanced in any way to appear more like, or to substitute for, the published journal article.

Published journal article (JPA): A published journal article (PJA) is the definitive final record of published research that appears or will appear in the journal and embodies all value-adding publishing activities including peer review co-ordination, copy-editing, formatting, (if relevant) pagination and online enrichment.

Policies for sharing publishing journal articles differ for subscription and gold open access articles:

Subscription Articles: If you are an author, please share a link to your article rather than the full-text. Millions of researchers have access to the formal publications on ScienceDirect, and so links will help your users to find, access, cite, and use the best available version.

Theses and dissertations which contain embedded PJAs as part of the formal submission can be posted publicly by the awarding institution with DOI links back to the formal publications on ScienceDirect.

If you are affiliated with a library that subscribes to ScienceDirect you have additional private sharing rights for others' research accessed under that agreement. This includes use for classroom teaching and internal training at the institution (including use in course packs and courseware programs), and inclusion of the article for grant funding purposes. 
Gold Open Access Articles: May be shared according to the authorselected end-user license and should contain a CrossMark logo, the end user license, and a DOI link to the formal publication on ScienceDirect.

Please refer to Elsevier's posting policy for further information.

18. For book authors the following clauses are applicable in addition to the above: Authors are permitted to place a brief summary of their work online only. You are not allowed to download and post the published electronic version of your chapter, nor may you scan the printed edition to create an electronic version. Posting to a repository: Authors are permitted to post a summary of their chapter only in their institution's repository.

19. Thesis/Dissertation: If your license is for use in a thesis/dissertation your thesis may be submitted to your institution in either print or electronic form. Should your thesis be published commercially, please reapply for permission. These requirements include permission for the Library and Archives of Canada to supply single copies, on demand, of the complete thesis and include permission for Proquest/UMI to supply single copies, on demand, of the complete thesis. Should your thesis be published commercially, please reapply for permission. Theses and dissertations which contain embedded PJAs as part of the formal submission can be posted publicly by the awarding institution with DOI links back to the formal publications on ScienceDirect.

20. Other Conditions: $v 1.8$ 
Assessment of Ecosystem Services and Water Accounting Methodologies for Integrated Water Resources Management in water scarce basins

\section{A.6 License agreement for Terrado et al. 2016}

This is an Open Access paper

\section{Terms and Conditions of Use}

The following Terms and Conditions of Use dated as of October 2013, govern use by all Users of Wiley Online Library, an online service (or any successor thereto) and the electronic edition of the Products subscribed to by the User or the User's institution (the "Electronic Product(s)"). Please read the following carefully because by using Wiley Online Library you are agreeing to abide by these Terms and Conditions of Use.

Your institution may have a License which permits you additional uses; contact your institution's librarian/administrator for more information.

Copyright

The entire contents of the Electronic Products, and each article and abstract and other material available through Wiley Online Library are protected by copyright (unless otherwise indicated on the title page of the article). As a User, you have certain rights specified below; all other rights are reserved.

\section{Definitions}

Wiley Online Library - The online service (or any successor thereto) available from Wiley or its affiliates on the Worldwide Web including all products, services and features offered via the service. Certain products and services under this License may be delivered from other platforms. The terms and conditions hereof are equally applicable to those products and services.

Licensee - The customer which has signed the License granting access to Licensed Electronic Products as applicable.

Authorized Users - Those persons who are authorized by the Licensee to have access to Wiley Online Library. Authorized Users must be current bona fide faculty members, students, researchers, staff members, librarians, executives or employees of the Licensee, or contractors engaged by the Licensee, provided such contractors have been informed of, and agree to abide by, the Terms and Conditions of Use set forth herein and they access Wiley Online Library via the Licensee's Secure Network as defined in the License signed by the Licensee as applicable. Walk-in Users from the general public or business invitees may also be permitted by the Licensee to access Wiley Online Library from designated terminals with a Licensee-controlled IP address. These designated terminals shall be physically located in libraries or similar physical premises directly controlled by the Licensee.

Intellectual Property Rights - These rights include, without limitation, patents, trademarks, trade names, design rights, copyright (including rights in computer software), database rights, rights in know-how and other intellectual property rights, in each case whether registered or unregistered, 
which may subsist anywhere in the world. The Authorized Users acknowledge that the Electronic Products and Wiley Online Library and the Intellectual Property Rights contained therein are protected by law. All rights not specifically licensed to the Licensee are expressly reserve by Wiley.

Electronic Products - All products, services and content available in Wiley Online Library shall be deemed included within the definition of Electronic Products.

Licensed Electronic Products - The electronic (online) editions of Wiley journals and other publication and the content therein, including but not limited to major reference works, Current Protocols laboratory manuals and databases which the Licensee has licensed hereunder.

Open Access License(s) - Some products, services and content available in Wiley Online Library may be made available on an open access basis. Such licenses make content openly accessible to all users not just Authorized Users or Licensees, subject to the terms set out in the relevant open access or creative commons license. In the event of any conflict between these Terms and Conditions and the applicable Open Access License, the latter shall apply with respect to that product, service or content.

Rules of Use

To make Wiley Online Library and the Electronic Product useful, the following rules apply:

Authorized Users, including Walk-in Users, will have access to all Content websites within Wiley Online Library. Authorized Users may browse all Tables of Content and for all Electronic Products on Wiley Online Library regardless of what Licensed Electronic Products the institution subscribes to and search the entire database of Tables of Content and abstracts. For most publications, Authorized Users may browse the abstracts as well.

Authorized Users at institutions which have subscribed to Electronic Products and Authorized Users who have access under a Society or Personal License will have access to the full text of such Licensed Electronic Products. Authorized Users may download, search, retrieve, display and view, copy and save to hard disk or diskette and store or print out single copies of individual articles or items for their own personal use, scholarly, educational or scientific research or internal business use. Authorized Users may also transmit such material to a third-party colleague in hard copy or electronically for personal use or scholarly, educational, or scientific research or professional use but in no case for re-sale, systematic redistribution or for any other use. In addition, Authorized Users have the right to use, with appropriate credit, figures, tables and brief excerpts from individual articles in the Electronic Product(s) in their own scientific, scholarly and educational works.

All Authorized Users have the option to create a My Profile Page which will allow them to create links to Electronic Product (s), articles of interest and search criteria which may be reused by them and manage their custom e- 
Assessment of Ecosystem Services and Water Accounting Methodologies for Integrated Water Resources Management in water scarce basins

mail alerting services. In order to do so, Authorized Users must register. During the registration process, Authorized Users will select and register a user name and password which they must keep confidential and not disclose to or share with anyone else.

Except as provided above or in any applicable Open Access License(s), Authorized Users may not copy, distribute, transmit or otherwise reproduce, sell or resell material from Electronic Products (s); store such material in any form or medium in a retrieval system; download and/or store an entire issue of a Electronic Product or its equivalent; or transmit such material, directly or indirectly, for use in any paid service such as document delivery or list serve, or for use by any information brokerage or for systematic distribution, whether or not for commercial or non-profit use or for a fee or free of charge.

Authorized Users agree not to remove, obscure or modify any copyright or proprietary notices, author attribution or any disclaimer as they appear on Wiley Online Library. Authorized Users may not integrate material from the Electronic Product(s) with other material or otherwise create derivative works in any medium. However, brief quotations for purposes of comment, criticism or similar scholarly purposes are not prohibited herein.

Authorized Users may not do anything to restrict or inhibit any other Authorized User's access to or use of Wiley Online Library and the Electronic Product(s).

If an Authorized User refuses or fails to abide by these Terms and Conditions or violates any other terms of this Agreement, Wiley reserves the right in its sole discretion to suspend or terminate their access to Wiley Online Library and the Electronic Products immediately without notice, in addition to any other available remedies.

Authorized Users shall not have the right to incorporate any material from the Licensed Electronic Products into any institutional or other repository under any circumstances without Wiley's prior written approval.

\section{Additional Terms}

Wiley is not responsible for any charges associated with accessing Wiley Online Library and the Electronic Products, including, but not limited to, any computer equipment, telephone or Internet connections and access software.

Wiley may modify any of these terms and conditions at any time by providing notice on Wiley Online Library. An Authorized User's continued use of Wiley Online Library shall be conclusively deemed acceptance of such modification.

Wiley Online Library may provide links to third-party websites. Where such links exist, Wiley disclaims all responsibility and liability for the content of such third-party websites. Authorized Users assume the sole responsibility for the 
accessing of third-party websites and the use of any content appearing on such websites.

Privacy and Data Protection Policy

Wiley recognizes the importance of protecting the information it collects in the operation of Wiley Online Library and will act in compliance with the Privacy Policy posted at http://www.wiley.com/WileyCDA/Section/id301465.html.

Warranty Limitations

WILEY ONLINE LIBRARY AND THE ELECTRONIC PRODUCTS AND ALL MATERIALS CONTAINED THEREIN ARE PROVIDED ON AN "AS IS" BASIS, WITHOUT WARRANTIES OF ANY KIND, EITHER EXPRESS OR IMPLIED, INCLUDING, BUT NOT LIMITED TO, WARRANTIES OF TITLE, OR IMPLIED WARRANTIES OF MERCHANTABILITY OR FITNESS FOR A PARTICULAR PURPOSE; THE USE OF THE ELECTRONIC PRODUCTS, WILEY ONLINE LIBRARY AND ALL MATERIALS IS AT THE AUTHORIZED USER'S OWN RISK; ACCESS TO WILEY ONLINE LIBRARY AND THE ELECTRONIC PRODUCTS MAY BE INTERRUPTED AND MAY NOT BE ERROR FREE; AND NEITHER WILEY NOR ANYONE ELSE INVOLVED IN CREATING, PRODUCING OR DELIVERING THE ELECTRONIC PRODUCTS OR THE MATERIALS CONTAINED IN WILEY ONLINE LIBRARY, SHALL BE LIABLE FOR ANY DIRECT, INDIRECT, INCIDENTAL, SPECIAL, CONSEQUENTIAL OR PUNITIVE DAMAGES ARISING OUT OF THE AUTHORIZED USER'S USE OF OR INABILITY TO USE WILEY ONLINE LIBRARY, THE ELECTRONIC PRODUCTS AND ALL MATERIALS CONTAINED THEREIN. 
Assessment of Ecosystem Services and Water Accounting Methodologies for Integrated Water Resources Management in water scarce basins

A.7 Detailed water accounts for the Júcar River Basin in the hydrological year $2007 / 2008$ in its original and improved versions.

WATER ASSETS

\section{Surface water assets}

Landscape Water Storage

Soil moisture - unsaturated zone

Surface water storage - unregulated

Unregulated river channel storage

$$
\begin{array}{r}
\text { Valdemembra } \\
\text { Arquillo-Canal } \mathrm{M}^{a} \text { Cristina } \\
\text { Reconque } \\
\text { Escalona } \\
\text { Sellent }
\end{array}
$$

Unregulated major storages (>1Mm³)

Surface water storage - regulated

Regulated river channel storage

$\begin{array}{rr}\text { Júcar } & 1.95 \\ \text { Cabriel } & 0.90 \\ \text { Magro } & 0.30 \\ \text { Albaida } & 0.40\end{array}$

Regulated major storages $\left(>1 \mathrm{Mm}^{3}\right)$

$$
\text { Escalona } \quad 4.56
$$

$\begin{array}{rrr} & \text { Alarcón } & 98.42 \\ & \text { Contreras } & 112.58 \\ & \text { Tous } & 55.36 \\ \text { Bellús } & 17.45 \\ \text { Regulated minor storages }\left(<1 \mathrm{Mm}^{3}\right) & \text { Forata } & 5.54 \\ & & \\ & \text { Escalona } & 0.38 \\ \text { Antella } & 0.27 \\ \text { Sueca } & 0.35 \\ \text { Cullera } & 0.57 \\ & 0.19\end{array}$

Water transport system storage

Distribution network carrier storage

$$
\begin{array}{r}
\begin{array}{r}
\text { Tajo-Segura aqueduct } \\
\text { Júcar-Turia Canal } \\
\text { Júcar Royal Ditch }
\end{array} \\
\end{array}
$$

Other surface water assets

\section{Groundwater assets}


Groundwater storages

Unconfined aquifer

TOTAL GROUNDWATER ASSETS

Other water assets

Water rights

TOTAL OTHER WATER ASSETS

TOTAL WATER ASSETS

Mancha Oriental $\quad 4,797.42 \quad 4,797.42$

Plana de Valencia Sur

Other aquifers

472.71

472.71

$8,696.19$

$13,966.32 \quad 5,270.13$

$0.00 \quad 0.00$

$0.00 \quad 0.00$

$14,552.39 \quad 5,564.04$

\section{WATER LIABILITIES}

Allocation remaining

Other water liabilities

TOTAL WATER LIABILITIES

Final net water assets

Initial net water assets

Changes in net water resources

Final water storage

Initial water storage

Changes in water storage

$0.00 \quad 0.00$

$$
\begin{array}{rr}
14,552.39 & 5,564.04 \\
14,411.52 & 5,509.52 \\
140.87 & 54.53 \\
& \\
14,552.39 & 5,564.04 \\
14,411.52 & 5,509.52 \\
140.87 & 54.53
\end{array}
$$

Table 23. Detailed statement of Water Assets and Water Liabilities for the JRB for the hydrological year 2007/2008 in its original and improved versions. Figures are in $\mathrm{Mm}^{3}$. 
Assessment of Ecosystem Services and Water Accounting Methodologies for Integrated Water Resources Management in water scarce basins

\section{WATER ASSET INCREASES}

Original Improved

\section{In surface water}

Precipitation

$$
\begin{aligned}
& \text { Into landscape } \\
& \text { Into surface water - unregulated }
\end{aligned}
$$

River channel

$\begin{array}{rr}\text { Vademembra River } & 0.14 \\ \text { Arquillo River-M }{ }^{a} \text { Cristina Canal } & 0.12 \\ \text { Reconque River } & 0.02 \\ \text { Escalona River } & 0.03 \\ \text { Sellent River } & 0.02\end{array}$

Major storages

Escalona reservoir $\quad 3.79$

3.79

Into surface water - regulated

River channel

$\begin{array}{rr}\text { Júcar River } & 2.44 \\ \text { Cabriel River } & 0.73 \\ \text { Albaida River } & 0.06 \\ \text { Magro River } & 0.13\end{array}$

Major storages

$\begin{array}{rrr}\text { Alarcón reservoir } & 29.54 & 29.54 \\ \text { Contreras reservoir } & 12.83 & 12.83 \\ \text { Tous reservoir } & 6.82 & 6.82 \\ \text { Bellús reservoir } & 6.20 & 6.20 \\ \text { Forata reservoir } & 1.39 & 1.39\end{array}$

Minor storages

$\begin{array}{rr}\text { Escalona weir } & 0.12 \\ \text { Antella weir } & 0.09 \\ \text { Sueca weir } & 0.16 \\ \text { Cullera weir } & 0.20 \\ \text { Marquesa weir } & 0.14\end{array}$

Into other surface waters

La Marquesa weir

Transport system

$\begin{array}{rr}\text { Tajo-Segura Aqueduct } & 0.55 \\ \text { Júcar-Turia Canal } & 0.41 \\ \text { Júcar Royal Ditch } & 0.28\end{array}$

Transfer of inter-region claim on water of another entity

Tajo-Segura Interbasin Transfer

River inflow to region

To unregulated water storage

To regulated water storage

$363.28 \quad 363.28$

Groundwater discharges to surface water 
To soil moisture - unsaturated zone

To surface water storage - regulated

Mancha Oriental aquífer to

Plana de Valencia Sur aquifer to Júcar River

To transport system

Other aquifers

28.05

Talave Tunnel leakages

$6.50 \quad 6.50$

Groundwater extraction for surface water storage

0.00

0.00

Surface returns from urban demands

$\begin{array}{rrr}\text { Albacete } & 7.85 & 7.85 \\ \text { La Ribera towns } & 15.60 & 14.40 \\ \text { Albacete and Cuenca towns } & 33.65 & 15.60\end{array}$

Surface water returns from irrigation demands

$\begin{array}{rrr}\text { Júcar-Turia Canal } & 0.62 & 0.62 \\ \text { Escalona and Carcaixent } & 1.54 & 1.54 \\ \text { Júcar Royal Ditch } & 32.17 & 32.17 \\ \text { Cuatro Pueblos } & 2.97 & 2.97 \\ \text { Sueca } & 38.31 & 38.31 \\ \text { Cullera } & 21.51 & 21.51 \\ \text { Other irrigation demands } & 27.00 & 27.00\end{array}$

Surface returns from industrial demands

Cofrents Nuclear Plant

Cortes-La Muela Hydropower $221.83 \quad 221.83$

Millars Hydropower Station $258.83 \quad 258.83$

Desalinated water

0.00 0.00

Increase of inter-region claim on water of another entity

0.00

0.00

\section{In groundwater}

Recharge from surface water

From landscape

Precipitation

Mancha Oriental aquifer $124.64 \quad 124.64$

Plana de Valencia Sur aquifer

79.38

79.38

Other aquifers

267.71

Irrigation demands returns

Mancha Oriental aquifer

63.75

63.75

Plana de Valencia Sur aquifer

91.53

91.53

Other aquifers

96.88 
Assessment of Ecosystem Services and Water Accounting Methodologies for Integrated Water Resources Management in water scarce basins

From surface water storage - unregulated

$$
M^{a} \text { Cristina Canal } \quad 12.87
$$

From surface water storage - regulated

$$
\begin{aligned}
& \text { Júcar River to Mancha Oriental } \\
& \text { aquifer } \\
& 0.00 \quad 0.00 \\
& \text { Júcar River to Plana de } \\
& \text { Valencia Sur aquifer } \\
& 0.00 \quad 0.00
\end{aligned}
$$

From transport system

$$
\begin{array}{rrr}
\text { Tajo-Segura Aqueduct } & 6.00 & 6.00 \\
\text { Júcar-Turia Canal } & 3.15 & 3.15 \\
\text { Júcar Royal Ditch } & 4.00 & 4.00
\end{array}
$$

$4.00 \quad 4.00$

Entries of external groundwater

$$
\text { Mancha Oriental aquifer }
$$

$0.00 \quad 53.95$

Plana de Valencia Sur aquifer

Artificial recharge

$0.00 \quad 0.00$

TOTAL WATER ASSET INCREASES

\section{WATER LIABILITIES DECREASES}

\section{In surface water}

Allocations adjustment

Urban allocations

Irrigation allocations

Industrial allocations

Environmental flows adjustment

Decrease of inter-region claim on water of the entity

In groundwater

Allocations adjustment

Urban allocations

0.24

Irrigation allocations

$38.42 \quad 32.70$

TOTAL WATER LIABILITY DECREASES

235.98

230.02

TOTAL WATER RESOURCES INCREASES

$9,698.08 \quad 2,753.54$

\section{WATER ASSET DECREASES}

\section{In surface water}

Evapotranspiration

From landscape

From surface water storage - unregulated 


\section{Sellent River $\quad 0.02$ \\ Escalona reservoir $\quad 6.29$}

From surface water storage - regulated

$\begin{array}{rrr}\text { Júcar River } & 4.87 & - \\ \text { Cabriel River } & 1.56 & - \\ \text { Albaida River } & 0.18 & - \\ \text { Magro River } & 0.08 & 15.59 \\ \text { Alarcón reservoir } & 15.59 & 5.68 \\ \text { Contreras reservoir } & 5.68 & 3.07 \\ \text { Tous reservoir } & 3.07 & 1.46 \\ \text { Bellús reservoir } & 1.46 & - \\ \text { Forata reservoir } & 0.25 & 0.25 \\ \text { Escalona weir } & 0.18 & - \\ \text { Antella weir } & 0.14 & - \\ \text { Sueca weir } & 0.18 & - \\ \text { Cullera weir } & 0.24 & - \\ \text { La Marquesa weir } & 0.17 & \end{array}$

From transport system

$\begin{array}{rr}\text { Tajo-Segura Aqueduct } & 1.57 \\ \text { Júcar-Turia Canal } & 0.60 \\ \text { Júcar Royal Ditch } & 0.43\end{array}$

Groundwater recharges from surface water

From landscape

471.73

From surface water storage - unregulated

$\begin{array}{lll}M^{a} \text { Cristina Canal } \quad 12.87 & 12.87\end{array}$

From surface water storage - regulated

$0.00 \quad 0.00$

From transport

system

Environmental flows allocation

$$
\begin{aligned}
& \text { Tajo-Segura Aqueduct } \\
& \text { Júcar-Turia Canal } \\
& \text { Júcar Royal Ditch }
\end{aligned}
$$

Outflows from region

$\begin{array}{lrr}\begin{array}{l}\text { Transfer of inter-region claim on water of the entity } \\ \text { Tajo-Segura Interbasin Transfer }\end{array} & 245.29 & 245.29 \\ \quad & 30.57 & 22.60 \\ \text { Treated wastewater } & 253.47 & 253.47 \\ \text { To the sea } & & \\ \text { To wetlands } & 30.01 & 30.01 \\ \quad \text { Júcar to Albufera through Júcar Royal Ditch } & 7.06 \\ \quad \text { Júcar to Albufera through Sueca Ditch } & 7.06 & 0.62 \\ \quad \text { Júcar to Albufera through Cullera Ditch } & 0.62 & \end{array}$


Assessment of Ecosystem Services and Water Accounting Methodologies for Integrated Water Resources Management in water scarce basins

To external surface bodies

\section{In groundwater}

Groundwater discharges to surface water

To soil moisture - unsaturated zone 0.00

To surface water storage - unregulated

0.00

To surface water storage - regulated

Mancha Oriental aquífer to Júcar River

36.94

36.94

Plana de Valencia Sur aquifer to Júcar River

12.26

12.26

Other aquifers

To transport system

28.05

Talave Tunnel leakages

Groundwater extraction for surface water storage

0.00

0.00

Evapotranspiration from aquifers

0.00

0.00

Outflows from region

To wetlands

Plana de Valencia Sur aquifer to Albufera

To the sea

Plana de Valencia Sur aquifer to the sea

26.34

26.34

To other aquifers

43.44

TOTAL WATER ASSET DECREASES

\section{WATER LIABILITIES INCREASES}

\section{In surface water}

Allocation to demands

Urban allocations

$\begin{array}{rrr}\text { Albacete } & 15.00 & 15.00 \\ \text { Valencia } & 94.61 & 94.61 \\ \text { Sagunto } & 7.00 & 7.00 \\ \text { Albacete and Cuenca towns } & 7.40 & 7.40\end{array}$

Irrigation allocations

$\begin{array}{lll}\text { Mancha Oriental } & 11.55 & 11.55 \\ \text { Júcar-Turia Canal } & 38.62 & 38.62\end{array}$

Júcar Royal Ditch $\quad 213.12 \quad 213.12$

Escalona and Carcaixent

$37.50 \quad 37.50$

Cuatro Pueblos $\quad 21.94 \quad 21.94$

$\begin{array}{lll}\text { Sueca } & 146.17 \quad 146.17\end{array}$

Cullera $\quad 85.40 \quad 85.40$

Other irrigation demands $\quad 182.56 \quad 182.56$

Industrial allocations

Cofrents Nuclear Plant $\quad 24.00 \quad 24.00$

Allocations increase

Urban allocations

$0.00 \quad 0.00$ 
Annexes

Irrigation allocations

$0.00 \quad 0.00$

Industrial allocations

537.75

537.75

Environmental flows adjustment

Decrease of inter-region claim on water of the entity

$0.00 \quad 0.00$

\section{In groundwater}

Allocation to demands

Urban allocations

$$
\begin{array}{rrr}
\text { Albacete and Cuenca towns } & 48.46 & 22.11 \\
\text { La Ribera towns } & 20.58 & 20.58
\end{array}
$$

Irrigation allocations

$\begin{array}{rrr}\text { Mancha Oriental } & 373.40 & 373.40 \\ \text { Júcar-Turia Canal } & 51.12 & 51.12 \\ \text { Other irrigation demands } & 223.55 & 57.83\end{array}$

Allocations adjustment

Urban allocations

$0.00 \quad 0.00$

Irrigation allocations

$0.00 \quad 0.00$

TOTAL WATER LIABILITY INCREASES

$2,139.73 \quad 1,947.66$

TOTAL DECREASE IN WATER RESOURCES

$9,882.99 \quad 2,755.48$

Changes in net water resources

$\begin{array}{rr}-184.91 & -1.92 \\ \mathbf{3 2 5 . 7 8} & \mathbf{5 6 . 4 5}\end{array}$

Unaccounted - for difference 1

Table 24. Detailed statement of changes in water assets and water liabilities for the JRB in the hydrological year $2007 / 2008$ in its original and improved version. Figures are in Mm3. 
Assessment of Ecosystem Services and Water Accounting Methodologies for Integrated Water Resources Management in water scarce basins

\section{WATER INFLOWS}

Original

To surface water

Precipitation

Into landscape

Into surface water - unregulated

River channel

Vademembra River

0.14

Arquillo River-Ma Cristina Canal

0.12

Reconque River

Escalona River

Sellent River

0.02

Major storages

Escalona reservoir

Into surface water - regulated

River channel

Albaida River

Major storages

Alarcón reservoir

Tous reservoir

Minor storages

Escalona weir

Antella weir

Sueca weir

0.16

Cullera weir

La Marquesa weir

Into other

Transport system

$$
\begin{array}{r}
\text { Tajo-Segura } \\
\text { Aqueduct }
\end{array}
$$

Transfer of inter-region claim on water of another entity

River inflow to region

To unregulated water storage

To regulated water storage 
Groundwater discharges to surface water

To soil moisture - unsaturated zone

0.00

To surface water storage - unregulated

0.00

To surface water storage - regulated

Mancha Oriental aquífer to Júcar River

Plana de Valencia Sur aquifer to Júcar River

12.26

Other aquifers

28.05

To transport system

Talave Tunnel leakages

Groundwater extraction for surface water storage

Surface returns from urban demands

Albacete

La Ribera towns

15.60

Albacete and Cuenca towns

33.65

Surface water returns from irrigation demands

$\begin{array}{rr}\text { Júcar-Turia Canal } & 0.62 \\ \text { Escalona and Carcaixent } & 1.54 \\ \text { Júcar Royal Ditch } & 32.17 \\ \text { Cuatro Pueblos } & 2.97 \\ \text { Sueca } & 38.31 \\ \text { Cullera } & 21.51 \\ \text { Other irrigation demands } & 27.00\end{array}$

Surface returns from industrial demands

$$
\text { Cofrents Nuclear Plant } \quad 13.79
$$

Cofrents Hydropower Station $\quad 44.74$

Cortes-La Muela Hydropower Station $\quad 221.83$

Millars Hydropower Station $\quad 258.83$

Desalinated water

0.00

Increase of inter-region claim on water of another entity

0.00

\section{To groundwater}

Recharge from surface water

From landscape

Precipitation

Mancha Oriental aquifer 124.64

Plana de Valencia Sur aquifer 79.38

Other aquifers

Irrigation demands returns

Mancha Oriental aquifer 63.75

Plana de Valencia Sur aquifer

Other aquifers

From surface water storage - unregulated

$M^{a}$ Cristina Canal 
Assessment of Ecosystem Services and Water Accounting Methodologies for Integrated Water Resources Management in water scarce basins

From surface water storage - regulated

$$
\text { Júcar River to Mancha Oriental aquifer } \quad 0.00
$$

Júcar River to Plana de Valencia Sur aquifer $\quad 0.00$

From transport system

$$
\begin{array}{rr}
\text { Tajo-Segura Aqueduct } & 6.00 \\
\text { Júcar-Turia Canal } & 3.15 \\
\text { Júcar Royal Ditch } & 4.00
\end{array}
$$

Entries of external groundwater

$$
\text { Mancha Oriental aquifer } \quad 0.00
$$$$
\text { Plana de Valencia Sur aquifer } \quad 0.00
$$

Other aquifers $\quad 0.00$

Artificial recharge

\section{TOTAL INFLOWS}

$9,462.08$

\section{WATER OUTFLOWS}

\section{From surface water}

Evapotranspiration

From landscape

$6,373.36$

From surface water storage - unregulated

Vademembra River

0.29

Arquillo River-M ${ }^{a}$ Cristina Canal

0.33

Reconque River

0.03

Escalona River

0.04

Sellent River

0.02

Escalona reservoir

6.29

From surface water storage - regulated

$\begin{array}{rr}\text { Júcar River } & 4.87 \\ \text { Cabriel River } & 1.56 \\ \text { Albaida River } & 0.18 \\ \text { Magro River } & 0.08 \\ \text { Alarcón reservoir } & 15.59 \\ \text { Contreras reservoir } & 5.68 \\ \text { Tous reservoir } & 3.07 \\ \text { Bellús reservoir } & 1.46 \\ \text { Forata reservoir } & 0.25 \\ \text { Escalona weir } & 0.18 \\ \text { Antella weir } & 0.14 \\ \text { Sueca weir } & 0.18 \\ \text { Cullera weir } & 0.24 \\ \text { La Marquesa weir } & 0.17\end{array}$

From transport system 
Groundwater recharges from surface water

From landscape

From surface water storage - unregulated

From surface water storage - regulated

From transport system

$\begin{array}{rr}\text { Tajo-Segura Aqueduct } & 6.00 \\ \text { Júcar-Turia Canal } & 3.15 \\ \text { Júcar Royal Ditch } & 4.00\end{array}$

Supply to demands

Urban allocations

114.30

Irrigation allocations

549.25

Industrial allocations

561.75

Environmental flows allocation

Artificial recharge

0.00

Outflows from region

Transfer of inter-region claim on water of the entity

Tajo-Segura Interbasin Transfer

Treated waste water

To the sea

To wetlands

Júcar to Albufera through Júcar Royal Ditch

To external surface bodies

\section{From groundwater}

Groundwater discharges to surface water To soil moisture - unsaturated zone

To surface water storage - regulated Mancha Oriental aquífer to Júcar River

Plana de Valencia Sur aquifer to Júcar River

To transport system

Supply to demands 
Assessment of Ecosystem Services and Water Accounting Methodologies for Integrated Water Resources Management in water scarce basins

Irrigation allocations

609.65

Outflows from region

To wetlands

Plana de Valencia Sur aquifer to Albufera

83.82

To the sea

Plana de Valencia Sur aquifer to the sea

26.34

To other aquifers

43.44

\section{TOTAL OUTFLOWS}

$9,646.99$

Changes in net water storage

Unaccounted - for difference 2

325.78

Table 25. Detailed statement of physical water flows for the JRB in the hydrological year $2007 / 2008$ in its original version. Figures are in $\mathrm{Mm}^{3}$.

\begin{tabular}{lrrrrrr}
\hline Demand & Alloc. & Supply & Deficit & Surplus & Return & Cons. \\
\hline Albacete & 15.00 & 15.00 & 0.00 & 0.00 & 7.85 & 7.15 \\
Valencia & 94.61 & 84.10 & 9.71 & 0.00 & 0.00 & 84.10 \\
Sagunto & 7.00 & 7.00 & 0.00 & 0.00 & 0.00 & 7.00 \\
La Ribera towns & 20.58 & 20.58 & 0.00 & 0.00 & 14.40 & 6.18 \\
Albacete and Cuenca towns & 29.51 & 29.51 & 0.00 & 0.00 & 15.60 & 13.91 \\
Total urban demands & $\mathbf{1 6 6 . 7 0}$ & $\mathbf{1 5 6 . 1 9}$ & $\mathbf{9 . 7 1}$ & $\mathbf{0 . 0 0}$ & $\mathbf{3 7 . 8 5}$ & $\mathbf{1 1 8 . 3 4}$ \\
\hline Mancha Oriental & 384.95 & 381.00 & 3.95 & 0.00 & 57.15 & 323.85 \\
Júcar-Turia Canal & 89.74 & 80.71 & 9.03 & 0.00 & 0.62 & 80.09 \\
Escalona and Carcaixent & 37.50 & 20.08 & 17.42 & 0.00 & 4.29 & 15.79 \\
Júcar Royal Ditch & 213.12 & 128.69 & 84.43 & 0.00 & 32.17 & 96.52 \\
Cuatro Pueblos & 21.94 & 12.67 & 9.27 & 0.00 & 3.39 & 9.28 \\
Sueca & 146.17 & 146.17 & 0.00 & 0.00 & 38.31 & 107.86 \\
Cullera & 85.40 & 85.40 & 0.00 & 0.00 & 29.51 & 55.89 \\
Other irrigation demands & 240.39 & 136.44 & 96.21 & 0.00 & 113.96 & 22.48 \\
Total irrigation demands & $\mathbf{1 , 2 1 9 . 2 1}$ & $\mathbf{9 9 1 . 1 6}$ & $\mathbf{2 2 0 . 3 1}$ & $\mathbf{0 . 0 0}$ & $\mathbf{2 7 9 . 4 0}$ & $\mathbf{7 1 1 . 7 6}$ \\
\hline Nuclear Plant Cofrents & 24.00 & 32.24 & 0.00 & 8.24 & 13.79 & 18.45 \\
Hydrop.st. Cofrents & 0.00 & 44.77 & 0.00 & 44.77 & 44.74 & 0.03 \\
Hydrop.st. Cortes-La Muela & 0.00 & 225.56 & 0.00 & 225.56 & 221.83 & 3.73 \\
Hydropower st. Millars & 0.00 & 259.18 & 0.00 & 259.18 & 258.83 & 0.35 \\
Total industrial demands & $\mathbf{2 4 . 0 0}$ & $\mathbf{5 6 1 . 7 5}$ & $\mathbf{0 . 0 0}$ & $\mathbf{5 3 7 . 7 5}$ & $\mathbf{5 3 9 . 1 9}$ & $\mathbf{2 2 . 5 6}$ \\
\hline
\end{tabular}

Table 26. Detailed statement of physical water flows for the JRB in the hydrological year 2007/2008 in its improved version. Figures are in $\mathrm{Mm}^{3}$. 
